
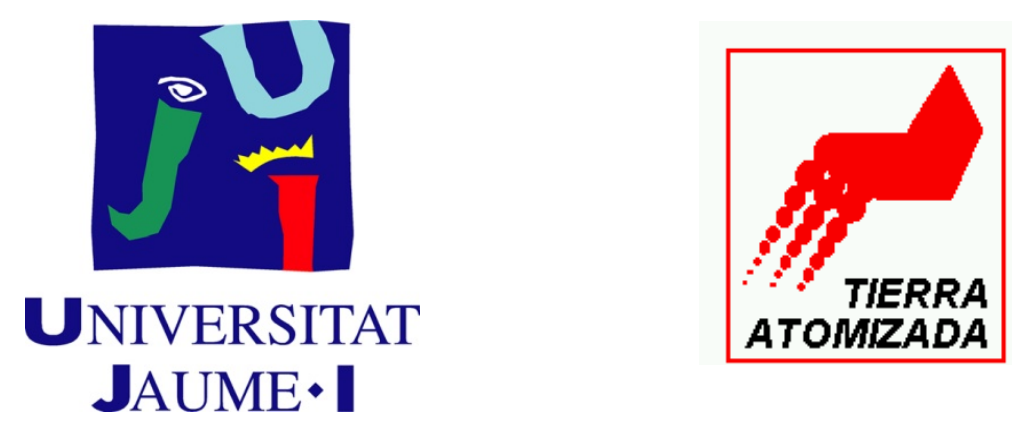

DEPARTAMENTO

DE QUÍMICA INORGÁNICA Y ORGÁNICA

\title{
VALORIZACIÓN DE ARCILLAS ESPAÑOLAS \\ PARA SU INCORPORACIÓN EN IA FORMULACIÓN \\ DE PASTAS CERÁMICAS DE COCCIÓN BLANCA
}

ESTER BARRACHINA ALBERT

MEMORIA PARA OPTAR AL GRADO DE DOCTORA EN QUÍMICA

\author{
DIRECTOR :
}

PROF. DR. JUAN BAUTISTA CARDA CASTELLÓ

CASTELLÓN, NOVIEMBRE DE 2011. 


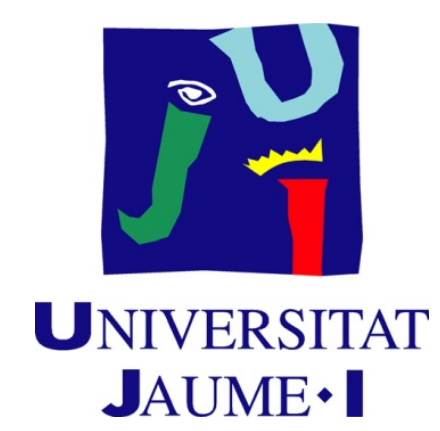

Juan Bautista Carda Castelló, Profesor Catedrático de Química Inorgánica del Departamento de Química Inorgánica y Orgánica de la Universitat Jaume I de Castellón,

\section{CERTIFICO QUE:}

Dña. Ester Barrachina Albert, Titulada en Ingeniería Química, ha desarrollado bajo mi dirección el trabajo titulado: "Valorización de arcillas españolas para su incorporación en la formulación de pastas cerámicas de cocción blanca", para aspirar al Grado de Doctora en Química por la Universitat Jaume I de Castellón.

Y para que conste, a los efectos oportunos, lo firmo en Castellón, a 25 de noviembre de 2011.

Fdo. Juan Bautista Carda Castelló. 
"Si tienes capacidad de entusiasmo, puedes lograrlo todo. Entusiasmo es la levadura que impulsa tus esperanzas hacia las alturas, entusiasmo es el brillo en tus ojos, el ímpetu en tu andar, el apretón de tu mano, tu irresistible fuerza de voluntad y la energía para realizar tus ideas. Los entusiastas son luchadores. Tienen fuerza de ánimo. Son resistentes. Entusiasmo es la base de todo progreso. Con él se alcanzan logros, sin él... a lo sumo, pretextos" 
A Santi, por su paciencia y apoyo constante en la vida que compartimos. 


\section{Agradecimientos}

La autora de este trabajo desea expresar su agradecimiento a todas las personas que han hecho posible la realización de esta Tesis Doctoral.

En primer lugar, quiero expresar mi agradecimiento al Grupo Tierra Atomizada, representado a través de su Director General D. Rafael Sáez Clemente y, en especial, a D. Jaime Ramos y a D. Enrique Cerisuelo, además de a mis compañeros del laboratorio (José A. Planas, Alejandra, Caridad, Noelia, Mamee y Rubén), por permitirme llevar a cabo el desarrollo de la presente Tesis, como parte del trabajo diario de investigación desarrollado en el laboratorio de I+D de este Grupo.

En segundo lugar, quiero agradecer al Profesor Dr. Juan Bautista Carda Castelló, su formidable labor de dirección de la presente Tesis.

También quiero agradecer a los compañeros del Departamento de Química Inorgánica y Orgánica de la Universitat Jaume I, en particular al grupo de investigación de Química del Estado Sólido, y al personal técnico del Servicio Central de Instrumentación Científica (SCIC). Quiero extender mi agradecimiento por la ayuda prestada, a la Escuela Superior de Cerámica de l'Alcora, a través de su Director D. Manuel Collado, así como a los Profesores: Jordi, Mado e Isaac. 
Destaco también mi agradecimiento al Centro para el Desarrollo Tecnológico Industrial (CDTI), Entidad Pública Empresarial dependiente del Ministerio de Ciencia e Innovación Español, por la aprobación de varios proyectos relacionados con el presente trabajo, que a continuación se detallan:

-CDTI, 2003. "Separación magnética en arcillas y caolines españolas".

-CDTI, 2006. "Diferenciador electromagnético para producción de arcillas blancas".

-CDTI, 2008. "Reducción del contenido de materia orgánica y hierro en arcillas para pasta blanca".

-CDTI, 2010. "Optimización de la técnica de tostación para la revalorización de arcillas españolas".

También deseo agradecer a la empresa Camacho Recycling de Caudete (Albacete), dedicada al tratamiento y clasificación del vidrio reciclado, especialmente a D. Sigfrido Allepuz y a D. Fernando Gómez, por su colaboración en el apartado de introducción de residuos en la confección de las pastas cerámicas.

Y, por último, aunque no por ser menos importante, mi más profundo agradecimiento a mi familia más próxima, especialmente a mi marido, por haberme animado y ayudado a realizar este trabajo. Gracias a todos ellos he aprendido, desde bien pequeña, que el saber hace a las personas más libres porque ofrece nuevas formas de felicidad. 


\title{
Resumen de la Tesis.
}

\begin{abstract}
Actualmente, el sector cerámico español se dirige hacia la fabricación de productos de pasta blanca, es decir, baldosas cerámicas en cuya composición, las arcillas contienen bajos contenidos de óxido de hierro y otros materiales colorantes, además de bajo contenido en materia orgánica. Sin embargo, esto hace que la industria española mantenga una fuerte dependencia en cuanto a la necesidad de importar dichas materias primas de otros países, por carecer de las suficientes reservas mineras de este tipo de materias primas. Por este motivo, se están importando arcillas caoliníticas de Ucrania y Reino Unido, feldespatos sódicos de Turquía, además de otros materiales.
\end{abstract}

Así pues, el resultado de dichas composiciones es la obtención de un producto de cocción blanca y altamente gresificado como es el denominado gres porcelánico. Dicho producto presenta, además, unas cualidades técnicas de muy baja porosidad y alta resistencia mecánica que permite su colocación como revestimiento en ambientes exteriores y en zonas de alto tránsito.

Con todo ello, resulta de alto interés científico y también industrial, el poder desarrollar composiciones de pasta blanca como son las pastas de gres porcelánico y las pastas para revestimiento de paredes (monoporosa), a partir de materias primas españolas, realizando los tratamientos previos y acondicionamientos necesarios para su uso.

Así pues, el objetivo que persigue esta Tesis Doctoral se divide en dos partes. Por una parte, se pretende valorizar las 
arcillas españolas mediante técnicas físicas, para que puedan sustituir a las arcillas de importación que se utilizan para la formulación de pasta blanca cerámica. Y, por otra parte, se van a introducir residuos cocidos procedentes del sector cerámico (chamota) y residuos del vidrio reciclado, en las distintas formulaciones de pastas cerámicas de cocción blanca que incluyen en su formulación arcillas españolas tratadas, tanto para pavimento (gres porcelánico) como para revestimiento (monoporosa).

Para el tratamiento de arcillas españolas con altos contenidos de compuestos de hierro, hematita $\left(\mathrm{Fe}_{2} \mathrm{O}_{3}\right)$ y siderita $\left(\mathrm{FeCO}_{3}\right)$ principalmente, se han aplicado tres técnicas físicas desarrolladas en las propias plantas industriales de Grupo Tierra Atomizada. La primera de ellas consiste en el tamizado a $100 \mu \mathrm{m}$ de la arcilla dispersada ${ }^{1}$ y corresponde a la etapa previa a las otras dos técnicas. Con esta técnica, se consigue eliminar las fracciones más gruesas de la arcilla, a saber, sílice libre y compuestos de hierro, destacando entre ellos la siderita (carbonato de hierro, $\mathrm{FeCO}_{3}$ ). Así, se favorece la concentración de los filosilicatos (arcillas) y la disminución de parte de la fracción rica en compuestos de hierro, en las arcillas españolas. Refiriéndose a la segunda técnica, se trata de una técnica de gravimetría mediante un hidrociclón por vía húmeda, capaz de separar partículas de diferente densidad específica. De este modo, se consigue extraer de una arcilla española rica en hematita $\left(\mathrm{Fe}_{2} \mathrm{O}_{3}\right)$, alrededor de un $20 \%$ de esta impureza. Con la tercera técnica, basada en el fenómeno del electromagnetismo, se ha tratado una arcilla española rica en hematita con un filtro electromagnético inducido, obteniéndose mejores resultados que en las dos anteriores técnicas, puesto que se ha logrado una reducción del 45\% en contenido de hematita $\left(\mathrm{Fe}_{2} \mathrm{O}_{3}\right)$ de la arcilla

\footnotetext{
1 Arcilla dispersada en agua (de aquí en adelante, la denominaremos arcilla turbodesleída, haciendo uso de la técnica de dispersión utilizada).
} 
ensayada, de forma que se ha conseguido un porcentaje de hematita muy bajo (1.18\%) .

La disminución de la materia orgánica procedente de carbón vegetal presente en algunas arcillas de Teruel, se ha llevado a cabo mediante tratamientos térmicos a distintas temperaturas utilizando un horno eléctrico tipo mufla de laboratorio. Se han determinado las condiciones idóneas según los resultados obtenidos (tratamiento térmico a $400^{\circ} \mathrm{C}$, durante 30 minutos), para eliminar gran parte de esta impureza contenida en algunas arcillas españolas de Teruel, cerca del 30\%. Además, se ha observado que, parte de la siderita $\left(\mathrm{FeCO}_{3}\right)$ contenida en estas arcillas, se descompone a las temperaturas de calcinación ensayadas, de forma que los productos de esta reacción se imantan, pudiéndose extraer el carbonato de hierro descompuesto. Los resultados obtenidos con este tratamiento han sido altamente positivos, puesto que se ha eliminado un 21\% de compuestos de hierro.

Por otra parte, se ha realizado un estudio documental, bibliográfico, sobre el estado del arte de la aplicación de las microondas en los procesos industriales, para modificar ciertas propiedades físicas y/o químicas de algunos materiales. Con esto, se ha pretendido estudiar las posibilidades que ofrece esta técnica para la disminución de la materia orgánica de origen vegetal, presente, como impureza, en algunas arcillas illiticocaolinitícas de Teruel.

La metodología experimental llevada a cabo, ha consistido en preparar varias composiciones de gres porcelánico de pasta blanca, partiendo de una composición de referencia, con arcillas de importación. Para ello, se han sustituido parte de las arcillas de importación por arcillas españolas para comprobar que las impurezas que contienen afectan negativamente a la calidad de la 
pasta. A continuación, se han introducido arcillas españolas tratadas, tal y como se ha explicado anteriormente: arcillas españolas desferritizadas mediante el separador magnético y arcillas españolas calcinadas en horno eléctrico tipo mufla. Se ha visto que la calidad de la pasta obtenida es comparable a la de la composición de referencia, formulada sólo con arcillas de importación. Partiendo también de una composición de referencia de revestimiento de pasta blanca, se han sustituido parte de arcillas de importación por las españolas tratadas y sin tratar, observándose que en este caso, al utilizar ciclos con menor temperatura de cocción, la calidad de la composición de revestimiento con arcillas españolas tratadas es prácticamente igual a la de referencia. Por todo ello, se ha constatado que es posible formular pasta blanca, tanto de pavimento (gres porcelánico) como de revestimiento (monoporosa), mediante arcillas españolas tratadas previamente, sin que se altere la calidad del producto final.

Por otra parte, se han introducido en las composiciones de gres porcelánico y de revestimiento preparadas en esta Tesis Doctoral, altos porcentajes de residuos cocidos (entre 15\%-20\%) procedentes del sector productivo cerámico (chamotas) y del sector del vidrio reciclado, que han permitido en ambos casos, reducir la temperatura de sinterización de la pasta cerámica de forma muy significativa. Esto supone un cambio muy notable en la producción de baldosas cerámicas, tanto por la incorporación de material reciclado que, en la actualidad se desecha, como por el ahorro energético que origina la disminución de la temperatura máxima de cocción. Así, el sector cerámico podrá contribuir también a fomentar el desarrollo sostenible, permitiendo un ahorro en la utilización de las materias primas naturales y una notable disminución en el consumo energético y, también de las emisiones de $\mathrm{CO}_{2}$. 


\section{Índice}

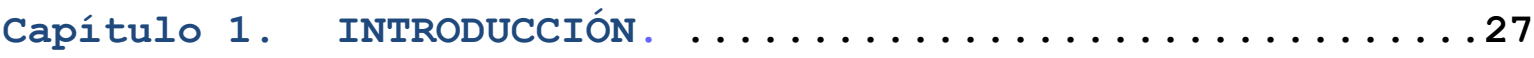

1.1. Descripción del proceso de fabricación cerámico de pasta blanca.

1.1.1. Definición de pasta cerámica. 28

1.1.2. Definición del proceso de atomización. 30

1.1.3. Función de las materias primas en la pasta. 43

1.1.4. Tipos de pasta blanca. 46

1.2. Descripción de las arcillas que se utilizan en la actualidad para formular pasta blanca.

1.2.1. Arcillas tipo "ball clay" de importación. 54

1.2.2. Arcillas tipo "ball clay" españolas. 57

1.2.3. Extracción minera de arcillas de cocción blanca. 59

1.3. Identificación de las impurezas de hierro en las arcillas españolas.

1.3.1. Susceptibilidad magnética de los materiales. 60

1.3.2. Tipos de compuestos de hierro. 62

1.3.3. Procedimiento de disminución de compuestos de hierro en las arcillas. 64 


\subsection{Descripción de las impurezas de materia orgánica en las arcillas españolas. 64}

1.4.1. Descripción química de la materia orgánica. 64

1.4.2. Descripción petrográfica de la materia orgánica. 66

1.4.3. Defecto provocado por la materia orgánica presente en las arcillas. 70

1.4.4. Procedimiento de disminución de materia orgánica en las arcillas. 75

1.4.5. Desferretización de una arcilla calcinada. 86

1.5. Introducción de residuos sólidos y líquidos en suspensión en la pasta cerámica. 87

1.5.1. Introducción de agua reciclada en la pasta cerámica. 88 1.5.2. Introducción de testillo crudo en la pasta cerámica. 90 1.5.3. Estudio del testillo cocido ("chamota") procedente del sector cerámico. 90

1.5.4. Estudio del vidrio reciclado. 91

1.5.5. Otros residuos añadidos a las formulaciones de pasta cerámica. 95

1.5.6. Desarrollo sostenible en el sector cerámico y del vidrio. 96

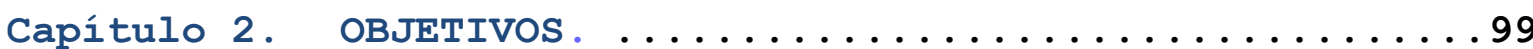


Capítulo 3. METOdología EXPERIMENTAL. .............. 101

3.1. Técnicas de caracterización. 101

3.1.1. Análisis térmico, (ATD/TG). 101

3.1.2. Espectrómetro secuencial de fluorescencia de rayos $x$, $(\mathrm{FRX})$. 102

3.1.3. Microscopio electrónico de barrido, (MEB) . 104

3.1.4. Difractómetro de rayos-X, (DRX). 105

3.1.5. Microscopio de calentamiento. 107

3.1.6. Analizador de carbono, (TOC). 109

3.1.7. Espectrofotómetro UV-Visible, método de reflectancia difusa. 110

3.1.8. Análisis dilatométrico. 111

3.1.9. Ensayos cerámicos característicos en las arcillas y composiciones de pastas. 112

3.2. Materias primas utilizadas. 119

3.3. Técnicas utilizadas para la disminución de los compuestos de hierro en las arcillas españolas.

3.3.1. Técnica del hidrociclonado. 122

3.3.2. Técnica del separador magnético. 128

3.4. Técnicas utilizadas para la disminución de la materia orgánica. 132

3.4.1. Calcinación en horno eléctrico tipo mufla. 132

3.4.2. Tratamiento en horno microondas. 133 
3.5. Introducción de residuos cocidos en la composición de las pastas cerámicas para optimizar el ciclo de cocción.

3.5.1. Testillo cocido (chamota).

3.5.2. Vidrio reciclado.

3.5.3. Composiciones de pastas cerámicas.

Capítulo 4. RESULTADOS Y DISCUSIÓN. ................ 141

4.1. Disminución del contenido de compuestos de hierro en las arcillas españolas. 141

4.1.1. Tamizado de las arcillas (N-B-te) y (N-A-Cr). 141

4.1.2. Técnica del hidrociclonado de las arcillas españolas.142 4.1.3. Separador magnético. 154

4.2. Disminución del contenido en materia orgánica. 161

4.2.1. Tratamiento de las arcillas españolas con horno eléctrico tipo mufla. 161

4.2.2. Tratamiento de las arcillas españolas con radiación de microondas. 179

4.3. Introducción de residuos cocidos en la pasta cerámica. 180

4.3.1. Composiciones de gres porcelánico. 185

4.3.2. Composiciones de revestimiento. 195

4.3.3. Ahorro energético en el consumo de energía térmica de un horno industrial de rodillos. 202 


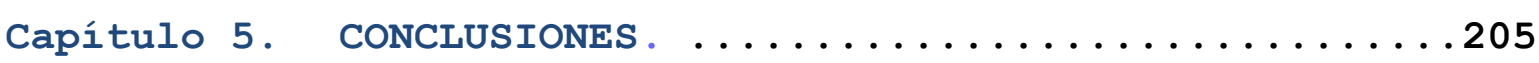

Capítulo 6. RECOMENDACIONES Y PROYECTOS FUTUROS .......209

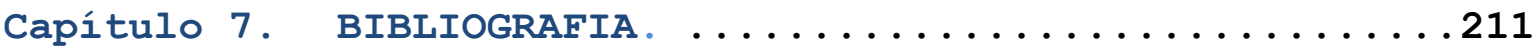

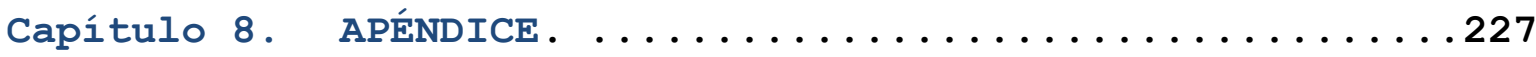

8.1. Listado de materias primas utilizadas. 227

8.2. Caracterización cerámica de la arcilla (A-I-1). 228

8.3. Caracterización cerámica de la arcilla (A-I-2). 229

8.4. Caracterización cerámica de la arcilla (N-A-cr). 230

8.5. Caracterización cerámica de la arcilla (N-A-te) . 231

8.6. Caracterización cerámica de la arcilla (N-B-te) sin tratar. 232

8.7. Difractogramas de las arcillas de importación. 233

8.8. Difractogramas de los feldespatos. 234

8.9. Ficha técnica del silicato sódico. 235

SILIFLUX AR 235

8.10. Caracterización cerámica de la arcilla (N-A-te) calcinada $400^{\circ} \mathrm{C}-30$ minutos en horno eléctrico mufla. 236

8.11. Caracterización cerámica de la arcilla (N-A-te) calcinada. Granulometría M1. 237

8.12. Caracterización cerámica de la arcilla (N-A-te) calcinada. Granulometría M2. 238

8.13. Caracterización cerámica de la arcilla (N-A-te) calcinada. Granulometría M3. 239 
8.14. Análisis térmico ATD/TG de las muestras preparadas I. 240 8.15. Análisis térmico ATD/TG de las muestras preparadas II. 241 8.16. Caracterización cerámica de la composición PORC-STD. _ 242 8.17. Caracterización cerámica de la composición (PORC-1A). 243 8.18. Caracterización cerámica de la composición (PORC-1B). 244 8.19. Caracterización cerámica de la composición (PORC-2) • 245 8.20. Caracterización cerámica de la composición (REV-STD). 246 8.21. Caracterización cerámica de la composición (REV-1A) • 247 8.22. Caracterización cerámica de la composición (REV-1B) • _ 248 8.23. Caracterización cerámica de la composición (REV-2) • _ 249 


\section{Índice de Figuras}

Figura 1. Muestrario de baldosas cerámicas. 28

Figura 2. Baldosas cerámicas a la salida de la prensa industrial.

Figura 3. Diversidad de arcillas.

Figura 4. Varios modelos de "turbodesleidores".

Figura 5. Molinos discontinuos en serie. 34

Figura 6. Batería de tamices a la salida del molino continuo. 35

Figura 7. Diferentes configuraciones de secado por pulverización.

Figura 8. Representación de los componentes de una tobera. 37

Figura 9. Micrografía de una muestra de gránulos de polvo atomizado. 39

Figura 10. Micrografía de la sección de un gránulo de polvo atomizado. 39

Figura 11. Instalación de un atomizador industrial. 40

Figura 12. Esquema del proceso de secado por atomización. 42

Figura 13. Disposición de un almacén de materias primas ("granero") de una empresa atomizadora de arcillas. 46

Figura 14. Explotación de arcillas tipo "ball clay" en Ucrania. 56 
Figura 15. Frente de un yacimiento de arcillas a cielo abierto. 60

Figura 16. Imagen de los compuestos de hierro: siderita y

hematita. 63

Figura 17. Pieza cerámica de pasta roja que presenta el defecto de "corazón negro". 71

Figura 18. Pieza con "corazón negro" fisurada durante la fase de enfriamiento. La parte más brillante señalada con las flechas corresponde a la zona fisurada.

Figura 19. Pieza esmaltada con presencia de "corazón negro" y abultamiento en la misma pieza. 74

Figura 20. Horno rotatorio para el tratamiento térmico de los minerales. 79

Figura 21. Subdivisión convencional de las ondas electromagnéticas, destacando la región correspondiente a las microondas. 85

Figura 22. Horno microondas industrial. 86

Figura 23. Distintos residuos generados en el proceso de producción cerámica: lodos, aguas sucias procedentes de la limpieza y tiestos crudos y cocidos. 88

Figura 24. Variación del volumen específico con la temperatura en un material vítreo comparado con otro cristalino. 92

Figura 25. Estado no cristalino del vidrio. 93

Figura 26. Vidrio procedente de diferentes envases y recipientes. 
Figura 27. Etiqueta del producto desarrollado por la empresa Azulejos Plaza de l'Alcora (Castellón) premiado con el Alfa de Oro en la pasada edición de Cevisama 2011, que aparece integrado en un ambiente marino.

Figura 28. Equipo de análisis térmico, (ATD/TG). 102

Figura 29. Esquema del estatus del espectrómetro de Rayos-X. 103

Figura 30. Microscopio electrónico de barrido perteneciente a Tierra Atomizada.

Figura 31. Esquema del comportamiento de la radiación difractada después de impactar sobre los planos cristalinos (Ley de Bragg).

Figura 32. Microscopio de calentamiento.

Figura 33. Analizador de carbono y azufre.

Figura 34. Diagrama de las coordenadas cromáticas, CIELab, 1976.

Figura 35. Dilatómetro Bähr modelo DIL 801L.

Figura 36. Flexímetro de Gabbrielli.

Figura 37. Tamices normalizados para el control del residuo de las arcillas.

Figura 38. Calcímetro de Bernard. 115

Figura 39. Plasticímetro de Pfefferkorn GT0675. 117

Figura 40. Deprimómetro DP600 de Gabbrielli. 118

Figura 41. Esquema de funcionamiento de un hidrociclón. 123 
Figura 42. Difractograma de la arcilla (N-A-te) sin tratar. 126

Figura 43. Difractograma de la arcilla (N-B-te) sin tratar. 127

Figura 44. Difractograma de la arcilla (N-A-Cr) sin tratar 127

Figura 45. Filtro magnético inducido a escala piloto. 128

Figura 46. Esquema de funcionamiento del filtro electromagnético de Master Magnets.

Figura 47. Filtro electromagnético industrial de Master Magnets adquirido por Tierra Atomizada y utilizado en la presente Tesis.

Figura 48. Gráfica esquemática del ciclo de cocción de un horno industrial de baldosas cerámicas. 136

Figura 49. Gráfica del ciclo de cocción de las composiciones preparadas a $1200^{\circ} \mathrm{C}$ en horno eléctrico tipo mufla.

Figura 50. Gráfica de los 4 montajes ensayados a las mismas condiciones de trabajo.

Figura 51. Detalle del pico de la hematita correspondiente a los difractogramas de las muestras de arcilla (N-A-Cr) tratadas. 160

Figura 52. Análisis ATD/TG de la muestra original de referencia $(\mathrm{N}-\mathrm{A}-\mathrm{te})$, sin tratar. 163

Figura 53. Procesos que ocurren durante el tratamiento térmico de la arcilla ( $\mathrm{N}-\mathrm{A}-\mathrm{te})$, durante 30 minutos de permanencia. 169

Figura 54. Distribución granulométrica de la arcilla (N-A-te) para su tratamiento a $400^{\circ} \mathrm{C}$ y 30 minutos. 
Figura 55. Análisis térmico, ATD/TG, correspondiente a la combustión de la materia orgánica de la arcilla (N-A-te), modificando la concentración de oxígeno de la atmósfera.

Figura 56. Comparación de permitividad relativa de diferentes arcillas españolas y de importación ensayadas, medida a $100 \mathrm{kHz}$.

Figura 57. Diagrama de gresificación de las composiciones de gres porcelánico.

Figura 58. Variación de la densidad aparente en cocido (medida con el método de inmersión en mercurio) con la temperatura en las composiciones de gres porcelánico.

Figura 59. Micrografías (x300 aumentos) de las composiciones de gres porcelánico ensayadas, utilizando el detector de electrones retrodispersados.

Figura 60. Valores estadísticos correspondientes a los análisis de imagen de las micrografías de las composiciones de gres porcelánico estudiadas, en la Figura 59.

Figura 61. Diagrama de gresificación de las composiciones de revestimiento.

Figura 62. Detalle comparativo de los difractogramas (DRX) de las composiciones (REV-STD) y (REV-2). 


\section{Indice de Tablas}

Tabla I. Requisitos técnicos de las pastas cerámicas. 50

Tabla II. Propiedades más importantes que presentan las baldosas cerámicas por tipología. 51

Tabla III. Requisitos para la preparación de las pastas y tipos de materias primas. 52

Tabla IV. Algunos ejemplos de formulaciones de pasta blanca descritos en la bibliografía, en on peso.

Tabla v. Características técnicas de las arcillas usadas en la formulación de pasta blanca. 59

Tabla VI. Análisis petrográfico de los carbones cretácicos de Teruel (año 1993). 69

Tabla VII. Datos procedentes del ATD-TG de la pirólisis de vitrinita e inertinita.

Tabla VIII. Combinaciones de accesorios para el montaje del hidrociclón.

Tabla IX. Características de las matrices tipo B1, B2 y B3.

Tabla x. Programa llevado a cabo en el horno eléctrico para el tratamiento de la materia orgánica de las arcillas.

Tabla XI. Programa de pruebas combinando la radiación infrarroja y la radiación de microondas. 135 
Tabla XII. Composiciones de gres porcelánico preparadas (\% en peso) .

Tabla XIII. Composiciones de revestimiento preparadas ( $\frac{\circ}{0}$ en peso). 138

Tabla XIV. Análisis químico por FRX de la arcilla (N-B-te). 142

Tabla XV. Análisis químico por FRX de la arcilla (N-A-Cr). 142

Tabla XVI. Análisis químico (FRX) de la arcilla (N-A-Cr) tamizada a $100 \mu \mathrm{m}$ e hidrociclonada a una densidad de la barbotina de 1.20 $\mathrm{g} / \mathrm{cm}^{3}$.

Tabla XVII. Relación de la presión de la bomba que alimenta al hidrociclón y el caudal volumétrico $\left(Q_{v}\right)$. 144

Tabla XVIII. Análisis químico (FRX) de la arcilla (N-A-Cr) hidrociclonada según el montaje $n^{\circ} 4$ a 1.5 bar de presión de bomba. 144

Tabla XIX. Análisis químico (FRX) de la arcilla (N-A-Cr) 145

Tabla xx. Análisis químico (FRX) de la arcilla (N-A-Cr) 145

Tabla XXI. Análisis químico (FRX) de la arcilla (N-A-Cr) 146

Tabla xxII. Análisis químico (FRX) de la arcilla (N-A-Cr) 147

Tabla XxIII. Análisis químico (FRX) de la arcilla (N-A-Cr) 147

Tabla xxIV. Análisis químico (FRX) de la arcilla (N-A-Cr) 148

Tabla XXV. Análisis químico (FRX) de la arcilla (N-A-Cr) 149

Tabla XXVI. Análisis químico (FRX) de la arcilla (N-A-Cr) 149 
Tabla xxVII. Análisis químico (FRX) de la arcilla (N-A-Cr) 150

Tabla XXVIII. Análisis químico (FRX) de la arcilla (N-A-Cr) 151

Tabla XxIX. Análisis químico (FRX) de la arcilla (N-A-Cr) 151

Tabla xxx. Análisis químico (FRX) de la arcilla (N-A-Cr) 152

Tabla XXXI. Análisis químico (FRX) de los "gruesos" (N-A-Cr) 154

Tabla XXXII. Comparación de los análisis químicos de las 3 matrices . 155

Tabla xxxIII. Comparación del $\frac{\circ}{\mathrm{Fe}_{2} \mathrm{O}_{3}}$ eliminado en cada matriz. 156 Tabla XXXIV. Comparación de los análisis químicos (FRX) obtenidos a diferentes caudales. 156

Tabla xxxv. Comparación del $\frac{\circ}{\circ} e_{2} \mathrm{O}_{3}$ eliminado para cada caudal empleado . 157

Tabla XXXVI. Análisis químico (FRX) para comparación del $\frac{\circ}{\mathrm{F}} \mathrm{e}_{2} \mathrm{O}_{3}$ eliminado a diferentes intensidades de campo magnético.

Tabla XXXVII. Comparación del $\frac{\circ}{\mathrm{F}} \mathrm{e}_{2} \mathrm{O}_{3}$ eliminado para cada intensidad de campo magnético.

Tabla xxxviII. Análisis químico (FRX) de (N-A-Cr) desferritizada trabajando en modo automático.

Tabla xxxIX. Resumen de los resultados obtenidos en la arcilla (NA-cr) tras la aplicación de las técnicas para disminuir el porcentaje de hematita.

Tabla XI. Pruebas realizadas con la arcilla de referencia (N-Ate), en un horno eléctrico tipo mufla, con los correspondientes resultados obtenidos con el $\mathrm{ATD} / \mathrm{TG}$. 
Tabla XII. Pérdidas de masa (TG) referentes al área del pico exotérmico en el ATD correspondientes a la combustión de la materia orgánica y a la deshidroxilación de la caolinita. 166

Tabla XLII. Porcentaje de pérdidas de masa (TG) respecto de la muestra sin tratar ${ }^{1}$.

Tabla XIIII. Comparación cerámica de la arcilla (N-A-te) calcinada con la misma arcilla sin tratar y con arcillas de importación. 171

Tabla XLIV. Análisis térmico ATD/TG (entre $50^{\circ} \mathrm{C}$ y $1150^{\circ} \mathrm{C}$ ) de las muestras de $(\mathrm{N}-\mathrm{A}-\mathrm{te})$, tratadas a $400^{\circ} \mathrm{C}$ y 30 minutos, preparadas a diferentes granulometrías (M1 a M3). 174

Tabla XIV. Variación del porcentaje de eliminación de carbono orgánico (TOC) con la granulometría de las muestras de (N-A-te) tratadas a $400^{\circ} \mathrm{C}$ y 30 minutos.

Tabla XLVI. Análisis térmico, ATD-TG, de $50^{\circ} \mathrm{C}$ a $1150^{\circ} \mathrm{C}$, de la arcilla (N-A-te) modificando la concentración y el caudal de oxígeno. 176

Tabla XIVII. Análisis químico (FRX) de la muestra (N-A-te) tratada a $400^{\circ} \mathrm{C}$ y 30 minutos y desferretizada. 178

Tabla XLVIII. Análisis químico (FRX) de las materias primas utilizadas. 181

Tabla XLIX. Análisis químico (FRX) del testillo cocido. 182

Tabla L. Análisis químico del vidrio plano y del vidrio hueco procedente del reciclado del vidrio. 182

Tabla LI. Microscopía de calentamiento del vidrio plano y del vidrio hueco comparada con la de los feldespatos ensayados. 184 
Tabla LII. Parámetros cerámicos de las composiciones de porcelánico antes de la cocción.

Tabla LIII. Análisis colorimétrico de las composiciones de gres porcelánico tratadas térmicamente.

Tabla LIV. Análisis dilatométrico de las composiciones de gres porcelánico preparadas.

Tabla LV. Análisis químico (FRX) de las composiciones de gres porcelánico preparadas.

Tabla LVI. Parámetros cerámicos de las composiciones de revestimiento antes de la cocción.

Tabla LVII. Análisis colorimétrico de las composiciones de revestimiento tratadas térmicamente.

Tabla LVIII. Análisis dilatométrico de las composiciones de revestimiento preparadas.

Tabla LIX. Análisis químicos (FRX) de las composiciones de revestimiento preparadas.

Tabla Lx. Comparativa entre el porcentaje de carbonato cálcico y de pérdida por calcinación (PPC) de las composiciones de revestimiento estudiadas.

Tabla LXI. Producción ( $\mathrm{m}^{2} /$ día), temperatura máxima y consumo de energía térmica en la etapa de cocción, referido al PCS ${ }^{1}$.

Tabla LXII. Listado de las materias primas utilizadas. 227 


\section{Capítulo 1. INTRODUCCIÓN.}

En el año 2006, El Periódico Mediterráneo publicó que el sector cerámico de Castellón apuesta por la pasta blanca por dos motivos principalmente. El primero de ellos, está relacionado con la fuerte campaña de marketing que la industria italiana viene realizando desde hace años, hasta tal punto que el mercado internacional ha asociado la pasta blanca a producto cerámico de máxima calidad. El segundo motivo se basa en el aspecto estratégico, ya que los consumidores de los principales países (Estados Unidos y miembros de la Unión Europea), tienen asumido que los productos de pasta blanca son más caros, por lo que las empresas se benefician de un margen comercial más elevado, obteniendo una mayor rentabilidad en cada operación [1], [2], [3], $[4],[5],[6]$.

Hoy en día, no existe empresa en el sector que no ofrezca en sus catálogos a los clientes, pavimentos (gres porcelánico) y revestimientos (monoporosa) de pasta blanca. Porcelanosa, Zirconio, Ceracasa, Pamesa y Rocersa son sólo algunas de las azulejeras que están apostando fuertemente por este tipo de productos, siguiendo la tendencia internacional [7]. 


\subsection{Descripción del proceso de fabricación cerámico de pasta blanca.}

\subsubsection{Definición de pasta cerámica.}

La pasta cerámica es una mezcla de materias primas, la mayor parte de ellas naturales, que da lugar, tras ser sometida al proceso de fabricación adecuado, al cuerpo o soporte de la baldosa cerámica, bien de revestimiento, bien de pavimento. En la Figura 1 se observan varias baldosas cerámicas típicas de pasta blanca [8], [9].

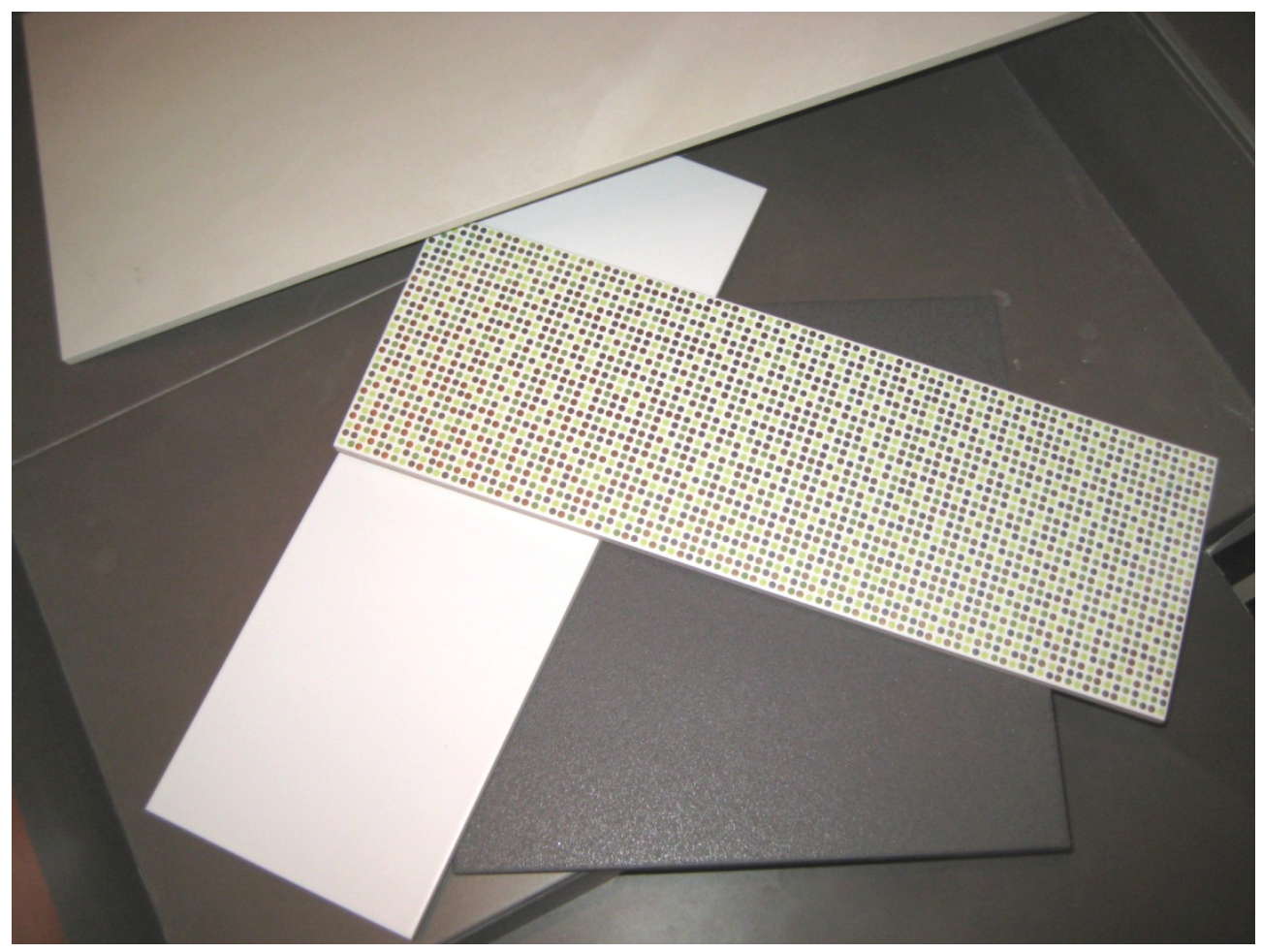

Figura 1. Muestrario de baldosas cerámicas. 
Las condiciones óptimas que ha de presentar una pasta cerámica se describen a continuación:

- Ha de ser suficientemente plástica.

- Ha de ser fácil de deflocular, ya que se suele fabricar vía húmeda.

- La barbotina a atomizar debe tener un contenido en sólidos alto, por encima del 65\%, para que el rendimiento del atomizador sea óptimo y el consumo de gas mínimo.

- Las condiciones óptimas de humedad y granulometría del polvo atomizado tiene que garantizar el adecuado llenado del molde de prensa, de manera que la densidad aparente de las piezas sea homogénea.

- Su resistencia mecánica en seco debe ser suficiente para que las piezas crudas no se rompan al atravesar las etapas de secado, engobado y esmaltado.

- El intervalo de temperatura de cocción tiene que ser suficientemente amplio, para mantener las dimensiones de la pieza cocida dentro de márgenes, independientemente de las variaciones del horno.

- El producto cocido ha de proporcionar las características técnicas y estéticas deseadas en el producto acabado, a pesar de la variabilidad propia del proceso (presiones, temperaturas, tiempos, etc.). 
Con todo ello, el proceso productivo es totalmente automatizado, donde la intervención de la mano de obra es mínima, como se puede apreciar en la Figura 2, que muestra la salida de las baldosas confeccionadas en una prensa industrial moderna [10].

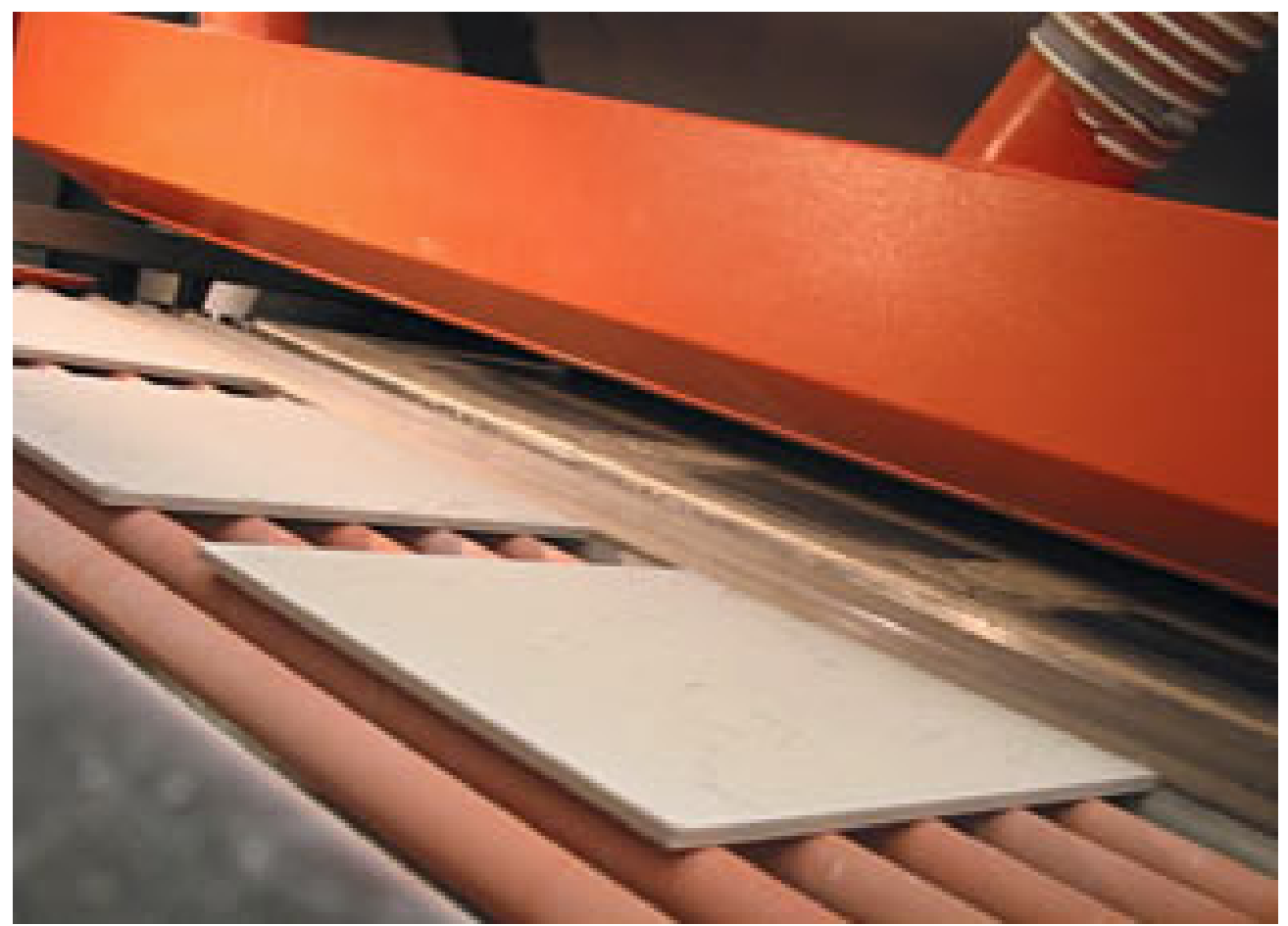

Figura 2. Baldosas cerámicas a la salida de la prensa industrial.

\subsubsection{Definición del proceso de atomización.}

El proceso de fabricación cerámico de pasta blanca que predomina en la actualidad en los principales países de tradición azulejera, como España e Italia, se desarrolla en una serie de etapas sucesivas que se puede esquematizar de la siguiente forma [8], [11], [12]: 
- SELECCIÓN DE LAS MATERIAS PRIMAS, a saber, arcillas, feldespatos, caolines, carbonatos y arenas, principalmente. Sobre todo en el caso de las arcillas, su procedencia natural exige una homogeneización previa que garantice la continuidad de sus características cerámicas. En Figura 3 se aprecian diferentes tipos de materias primas utilizadas en el sector cerámico [13].

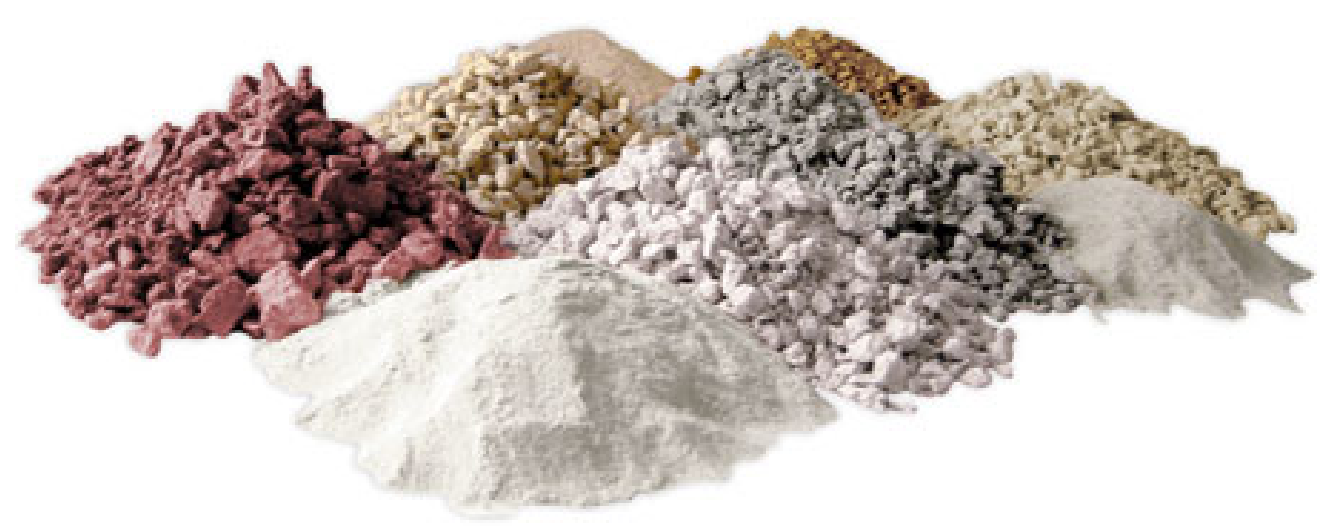

Figura 3. Diversidad de arcillas.

- TRITURACIÓN PREVIA DE LAS ARCILLAS, antes de su incorporación al molino de bolas de alúmina en continuo o al agitador mecánico potente que dispersa la arcilla en agua, en adelante "turbodesleidor". Con esta operación se reduce el tamaño del mineral "todo uno" procedente de la mina a un tamaño adecuado para la alimentación al molino industrial. Las arcillas, fundamentalmente las de importación, que vienen en barco, suelen presentar grandes tamaños, a veces aglomerados muy compactos de $30 \mathrm{~cm}$ de diámetro, debido a que la arcilla se apelmaza cuando contiene valores superiores de humedad al 10\%. Estos aglomerados deben deshacerse previamente para no obstruir la tolva de alimentación al 
molino continuo, el cual contiene de bolas de alúmina como elemento molturante [14].

- las arcillas españolas se suelen dispersar con agua y una cantidad de defloculante inferior al 1\% con el "turbodesleidor". En estos casos se trabaja a densidades bajas, del orden de $1,5 \mathrm{~g} / \mathrm{cm}^{3}$. De esta forma, es posible eliminar parte de la fracción arenosa y del hierro en forma de siderita de algunas arcillas procedentes de Teruel o, bien, rocas de hematita procedentes de las arcillas de Ciudad Real. Por tanto, estas arcillas se introducen en el molino continuo de bolas de alúmina en forma de una suspensión de barbotina, de manera que, para mantener el contenido en sólidos de la pasta en el molino, hay que reducir la cantidad de agua y defloculante que sería necesario utilizar inicialmente para una carga total de sólidos secos. El uso de estas arcillas españolas queda restringido a pastas que presenten un porcentaje en hierro superior a $0,6 \%$ y su composición en la fórmula raras veces alcanza el 15\% en peso. En la Figura 4 se observan 3 tipos de modelos de "turbodesleidores" [15]. 

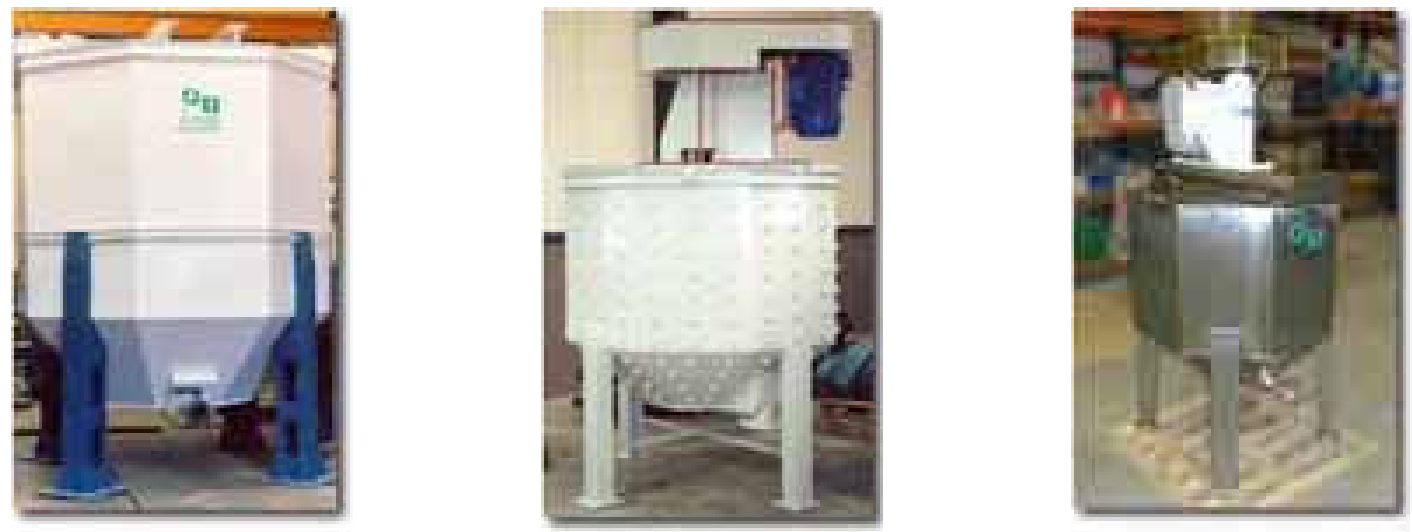

Figura 4. Varios modelos de "turbodesleidores".

- INTRODUCCIÓN DE LAS MATERIAS PRIMAS SÓLIDAS AL MOLINO DE BOLAS por cintas elevadoras, junto con la entrada de los componentes líquidos: barbotina de las arcillas españolas, agua procedente del lavado de los tamices presentes a la salida del molino (luz de malla de $114 \mu \mathrm{m}$ ), agua residual procedente de los clientes de pasta blanca y defloculante diluido.

- MOLTURACIÓN EN EL MOLINO DE BOLAS DE ALÚMINA a una densidad media de $1,70 \mathrm{~g} / \mathrm{cm}^{3}$ y a un rechazo másico a $63 \mu \mathrm{m}$ menor de 1,5\%. Los molinos estándares de pasta blanca pueden producir desde $10 \mathrm{Tm} / \mathrm{h}$ hasta $60 \mathrm{Tm} / \mathrm{h}$ aproximadamente. En la Figura 5 se pueden observar varios molinos discontinuos de pasta blanca [16]. 


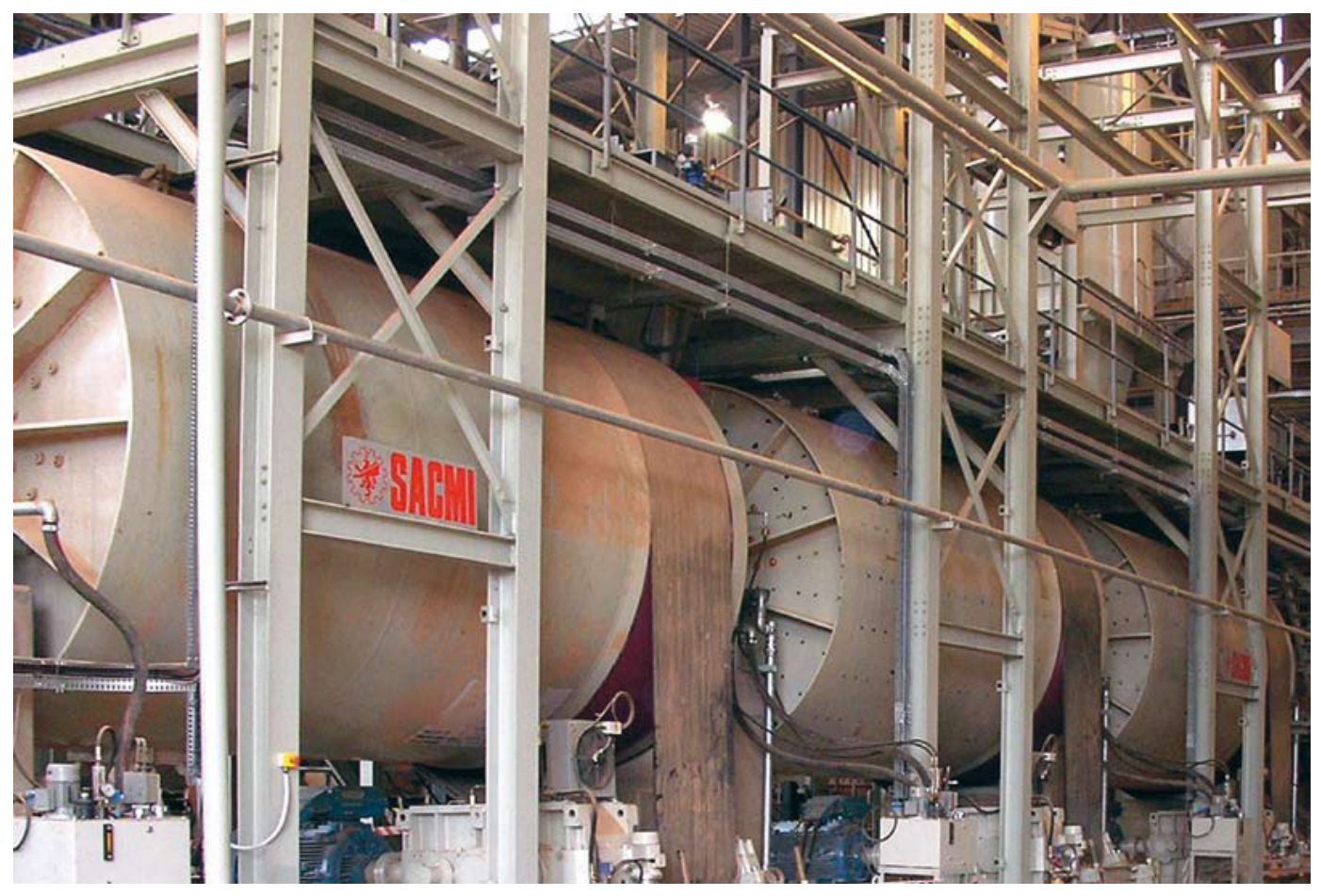

Figura 5. Molinos discontinuos en serie.

- tAMIZADO A $114 \mu \mathrm{M}$ a la salida del molino de la barbotina molturada, con el fin de evitar aglomerados o pequeñas bolas de alúmina, producidos por el desgaste de los mismos durante el propio proceso de producción. En la Figura 6, se observan las baterías de tamices situadas a la salida de los molinos discontinuos. 


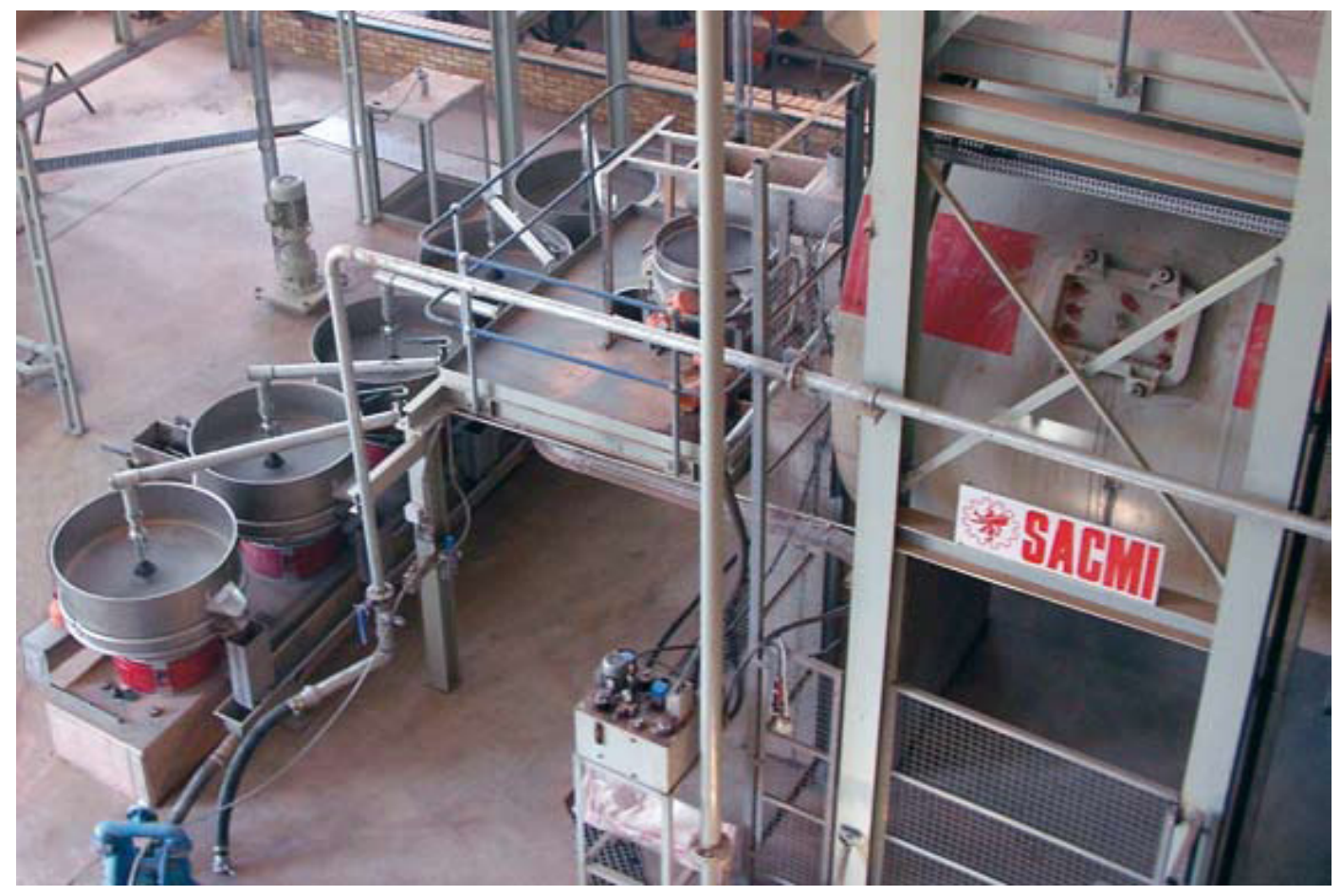

Figura 6. Batería de tamices a la salida del molino continuo.

- ATOMIZACIÓN DE LA BARBOtinA con una humedad de salida comprendida entre 6-7\%. De las diferentes configuraciones de secado por pulverización que existen, mostradas en la Figura 7, en cerámica se utiliza habitualmente el secado por pulverización tipo contracorrientes mixtas con aire descendente. De esta forma, la barbotina se nebuliza en finas gotas desde las toberas del anillo central en sentido ascendente, interaccionando con la corriente de aire caliente que desciende y es empujado hacia el exterior de la torre de secado por depresión (Figura 12). Así, por la parte inferior de la torre, se producen partículas sólidas con bajo contenido en agua [9]. 


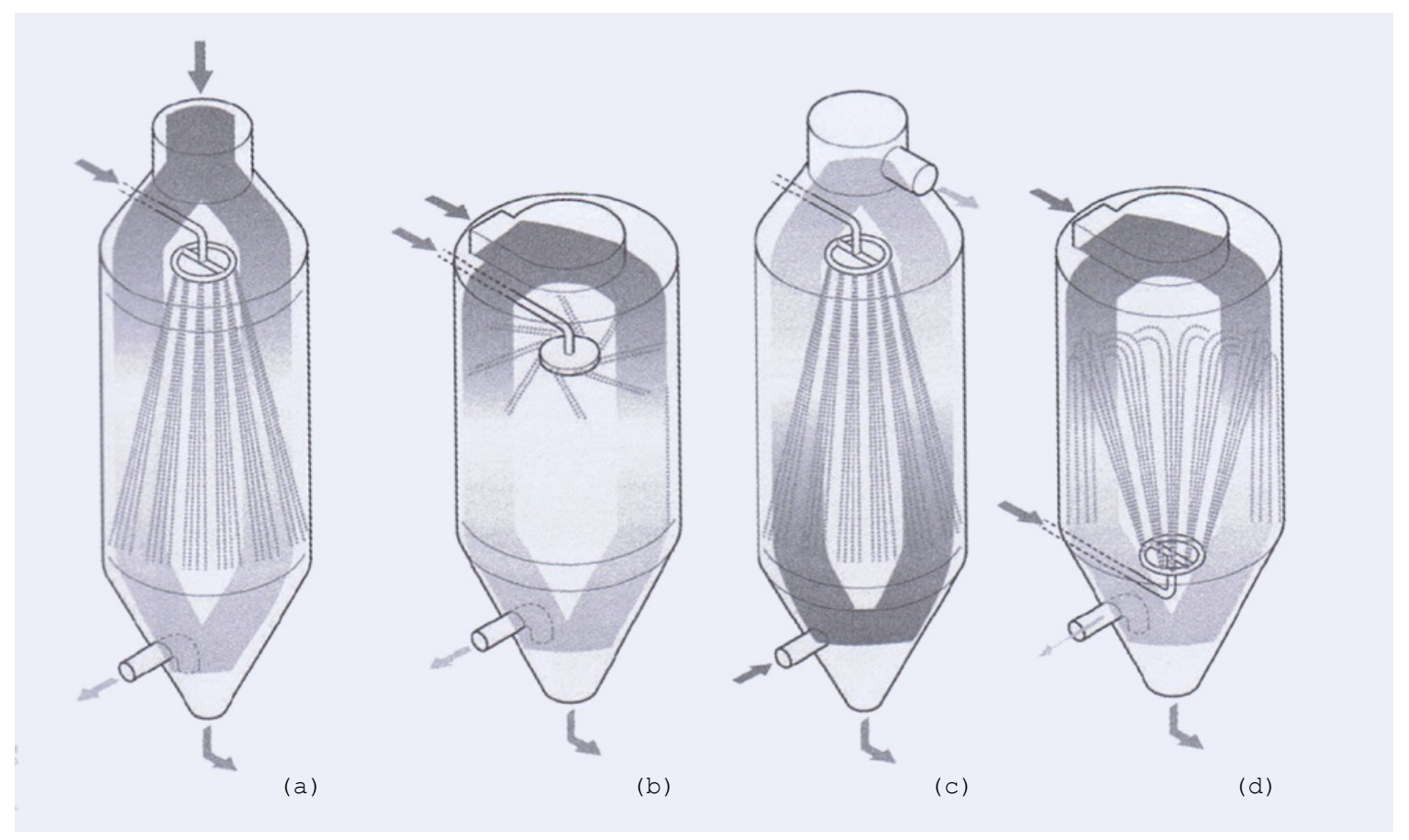

Figura 7. Diferentes configuraciones de secado por pulverización.

- Tipo equicorriente descendente, nebulización con toberas.

- Tipo equicorriente descendente, nebulización con turbinas.

- Tipo contracorriente, nebulización con toberas descendente, aire ascendente.

- Tipo contracorrientes mixtas, nebulización con toberas, aire descendente.

Para la nebulización de la suspensión se emplea generalmente el sistema con tobera, llamado centrífugo por presión, donde las condiciones de flujo bajo presión provocan, a través de insertos en forma de caracol, un movimiento rotatorio de las partículas a la salida de la tobera. En la Figura 8, se puede ver el esquema de las típicas toberas utilizadas en cerámica, de tipo llamado "caracol", donde un dispositivo en espiral imparte al fluido, bajo la acción de la presión aguas arriba, el movimiento rotatorio necesario para la dispersión del chorro con el impacto del aire externo. 


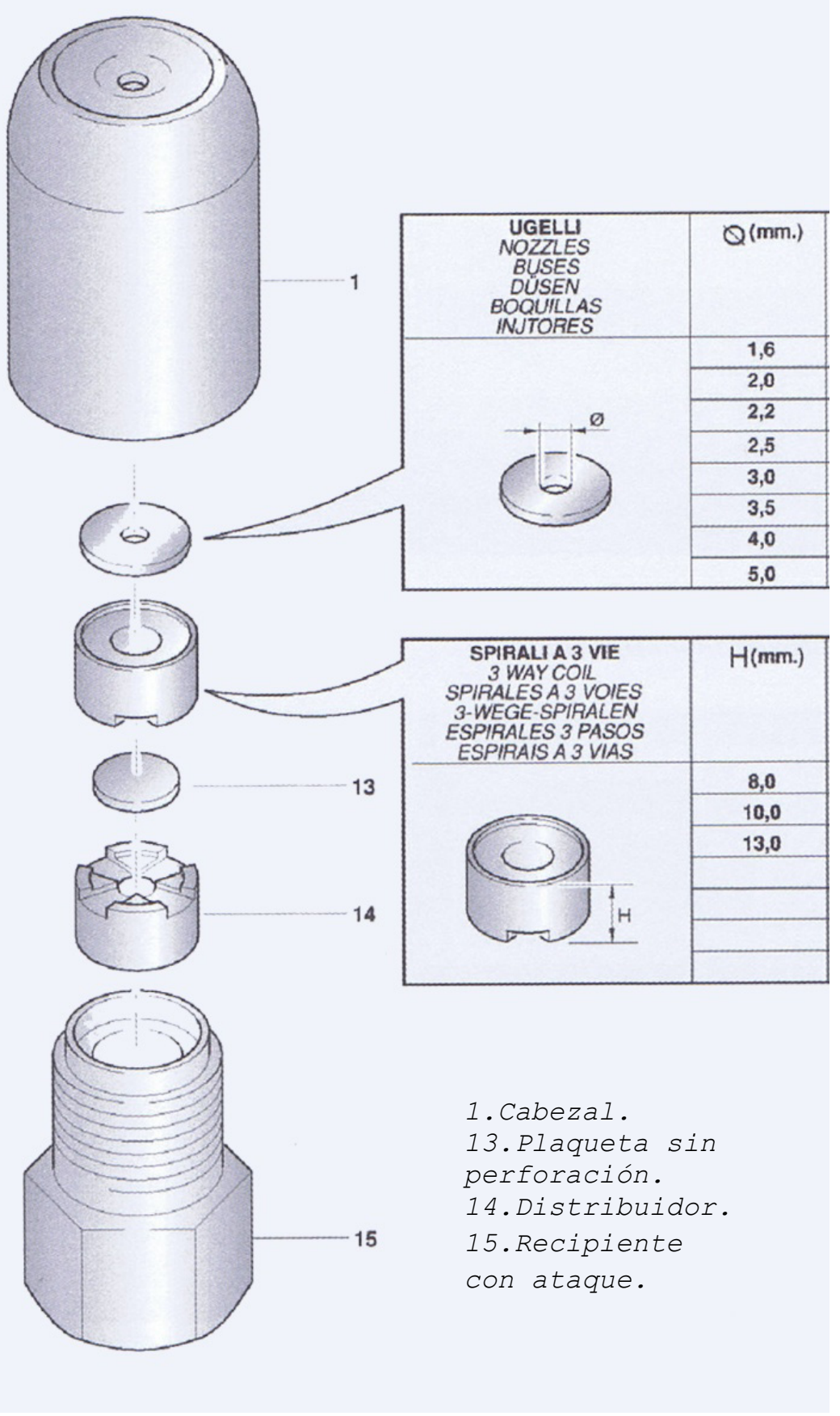

Figura 8. Representación de los componentes de una tobera.

La calidad de la nebulización depende de las características reológicas de la barbotina, de las dimensiones del atomizador y de las variables de funcionamiento de éste, como son: 
- Contenido en sólidos de la barbotina.

- Viscosidad, tensión superficial y temperatura de la barbotina.

- Presión y volumen de la torre del atomizador.

- Dimensiones de las toberas.

El sistema de nebulización por toberas presenta la ventaja de obtener una tolerancia granulométrica muy elevada, por lo que, una vez fijado el caudal y las características de la suspensión alimentada, resulta relativamente fácil alcanzar un óptimo control de todas las variables, hasta el punto que la distribución granulométrica del polvo producido puede modificarse empleando simplemente toberas de características diferentes en el mismo dispositivo. De este modo, se producen gránulos más o menos esféricos, huecos en su interior y muy uniformes, lo que confiere al polvo atomizado una elevada fluidez, facilitando las operaciones de llenado de los moldes de las prensas y también el prensado de piezas de gran formato. La Figura 9 y la Figura 10 muestran las micrografías realizadas a una muestra de los gránulos atomizados, mediante la observación a través del microscopio electrónico de barrido (MEB) [17]. 


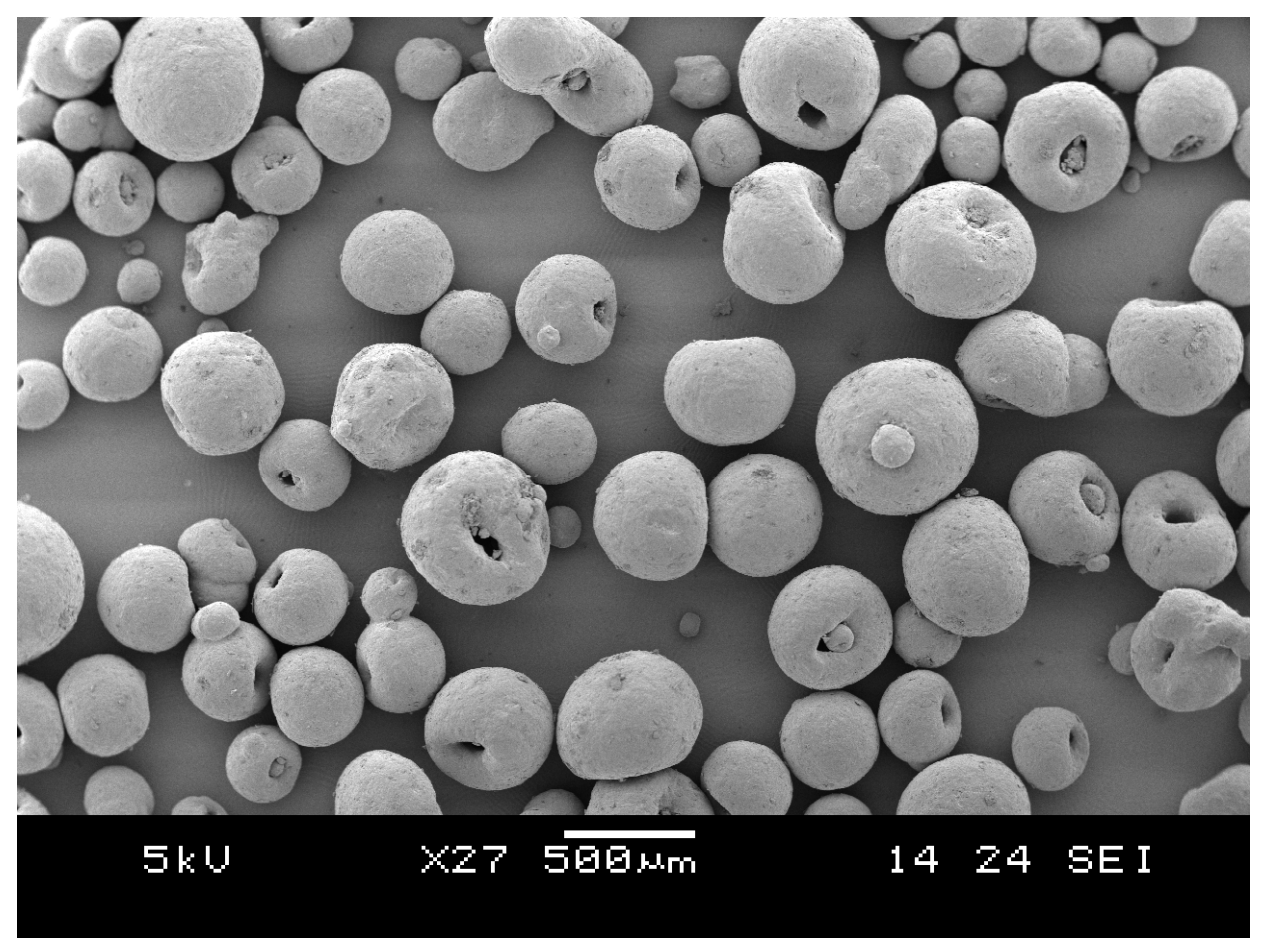

Figura 9. Micrografía de una muestra de gránulos de polvo atomizado.

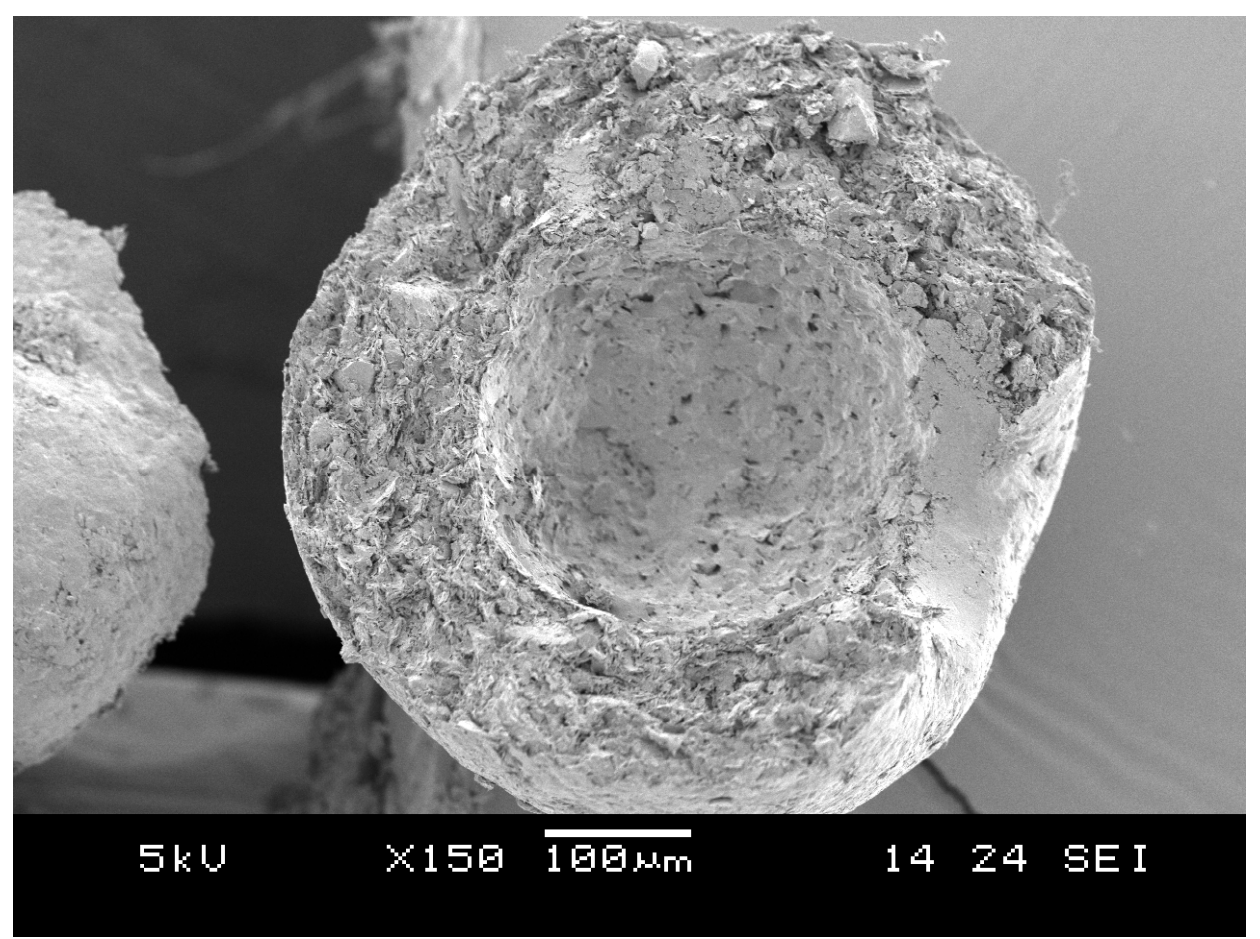

Figura 10. Micrografía de la sección de un gránulo de polvo atomizado. 
En la Figura 11, se observa la instalación de un atomizador industrial, en la que se destaca el atomizador (a la izquierda de la imagen), el ciclón (situado detrás de la escalera metálica), encargado de la primera eliminación de partículas de polvo, procedentes de los gases húmedos y, el "abatidor" (colocado a la derecha de la instalación), responsable de la eliminación de las partículas más finas que el ciclón no ha podido separar, mediante una pulverización de agua fría en sentido descendente [18].

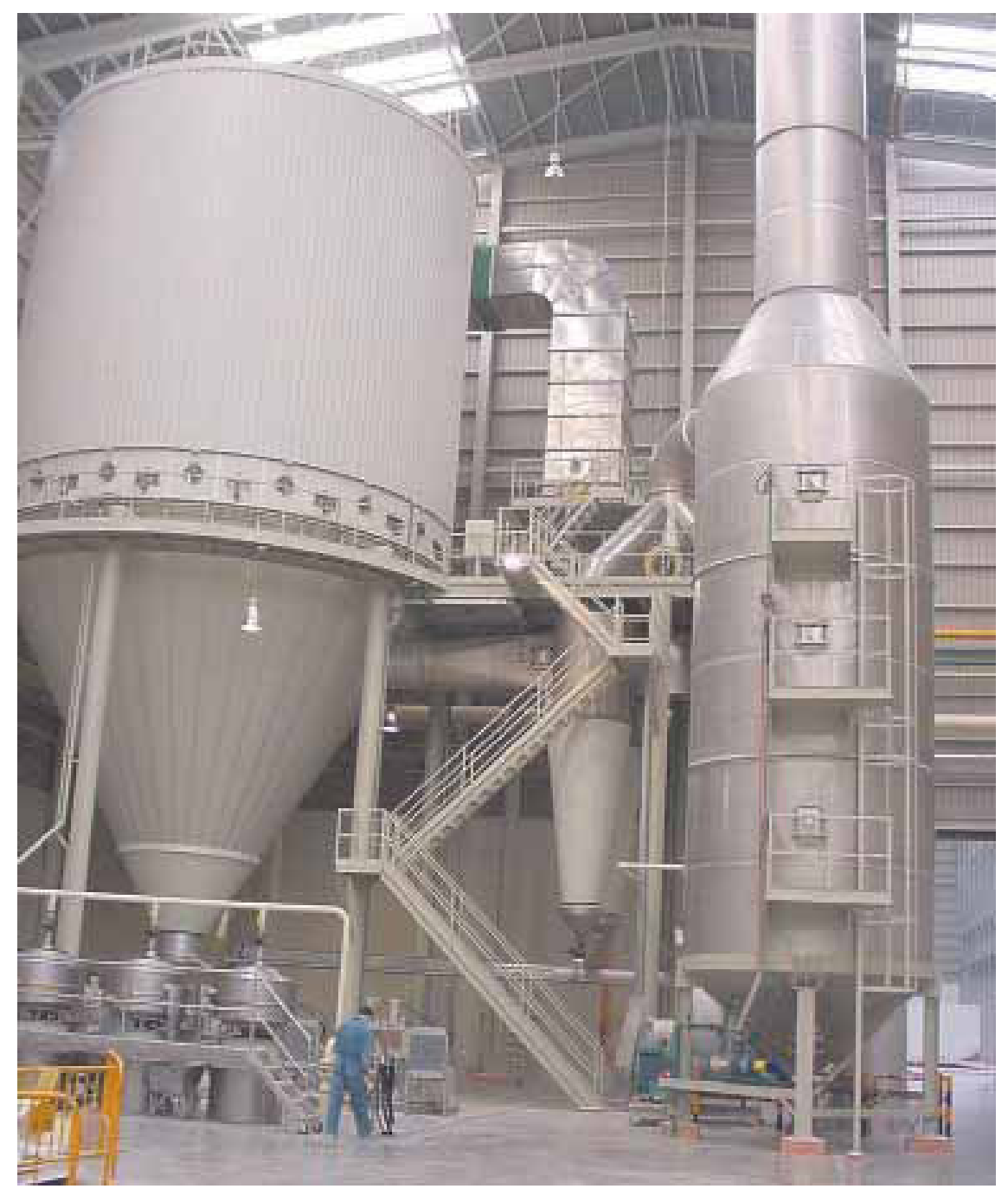

Figura 11. Instalación de un atomizador industrial. 
A continuación, en la Figura 12, se puede ver el esquema del proceso de atomización. El electroventilador de presurización empuja el aire a través del quemador que lo calienta a lo largo de una tubería de acero aislada térmicamente en el distribuidor anular que lo pone en rotación dentro de la torre de secado. El aire también puede proceder de una turbina de cogeneración, aprovechando los gases calientes a la salida de ésta. En la torre de secado el aire se encuentra con la barbotina que las bombas han enviado a presión constante, a través de los filtros, en una serie de toberas con orificio calibrado. Las toberas ubicadas en el anillo distribuidor o en lanzas radiales pulverizan la barbotina cerámica, de manera que las gotas salen disparadas a gran velocidad. El producto secado hasta una humedad entre 5-7\%, cae hacia el fondo de la torre donde se descarga en una cinta que lo transporta a los silos de almacenado. Los ciclones separadores capturan el aire húmedo y abaten gran parte del polvo fino en suspensión. El ventilador principal introduce el aire húmedo en el "abatidor" que acaba el tratamiento de filtrado del polvo. El aire limpio se expulsa hacia el exterior a través de la chimenea. Todo el ciclo de atomización está controlado mediante un equipo electrónico. 


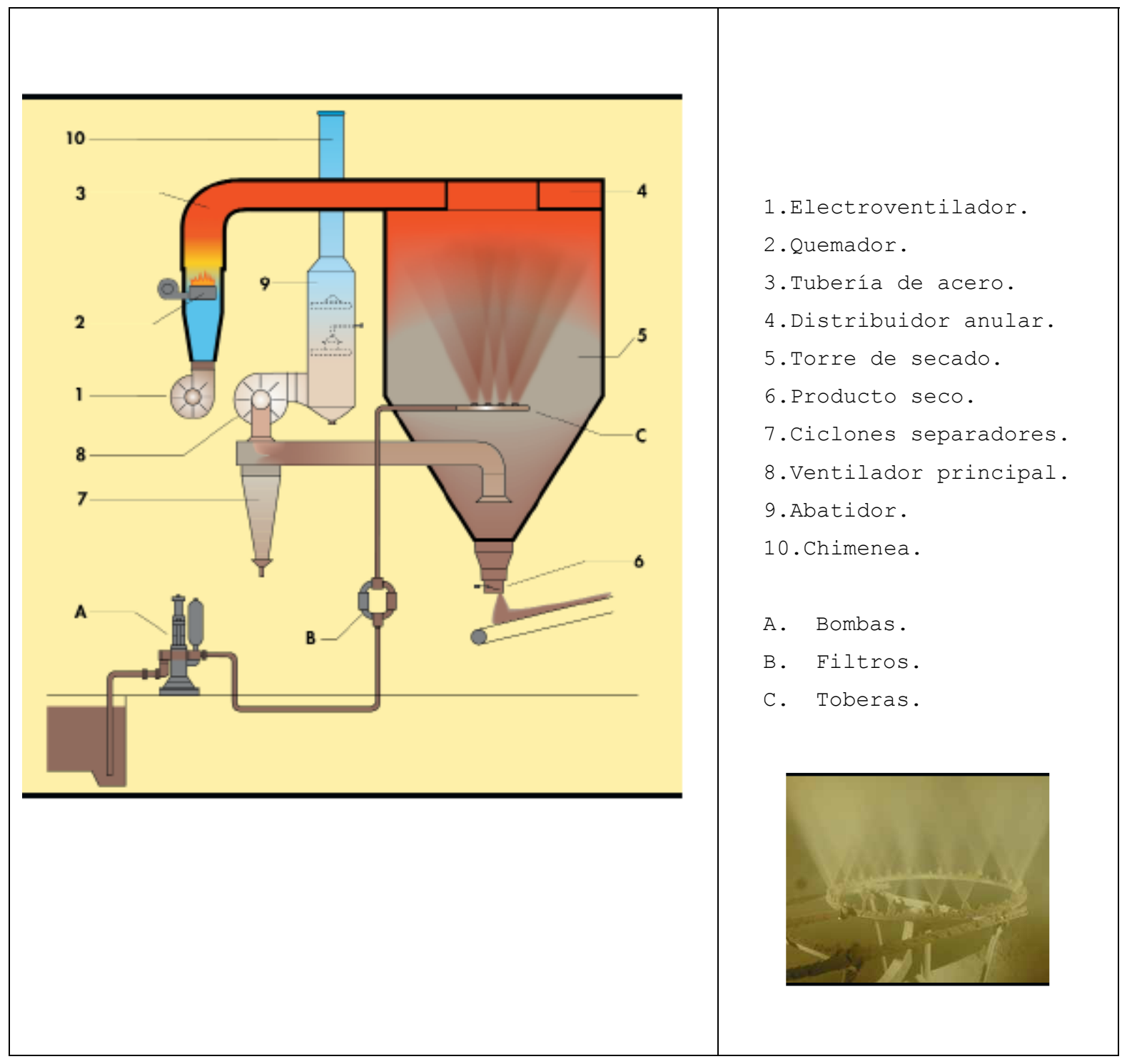

Figura 12. Esquema del proceso de secado por atomización.

La rentabilidad de este proceso de secado, de alto consumo energético, se consigue aumentar gracias a la etapa de cogeneración. Esta técnica permite producir calor y electricidad en un único proceso, de modo que, se aprovecha el calor de los gases procedentes de las turbinas que generan electricidad. Una central de cogeneración de electricidad-calor funciona con turbinas o motores de gas. El gas natural (gas metano) es la 
energía primaria más utilizada corrientemente para hacer funcionar las centrales de cogeneración del sector cerámico [19].

\subsubsection{Función de las materias primas en la pasta.}

En este apartado, se va a detallar la función de cada materia prima en la formulación de la pasta, así como los porcentajes en peso de una composición tipo de pasta blanca [3], [8], [20], [21], [22], [23]:

- arcillas (35-50\% en peso). Su cometido en la pasta es aportar las propiedades de plasticidad y resistencia mecánica al conjunto de la composición, muy rica en desgrasantes (feldespatos y arenas). Además, las arcillas deben ser suficientemente fundentes y presentar una pauta de sinterización-vitrificación y de producción de mullita adecuada, siendo ésta el silicato de alúmina producto de la descomposición de la caolinita (silicoaluminato con estructura cristalina constituida por capas, $\left.\mathrm{Al}_{2}\left(\mathrm{Si}_{2} \mathrm{O}_{5}\right)(\mathrm{OH})_{4}\right)$. Por último, la arcilla debe poseer también un nivel muy bajo de impurezas coloreadas para proporcionar un color de cocción de elevada blancura. Por estos tres motivos, a saber, la plasticidad, la fundencia y la blancura, se vienen utilizando arcillas tipo "ball clay" de importación, procedentes de Ucrania e Inglaterra principalmente. Las arcilla tipo "ball clay" son arcillas caolinítico-illíticas de elevada plasticidad y dispersables en agua, en las que la caolinita se encuentra en un mayor grado de degradación cristalina, y en partículas de menor tamaño, que en el caso de los caolines. 
- CAOLINES (5-10\% en peso). Se utilizan en pastas que requieren un nivel mayor de blancura, sustituyendo parte de las arcillas plásticas. Son arcillas que cuecen de color blanco o crema y cuya composición mineralógica se aproxima a la de la caolinita pura. Se obtienen por un proceso de beneficio del caolín bruto.

- FELDESPATOS (40-50\% en peso). Representan la fracción responsable de la formación de fase vítrea que inicia la sinterización y promociona la disolución de los demás componentes. Se trata de minerales silicoaluminosos, cuya estructura cristalina es tridimensional en armazón. Habitualmente se prefiere el feldespato sódico $\left(\mathrm{NaAlSi}{ }_{3} \mathrm{O}_{8}\right.$, del grupo de la plagioclasa) por su mayor fundencia y bajos contenidos de hierro. El feldespato potásico (KAlSi ${ }_{3} \mathrm{O}_{8}$, del grupo de la ortoclasa) proporciona viscosidades más elevadas unidas a una temperatura de fusión mayor. En España existen yacimientos de feldespato potásico, pero es deficitario en feldespato sódico, que necesariamente se tiene que importar de Turquía o Cerdeña, principalmente. Cuando se utiliza en la pasta de revestimiento poroso, la función del feldespato consiste sólo en mejorar la permeabilidad para la desgasificación, al tiempo que aumenta la compacidad, disminuye la contracción de secado y facilita la defloculación.

- arenas silíceas y ARENAS Feldespáticas (0-10\% en peso). En la pasta blanca, éstas tienen la función de agentes desgrasantes para mejorar la compactación. El cuarzo introducido permanece la mayor parte sin disolverse en la fase vítrea, en función de su granulometría y condiciones de cocción. Contribuye de este modo al refuerzo y a la opacificación de la matriz 
vítrea en el producto cocido. Se trata de los componentes más económicos, con diferencia, de la composición. En el caso de revestimiento poroso, funcionan de la misma manera que los feldespatos. Las arenas feldespáticas presentan en su composición restos de mineral feldespático, seguramente procedente de su roca madre, la pegmatita.

- talco, wOLLASTONita Y DiÓPsido. Se pueden introducir en pequeñas proporciones en la pasta blanca de pavimento, hasta el 2\% en peso, para formar eutécticos de baja temperatura de fusión $y$, poder disminuir el porcentaje de feldespato utilizado, reduciendo el coste de la fórmula. Sin embargo, su empleo puede perjudicar el intervalo de estabilidad de la pasta. Por eso, apenas se utilizan en la actualidad. Las fórmulas empíricas de cada uno de estos minerales son: talco $\left(\mathrm{Mg}_{3}(\mathrm{OH})_{2}\left(\mathrm{Si}_{2} \mathrm{O}_{5}\right)_{2}\right)$, wollastonita $\left(\mathrm{CaSiO}_{3}\right)$, diópsido $\left(\mathrm{MgCaSi}_{2} \mathrm{O}_{6}\right)$.

- CARBONAto de CALCiO $(0-15 \%$ peso). Se utiliza sólo para fabricar pasta blanca de revestimiento. Durante la cocción, el óxido de calcio reacciona con las fases amorfas provenientes de la descomposición de los minerales arcillosos para formar silicatos y silicoaluminatos estables frente a la acción de la humedad. Así los carbonatos retrasan el proceso de gresificación conteniendo la contracción lineal, ya que predominan las fases cristalinas frente a las amorfas. Su función en la pasta consiste en garantizar la estabilidad dimensional de las piezas cocidas y también, en reducir la expansión por humedad de las mismas. Su fórmula empírica es $\mathrm{CaCO}_{3}$.

En la Figura 13, se muestra una panorámica general de un almacén de materias primas, pertenecientes a una empresa atomizadora de Castellón [24]. 


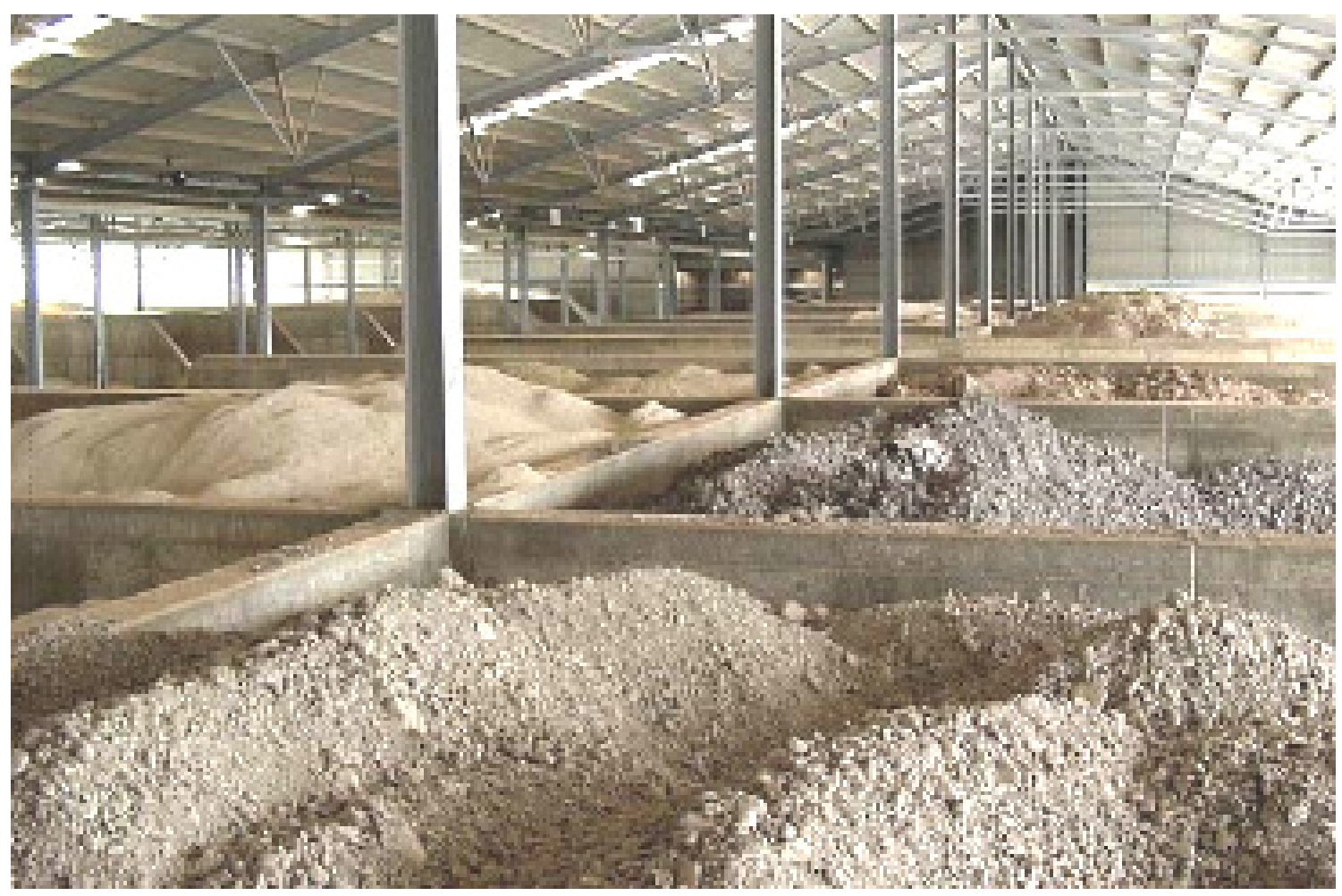

Figura 13. Disposición de un almacén de materias primas ("granero") de una empresa atomizadora de arcillas.

\subsubsection{Tipos de pasta blanca.}

Seguidamente, se hará una breve introducción de los tres tipos básicos de pasta blanca que se produce en la actualidad, dentro del sector cerámico [1], [8], [11].

a) Porcelánico Técnico.

Se trata de un producto que, en principio, se destinó al recubrimiento de suelos con elevadas prestaciones técnicas, como espacios industriales o públicos sometidos a altas solicitaciones de resistencia mecánica, química, a la abrasión y a la helada. Se 
trataba de piezas homocromáticas y tamaños no superiores a 100x200 $\mathrm{mm}^{2}$. Posteriormente, se extienden sus posibilidades de aplicación a las viviendas familiares, mejorando sus cualidades estéticas a través del pulido y ampliando el rango cromático de la pasta. Un requisito importante que debe presentar esta pasta es además, un elevado grado de blancura (contenido de $\mathrm{Fe}_{2} \mathrm{O}_{3}<0.5 \%$ ) y un buen desarrollo del color mediante pigmentos cerámicos [21], [25], $[26],[27]$.

Para lograr estos requisitos, el porcelánico técnico cocido debe presentar una microestructura caracterizada por:

- Una porosidad abierta prácticamente nula, para evitar la absorción de agua y la retención de materiales capaces de producir manchas y que minimice la superficie expuesta al ataque químico. Para ello, se necesita una fuerte micronización de la pasta, que presente un residuo a 63 micrómetros inferior al 1\%.

- Mínima porosidad cerrada, la cual pudiera quedar expuesta al exterior tras un tratamiento de pulido. Además, conviene que esta microestructura porosa cerrada esté constituida por poros de pequeño tamaño aislados entre sí, lo que contribuye mejorar las prestaciones mecánicas del material.

- Una matriz vítrea con abundante fase cristalina que actúe a modo de refuerzo, mejorando las cualidades mecánicas del producto. A su vez, la proporción de fase cristalina y su poder opacificante influirán en la blancura y desarrollo del color. 
b) Porcelánico Esmaltado.

En el caso del porcelánico esmaltado, se reduce la problemática de la elevada blancura y la resistencia a las manchas que se le exige al porcelánico técnico, de manera que es posible utilizar materias primas de menor calidad y se reduce, a su vez el grado de molienda:

- La tolerancia de contenido en $\mathrm{Fe}_{2} \mathrm{O}_{3}$ de la composición se eleva a rangos superiores al 1\%.

- El residuo de la pasta sobre 63 micrómetros aumenta hasta valores del orden de $1,5-2,0 \%$ en peso.

En estas condiciones se puede sustituir parte de arcillas plásticas de importación por arcillas españolas de menor calidad, procedentes de Teruel y en menor medida, de Palencia o Ciudad Real.

c) Revestimiento.

El revestimiento corresponde al polvo atomizado usado para fabricar el soporte de los azulejos que revisten las paredes. En general, a la pasta de revestimiento se le exige una alta estabilidad dimensional, para lo cual interesa una composición con una baja contracción de cocción, que va unida a una alta porosidad. De este modo, las piezas de revestimiento presentan una mayor facilidad para su colocación, mejorando el agarre sobre superficies verticales. 
Sin embargo, la pieza de revestimiento es accesible al agua, haciéndola susceptible de sufrir la hidratación de las fases amorfas y vítreas presentes, lo que lleva consigo una expansión por humedad y puede llegar a producir, curvaturas o cuarteos en el esmalte. Debido a esto, es necesario que las piezas cocidas presenten una elevada proporción de fases cristalinas con mínima presencia de fases amorfas.

La estabilidad dimensional, la alta porosidad y la formación de fases cristalinas se consiguen, normalmente, mediante el empleo de una mezcla de arcillas no calcáreas de bajo contenido en óxido de hierro, junto a un conjunto de materias primas desgrasantes, destacando las materias primas que aporten óxido de calcio a la composición. Este óxido reacciona con la sílice y alúmina provenientes de la deshidroxilación de los minerales arcillosos para formar silicatos y silicoaluminatos cálcicos estables frente a la acción de la humedad. Como ejemplos de silicatos y silicoaluminatos formados tras la cocción, se citan la wollastonita $\left(\mathrm{CaSiO}_{3}\right)$, la gelenita $\left(\mathrm{Ca}_{2} \mathrm{Al}(\mathrm{AlSi}) \mathrm{O}_{7}\right)$ y la anortita $\left(\mathrm{CaAl}_{2} \mathrm{Si}_{2} \mathrm{O}_{8}\right) \quad[28]$.

Las características técnicas requeridas de las pastas se pueden ver en la Tabla I, Tabla II y Tabla III, donde se resumen las propiedades más destacables del producto acabado. 
Tabla I. Requisitos técnicos de las pastas cerámicas.

\begin{tabular}{|c|c|c|c|}
\hline REQUISITOS & $\begin{array}{l}\text { PORCELANICO } \\
\text { TÉCNICO }\end{array}$ & $\begin{array}{l}\text { PORCELANICO } \\
\text { ESMALTADO }\end{array}$ & POROSA \\
\hline $\begin{array}{c}\text { Granulometría } \\
(63 \mu \mathrm{m})\end{array}$ & $<1,0 \%$ & $<2,0 \%$ & $<2,5$ 응 \\
\hline Defloculación & $\begin{array}{c}\mathrm{CS}^{1}>65 \% \\
\frac{\circ \operatorname{Def} l o C^{2}<0,6}{} \div\end{array}$ & $\begin{array}{c}C S>65 \% \\
\text { Defloc }<0,6 \%\end{array}$ & $\begin{array}{c}\mathrm{CS}>65 \% \\
\% \operatorname{Defloc}<0,6 \%\end{array}$ \\
\hline $\begin{array}{c}\text { Compacidad } \\
\text { seco }\end{array}$ & $\operatorname{Dap}^{3}>1,92 \mathrm{~g} / \mathrm{cm}^{3}$ & Dap $>1,92 \mathrm{~g} / \mathrm{cm}^{3}$ & Dap $>1,92 \mathrm{~g} / \mathrm{cm}^{3}$ \\
\hline $\begin{array}{c}\text { Expansión } \\
\text { post-prensado }\end{array}$ & $<0,7$ \% & $<0,7 \div$ & $<0,6 \div($ baja $)$ \\
\hline $\begin{array}{c}\text { Contracción de } \\
\text { secado }\end{array}$ & $<0,3$ 응 & $<0,3 \%$ & $<0,2 \%($ baja $)$ \\
\hline $\begin{array}{c}\text { Resistencia } \\
\text { mecánica en } \\
\text { seco }\end{array}$ & $\begin{array}{c}>30 \mathrm{Kg} / \mathrm{cm}^{2} \\
(\text { alta })\end{array}$ & $\begin{array}{c}>30 \mathrm{Kg} / \mathrm{cm}^{2} \\
(\text { alta })\end{array}$ & $\begin{array}{c}>25 \mathrm{Kg} / \mathrm{cm}^{2} \\
(\text { media) }\end{array}$ \\
\hline$\frac{\circ}{2} \mathrm{Fe}_{2} \mathrm{O}_{3}$ & $<0,5$ 응 & $<1,0 \div$ & $<1,2 \%$ \\
\hline $\begin{array}{l}\text { Contracción } \\
\text { por cocción }\end{array}$ & $>7 \%$ & $>7 \%$ & $<1,5 \div($ baja $)$ \\
\hline $\begin{array}{c}\text { Expansión por } \\
\text { humedad }\end{array}$ & - & - & $<0,06 \div($ baja $)$ \\
\hline $\begin{array}{l}\text { Formación de } \\
\text { fase vítrea }\end{array}$ & $\begin{array}{c}\text { Alta, a } \\
\text { temperatura de } \\
\text { trabajo } \\
1180^{\circ} \mathrm{C}-1230^{\circ} \mathrm{C}\end{array}$ & $\begin{array}{c}\text { Alta, a } \\
\text { temperatura de } \\
\text { trabajo } \\
1180^{\circ} \mathrm{C}-1230^{\circ} \mathrm{C} .\end{array}$ & $\begin{array}{c}\text { Baja a } \\
\text { temperatura de } \\
\text { trabajo } \\
1050^{\circ} \mathrm{C}-1140^{\circ} \mathrm{C}\end{array}$ \\
\hline
\end{tabular}

${ }^{1}$ Contenido en sólidos.

${ }^{2}$ Porcentaje de defloculante respecto del sólido seco.

${ }^{3}$ Densidad aparente en seco de las piezas cerámicas. 
Tabla II. Propiedades más importantes que presentan las baldosas cerámicas por tipología.

\begin{tabular}{|c|c|c|c|}
\hline CONCEPTO & $\begin{array}{l}\text { PORCELANICO } \\
\text { TÉCNICO }\end{array}$ & $\begin{array}{l}\text { PORCELANICO } \\
\text { ESMALTADO }\end{array}$ & POROSA \\
\hline \multirow{4}{*}{ PRODUCTO } & $\begin{array}{c}\text { Alta resistencia } \\
\text { mecánica }\end{array}$ & $\begin{array}{c}\text { Alta resistencia } \\
\text { mecánica }\end{array}$ & $\begin{array}{l}\text { Estabilidad } \\
\text { dimensional. }\end{array}$ \\
\hline & Blancura & Blancura & $\begin{array}{c}\text { Baja } \\
\text { expansión por } \\
\text { humedad }\end{array}$ \\
\hline & $\begin{array}{c}\text { Resistencia a las } \\
\text { manchas }\end{array}$ & $\begin{array}{c}\text { Resistencia a las } \\
\text { manchas }\end{array}$ & \\
\hline & $\begin{array}{c}\text { Resistencia a la } \\
\text { helada }\end{array}$ & $\begin{array}{c}\text { Resistencia a la } \\
\text { helada }\end{array}$ & \\
\hline \multirow{4}{*}{ PROCESO } & $\begin{array}{l}\text { Molienda vía } \\
\text { húmeda }\end{array}$ & $\begin{array}{l}\text { Molienda vía } \\
\text { húmeda }\end{array}$ & $\begin{array}{l}\text { Molienda vía } \\
\text { húmeda }\end{array}$ \\
\hline & Atomización & Atomización & Atomización \\
\hline & Prensado & Prensado & Prensado \\
\hline & $\begin{array}{l}\text { Monococción } \\
\text { rápida }\end{array}$ & $\begin{array}{l}\text { Monococción } \\
\text { rápida }\end{array}$ & $\begin{array}{l}\text { Monococción } \\
\text { rápida }\end{array}$ \\
\hline \multirow{3}{*}{$\begin{array}{l}\text { MECANISMO Y } \\
\text { MORFOLOGIA }\end{array}$} & $\begin{array}{l}\text { Disminución de } \\
\text { porosidad por } \\
\text { formación de fase } \\
\text { líquida }\end{array}$ & $\begin{array}{l}\text { Disminución de } \\
\text { porosidad por } \\
\text { formación de fase } \\
\text { líquida }\end{array}$ & $\begin{array}{c}\text { Formación de } \\
\text { fases } \\
\text { cristalinas }\end{array}$ \\
\hline & $\begin{array}{c}\text { Estructura de } \\
\text { material } \\
\text { compuesto }\end{array}$ & $\begin{array}{c}\text { Estructura de } \\
\text { material } \\
\text { compuesto }\end{array}$ & $\begin{array}{c}\text { Estructura de } \\
\text { material } \\
\text { cristalino }\end{array}$ \\
\hline & $\begin{array}{c}\text { Granulometría muy } \\
\text { fina }\end{array}$ & $\begin{array}{l}\text { Granulometría } \\
\text { fina }\end{array}$ & $\begin{array}{c}\text { Granulometría } \\
\text { fina }\end{array}$ \\
\hline
\end{tabular}


Tabla III. Requisitos para la preparación de las pastas y tipos de materias primas.

\begin{tabular}{|c|c|c|c|}
\hline CONCEPTO & $\begin{array}{l}\text { PORCELANICO } \\
\text { TÉCNICO }\end{array}$ & $\begin{array}{l}\text { PORCELANICO } \\
\text { ESMALTADO }\end{array}$ & POROSA \\
\hline \multirow{8}{*}{$\begin{array}{c}\text { REQUISITOS } \\
\text { PARA LA } \\
\text { PREPARACIÓN } \\
\text { DE LAS PASTAS }\end{array}$} & Fundencia & Fundencia & $\begin{array}{l}\text { Estabilidad } \\
\text { dimensional }\end{array}$ \\
\hline & Empaquetamiento & Empaquetamiento & Plasticidad \\
\hline & $\begin{array}{c}\text { Sin } \\
\text { desgasificaciones } \\
\text { a altas } \\
\text { temperaturas }\end{array}$ & $\begin{array}{c}\text { Sin } \\
\text { desgasificaciones } \\
\text { a altas } \\
\text { temperaturas }\end{array}$ & \\
\hline & Molienda fácil & Molienda fácil & \\
\hline & Plasticidad & Plasticidad & \\
\hline & $\begin{array}{c}\text { Resistencia } \\
\text { mecánica }\end{array}$ & $\begin{array}{c}\text { Resistencia } \\
\text { mecánica }\end{array}$ & \\
\hline & $\begin{array}{l}\text { Bajo contenido en } \\
\text { materia orgánica }\end{array}$ & $\begin{array}{l}\text { Bajo contenido en } \\
\text { materia orgánica }\end{array}$ & \\
\hline & $\begin{array}{c}\text { Sistema } \\
\mathrm{SiO}_{2}-\mathrm{Al}_{2} \mathrm{O}_{3}- \\
\mathrm{K}_{2} \mathrm{O} / \mathrm{Na}_{2} \mathrm{O}\end{array}$ & $\begin{array}{c}\text { Sistema } \\
\mathrm{SiO}_{2}-\mathrm{Al}_{2} \mathrm{O}_{3}- \\
\mathrm{K}_{2} \mathrm{O} / \mathrm{Na}_{2} \mathrm{O}\end{array}$ & $\begin{array}{c}\text { Sistema } \\
\mathrm{SiO}_{2}-\mathrm{Al}_{2} \mathrm{O}_{3}-\mathrm{CaO}\end{array}$ \\
\hline \multirow{4}{*}{$\begin{array}{l}\text { TIPOS DE } \\
\text { MATERIAS } \\
\text { PRIMAS }\end{array}$} & $\begin{array}{l}\text { Arcillas de } \\
\text { cocción blanca }\end{array}$ & $\begin{array}{c}\text { Arcillas de } \\
\text { cocción } \\
\text { blanca/crema }\end{array}$ & $\begin{array}{c}\text { Arcillas de } \\
\text { cocción } \\
\text { blanca/crema }\end{array}$ \\
\hline & Feldespatos & Feldespatos & $\begin{array}{c}\text { Feldespatos } \\
\text { Sódicos }\end{array}$ \\
\hline & $\begin{array}{c}\text { Arenas } \\
\text { feldespáticas }\end{array}$ & $\begin{array}{c}\text { Arenas } \\
\text { feldespáticas }\end{array}$ & $\begin{array}{c}\text { Arenas } \\
\text { silíceas }\end{array}$ \\
\hline & Caolines & & Carbonatos \\
\hline
\end{tabular}

En la Tabla IV se indican algunas formulaciones típicas de pasta blanca. 
Tabla IV. Algunos ejemplos de formulaciones de pasta blanca descritos en la bibliografía, en $\frac{\circ}{0}$ en peso.

\begin{tabular}{|c|c|c|c|}
\hline $\begin{array}{c}\text { MATERIAS } \\
\text { PRIMAS }\end{array}$ & $\begin{array}{c}\text { PORCEIANICO } \\
\text { TÉCNICO }\end{array}$ & $\begin{array}{l}\text { PORCELANICO } \\
\text { ESMALTADO }\end{array}$ & POROSA \\
\hline $\begin{array}{l}\text { Arcillas } \\
\text { españolas }\end{array}$ & $0-10 \%$ & $30-55 \div$ & $30-60 \div$ \\
\hline $\begin{array}{l}\text { Arcillas de } \\
\text { importación }\end{array}$ & $35-50 \%$ & $0-20 \div$ & $0-25 \div$ \\
\hline Caolín & $0-10 \%$ & $0-10 \%$ & $0-10 \div$ \\
\hline $\begin{array}{l}\text { Carbonato } \\
\text { cálcico }\end{array}$ & - & - & $12-15 \%$ \\
\hline $\begin{array}{c}\text { Arena } \\
\text { feldespática }\end{array}$ & $0-10 \%$ & $0-10 \%$ & $15-25 \%$ \\
\hline Feldespato & $35-55 \%$ & $35-55 \%$ & $0-10 \%$ \\
\hline
\end{tabular}

\subsection{Descripción de las arcillas que se utilizan en la actualidad para formular pasta blanca.}

En la mayoría de los casos, para formular pasta blanca, las arcillas que se utilizan son del tipo "ball clay" [2], [5], [8], [6], ya que su alta calidad facilita la conformación de las piezas y las dotan de alta resistencia mecánica en crudo y en cocido. Sus características se enumeran a continuación:

- Arcillas sedimentarias de cocción blanca.

- Se dispersan en agua sin excesivas dificultades, con un defloculante adecuado. 
- Presentan colores oscuros causados por la presencia de materia orgánica, pero después de la cocción presentan color blanco.

- Suelen contener fases mineralógicas de caolinita muy desordenada.

- Su granulometría se caracteriza por contener altos porcentajes de partículas finas, de tamaño inferior a 2 $\mu \mathrm{m}$.

- Poseen una elevada plasticidad.

La forma de presentación comercial de las arcillas tipo "ball clay" es bien a granel o bien depuradas (lavadas) en forma de aglomerados (pélets) extrusionados. Las arcillas tipo "ball clay" que se consumen en la industria cerámica española se pueden dividir en dos grupos según su lugar de procedencia: arcillas de importación y arcillas españolas.

\subsubsection{Arcillas tipo "ball clay" de importación.}

Las arcillas de importación tipo "ball clay" proceden de los siguientes países.

- REINO UNIDO: Son las arcillas de mayor volumen de consumo. Los depósitos se encuentran en el sureste de Inglaterra, distinguiéndose tres áreas de explotación: Dorset, Devon Sur y Devon Norte. En los tres casos se trata de depósitos lacustres pero, las variaciones en el tipo de roca madre y en los procesos de meteorización y sedimentación sufridos ha originado un amplio rango de calidades. Debido a ello, se explotan los distintos yacimientos y las distintas capas por separado para 
después, mezclarse en proporciones adecuadas y obtener, de este modo, productos uniformes y constantes. Las arcillas de Devon sur destacan por su bajo contenido en óxidos colorantes, mayor proporción de caolinita y de mayor cristalinidad, menor proporción de cuarzo y un mayor contenido en materia orgánica (recuerdan a un caolín con mayor plasticidad). Las arcillas de Devon Norte presentan un mayor tamaño de grano y mayor contenido en cuarzo, pudiendo contener pequeñas cantidades de montmorillonita, ofreciendo una mejor compacidad. Las arcillas de Dorset se caracterizan por su pequeño tamaño de grano y elevada plasticidad, presentando cierta coloración crema a causa de sustituciones isomorfas de hierro en la estructura de la caolinita. Destaca su elevada resistencia mecánica en seco. Los principales productores son ECC International y WBB Minerals.

- ALEMANIA: La principal zona de explotación se localiza al oeste del país, en la región de Westerwald. Su origen difiere del de las "ball clays" inglesas, ya que presentan una mayor variabilidad en su composición mineralógica. También contienen materia orgánica, un contenido variable de cuarzo (10-60\%) y un escaso porcentaje de feldespato. El contenido en hierro también es variable y puede presentar proporciones elevadas de montmorillonita, un tipo de arcilla muy plástica. El mayor productor en este país es también la compañía WBB Minerals. 
- UCRANIA: Se trata de depósitos sedimentarios localizados en la región de Donetsk, cerca del mar de Azov, donde son transportadas vía marítima a los centros de consumo. Son arcillas caolinitico-illíticas, con proporción media en cuarzo y bajo contenido en hierro. Destacan por la conjunción de sus propiedades: plasticidad, blancura y fundencia. Su destino principal es la elaboración de gres porcelánico. Las principales productoras son WBB Minerals, Vesco y Damrec. En la Figura 14, se puede observar una explotación "a cielo abierto" de arcillas de tipo "ball clay" ubicada en Ucrania.

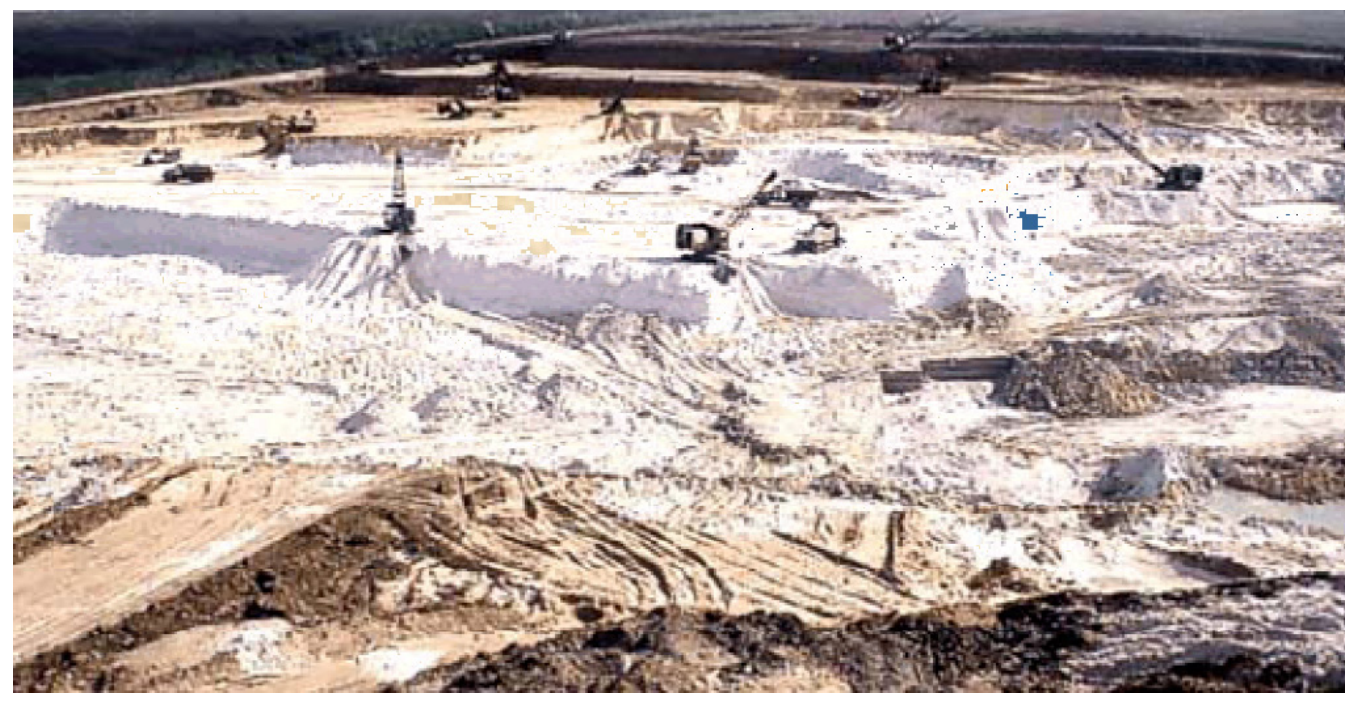

Figura 14. Explotación de arcillas tipo "ball clay" en Ucrania. 


\subsubsection{Arcillas tipo "ball clay" españolas.}

Destacan las arcillas procedentes de la zona norte de Teruel, más concretamente de las áreas de Cañada de Verich, EstercuelCrivillén y Ariño-Oliete.

Los yacimientos de Cañada de Verich son de arcillas de carácter caolinítico, con bajo contenido en cuarzo de granulometría fina y con elevada plasticidad. Destaca su bajo contenido en $\mathrm{K}_{2} \mathrm{O}$ y contenido variable en $\mathrm{Fe}_{2} \mathrm{O}_{3}$ y $\mathrm{TiO}_{2}$. Cuando el contenido en hierro y titanio es reducido, se pueden emplear en cerámica decorativa y, cuando este contenido es más elevado, resultan adecuadas para su utilización en la elaboración de refractarios o pavimento rústico gresificado. La principal empresa explotadora es Arcimusa.

Por otra parte, las arcillas de Estercuel-Crivillén son muy silíceas, con contenidos en cuarzo entorno al 40-50\% y de mayor tamaño que en el caso anterior. Su contenido en materia orgánica y en compuestos de hierro es bajo. La fracción arcillosa es de carácter illitico-caolinítico, poco degradada, lo que les confiere una baja plasticidad. Su destino comercial suele ser la fabricación de pavimentos cerámicos gresificados de pasta blanca. La principal empresa explotadora es Minera Sabater.

Las arcillas de la zona Ariño-Oliete son de carácter illíticocaolinítico, predominantemente plásticas, con contenidos en materia orgánica inferiores a $0.6 \%$ y el $\mathrm{Fe}_{2} \mathrm{O}_{3}$ entre 1.7-2.5\%. Su uso comercial, como en el caso anterior, también está destinado a la pasta blanca, siendo la principal empresa productora Euroarce.

Las arcillas tipo "ball clay" extraídas de Asturias y Galicia son arcillas arenosas y presentan un contenido variable en óxido 
de hierro y elevado en materia orgánica, por lo que su utilización en el sector de pavimentos y revestimientos es reducido.

En la provincia de Badajoz existen depósitos de arcillas laminares, de carácter illitico-caolinítico, poco plásticas y con interestratificados de hematita. Se trata de minerales de poco interés en el sector cerámico.

En la provincia de Valencia se localizan explotaciones de arcillas semejantes a las de Estercuel-Crivillén en Villar de Arzobispo. En general, son algo más plásticas y pueden contener impurezas como sulfatos. Debido a la variabilidad de su composición no son muy empleadas.

Así pues, la mayor parte de arcillas que se utilizan para formular pasta blanca son arcillas de importación, dadas las características técnicas que estas presentan, frente a las arcillas españolas, que carecen de la calidad necesaria para utilizarse exclusivamente en este tipo de pastas. Con el lanzamiento del gres porcelánico esmaltado, se ha podido rebajar ligeramente el nivel de blancura exigido en el porcelánico técnico, introduciéndose arcillas españolas de prestaciones inferiores [17]. Por otra parte, el revestimiento suele combinar los dos tipos de arcilla, ya que suele ser menos exigente en blancura, puesto que cuece a temperaturas inferiores al porcelánico, donde la pasta es aparece más blanca que cuando las temperaturas son más elevadas. Las características técnicas de las arcillas utilizadas en pasta blanca se indican en la Tabla V. 
Tabla V. Características técnicas de las arcillas usadas en la formulación de pasta blanca.

\begin{tabular}{|c|c|c|c|c|}
\hline $\begin{array}{l}\text { Parámetros } \\
\text { cerámicos }\end{array}$ & $\begin{array}{l}\text { ESPAÑOLA } \\
\text { BAJA } \\
\text { ALUMINA }\end{array}$ & $\begin{array}{c}\text { ESPAÑOLA } \\
\text { ALTA } \\
\text { ALÚMINA }\end{array}$ & $\begin{array}{c}\text { IMPORTADA } \\
\text { BAJA } \\
\text { ALUMINA }\end{array}$ & $\begin{array}{c}\text { IMPORTADA } \\
\text { ALTA } \\
\text { ALÚMINA }\end{array}$ \\
\hline$\frac{\circ}{\circ} \mathrm{Al}_{2} \mathrm{O}_{3}$ & $19-22$ & $24-28$ & $20-23$ & $26-29$ \\
\hline$\frac{\circ}{8} \mathrm{Fe}_{2} \mathrm{O}_{3}$ & $1,5-3,0$ & $2,0-8,0$ & $<1,0$ & $1,0-1,5$ \\
\hline Mineral de hierro & Siderita & $\begin{array}{l}\text { Siderita/ } \\
\text { Hematita }\end{array}$ & - & - \\
\hline$\frac{\circ}{8}$ Contenido en $\mathrm{MO}^{1}$ & 20 & 80 & 0 & 5 \\
\hline Plasticidad & 20 & 22 & 24 & 26 \\
\hline \multicolumn{5}{|c|}{ Comportamiento en cocido a $1185^{\circ} \mathrm{C}$} \\
\hline$(\%) C . L .^{2}$ & 6,5 & 7,2 & 6,25 & 9,28 \\
\hline$\left(\frac{\circ}{0}\right) \mathrm{A} \cdot \mathrm{A} \cdot{ }^{3}$ & 5,1 & 1,5 & 3,85 & 0,06 \\
\hline$L \star^{4}$ & 66,7 & 65 & 79 & 74 \\
\hline$a \star^{4}$ & 6,3 & 5,5 & 2,5 & 2,6 \\
\hline $\mathrm{b}^{4}$ & 15,3 & 15,9 & 15,0 & 12,4 \\
\hline
\end{tabular}

${ }^{1}$ Materia orgánica.

${ }^{2}$ Contracción lineal.

${ }^{3}$ Absorción de agua.

${ }^{4}$ Coordenadas cromáticas espacio de color CIELab. L* ( L*=100, blanco; L*=0, negro); $a^{*}$ $(a *<0$, verde; $a *>0, \operatorname{roj} 0) ; b *\left(b *<0, \operatorname{azul} ; b^{*}>0, \operatorname{amarillo}\right)$.

\subsubsection{Extracción minera de arcillas de cocción blanca.}

Para la extracción de las arcillas de cocción blanca, sobre todo en el caso de arcillas españolas, hay que tener en cuenta que la selección de materia prima a pie de mina es el inicio de la eliminación de impurezas, puesto que las materias primas son materiales naturales, sin que hayan sufrido ningún tratamiento previo. Se necesita un técnico cualificado con una máquina retroexcavadora capaz de extraer y separar las capas ricas en 
impurezas, de las capas más valiosas. Por otro lado, también es importante que las muestras de arcillas para controlar su calidad sean representativas de las toneladas que representan [29]. En la Figura 15 se pueden observar varias máquinas extrayendo escombro carbonoso en la base de un frente de arcillas ubicado en la provincia de Teruel [30].

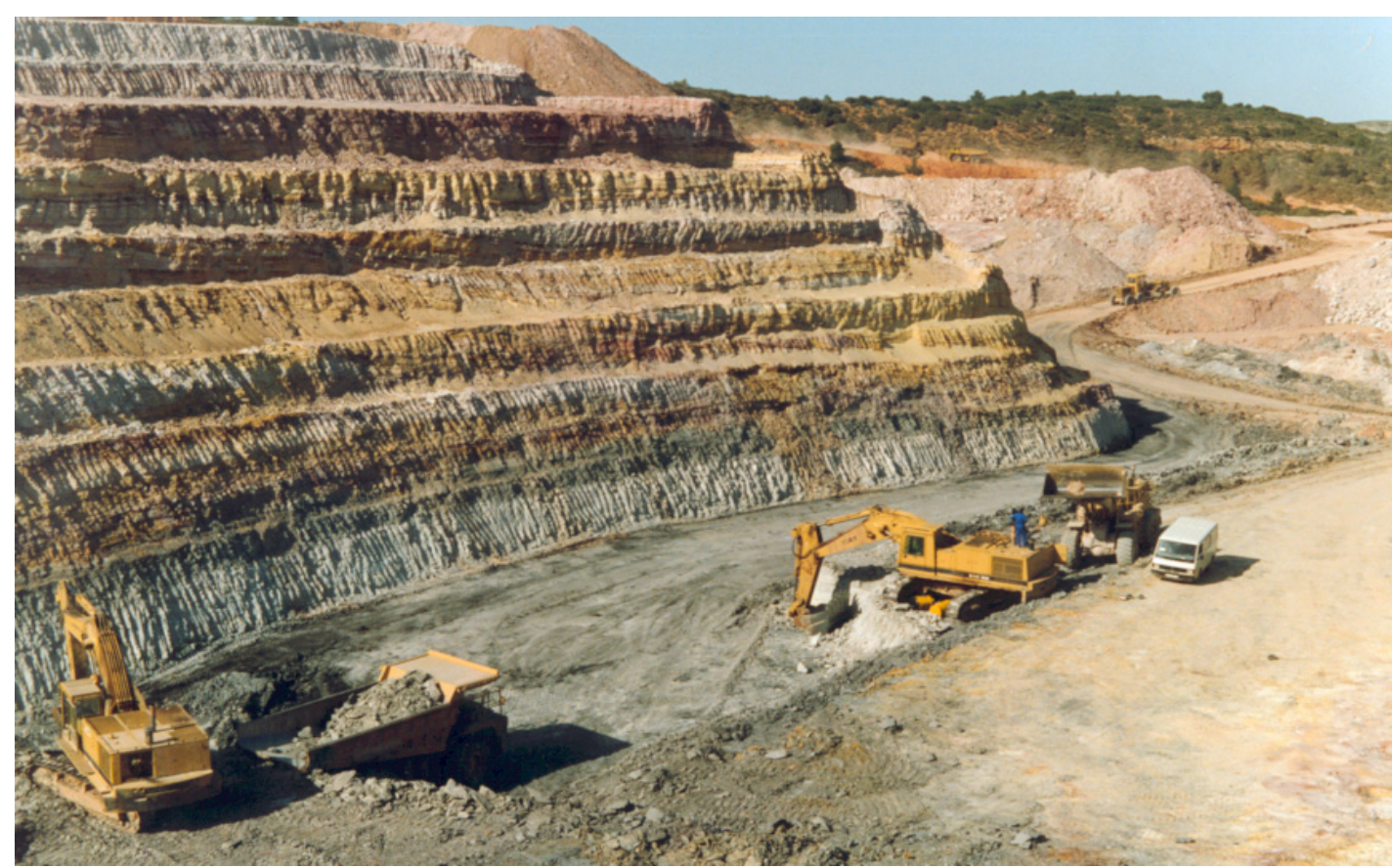

Figura 15. Frente de un yacimiento de arcillas a cielo abierto.

\subsection{Identificación de las impurezas de hierro en las arcillas españolas.}

\subsubsection{Susceptibilidad magnética de los materiales.}

La susceptibilidad magnética es la relación entre la intensidad de magnetización producida en un material y el campo magnético que produce dicha magnetización. Según los distintos 
valores de la susceptibilidad magnética, los minerales se pueden clasificar de la siguiente manera [31], [32], [33]:

- MATERIALES DIMAGNÉtiCOS. Estos materiales se magnetizan débilmente en el sentido opuesto al del campo magnético aplicado, de forma que aparece una fuerza de repulsión sobre el cuerpo respecto del campo aplicado. Ejemplos de materiales diamagnéticos son el cobre y el helio.

- MATERIALES PARAMAGNÉTICOS. Los materiales paramagnéticos se caracterizan por átomos con un momento magnético neto, que tienden a alinearse, en el mismo sentido que el campo magnético aplicado. Su susceptibilidad magnética es positiva y pequeña. El aluminio y el sodio son dos ejemplos de materiales paramagnéticos.

- MATERIALES FERROMAGNÉTICOS. En los materiales ferromagnéticos los momentos magnéticos individuales de grandes grupos de átomos o moléculas se mantienen alineados entre sí debido a un fuerte acoplamiento, aún en ausencia de campo exterior. Estos materiales se magnetizan fuertemente en el mismo sentido que el campo magnético aplicado y su susceptibilidad magnética es positiva y grande. Ejemplos de materiales ferromagnéticos son el hierro, el cobalto, el níquel y la mayoría de los aceros.

- MATERIALES ANTIFERROMAGNÉtiCOS. Estos tienen un estado natural en el cual los espines atómicos de átomos adyacentes son opuestos, de manera que el momento magnético neto es nulo, siendo difícil que el material se magnetice. Como ejemplo, se cita el fluoruro de manganeso. 
- MATERIALES FERRIMAgnéticos. Se trata de materiales similares a los antiferromagnéticos, salvo que las especies de átomos alternados son diferentes y presentan momentos magnéticos diferentes. Existe una magnetización neta, que puede ser en casos muy intensa. La magnetita $\left(\mathrm{Fe}_{3} \mathrm{O}_{4}\right)$ es un ejemplo que se conoce como imán desde la antigüedad y otro ejemplo de materiales ferrimagnéticos son las ferritas.

\subsubsection{Tipos de compuestos de hierro.}

Los minerales de hierro presentes en las rocas arcillosas, de los que depende en gran parte el color de la arcilla tanto en crudo como en cocido, son la magnetita $\left(\mathrm{Fe}_{3} \mathrm{O}_{4}\right)$, la hematita $(\alpha-$ $\left.\mathrm{Fe}_{2} \mathrm{O}_{3}\right)$, la limonita $\left(\mathrm{FeO} \cdot \mathrm{OH} \cdot \mathrm{nH}_{2} \mathrm{O}\right)$, la goetita $(\alpha-\mathrm{FeO} \cdot \mathrm{OH})$ y la siderita $\left(\mathrm{FeCO}_{3}\right)$ [8].

Teniendo en cuenta la experiencia adquirida en el conocimiento de arcillas durante los años trabajados en el sector cerámico, de los yacimientos de arcillas posibles que existen en España, únicamente se destacan como más viables en este estudio, los correspondientes a las arcillas de Teruel y de Ciudad Real. Las características específicas de cada una de ellas, se indican a continuación.

\section{ARCILLAS DE TERUEL}

Las arcillas turolenses están situadas dentro la subzona norte del Distrito Minero Turolense, que abarca las áreas mineras de Ariño-Andorra, Estercuel y Foz Calanda. La fracción arcillosa de 
estas áreas procede de las continuas inundaciones a que estaban sometidas las turberas, según el modelo sedimentario de la Formación Escucha. Las principales impurezas que acompañan a estas arcillas son la materia orgánica, los compuestos de hierro y los de azufre. Los compuestos de hierro son mayoritariamente carbonato férrico o siderita, tal y como se observa en la Figura 16 [34], [35].

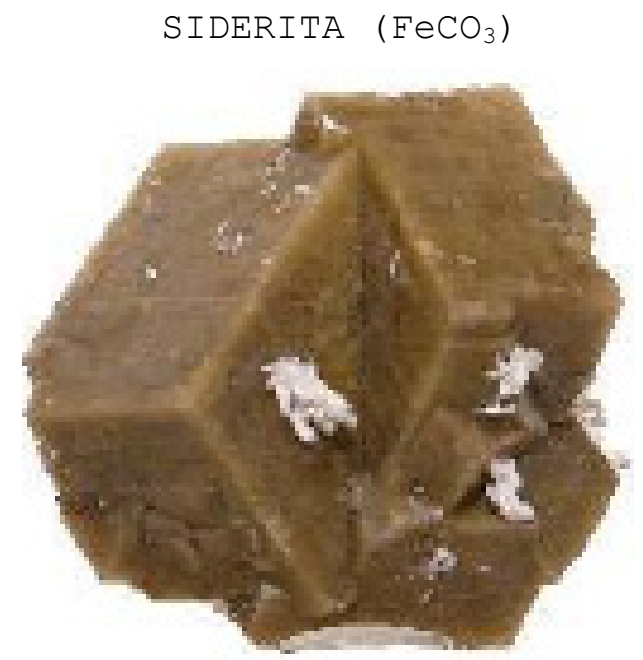

HEMATITA $\left(\mathrm{Fe}_{2} \mathrm{O}_{3}\right)$

Figura 16. Imagen de los compuestos de hierro: siderita y hematita.

\section{ARCILLAS DE CIUDAD REAL}

Son arcillas caoliníferas, procedentes de caolines sedimentarios de los niveles paleozoicos, de muy bajo grado de metamorfismo, con contenidos en caolinita, moscovita (mica

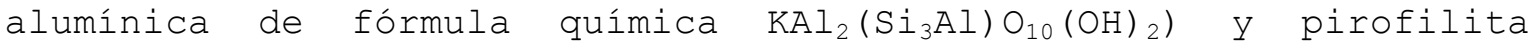
(silicato de alúmina hidratado, de fórmula química $\mathrm{Al}_{2} \mathrm{Si}_{4} \mathrm{O}_{10}(\mathrm{OH})_{2}$ ) . No suelen presentar materia orgánica, aunque la concentración de hematita suele ser elevada (ver Figura 16) [36], [37]. 


\subsubsection{Procedimiento de disminución de compuestos de hierro en las arcillas.}

El procedimiento industrial más comúnmente utilizado para reducir los compuestos de hierro en las arcillas consiste en dispersar éstas en un medio acuoso defloculado. Se trabaja habitualmente con un contenido en sólidos de 50\%, para dispersar las partículas de forma óptima. Esta dispersión en agua facilita el tamizado de la barbotina formada, a través de un tamiz de 100 $\mu \mathrm{m}$. Así, se rechazan las fracciones más gruesas de la arcilla "turbodesleída", entre las que se encuentran parte de los compuestos de hierro y arenas. De esta forma, aunque disminuye el rendimiento de la arcilla, se consiguen reducir moderadamente los compuestos de hierro presentes.

\subsection{Descripción de las impurezas de materia orgánica en las arcillas españolas.}

\subsubsection{Descripción química de la materia orgánica.}

Desde el punto de vista químico, la materia orgánica dispersa en las arcillas naturales consiste principalmente en ácidos húmicos y carbón. Las moléculas de estos ácidos húmicos constan de sistemas aromáticos condensados, el principal de los cuales es benzopireno con grupos funcionales ligados a él, principalmente, en forma de carboxilos ( $\mathrm{COOH}$ ) y fenilhidróxilos (OH) . Durante el calentamiento de los ácidos húmicos por debajo de $500^{\circ} \mathrm{C}$, se produce un desprendimiento de $\mathrm{CO}_{2}$ y $\mathrm{H}_{2} \mathrm{O}$, a costa de dichos grupos funcionales, que podría representarse mediante las reacciones $[38], \quad[39]:$ 


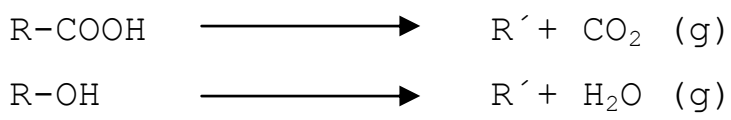

en las que $R$ y $R^{\prime}$ representan los diversos anillos aromáticos contenidos en la macromolécula.

Si se continúa calentando, el residuo sólido resultante ("semicoque") reacciona de nuevo vigorosamente, entre $500^{\circ} \mathrm{C}$ y $700^{\circ} \mathrm{C}$, produciéndose una reacción de policondensación de los núcleos aromáticos, aunque termodinámicamente es posible que se produzca a temperaturas más bajas. Por encima de $700^{\circ} \mathrm{C}$ se desarrollan reacciones de deshidrogenación:

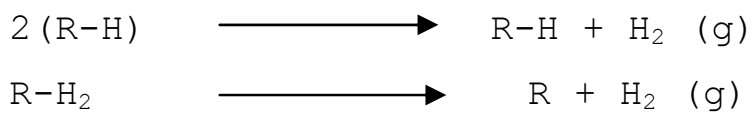

Además, dado que los materiales arcillosos son fundamentalmente silicoaluminatos, los cuales catalizan las reacciones de pirólisis o coquizacion entre los 400-500 C, se puede producir dicha reacción a partir de los hidrocarburos y del co formados por descomposición de la materia orgánica, según:

$$
\begin{array}{llll}
\mathrm{CO}(\mathrm{g})+\mathrm{H}_{2}(\mathrm{~g}) \longrightarrow & \mathrm{C}(\mathrm{s})+\mathrm{H}_{2} \mathrm{O}(\mathrm{g}) \\
\mathrm{C}_{\mathrm{m}} \mathrm{H}_{2 \mathrm{n}}(\mathrm{s}) & \longrightarrow & \mathrm{mC}(\mathrm{s})+\mathrm{nH}_{2} \quad(\mathrm{~g})
\end{array}
$$

Por otra parte, A. Escardino [40] aplica el modelo cinético de núcleo sin reaccionar a la oxidación del coque formado a partir de la materia orgánica, en el interior de piezas cerámicas, durante la fase de calentamiento del ciclo de cocción, considerando que, además de la etapa de reacción, intervienen simultáneamente cuatro etapas individuales de transferencia de materia y dos de transmisión de calor [41]. 


\subsubsection{Descripción petrográfica de la materia orgánica.}

Desde el punto de vista petrográfico, la materia orgánica contenida en la arcilla utilizada en esta Tesis Doctoral es, en gran medida, carbón vegetal. Las arcillas españolas con alta alúmina explotadas en la zona de Teruel están ubicadas en la comarca de las Cuencas Mineras, junto a los yacimientos de carbón a cielo abierto que se extraen para la central térmica de Andorra. Tal y como describen algunos autores, como X. Querol [42], M.A. Albéniz [43], y R. Juan [34], el distrito minero de Teruel se centra principalmente en la explotación de capas de carbón y arcillas cretácicas y está ubicado en las áreas oriental y suroriental de la provincia de Teruel. Dentro del Distrito, se distinguen dos zonas claramente diferenciadas y separadas por la alineación estructural de Portalrubio-Casteldecabra-MolinosCastellote.

- SUBZONA NORTE, compuesta por las áreas mineras de Ariño-Andorra, Estercuel y Foz Calanda. En ellas, los materiales del Cretácico superior presentan potencias muy reducidas $(<25 \mathrm{~m})$ o incluso nulas.

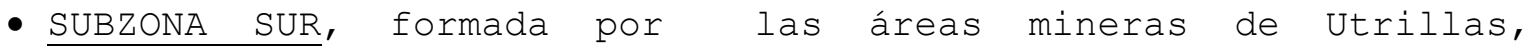
Portalrubio, Galve y Castellote. Presenta importantes espesores de materiales del Cretácico superior entre la Formación Escucha o la Formación Utrillas y los sedimentos terciarios.

La arcilla utilizada en este trabajo (N-A-te) pertenece a la subzona norte.

En el año 2003, aparece una publicación de Qinglei sun y col. [44] donde explican que el carbón es un material 
extraordinariamente complejo y heterogéneo, cuyas propiedades físicas y químicas son difíciles de determinar. Por eso, interesa separar los macerales del carbón para simplificar su estudio. Los macerales son componentes orgánicos diferenciados microscópicamente del carbón, y que presentan propiedades físicoquímicas características. Sin embargo, en este artículo se advierte de la dificultad que existe para separar los macerales puros del carbón, debido a la dificultad de aislarlos en ausencia de impurezas.

Según O. Gómez y col. [45], indicaron que el carbón no es una sustancia homogénea, está constituido por varios componentes microscópicos de origen orgánico a los cuales se les denomina macerales, término introducido por stopes en el año 1935 [46]. En el mismo artículo se indica que el Comité Internacional de Petrografía del carbón (ICCP, 1994 y 2001) los ha clasificado en tres grupos:

- Vitrinitas/huminitas.

- Liptinitas/Exinitas

- Inertitas.

Los macerales se distinguen microscópicamente por la forma, tamaño, estructura, color, relieve, poder reflector, anisotropía, dureza y fluorescencia, según Bustin en 1983 [47]. Los procesos de separación de los grupos macerales requieren una fase inicial de liberación. Tradicionalmente, el análisis de liberación se ha efectuado en rocas duras y en los carbones, con el fin de remover la materia mineral asociada. El análisis de liberación del carbón consiste en la disminución de tamaño y cuantificación petrográfica de la fracción liberada y de sus mixtos, gracias a que los grupos de macerales presentan el mismo comportamiento que los minerales 
durante la disminución de tamaño: el número de componentes libres incrementa.

En 1999, C.R. Ward y col. [48] utilizaron una microsonda para analizar en un único punto la composición elemental in situ. Este método se ha usado ampliamente en otras ramas de la geología para estudiar la composición de partículas minerales en un rango de diferentes tipos de rocas, permitiendo comprender más profundamente muchos procesos geológicos. La técnica de la microsonda les permitió estudiar la composición química de los macerales individuales de carbones australianos.

En 2010, Khandelwal y Singh [49], predijeron la concentración de macerales de carbones de la India usando una red neuronal artificial (ANN), a la que incorporan los análisis elemental e inmediato del carbón. Una ANN consiste en un modelo matemático o modelo computacional inspirado en las estructuras y/o aspectos funcionales de las redes neuronales biológicas. El análisis elemental permitió determinar el contenido de cada uno de los elementos fundamentales del carbón, es decir, carbono, hidrógeno, oxígeno y azufre. Por otra parte, el análisis inmediato se basa en la determinación del contenido de humedad (H), materias no combustibles (CZ), carbono fijo (CF) y materias volátiles (MV), de manera que $\mathrm{H}+\mathrm{CZ}+\mathrm{CF}=100$. Estos investigadores comprobaron que la predicción de la concentración de los grupos macerales es más precisa si se utiliza la técnica de la ANN que la técnica convencional de análisis de regresión multivariante.

La materia orgánica presente en las arcillas de Teruel mencionadas anteriormente se caracteriza por los siguientes parámetros: 
- Bajo grado de carbonificación.

- Alta retención de agua.

- Baja potencia calorífica.

- Baja compacidad.

- Alto contenido en los tres tipos de compuestos de azufre (pirita $\left(\mathrm{Fe}_{2} \mathrm{~S}\right)$, sulfato y orgánico).

Según un estudio petrográfico realizado por $\mathrm{R}$.Juan y col., en el año 1993 [34], se supone que los macerales de las Cuencas Mineras de Teruel son vitrinitas e inertinitas, a razón (3:1), con presencia de exinita. En la Tabla VI se indican los porcentajes de cada tipo de los componentes del carbón.

Tabla VI. Análisis petrográfico de los carbones cretácicos de Teruel (año 1993).

\begin{tabular}{|c|c|}
\hline Tipos & Macerales \\
\hline Vitrinita & $\mathbf{7 4 . 0}$ \\
\hline Inertinita & 24.5 \\
\hline Exinita & 1.5 \\
\hline
\end{tabular}

En el año 2003, Qinglei Sun y col. [44], realizaron un estudio de cómo se comportan los macerales durante la pirólisis, usando como materia prima un carbón bituminoso de una zona de China llamada Shenmu. Utilizaron el método de centrifugación por gravedad (DGC) para separar la vitrinita y de la inertinita, con lo que consiguieron caracterizar a cada una individualmente. En la Tabla VII, se observa entre estos dos macerales, una diferencia de temperatura de descomposición de unos $15^{\circ} \mathrm{C}$, que se mantiene hasta la máxima velocidad de descomposición. 


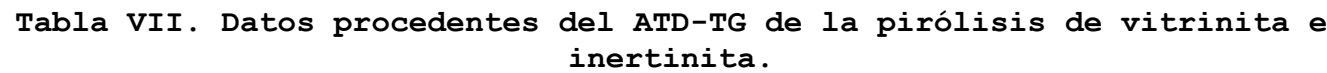

\begin{tabular}{|c|c|c|}
\hline & $\begin{array}{c}\mathrm{T}\left({ }^{\mathrm{a}} \mathrm{C}\right) \text { inicio } \\
\text { descomposición }\end{array}$ & $\begin{array}{c}\mathrm{T}\left({ }^{\mathrm{a}} \mathrm{C}\right) \text { máxima } \\
\text { velocidad } \\
\text { descomposición }\end{array}$ \\
\hline Vitrinita & 372 & 496 \\
\hline Inertinita & 387 & 514 \\
\hline
\end{tabular}

Además, según L. Kozdrowska y col. [50] en 2004, la vitrinita presenta varios grupos de centros paramagnéticos, que se incrementan con la descomposición térmica, lo que puede ser favorable en el estudio que nos compete en este trabajo.

\subsubsection{Defecto provocado por la materia orgánica presente en las arcillas.}

Los minerales arcillosos utilizados en las formulaciones de las composiciones cerámicas suelen contener compuestos de hierro y materia orgánica como impureza, según [8], [38], [39], [40], [51]. Durante la cocción de las piezas cerámicas, cuya composición presenta materia orgánica, puede presentarse un núcleo oscuro en su interior que se conoce con el nombre de "corazón negro" [52], tal y como se ve en la Figura 17. Este defecto se ve potenciado en los ciclos de cocción excesivamente cortos, pero necesarios, a veces, para rentabilizar la producción y, en los casos de piezas de pavimento, en las que ha sido preciso aumentar su espesor y su compactación, con vistas a incrementar su resistencia mecánica. 


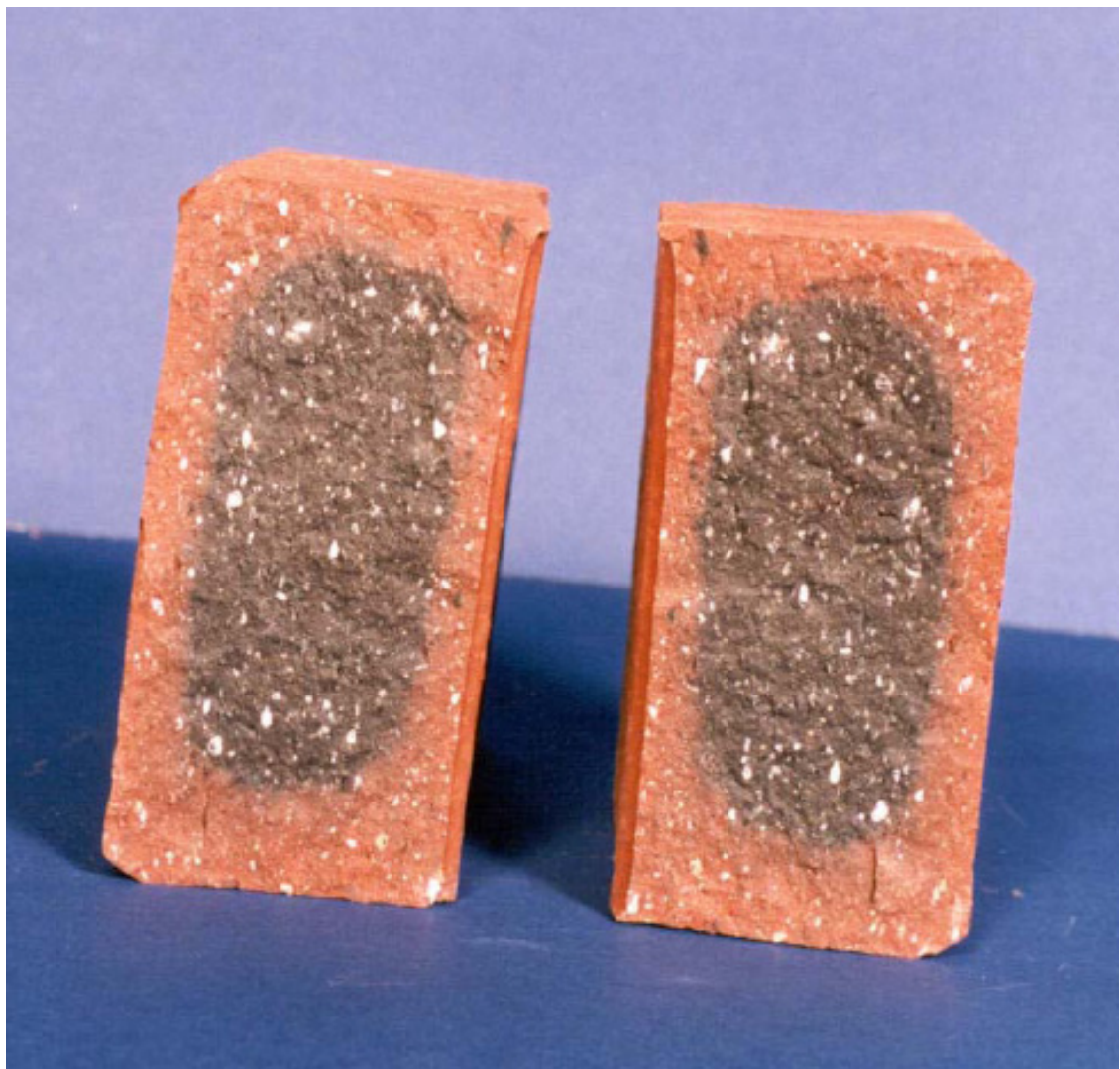

Figura 17. Pieza cerámica de pasta roja que presenta el defecto de "corazón negro".

F. Negre y A. Barba, [38] y [39], afirmaron que el "corazón negro" se debe a residuos de carbón formado por la descomposición de la materia orgánica contenida en las pastas cerámicas, a temperaturas comprendidas entre $300^{\circ} \mathrm{C}-500^{\circ} \mathrm{C}$. Y, algunos autores, en las citas [53] y [54], señalan que el oscurecimiento de la zona central de los azulejos cocidos es consecuencia de la reducción del $\mathrm{Fe}_{2} \mathrm{O}_{3}$ contenido en la arcilla, a $\mathrm{FeO}$, que puede estar presente también en forma de magnetita $\left(\mathrm{Fe}_{3} \mathrm{O}_{4}\right)$, a temperaturas superiores a $800^{\circ} \mathrm{C}$.

Por otra parte, A. Escardino concluyó que la cantidad de materia orgánica que contienen las arcillas naturales, se coquiza por encima de los $150^{\circ} \mathrm{C}$, siendo catalizada por el $\mathrm{SiO}_{2}$ y $\mathrm{Al}_{2} \mathrm{O}_{3}$. Este carbón, uniformemente distribuido en el seno del sólido, en 
forma casi coloidal, puede además, reducir el $\mathrm{Fe}_{2} \mathrm{O}_{3}$ presente en el mismo sólido a FeO (wustita, de color negro). El coque formado a partir de la materia orgánica, tanto si va acompañado de FeO como si no, oscurece el interior de la pieza cerámica, dando lugar al efecto que se conoce en el sector cerámico como "corazón negro".

En cuanto a las consecuencias de la aparición de "corazón negro", destacan los siguientes puntos [52]:

- Disminución de la resistencia mecánica, en el caso de que pequeñas burbujas de gases hayan quedado ocluidas en la fase vítrea.

- Fisuraciones de enfriamiento. La existencia de "corazón negro" hace que determinadas zonas de la pieza cerámica pierdan parte de su elasticidad, por lo que se ven mucho más afectadas por las contracciones y dilataciones que se producen en el enfriamiento de las piezas, corriendo peligro de agrietarse. Por tanto, será necesario extremar las precauciones en la curva de enfriamiento. En la Figura 18 se aprecia una pieza cerámica de laboratorio de pasta roja que presenta este tipo de fisuraciones. 


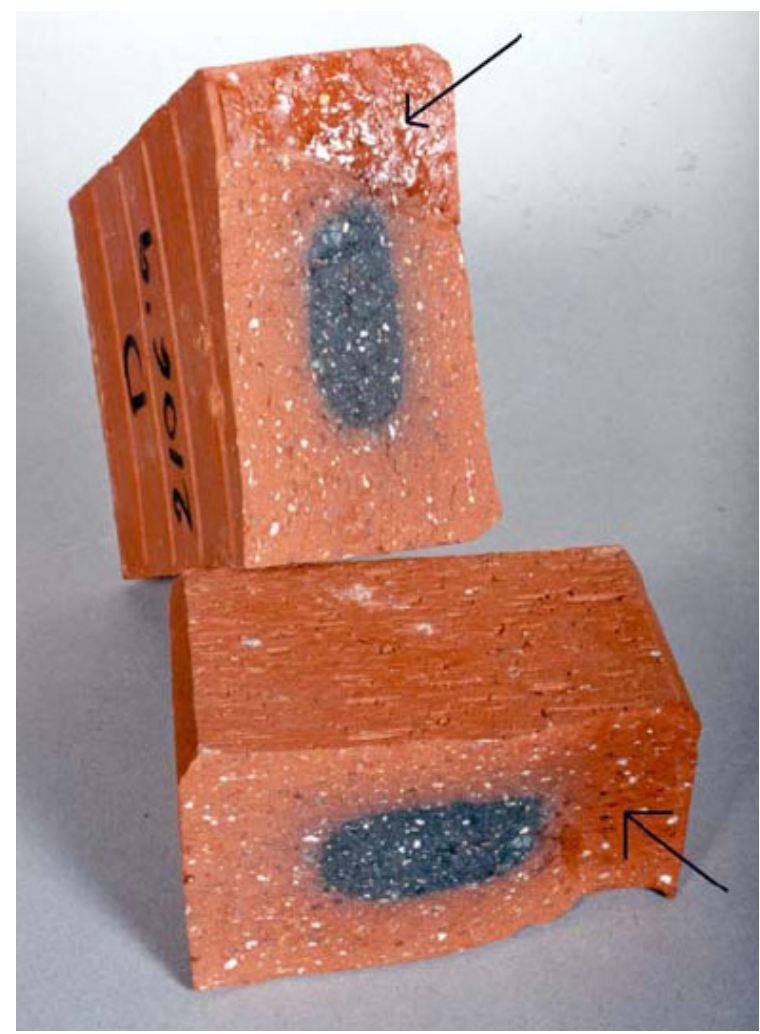

Figura 18. Pieza con "corazón negro" fisurada durante la fase de enfriamiento. La parte más brillante señalada con las flechas corresponde a la zona fisurada.

- Hinchamientos. Como se ha comentado, la aparición de "corazón negro" produce una disminución de porosidad, que impide la salida de los gases producidos durante la cocción en el interior de la pieza. Esta situación se ve acentuada cuando la pieza se encuentra esmaltada, puesto que la transferencia de materia con el exterior es aún más complicada, como se observa en la Figura 19. 


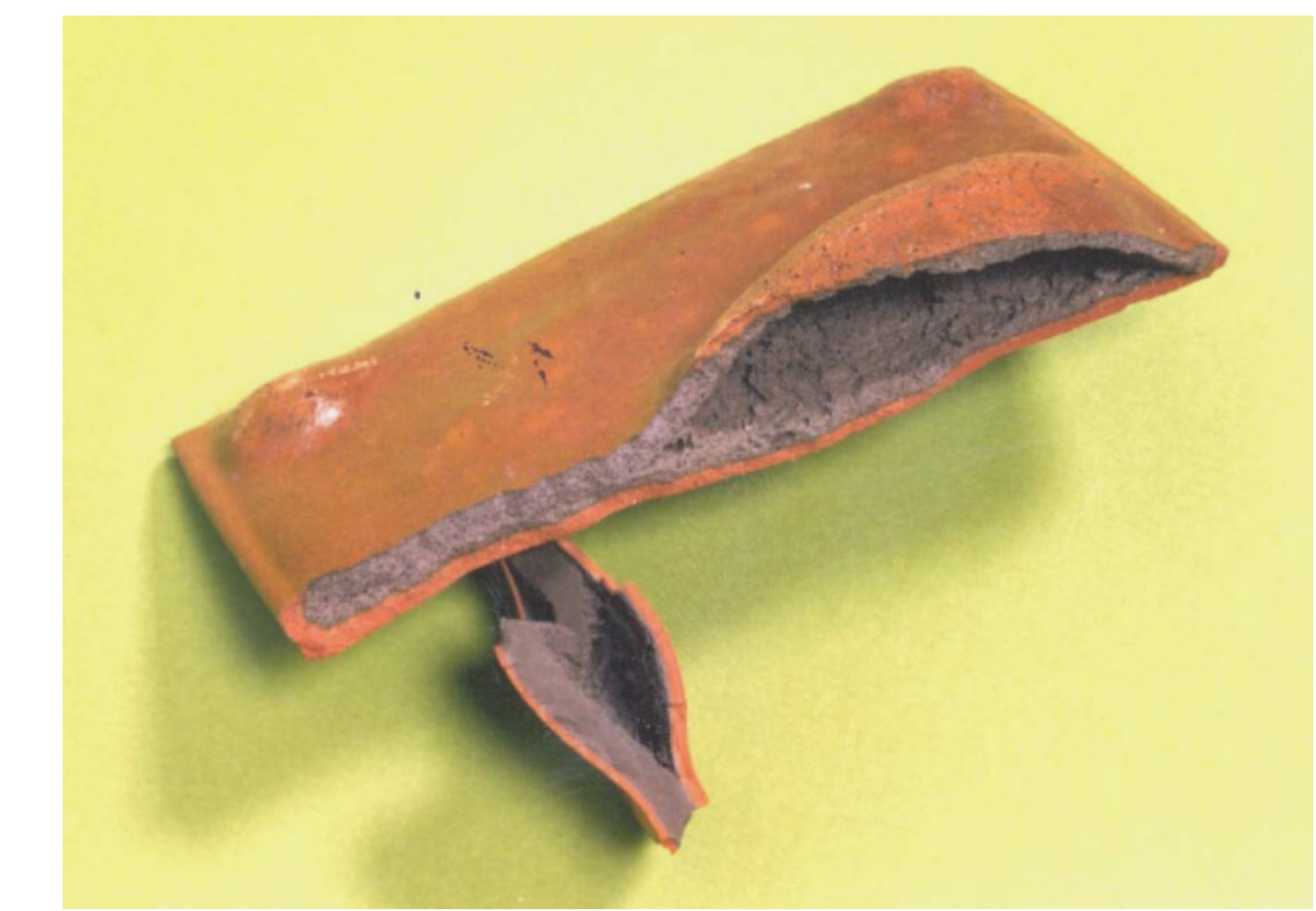

Figura 19. Pieza esmaltada con presencia de "corazón negro" y abultamiento en la misma pieza.

Finalmente, según J. Velasco [52], la aparición de esta patología de la cerámica, se puede prevenir actuando en los siguientes puntos:

- Controlando el tipo y la cantidad de materia orgánica que presentan las materias primas arcillosas.

- Añadiendo pequeñas cantidades de pirolusita $\left(\mathrm{MnO}_{2}\right)$ o de permanganato potásico $\left(\mathrm{KMnO}_{4}\right)$, ambos compuestos químicos que presentan una importante capacidad de oxidación, que puede contribuir a reducir la formación de "corazón negro". 
- Optimizando el perfil de temperaturas de horno de manera que, a temperatura apropiada, entre $600^{\circ} \mathrm{C}-800^{\circ} \mathrm{C}$, sea lo suficientemente largo para que los procesos de descomposición y oxidación en el interior de la pieza se completen, antes de que la permeabilidad de la misma sea tan baja que impida la difusión hacia el exterior de los componentes gaseosos que se forman y el paso hacia el interior de la pieza del oxígeno necesario para que se produzcan todas las reacciones de oxidación.

\subsubsection{Procedimiento de disminución de materia orgánica en las arcillas.}

Antes de empezar con los procedimientos de disminución de materia orgánica en las arcillas, se hace un repaso de las transformaciones térmicas que sufren los minerales arcillosos.

a) TRANSFORMACIONES TÉRMICAS DE LOS MINERALES ARCILLOSOS.

Cuando se calientan los minerales arcillosos, la caolinita [8], [55], [56], no experimenta ningún cambio hasta los $470{ }^{\circ} \mathrm{C}$, momento en que los iones $\mathrm{OH}^{-}$de la estructura cristalina comienzan a ser eliminados en forma de vapor de agua:

$$
\begin{array}{rcc}
\mathrm{Al}_{2} \mathrm{O}_{3} \cdot 2 \mathrm{SiO}_{2} \cdot 2 \mathrm{H}_{2} \mathrm{O} & \rightarrow & \mathrm{Al}_{2} \mathrm{O}_{3} \cdot 2 \mathrm{SiO}_{2} \\
\text { Caolinita } & 470^{\circ} \mathrm{C} & \text { Metacaolinita }
\end{array}
$$

Durante esta transformación se produce una pérdida de peso y una destrucción parcial de la estructura cristalina debido al reordenamiento de los átomos, formándose una fase amorfa y metaestable denominada metacaolín. Este material no muestra las propiedades plásticas que desarrolla la caolinita al mezclarse con agua y su superficie específica es mayor. Si el material continúa 
siendo calentado, se produce una reacción exotérmica muy marcada sobre los $980^{\circ} \mathrm{C}$. La naturaleza de las fases desarrolladas en esta reacción no está totalmente esclarecida, existiendo una gran controversia. De acuerdo con Chakravorty y Ghosh, a esta temperatura tiene lugar la siguiente reacción de descomposición:

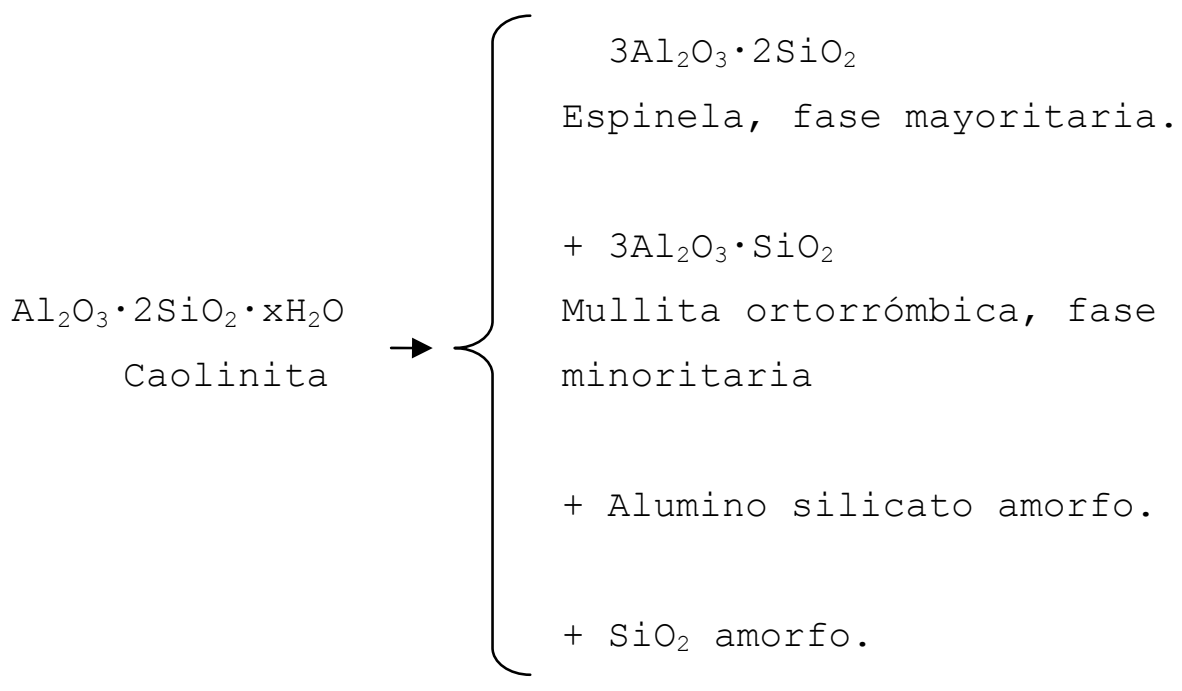

La espinela de sílice-alúmina formada, con una composición aproximada de $3 \mathrm{Al}_{2} \mathrm{O}_{3} \cdot 2 \mathrm{SiO}_{2}$, presenta una estructura cristalina cúbica y es la fase cristalina mayoritaria (30-40\%). Por otro lado, hay que indicar que la naturaleza de la mullita ortorrómbica obtenida a $980^{\circ} \mathrm{C}$, cuya proporción se sitúa en torno al 5\%, es bastante diferente de la mullita bien cristalizada que se considera como estándar. Paralelamente a estas dos fases cristalinas se forman dos fases amorfas, una de silicoaluminato (30-40\%) y otra de sílice. Estos autores [56] postulan que la presencia de enlaces Si-O-Si en la caolinita es responsable de la fácil formación de mullita. La espinela de sílice-alúmina y el aluminosilicato amorfo obtenidos a $980^{\circ} \mathrm{C}$ son dos fuentes diferentes de tales enlaces, produciendo mullita por dos caminos diferentes. Así, la espinela se transforma rápidamente a mullita por reacción polimórfica en el intervalo de $1150^{\circ} \mathrm{C}-1250^{\circ} \mathrm{C}$, 
mientras que la mullita se nuclea y crece más lentamente a partir de la fase amorfa por encima de los $1250^{\circ} \mathrm{C}$. Las especies cristalinas de mullita que se obtienen por estos dos mecanismos son diferentes. Así, la especie desarrollada a partir de la espinela, denominada mullita primaria, forma grandes bloques o cristales escamosos y no beneficia a la resistencia mecánica del producto final. Esta reacción es la causante del segundo pico exotérmico observado en las curvas de ATD/TG y se produce sin pérdidas de $\mathrm{SiO}_{2}$. Por otro lado, la mullita obtenida a partir de la fase amorfa, denominada mullita secundaria, presenta cristales aciculares que refuerzan la resistencia mecánica del material.

\section{b) CALCINACIÓN.}

En lo que se refiere al estado del arte sobre la eliminación de la materia orgánica presente en minerales arcillosos, cabe destacar la única patente española encontrada [57], desarrollada en Valencia. Ésta describe un procedimiento para la eliminación de la materia orgánica presente en arcillas cerámicas y en materiales arcillosos en general. La invención radica en un nuevo tratamiento aplicable a arcillas con contenidos en materia orgánica demasiado elevados para ser utilizados en determinados procesos industriales, como es la fabricación de pastas cerámicas. El proceso consiste en un calentamiento del material arcilloso en las condiciones que a continuación se especifican:

- La temperatura aconsejable está comprendida entre $350^{\circ} \mathrm{C}$ y $450^{\circ} \mathrm{C}$ y la presión parcial de oxígeno puede ser incluso inferior a 0.21 atmósferas.

- El tiempo del tratamiento es variable, en función del contenido inicial de materia orgánica $y$, deberá ser optimizado en cada caso. 
- Es importante optimizar el tamaño de partícula del sólido para reducir el tiempo de tratamiento y, en consecuencia, el consumo energético y costes de operación.

- El proceso de calentamiento puede realizarse empleando diversos tipos de hornos (rotatorio, vertical, de cámaras, túnel...), pudiendo operar en continuo o en discontinuo. Se recomienda el horno rotatorio similar al que se utiliza para producir chamota para la cerámica estructural.

A continuación, en la Figura 20 se muestra un ejemplo de horno rotatorio o también horno "tromel", formado por un cilindro metálico que está revestido interiormente de material refractario. Su longitud puede sobrepasar los 150 metros, con diámetros de hasta 4.5 metros. Está inclinado ligeramente (entre el 2\% y 5\%) y gira a una velocidad lenta $(100$ a 180 revoluciones por hora, dependiendo de su diámetro e inclinación). La alimentación es continua y se efectúa por la parte superior, en forma de pasta cuando se trata del proceso de vía húmeda o en forma de polvo seco cuando se trata del proceso de vía seca. El producto se mueve en el interior por gravedad, debido a la inclinación del horno y favorecido por la rotación del mismo, de modo que el producto va avanzando por el horno desde la entrada por la parte superior hasta la salida por la parte inferior, pasando por todas las zonas del horno y por lo tanto, viéndose expuesto a todas las fases que se producen a lo largo del mismo. La carga de producto suele cubrir únicamente el 10-12\% de la sección interior del horno. El combustible se inyecta por el extremo inferior del horno mediante una tobera o mechero que se alimenta con gas natural [58], [59], $[60],[61],[62]$. 


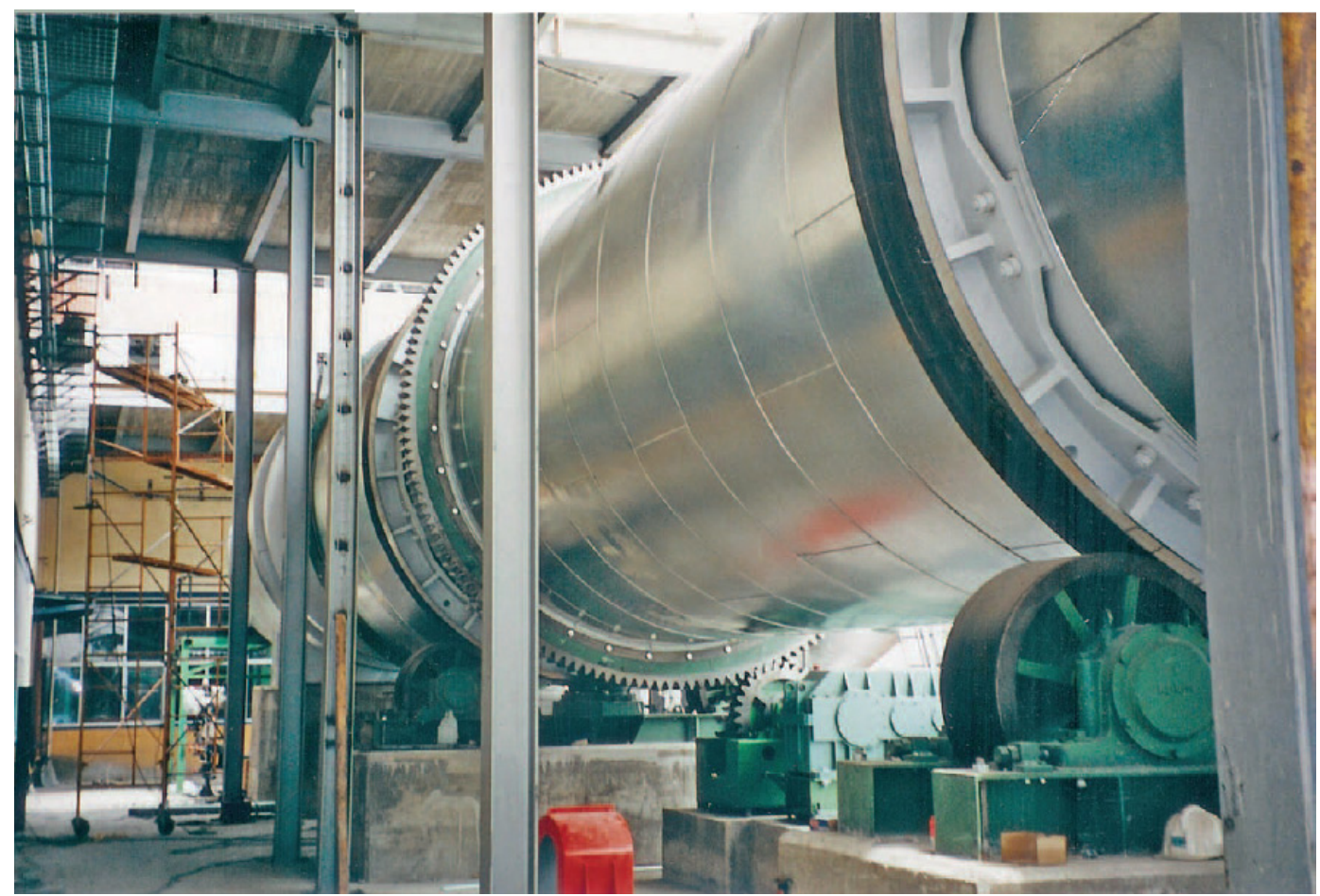

Figura 20. Horno rotatorio para el tratamiento térmico de los minerales.

El horno rotatorio funciona según el principio de contracorriente: el crudo se suministra por el extremo superior frío y se inyecta el combustible, y por tanto el calor, por el extremo inferior caliente. Así, los gases calientes se mueven en contracorriente del crudo: el aire frío que entra por la parte inferior sirve para enfriar el material calcinado que va saliendo del horno y a su vez este aire se va calentando, de modo que sirve para avivar la combustión, aportando el aire necesario para que ésta se produzca; cuando este aire, a gran temperatura, llega a la parte superior del horno, sirve para precalentar y secar el crudo que va entrando por la parte superior del horno. Finalmente, el aire sale del horno por una chimenea y aún a una temperatura considerable, acompañado de polvo del crudo, por lo que es necesario disponer algún sistema de filtro para evitar la emisión de polvo al aire ambiente [63]. 
C) TRATAMIENTO POR MICROONDAS.

Por otro lado, a nivel internacional sólo se ha encontrado una patente europea premiada en 2007 [64] relacionada con la aplicación del microondas a los minerales. Su invención está relacionada con el tratamiento previo de rocas mediante horno microondas. Describe la forma de incorporar el microondas como una etapa más previa a la de molturación de rocas en las explotaciones mineras. Así pues, tras un exhaustivo estudio, se considera que, hasta la fecha, no se ha encontrado patente registrada ni documentación relativa a la eliminación de la materia orgánica presente en las arcillas mediante un horno microondas propiamente dicho.

En cuanto al horno microondas, a continuación se comentan diferentes artículos encontrados en la bibliografía, sobre la aplicación de este tipo de horno a diversos campos científicos.

En 1995, C.Y. Yue y col. [65], consiguieron reducir considerablemente el tiempo de curado de los composites termoestables. Afirman que la ventaja principal del procesado por microondas es que permite ahorrar tiempos de curado comparado con el procesado térmico tradicional.

En este mismo año, J. Berlan [66] comprobaron que la activación por microondas de las reacciones químicas es posible, distinguiendo reacciones homogéneas de las heterogéneas. En las reacciones homogéneas se observó que el calentamiento por microondas influye en la selectividad química, mientras que el efecto sobre las heterogéneas varía en función del tipo de componentes de la mezcla. 
En 1996, J.M. Hilly Col. [67], indicaron que, aunque la radiación por microondas es bien conocida para calentar alimentos en la cocina, también se empieza a aplicar a procesos industriales en los que intervienen operaciones de fusión, sinterizado, secado y/o sellado. Esta nueva técnica supone comportamientos físicos inesperados como, por ejemplo, la aparición de puntos negros. En numerosas aplicaciones industriales se ha observado que el calentamiento no es uniforme. Para predecir este tipo de fenómenos es necesario desarrollar modelos matemáticos simplificados.

Steven Bodman y col. [68], en 1997 analizaron que, en las condiciones utilizadas para realizar el estudio $\left(\mathrm{T}<200^{\circ} \mathrm{C}\right)$, no hay evidencias de que el calor por microondas altere el curso de la química del carbón. El calentamiento sólo consigue acelerar la velocidad de equilibrio de las reacciones heterogéneas.

Kingman y Rowson concluyeron en su artículo de 1998 [69], que la mayoría de silicatos, carbonatos y sulfatos, algunos óxidos y algunos sulfitos son transparentes a la radiación por microondas. Sin embargo, la mayoría de los sulfitos de arsénico, sulfosales y sulfoarsénicos si se calientan a mucha temperatura, emiten humos y se funden.

Según H.S. Tai y C.G. Jou en 1998 [70], quienes desarrollaron un proceso aplicando carbón granular activo para absorber fenol, las cuatro frecuencias asignadas para aplicaciones industriales son $915 \mathrm{MHz}, 2450 \mathrm{MHz}$, $5800 \mathrm{MHz}$ y $22125 \mathrm{MHz}$.

Thostenson y Chou en 1999 [71], realizaron un estudio sobre los fundamentos y las aplicaciones del microondas a nivel de proceso industrial, en el que destacan las variables importantes que influyen en la operación con microondas: 
- Propiedades del campo electromagnético.

- Composición química del material a procesar.

- Cambios estructurales que puedan ocurrir durante el procesado.

- Tamaño y forma del objeto que se está calentando.

- Física de las interacciones microondas/material.

En el año 2000, investigadores de la Universidad de Florida [72] trabajaron para identificar y cuantificar los mecanismos de interacción entre las microondas y los materiales. En este artículo también describen los fundamentos generales del calentamiento por microondas, según el tipo de material no compuesto (transparente, conductor o absorbente de microondas).

T.J. Appleton y col., en el año 2004 [73], analizaron la técnica del microondas como alternativa de energía eficiente para el tratamiento térmico de residuos urbanos.

Lester y Kingman realizaron un trabajo en 2004 en el que demuestran que la resistencia que opone el carbón a molturarse puede ser reducida mediante un pretratamiento con microondas [74], $[75],[76]$.

Pedreño, Monzó y Pinzotas [77], en el año 2007 también desarrollaron un nuevo método de optimización de eficiencia basado en la búsqueda iterativa de la posición de la muestra dentro del horno que aporta incrementos de temperatura máxima a lo largo de la muestra.

Según Zhao y Chen [78], en el año 2008, la aplicación de la energía de microondas en química nuclear e ingeniería, está en sus 
inicios, a nivel de laboratorio todavía, pues queda mucho por descubrir.

En Tailandia en 2009 [79], dos ingenieros mecánicos usaron las microondas para secar madera mediante un microondas en continuo y lo comparan con un secadero tradicional.

En el año 2009, en la Universidad de Guangxi (R.P. China), S.J. Ma y col. [80], desarrollaron un método práctico para determinar la habilidad de los materiales para absorber energía de microondas.

Serpone, Horikorhi y Emeline [81] realizaron en 2010 una breve revisión sobre el uso de microondas para aplicaciones medioambientales.

Un equipo de ingenieros de la Universidad de Sichuan, Chengdu, China en 2010 [82], afirmaron que existen numerosas ventajas del procesado por microondas respecto de los métodos tradicionales de calentamiento.

Leonelli y Mason, en 2010 [83] explicaron que la irradiación por microondas produce calentamiento interno eficiente para muchas reacciones químicas, proporcionando energía justamente donde se requiere, incluso bajo condiciones exotérmicas.

Las ventajas más destacables de un horno microondas, según [19] y [84], son: 
- Calentamiento selectivo en todo el volumen de la muestra.

- Ahorro de energía (hasta un 70\%)

- Reducción de tamaño de los equipos (hasta un 20\%)

- Control instantáneo.

En la Figura 21 aparece el esquema del espectro de energías, indicando la región de ondas electromagnéticas pertenecientes a las microondas. Las frecuencias más destacadas en los hornos microondas son 2.45 GHz y $900 \mathrm{MHz}$ [85]. 


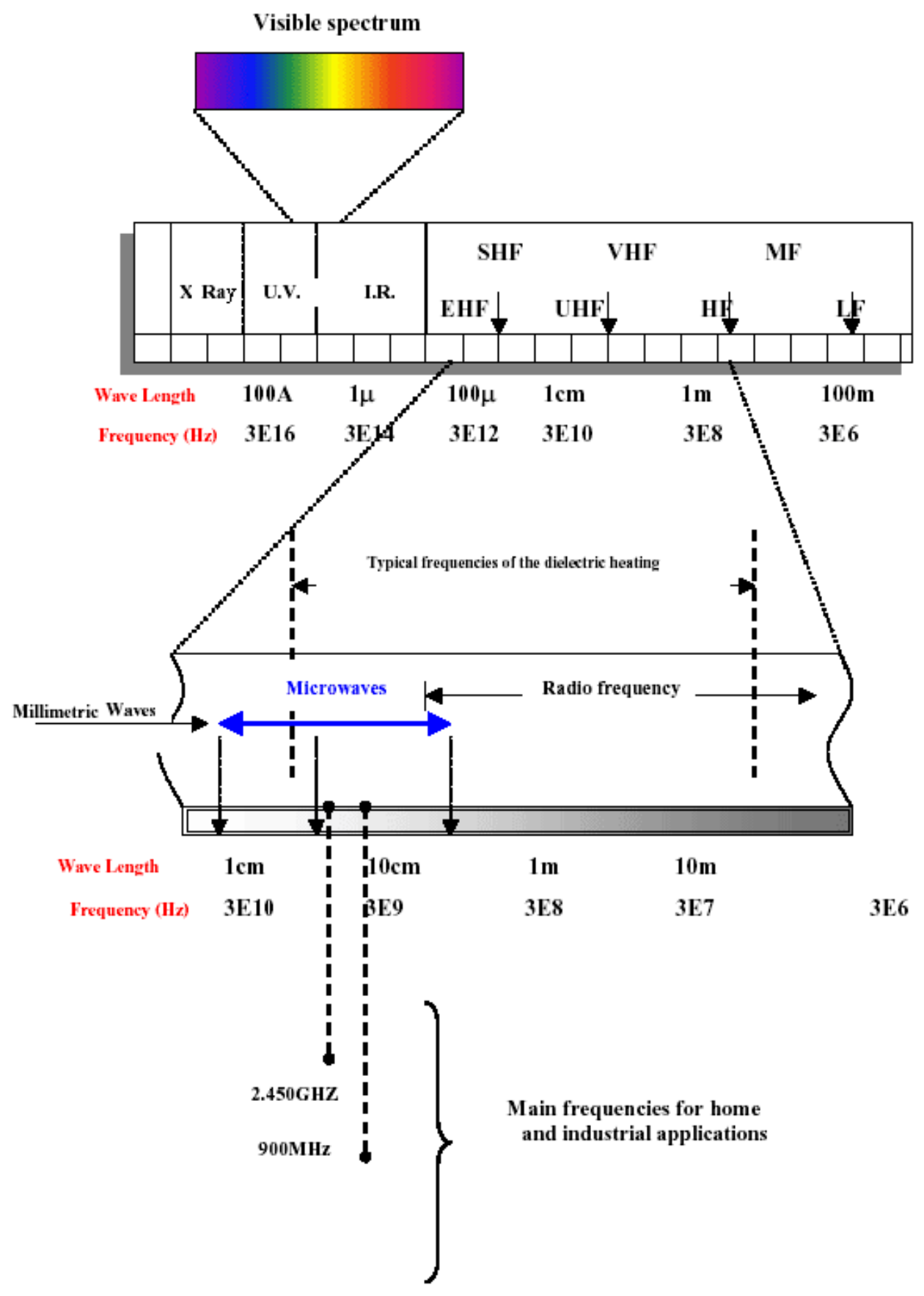

Figura 21. Subdivisión convencional de las ondas electromagnéticas, destacando la región correspondiente a las microondas. 
Por último, se muestra la imagen de un horno microondas industrial en la Figura 22, utilizado en el sector de la alimentación.

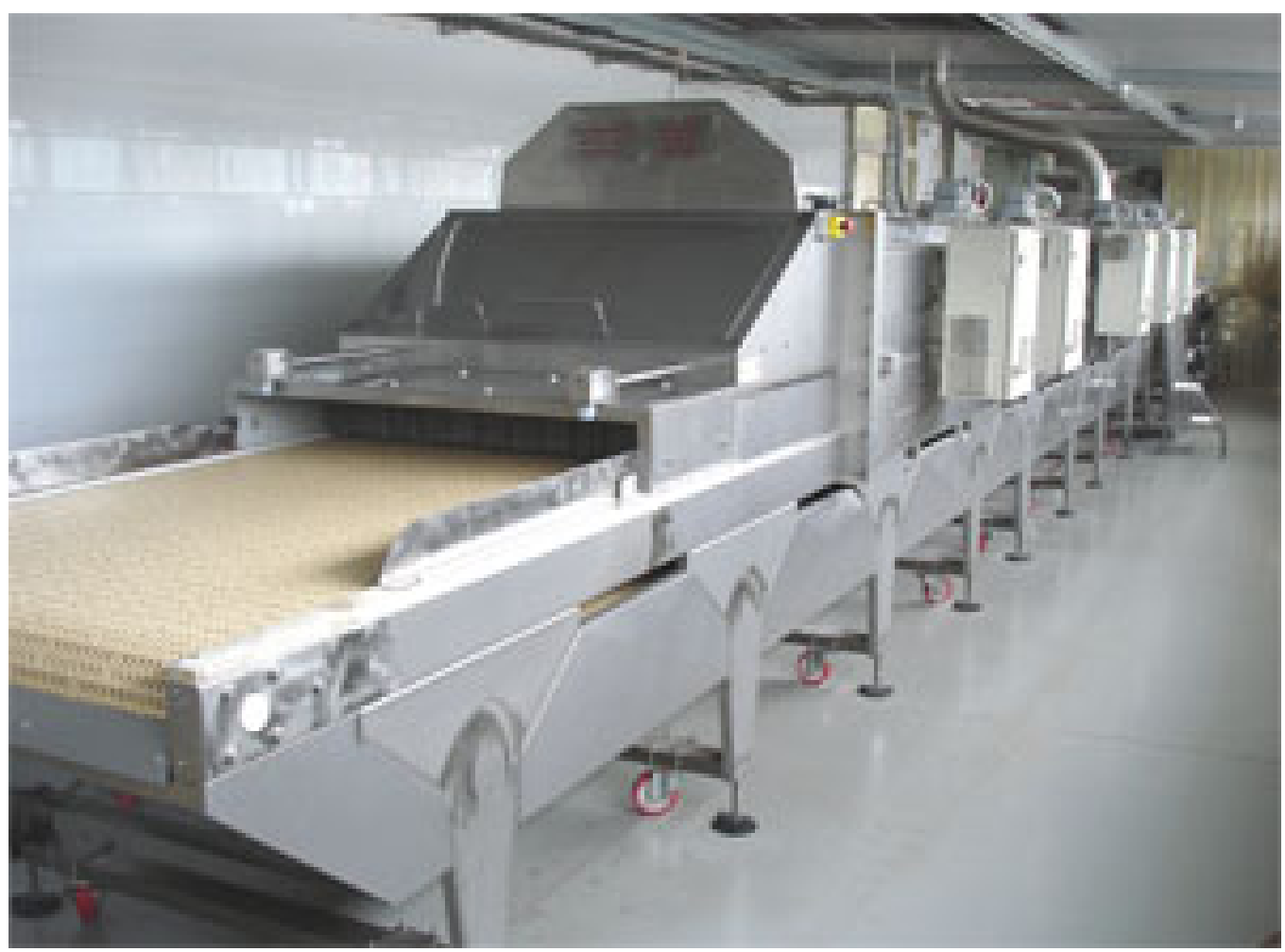

Figura 22. Horno microondas industrial.

\subsubsection{Desferretización de una arcilla calcinada.}

Según Yongxin Pan y col. [86], la siderita natural puede descomponerse significativamente incluso a temperaturas por debajo de $250^{\circ} \mathrm{C}$. Los productos obtenidos térmicamente son hematita $\left(\mathrm{Fe}_{2} \mathrm{O}_{3}\right)$ y probablemente maghemita $\left(\gamma-\mathrm{Fe}_{2} \mathrm{O}_{3}\right)$ superparamagnética debido a la rápida oxidación. La arcilla calcinada se puede desferrizar por vía húmeda o vía seca mediante imanes permanentes o inducidos. De este modo, arcillas a las que se les ha eliminado la materia orgánica serían doblemente purificadas, tras el proceso de desferrización. 
En relación con la modificación de las propiedades magnéticas de la siderita, I. Znamenackova y col. [87], en el año 2005, consiguen potenciar la eficiencia de la separación magnética de este mineral, tras calentarlo con un horno microondas de $900 \mathrm{~W}$. De esta forma, se introduce la importancia de las microondas en la calcinación.

Por otra parte, otros autores también han estudiado el efecto positivo que tiene el calentamiento por microondas sobre la pirita $\left(\mathrm{FeS}_{2}\right)$ contenida en el carbón [88], [89] y [90].

\title{
1.5. Introducción de residuos sólidos y líquidos en suspensión en la pasta cerámica.
}

\begin{abstract}
Desde hace años, el sector cerámico está introduciendo residuos sólidos crudos y líquidos en suspensión como materia prima para formular tanto pasta roja como pasta blanca. De esta manera, se han disminuido los residuos del sector cerámico reciclándolos como materia prima [91], [92], [93].
\end{abstract}

Entre los residuos cocidos más comunes del sector cerámico y del vidrio, destacan el testillo cocido (denominado "chamota") y el vidrio reciclado, bien vidrio hueco o vidrio plano. En la Figura 23 se presentan varios tipos de los residuos generados en el proceso de producción cerámico [94]. 

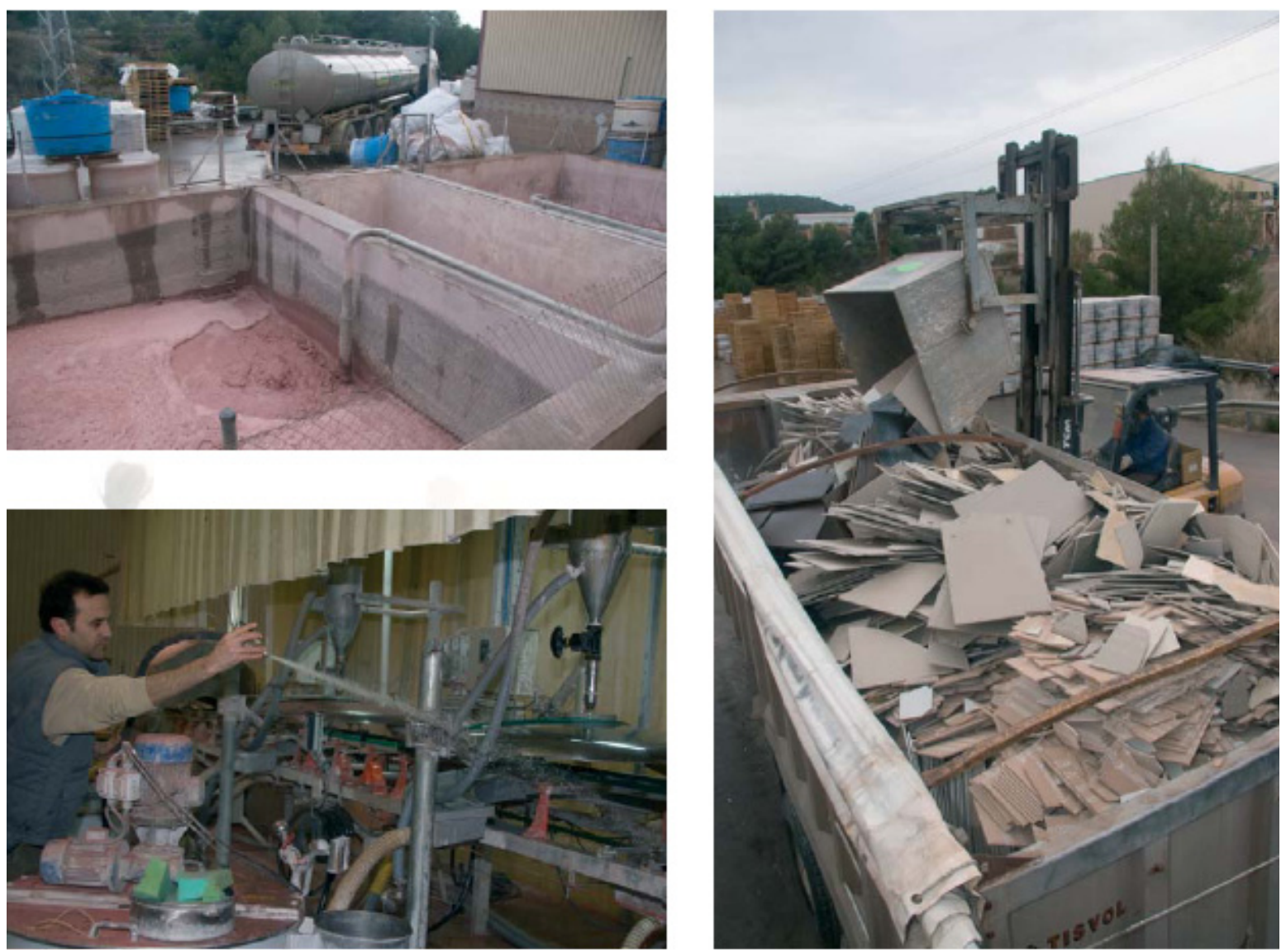

Figura 23. Distintos residuos generados en el proceso de producción cerámica: lodos, aguas sucias procedentes de la limpieza y tiestos crudos y cocidos.

\subsubsection{Introducción de agua reciclada en la pasta} cerámica.

La barbotina de la pasta cerámica es una suspensión arcillosa que suele contener entre 65-67\% de sólidos, de modo que el resto es agua que puede proceder de:

- AgUA RECICLADA EXTERNA originada durante la operación de limpieza de las plantas de producción de baldosas mayoritariamente. Es muy importante controlar la calidad de este tipo de agua, debido a su procedencia tan irregular. Los parámetros que se controlan en las 
plantas de atomización atomizadora de forma continua son: el contenido en sólidos, el pH y la conductividad. Esos valores han de estar dentro de unos intervalos específicos para que no inhiban la acción del producto defloculante (este último permite la fluidez de la barbotina a contenidos en sólido elevados) mientras la pasta está en forma de barbotina. El pH ha de ser neutro - básico y la conductividad ha de estar por debajo de $3000 \mu \mathrm{S} / \mathrm{cm}$ referenciada a $25^{\circ} \mathrm{C}$ de temperatura. En cuanto al contenido en sólidos de las aguas recicladas, este suele ser bajo (inferior al 10\%), de forma que estos sólidos se consideran despreciables frente a los sólidos totales que contiene la barbotina de pasta cerámica $[17]$.

- AGUA RECICLADA INTERNA procedente de la limpieza de los tamices ubicados a la salida del molino continuo, antes de que la barbotina entre en las balsas de homogeneización que, posteriormente, alimentan al atomizador. Su parámetro más importante a tener en cuenta es el contenido en sólidos.

- AGUA LIMPIA procedente de pozos o balsas de agua al aire libre.

Se intenta utilizar la mínima cantidad posible de agua limpia, con vistas a economizar el proceso y también favorecer el medio ambiente. No obstante, el agua reciclada interna se consume al $100 \%$ y el resto, se completa con agua reciclada externa y agua limpia, según la calidad de la externa, siguiendo los parámetros explicados anteriormente, [91]. 


\subsubsection{Introducción de testillo crudo en la pasta cerámica.}

El testillo crudo procede de las baldosas crudas, esmaltadas a veces, que presentan algún tipo de rotura o de defecto originado durante su fabricación. Habitualmente, los fabricantes de baldosas cerámicas recogen y transportan este testillo desde sus instalaciones hasta las empresas atomizadoras [17]. Una vez allí, el testillo crudo entra en el proceso de molienda, siendo "turbodesleído" previamente, con el fin de homogeneizar el material y sobre todo, de detectar y eliminar restos de cualquier residuo ajeno a la composición cerámica. Tras el tamizado, la barbotina del testillo crudo se incorpora al molino industrial como una materia prima más en forma de suspensión, de la que habrá que tener en cuenta el contenido en sólidos para regular su porcentaje de participación en la fórmula total que entra en producción.

En la actualidad, en la propia planta industrial de Grupo Tierra Atomizada, el testillo crudo hace tiempo que se utiliza en porcentajes inferiores al $10 \%$ en la composición de pasta roja y blanca, reduciendo el coste de materia prima no reciclada, además de no contaminar con estos residuos el medio ambiente.

\subsubsection{Estudio del testillo cocido ("chamota") procedente del sector cerámico.}

En el argot cerámico, al testillo cocido también se le denomina "chamota". Se define como "chamota" al material cocido de recuperación, procedente del proceso de valorización de residuos no peligrosos de origen refractario. Dicho material es 100\% 
inerte, encontrándose exento de todo elemento perjudicial, tanto para la salud de las personas como para el medio ambiente [95].

El testillo cocido procedente de la fabricación de baldosas y azulejos se utiliza mayoritariamente, como material de relleno en el sector de la construcción. Se trata de un producto muy duro, difícil de molturar. Normalmente, se utilizan molinos pendulares de gran resistencia a la abrasión, que sufren un desgaste importante durante el proceso.

En el año 2002, investigadores del Instituto de Tecnología Cerámica de la Universitat Jaume I de Castellón, estudiaron que, la adición de alrededor de un 5\% en peso de "chamota" procedente del sector cerámico, como materia prima en la formulación de pasta roja, es viable técnica (se incrementa la resistencia mecánica en cocido) y económicamente (los costes de trituración de la "chamota" compensan los costes de gestión del residuo cocido en un vertedero autorizado y los costes de materia prima que es sustituida por la "chamota") [96].

\subsubsection{Estudio del vidrio reciclado.}

a) DEFINICIÓN DE VIDRIO.

El vidrio es una masa amorfa transparente. Se caracteriza porque carece de punto de fusión determinado y desde su estado líquido, se vuelve cada vez más viscoso a medida que se enfría, adquiriendo un aspecto denso en un rango de temperaturas, siendo un material amorfo. Esto se debe a la viscosidad del vidrio que aumenta rápidamente con el descenso de temperatura e impide que los átomos se ordenen en forma cristalina. En la Figura 24 se muestra la variación del volumen específico en función de la temperatura [97]. 


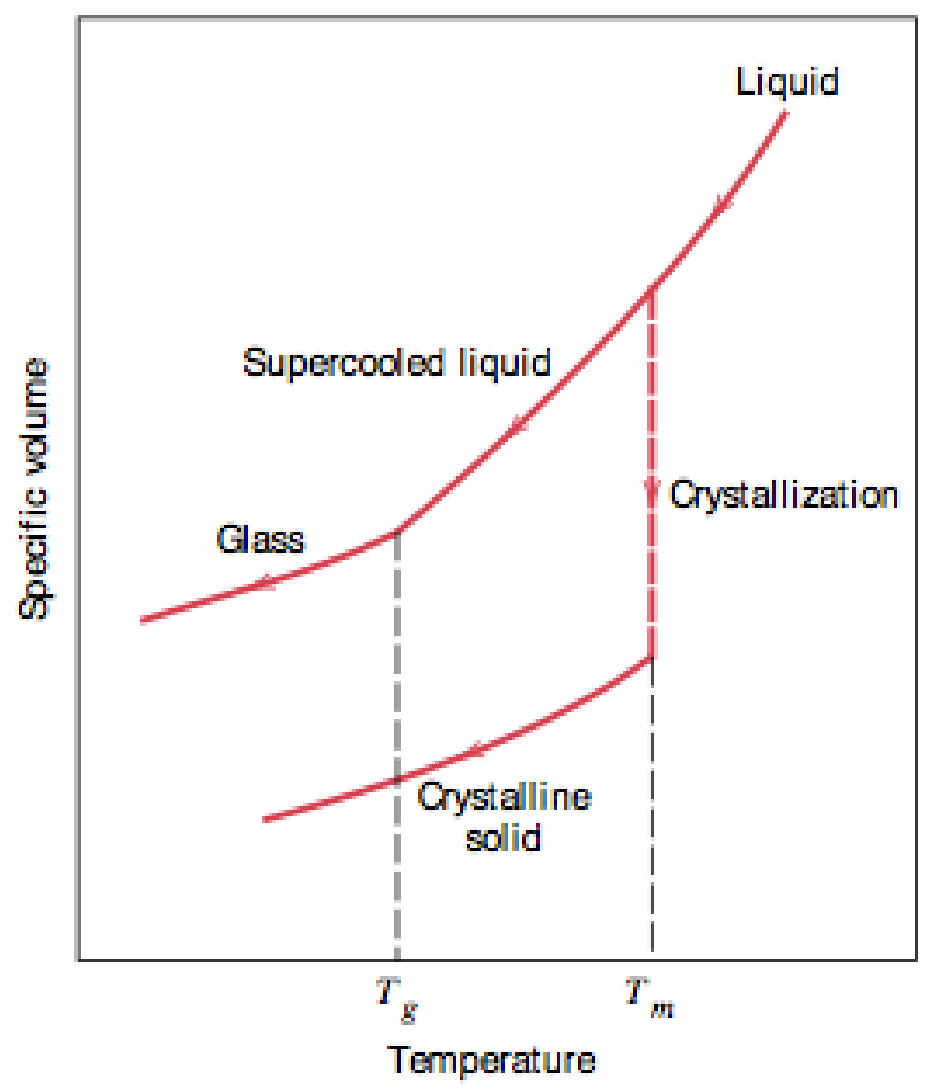

Figura 24. Variación del volumen específico con la temperatura en un material vítreo comparado con otro cristalino.

La viscosidad, propiedad característica del vidrio, permite elaborar productos soplados, pero trae dificultades en la elaboración, al oponerse al desprendimiento de burbujas gaseosas retenidas durante la fusión y exige una fluidificación final alrededor de $1400^{\circ} \mathrm{C}$. Además, si se enfría muy rápidamente, se desarrollan en el vidrio tensiones que lo hacen frágil.

La definición de vidrio en el ámbito científico es muy compleja, debido a la naturaleza de éste [98]. Uno de los primeros científicos de la era moderna en estudiar el estado vítreo fue Tammann [99]. Definió los vidrios como "líquidos subenfriados pero que, a diferencia de los líquidos, no poseen un equilibrio 
interno". Teniendo en cuenta las propiedades técnicas del vidrio, se podría definir como "un producto inorgánico amorfo", constituido principalmente por sílice, duro, frágil y transparente, de elevada resistencia química y deformable a alta temperatura. Según la "American Society for Testing Materials" (ASTM), otra posible definición sería la de "producto inorgánico de fusión, el cual se ha enfriado hasta un estado rígido, pero sin sufrir cristalización", como se muestra en la Figura 25.

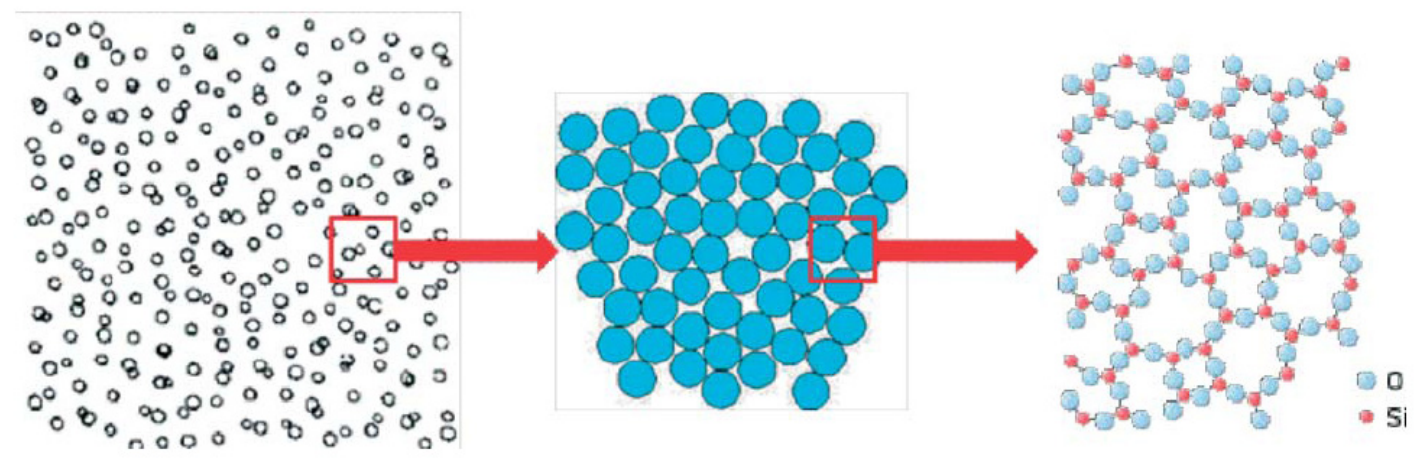

Figura 25. Estado no cristalino del vidrio.

Estas definiciones son bastante restrictivas, ya que se conocen vidrios de composición orgánica y la fusión no es la única vía para generar vidrios: el proceso sol-gel o la deposición química en fase vapor son otras técnicas que permiten la formación de vidrio. Otro de los grandes investigadores en el campo del vidrio, Dietzel [100], en su definición de vidrio incluye el término vitroide, el cual engloba los vidrios convencionales y las sustancias orgánicas vítreas. El término vitroide se define como "sustancia compacta (excepto polvos amorfos y geles) físicamente uniforme que se encuentra en un estado amorfo (no cristalino) y estructuralmente desordenado) que a temperaturas bajas se hace rígida y frágil, reblandeciendo a temperaturas elevadas" [101]. 
La naturaleza amorfa del vidrio y su composición (rica en álcalis) le configura un carácter fundente. En la Figura 26 se aprecian diferentes envases y recipientes de vidrio.
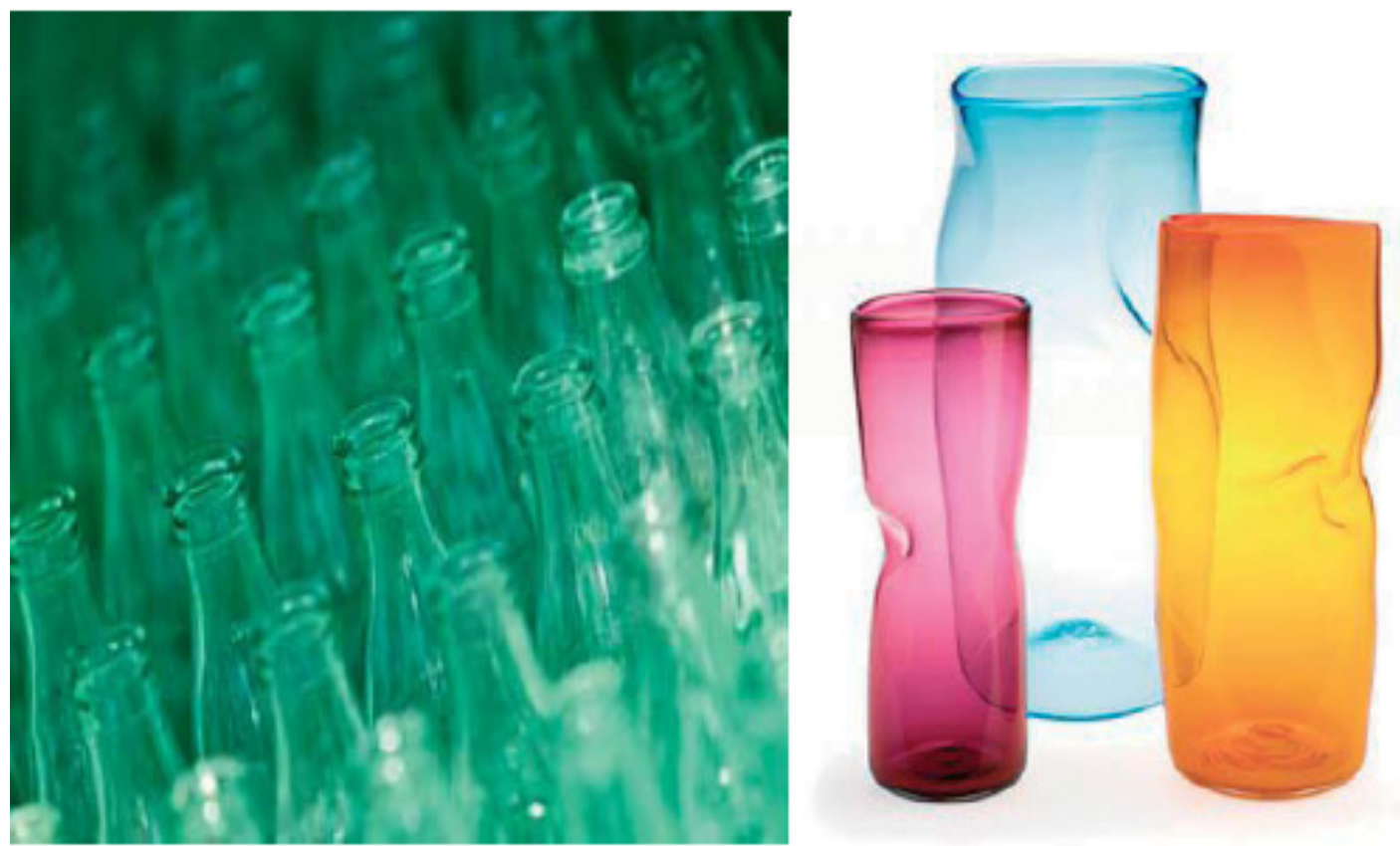

Figura 26. Vidrio procedente de diferentes envases y recipientes.

b) Utilización de vidrio reciclado en las formulaciones de pastas cerámicas.

El vidrio reciclado se puede utilizar como materia prima en la formulación de cerámica estructural (ladrillos y tejas). Así, en el año 2009, destacan dos trabajos científicos que indican que la adición de vidrio reciclado (vidrio de pantalla y vidrio plano) en la composición cerámica estructural, mejora la resistencia mecánica en cocido, si bien, altos porcentajes en peso de vidrio en la composición, provoca la deformación de las piezas cerámicas $[102], \quad[103]$. 
Por otro lado, en lo que se refiere al gres porcelánico, también se encuentran varios artículos de reciente publicación [104], [105], [106], en los que se ha añadido vidrio reciclado (vidrio plano o vidrio de pantalla). Se observa que el vidrio reciclado, en porcentajes de inferiores al 5\% en peso de la formulación de porcelánico, actúa como agente fluidificante, de forma que acelera el proceso de densificación, lo que mejora las propiedades mecánicas y disminuye la porosidad de las piezas de porcelánico. Sin embargo, adiciones elevadas de vidrio reciclado en las composiciones de porcelánico, modifican la estructura cristalina de las fases cocidas presentes en la pieza cerámica.

\subsubsection{Otros residuos añadidos a las formulaciones de pasta cerámica.}

Dada la diversidad de residuos sólidos que generan las industrias relacionadas con el procesado de materiales, son numerosos los estudios realizados para utilizar estos residuos como materia prima en la formulación de pastas cerámicas. Así, se ha estudiado la adición de varios tipos de residuos sólidos a las composiciones cerámicas: lodos procedentes del procesado del granito adicionados a la formulación de pavimento [107], [108]; subproductos procedentes de los altos hornos (fundición), [109], [110] añadidos a la composición de ladrillo; cenizas volantes procedentes de la industria de procesado de minerales [111], [112]; residuos provenientes de la minería del carbón para introducirlos como materia prima de gres porcelánico rojo [113]; sedimentos marinos altamente contaminantes recogidos en el litoral Cantábrico para la fabricación de ladrillos y baldosas [114]; residuos de carburo de silicio que se han introducido en la formulación de porcelánico [115]; residuos de fritas del sector de los esmaltes cerámicos añadidos como materia prima para formular porcelánico [116] y, por último, entre un 5-10\% en peso de basuras 
sólidas municipales incineradas, añadidas como materia prima en la fabricación de porcelánico [117]. Todos ellos, según los estudios publicados, tienen en común que, introducidos en bajos porcentajes en las composiciones cerámicas, actúan de agentes fluidificantes, mejorando la densificación y la resistencia mecánica en cocido de las piezas cerámicas correspondientes.

\subsubsection{Desarrollo sostenible en el sector cerámico y del vidrio.}

Los dos tipos de testillo, el crudo y el cocido, junto con el vidrio reciclado, son residuos de producto acabado procedentes del sector cerámico y del sector del vidrio que forman parte de los residuos relacionados con todo lo que conlleva el sector de la minería y de la construcción, uno de los principales flujos de residuos en los países desarrollados y uno de los mayores problemas debido a su volumen y a su importante impacto ecológico y paisajístico [118], [119].

El reciclaje controlado y la reutilización de estos residuos es un objetivo fundamental para alcanzar el desarrollo sostenible. La reutilización más extendida de este tipo de residuos es la elaboración de áridos que se pueden utilizar como componente de hormigones y, sobre todo, como base para carreteras y rellenos de terrenos en general y de canteras abandonadas. El uso de este tipo de materiales reciclados comporta una serie de beneficios medioambientales [120], [121]:

- Reciclando vidrio se ahorra energía: con la energía que ahorra el reciclaje de una botella, se podría mantener encendida una bombilla de 100 watios durante 4 horas. 
- Se ahorran materias primas y se evita el impacto medioambiental con la destrucción de terrenos por extracción: reciclando 3.000 botellas se ahorra más de una tonelada de materias primas.

- Se reducen los residuos que van a parar a los vertederos: 3.000 botellas recicladas son 1.000 kilos menos de basura.

- Se reduce la contaminación del aire en un 20\%, al quemar menos combustible para la fabricación de nuevos envases.

- Se evita el grave problema de los vertidos incontrolados.

- Se elimina parte de la emisión de $\mathrm{CO}_{2}$, al introducir agentes alcalinos y alcalinotérreos sin la necesidad de añadirlos como carbonatos o como materia prima natural, en la formulación de diferentes composiciones cerámicas.

- Supone un ahorro energético, ya que la temperatura de fusión del vidrio recuperado o "calcín" es sensiblemente inferior a la de la materia prima original (en promedio el ahorro en los hornos de fusión es de $130 \mathrm{Kg}$. de "fuel oil" por tonelada de vidrio reciclado), evitando además nuevas emisiones contaminantes a la atmósfera responsables del llamado cambio climático. 
En la pasada edición de CEVISAMA 2011, la empresa Azulejos Plaza, en colaboración con Tierra Atomizada y otros [94] fue premiada con el Alfa de Oro 2011, máximo galardón que otorga la Sociedad Española de Cerámica y Vidrio, por un proyecto en el que incorpora vidrio y "chamota" a las composiciones de pasta y también de esmalte, mostrado en la Figura 27.
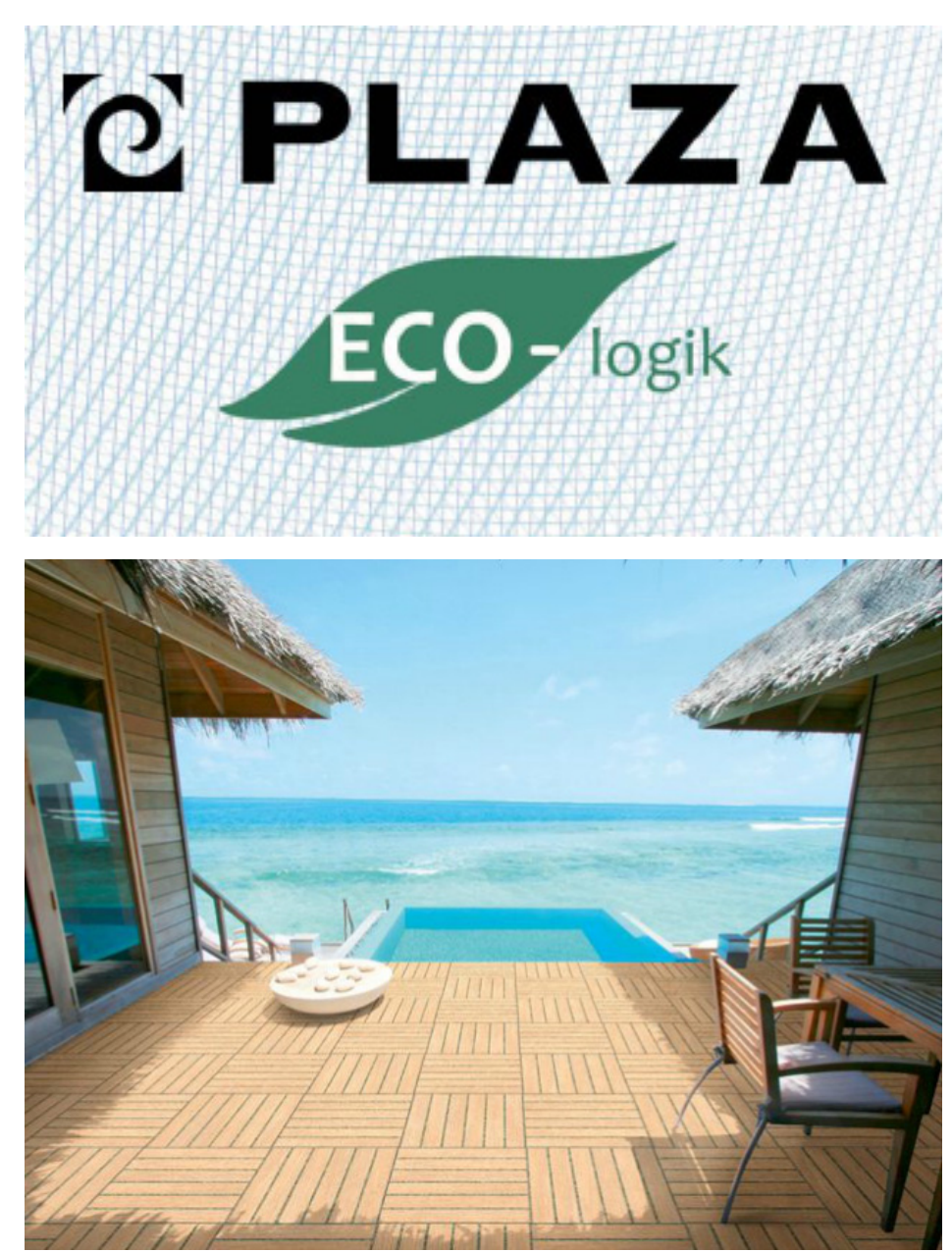

Figura 27. Etiqueta del producto desarrollado por la empresa Azulejos Plaza de l'Alcora (Castellón) premiado con el Alfa de Oro en la pasada edición de Cevisama 2011, que aparece integrado en un ambiente marino. 


\section{Capítulo 2. OBJETIVOS.}

El objetivo principal de la presente Tesis Doctoral ha sido el tratamiento de arcillas españolas con contenidos moderados en compuestos de hierro y materia orgánica, para su introducción, junto con residuos procedentes tanto del sector cerámico como del vidrio proveniente del reciclado, en la formulación de pastas cerámicas de coloración blanca que permitan la fabricación de baldosas de gres porcelánico y de revestimiento.

Para llevar a cabo este objetivo principal, se han desarrollado los siguientes objetivos parciales:

1. Estudio de arcillas de diferente naturaleza con contenidos bajos o moderados de compuestos de hierro procedentes de Ciudad Real y Teruel.

2. Tratamiento de las arcillas españolas preseleccionadas (Ciudad Real) con los sistemas de hidrociclonado que permiten una disminución significativa de los contenidos de hierro.

3. Estudio de la desferritización y tratamiento de arcillas españolas preseleccionadas, mediante el separador magnético, para disminuir el contenido de hierro en las mismas.

4. Estudio y tratamiento térmico de las arcillas de Teruel que presentan moderados contenidos en carbón, para la disminución de materia orgánica. 
5. Estudio documental y bibliográfico sobre la aplicación de la radiación de microondas para el procesamiento industrial de arcillas con un contenido moderado de materia orgánica.

6. Estudio de los residuos generados por el propio sector de fabricación de baldosas cerámicas (aguas residuales, testillo crudo y testillo cocido) para su incorporación en la formulación de pastas cerámicas de gres porcelánico y revestimiento de monoporosa.

7. Estudio de la incorporación de residuo provenientes del sector cerámico y del vidrio reciclado, en la formulación de pastas cerámicas de gres porcelánico y revestimiento de monoporosa.

8. Optimización del ciclo de cocción de los hornos industriales de pasta blanca, mediante la introducción de residuos cocidos ("chamota" y vidrio reciclado) en las composiciones de pasta blanca, tanto para pavimento (gres porcelánico) como revestimiento (monoporosa).

Para llevar a cabo todos los objetivos, se ha partido del supuesto de poder formular composiciones cerámicas de cocción blanca, de alta calidad, sustituyendo parcialmente las arcillas que actualmente se utilizan de importación de otros países (Reino Unido, Alemania, Ucrania, etc.), por arcillas españolas, con el consiguiente abaratamiento de costes y, también, el poder asegurar el suministro de materia prima. Y, asimismo, a través de la introducción de residuos, tanto generados por el propio sector cerámico como de otros sectores, como el del vidrio procedente del reciclado, el poder desarrollar nuevas baldosas cerámicas más ecológicas. 


\section{Capítulo 3. METODOLOGÍA EXPERIMENTAL.}

\subsection{Técnicas de caracterización.}

En este apartado se incluye la descripción de cada uno de los métodos y técnicas utilizados en el laboratorio para el análisis de las muestras y las composiciones desarrolladas.

\subsubsection{Análisis térmico, (ATD/TG).}

El análisis térmico estudia la variación de masa y de energía térmica que sufre un compuesto al aplicarle un ciclo de calentamiento en unas condiciones determinadas [98]. Las variables más importantes a tener en cuenta son: el tamaño de partícula del compuesto, la atmósfera del horno y la velocidad de calentamiento del ciclo elegido. Su principal utilidad es el estudio de los materiales a través de sus transformaciones térmicas, como son deshidrataciones, procesos de combustión, descomposiciones, reacciones de cristalización, reacciones de cambio de fase, transformaciones alotrópicas, etc. En este caso, el estudio se ha centrado principalmente en las reacciones exotérmicas debidas a la combustión de la materia orgánica y las reacciones endotérmicas referidas a la deshidroxilación, ocasionada por la pérdida de la caolinita constituyente de las arcillas. Se ha trabajado para ello, con un equipo ATD-TG de Perkin Elmer, modelo Pyris Diamond TG/DTA en atmósfera ambiental y se ha programado de $50^{\circ} \mathrm{C}$ a $1150^{\circ} \mathrm{C}$ con una velocidad de calentamiento de $10^{\circ} \mathrm{C} / \mathrm{min}$. El equipo utilizado se ubica en los laboratorios de Grupo Tierra Atomizada [17] y se muestra en la Figura 28. 


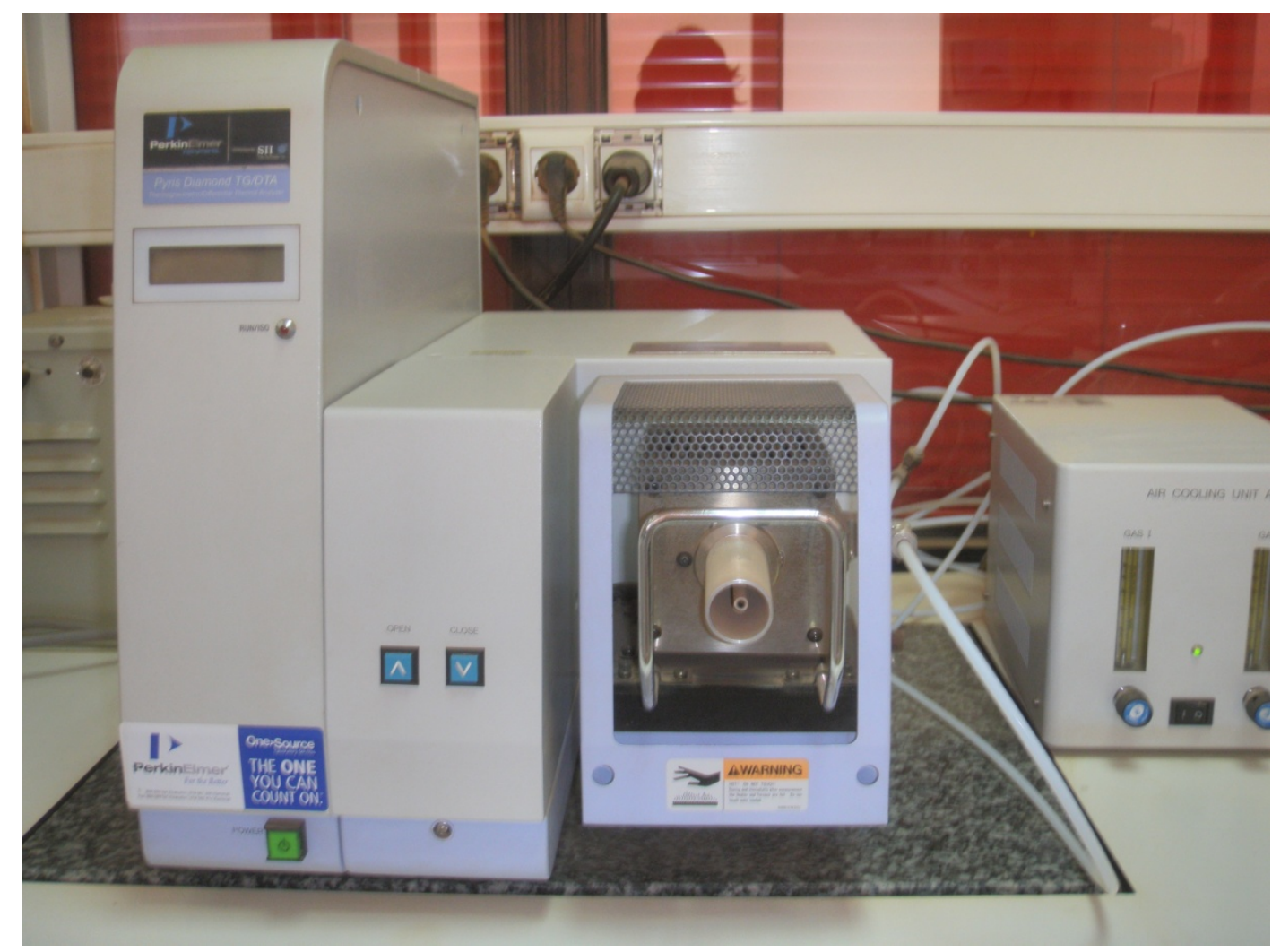

Figura 28. Equipo de análisis térmico, (ATD/TG) .

\subsubsection{Espectrómetro secuencial de fluorescencia de rayos- $X,(F R X)$.}

Se trata de un equipo que genera rayos $\mathrm{x}$ mediante electrones acelerados debido a una diferencia de potencial aplicada entre el cátodo (filamento generalmente de wolframio) y el ánodo (placa metálica), colocados dentro de una ampolla de vidrio al vacío, que es el propio tubo de rayos X [98]. Los electrones impactan sobre el ánodo, donde una pequeña parte de la energía cinética se invierte en la producción de rayos X y el resto se disipa en forma de calor, por lo que se requiere una refrigeración continua del ánodo. Los rayos X generados se emplean en la generación de radiación X secundaria, fenómeno que se conoce como fluorescencia 
de rayos $\mathrm{x}$ : los rayos $\mathrm{x}$ primarios inciden sobre la muestra produciendo la extracción de un electrón de los niveles internos del átomo, quedando éste excitado. La vacante electrónica que se genera puede pasar a ser ocupada por un electrón de los niveles inmediatamente superiores, liberándose fotones de rayos $\mathrm{X}$ de energía correspondiente a la diferencia de energías entre los niveles de origen y de destino, siendo característica de cada elemento químico.

Los análisis químicos presentados en esta Tesis Doctoral, se han realizado con un espectrómetro de rayos-X de Bruker-AXS, modelo S4 Explorer, que dispone también el Grupo Tierra Atomizada en sus laboratorios y cuyo esquema de funcionamiento se muestra en la Figura 29.

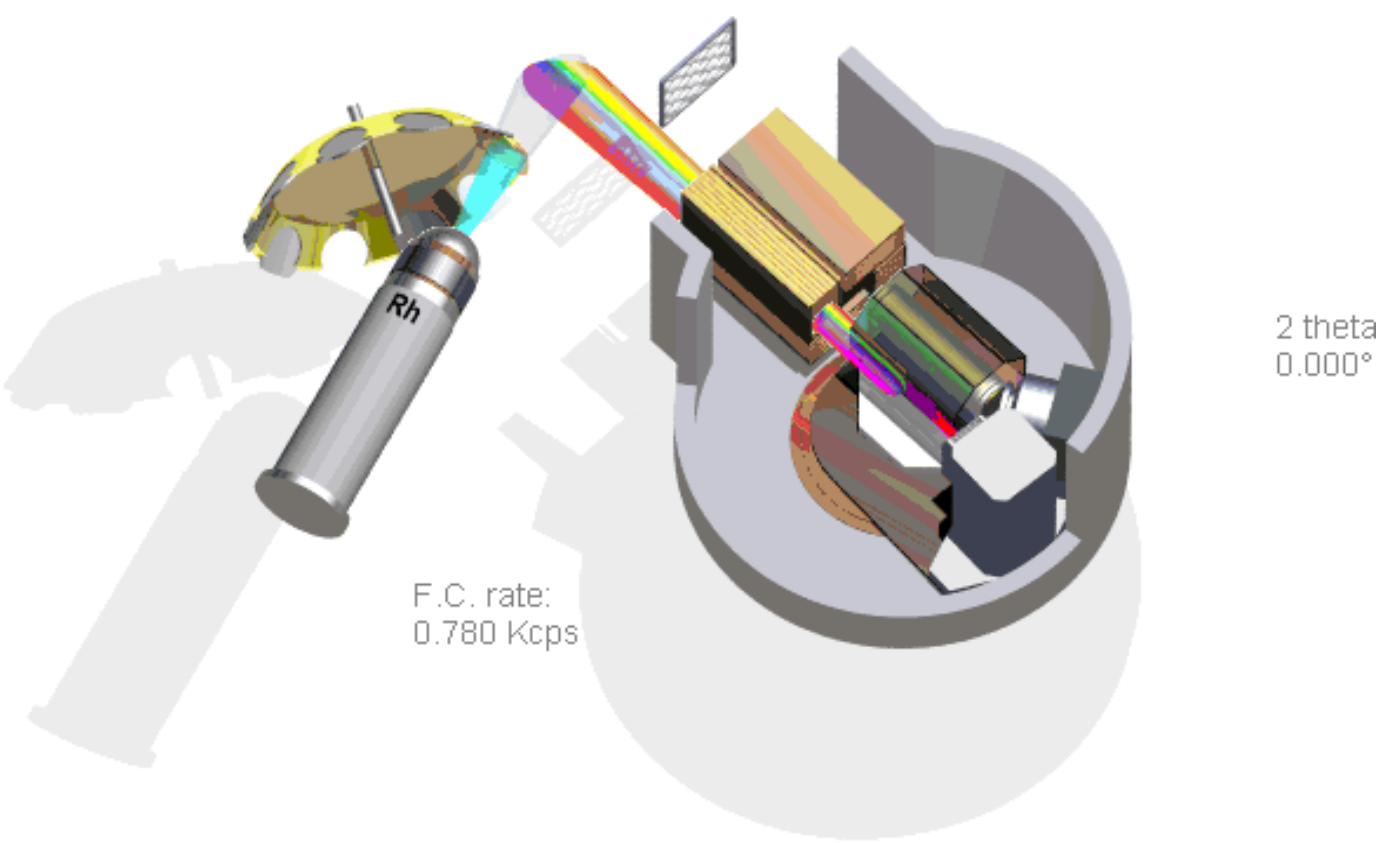

Figura 29. Esquema del estatus del espectrómetro de Rayos-X.

Las muestras han sido preparadas añadiendo a las mismas un 27\% en peso de ácido bórico, como agente compactante, homogeneizando 
la muestra con un molino de anillos (marca Herzog) y han sido prensadas en forma de pastillas circulares para medirlas en el espectrómetro S4 Explorer, previamente calibrado con una curva cuantitativa, cuyos patrones han sido materias primas naturales.

\subsubsection{Microscopio electrónico de barrido, (MEB).}

La microscopía electrónica de barrido se basa en el estudio de señales que emite una muestra al ser bombardeada por un haz acelerado de electrones [98]. Según el tipo de detector utilizado para la recogida de la señal, se obtiene una información topográfica, estructural o química. De este modo, el detector de electrones secundarios (SE) aporta la topográfica de la muestra, de manera que las zonas más brillantes corresponden a montículos y por el contrario, las más oscuras a valles que presenta la morfología de la muestra. El detector de electrones retrodispersados (QSB) aporta la información estructural de la muestra, de manera que las zonas más claras o brillantes contienen elementos con mayor peso atómico y las más oscuras, la de aquellos elementos con menor peso atómico. En cuanto a la información química, es del detector de microanálisis por energías dispersivas de rayos-X (EDX) el que recoge los rayos característicos de la muestra y ofrece resultados similares a una fluorescencia de rayos $-\mathrm{X}$.

El equipo utilizado para ello, es un microscopio electrónico de barrido de la marca JEOL modelo 207JSM-6360LV dotado de un microanálisis de oxford Instruments. Las condiciones de trabajo utilizadas para analizar la porosidad interna de las probetas cocidas son: $15 \mathrm{kV}$ de voltaje a alto vacío, $10 \mathrm{~mm}$ de distancia de trabajo, con el detector de electrones retrodispersados. El programa informático que ha servido para realizar el análisis de 
imagen de las micrografías realizadas, es "INCA, The Microanalysis Suite-Issue 16. Suite version 4.06". En la Figura 30 se observa el microscopio electrónico de barrido utilizado en este trabajo y disponible en el laboratorio de Grupo Tierra Atomizada.

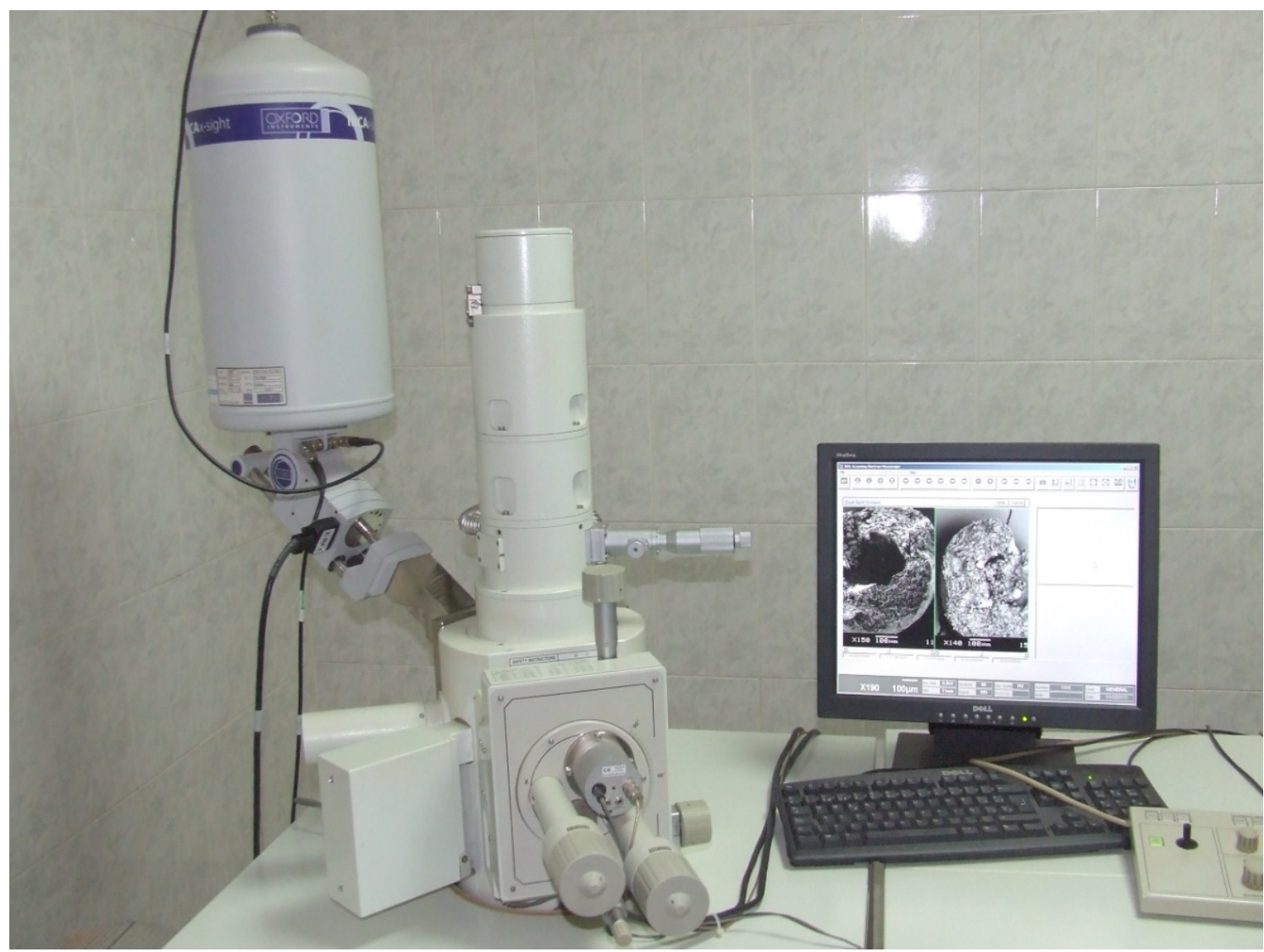

Figura 30. Microscopio electrónico de barrido perteneciente a Tierra Atomizada.

\subsubsection{Difractómetro de rayos-X, (DRX).}

El análisis por difracción de Rayos-X permite conocer las fases cristalinas presentes en una mezcla de varios minerales, en un tiempo breve y con poca cantidad de muestra [98]. Esta técnica se basa en la Ley de Bragg, donde se cumple la coherencia de la radiación cuando impacta sobre los planos cristalinos de las 
muestras y es difractada: $(\mathrm{n} \lambda=2 \mathrm{~d} \operatorname{sen} \theta)^{2}$, representada en la Figura 31 [122].

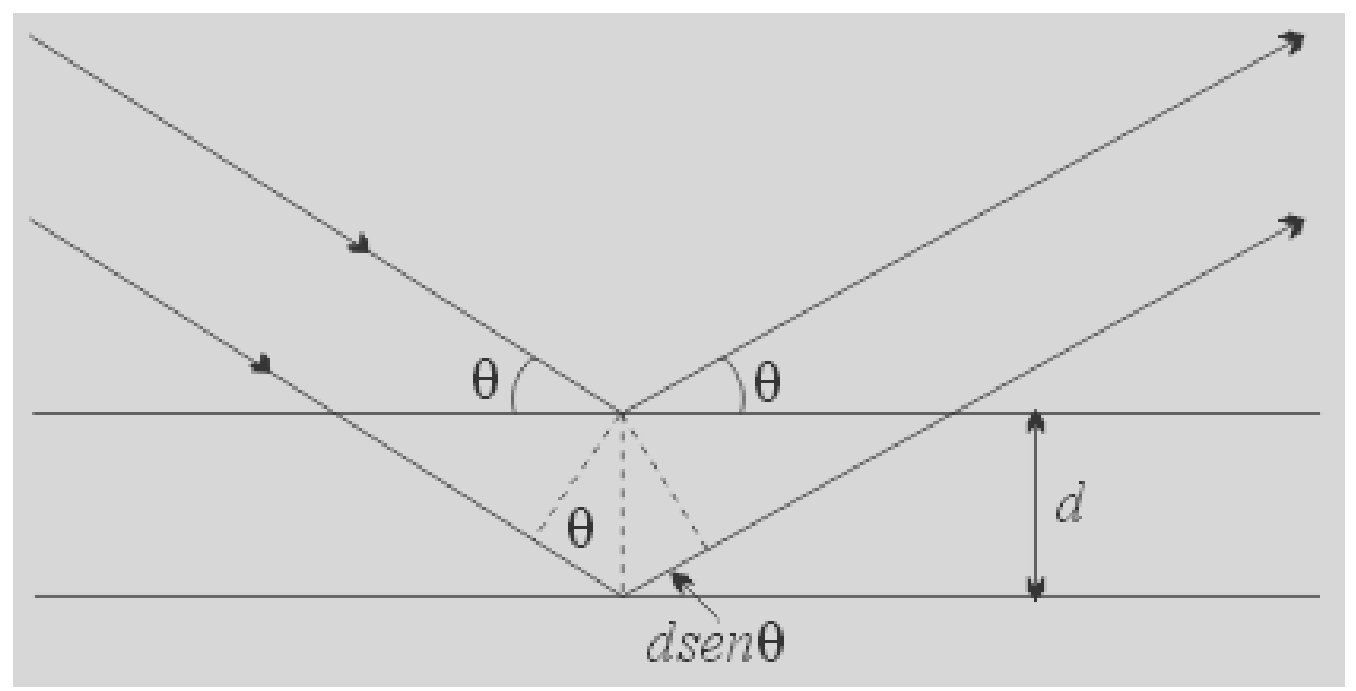

Figura 31. Esquema del comportamiento de la radiación difractada después de impactar sobre los planos cristalinos (Ley de Bragg).

Para la obtención de los correspondientes difractogramas se ha utilizado un difractómetro Siemens, D500, equipado con contador proporcional y sistema de discriminación de altura de impulsos. Las condiciones de trabajo han sido: tensión $40 \mathrm{kV}$, intensidad 30 $\mathrm{mA}$, anticátodo de cobre y rendija de ventana $1^{\circ}$, rendija de contador $0,1^{\circ}$, velocidad de exploración $2 \% / \mathrm{min}$ y sensibilidad 8 .

Para la preparación de las muestras se ha efectuado una molienda de las mismas hasta alcanzar un tamaño de partícula inferior a 0,05 mm y se ha acondicionado en el portamuestras bajo el sistema de polvos distribuidos al azar. Para la interpretación de los difractogramas se ha utilizado el programa "DRXWin 2.3 (5)" .

\footnotetext{
${ }^{2} \lambda$ : Longitud de onda de la radiación incidente (La radiación utilizada es CuKa). d: Espaciado de los planos cristalinos.

$\Theta$ : Ángulo de difracción.
} 


\subsubsection{Microscopio de calentamiento.}

Esta técnica estudia la variación dimensional y de viscosidad de una muestra al aplicarle un ciclo de temperaturas, [8], [98]. Permite la observación de las variaciones morfológicas y dimensionales que sufre una muestra de material al ser calentada, pudiéndose determinar los intervalos de temperatura en los que se produce la contracción y la fusión del material en estudio.

El ensayo consiste en preparar una probeta compacta con la muestra micronizada y homogénea, en forma de cilindro de $3.0 \mathrm{~mm}$ de altura y $1.8 \mathrm{~mm}$ de diámetro. A continuación, se introduce sobre un portamuestras de alúmina en el interior del horno del microscopio de calentamiento, de la Figura 32. Una cámara de vídeo es la encargada de registrar los cambios morfológicos que sufre la probeta, sometida a un programa de temperaturas determinado, en función de las necesidades y del tipo de muestra. De esta forma, el microscopio de calentamiento es capaz de definir la fundencia de los materiales a partir de 5 formas fundamentales [123] que automáticamente elige de entre todas las imágenes grabadas.

\section{Sinterización.}

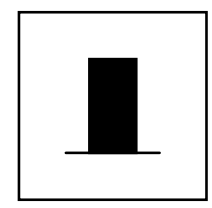

Durante la fase de sinterización, las dimensiones de la muestra se reducen, pero la forma permanece prácticamente igual. El valor de la temperatura de sinterización medido por el instrumento, se refiere a la temperatura a la cual la muestra ha sufrido una variación de las dimensiones correspondiente al valor indicado en la tarjeta de parámetros, que está predefinido en un $5 \%$ 


\section{Ablandamiento.}

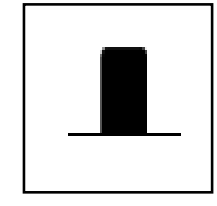

El punto de ablandamiento se obtiene cuando las fases líquidas que se forman en la muestra emergen a la superficie. Para medirlo, se consideran el redondeamiento de los ángulos de la muestra y la atenuación de la rugosidad en la parte superior y en las partes de la muestra.

\section{Esfera.}

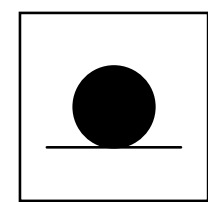

A la temperatura de la esfera, la muestra está constituida fundamentalmente por fases líquidas y la forma de la muestra está controlada por la tensión superficial. Por comparación, se entiende una semejanza de posición en algunos puntos de la muestra con los pertenecientes a una esfera, cuyo centro coincide con el de la muestra.

\section{Media esfera.}

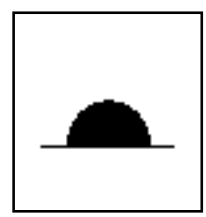

La temperatura de media esfera se obtiene cuando la altura de la muestra corresponde a la mitad de la anchura de la base. 


\section{Fusión.}

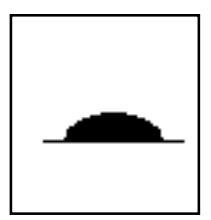

Cuando la altura de la muestra desciende por debajo de un tercio de la inicial y, al mismo tiempo, la relación entre la base de la muestra y la altura supera un valor máximo, se establece que la muestra es completamente líquida y, por lo tanto, fundida.

En este caso, las muestras de vidrio se han sometido al ciclo de calentamiento siguiente: velocidad de calentamiento a $1200^{\circ} \mathrm{C}$ de $30^{\circ} \mathrm{C} / \mathrm{min}$. Para el caso de los feldespatos, al ser más refractarios, el calentamiento ha sido de $20^{\circ} \mathrm{C} / \mathrm{min}$ hasta $1350^{\circ} \mathrm{C}$. Al final del ciclo, el enfriamiento del horno es libre.

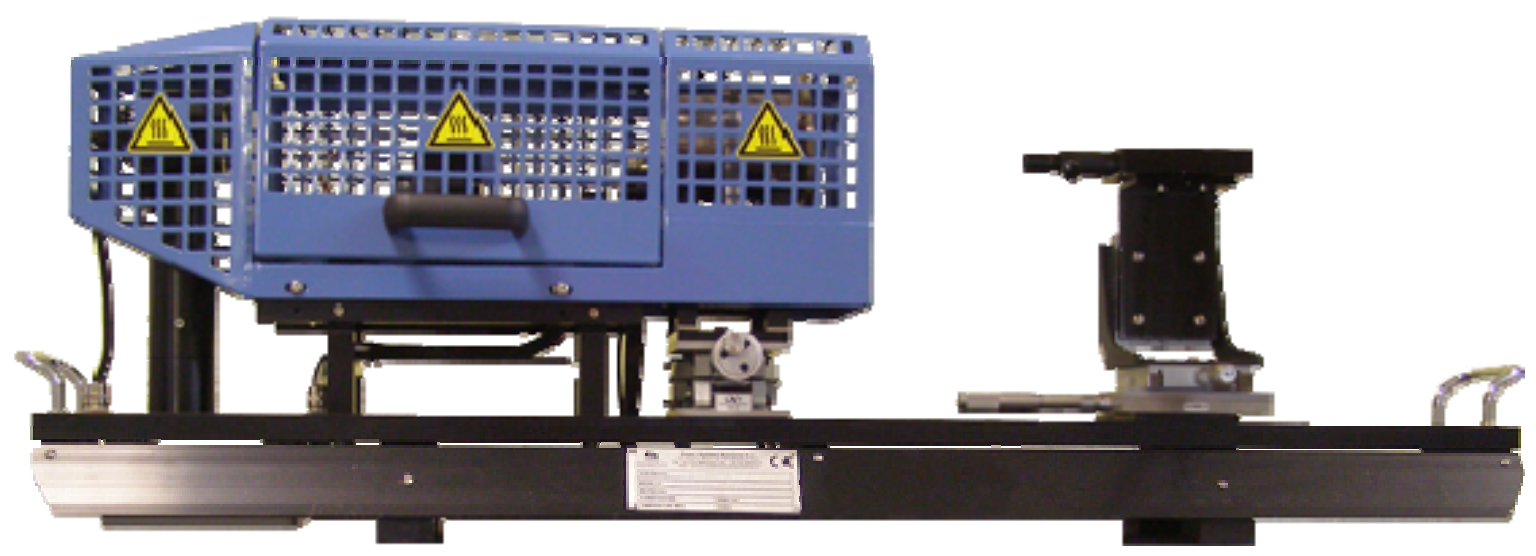

Figura 32. Microscopio de calentamiento.

\subsubsection{Analizador de carbono, (TOC).}

El funcionamiento del analizador de carbono consiste en aportar el oxígeno necesario para la calcinación de la muestra a alta temperatura [124]. Para la determinación del carbono y azufre se utilizan unas celdas de detección individuales y específicas 
para ambos elementos de estado sólido de NIR. Como el equipo no determina el agua, esta se atrapa en un filtro relleno de anhidrona, que es perclorato magnésico anhidro, para que no interfiera y se elimine del circuito de medida. El equipo del que se dispone en los laboratorios de Grupo Tierra Atomizada es un equipo SC-144 de LECO y permite obtener tanto el carbono y azufre total, de forma simultánea (calentando hasta $1350^{\circ} \mathrm{C}$ ), como el carbono orgánico (calentando hasta $550^{\circ} \mathrm{C}$ ). El carbono inorgánico se obtiene de la diferencia entre el carbono total y el carbono orgánico. En la Figura 33 aparece el analizador de carbono utilizado. Para analizar el porcentaje de carbono orgánico de las arcillas y de las composiciones preparadas, las muestras se han calentado utilizando el ciclo de $550^{\circ} \mathrm{C}$, donde se supone que todo la materia orgánica combustiona.

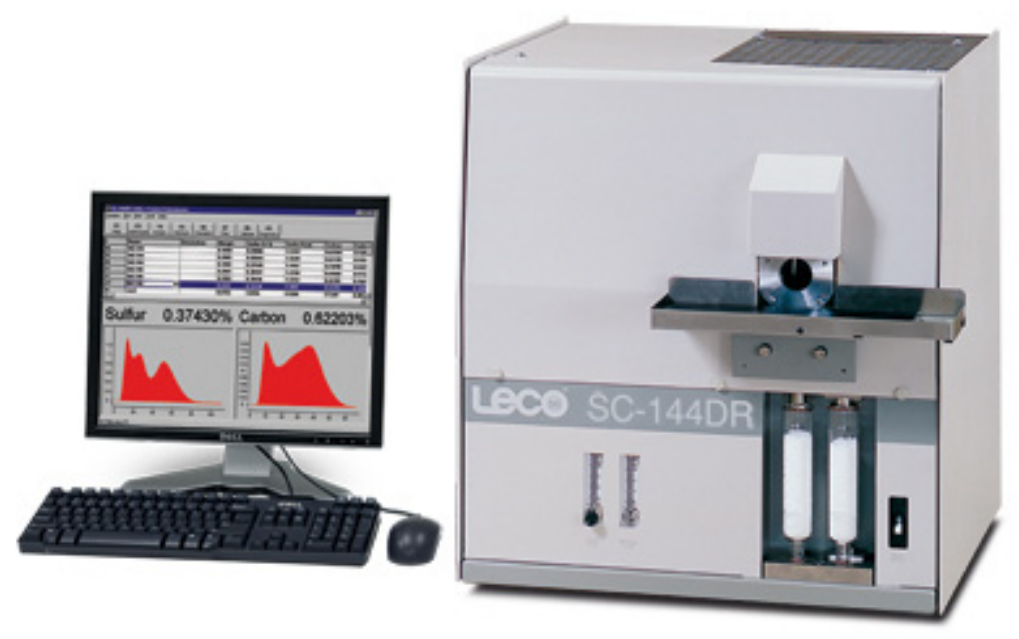

Figura 33. Analizador de carbono y azufre.

\subsubsection{Espectrofotómetro UV-Visible, método de reflectancia difusa.}

Para poder medir el color de las probetas cerámicas cocidas de pasta blanca, tanto de pavimento como de revestimiento, 
se ha utilizado un espectrofotómetro UV-Visible de Konica Minolta (modelo CM-3600D), ubicado en los laboratorios de Grupo Tierra Atomizada [17], cuyas medidas se han basado en el método de reflectancia difusa. La medida del color de las probetas cerámicas con este equipo, se ha basado en el espacio de color CIE-Lab, de 1976, donde se representan los colores mediante puntos, según la teoría tricromática de colores primarios, rojo, verde y azul [125]. El espacio de color CIE-Lab presenta 3 ejes: el eje de luminosidad o claridad ( $L^{*}=100$, blanco; L*=0 negro), el eje rojoverde $(a *<0$, verde; $a *>0$, rojo) y el eje amarillo-azul $(b *<0$, azul; b*>0, amarillo). En la Figura 34, se muestra el diagrama de coordenadas cromáticas, CIE-Lab, 1976.

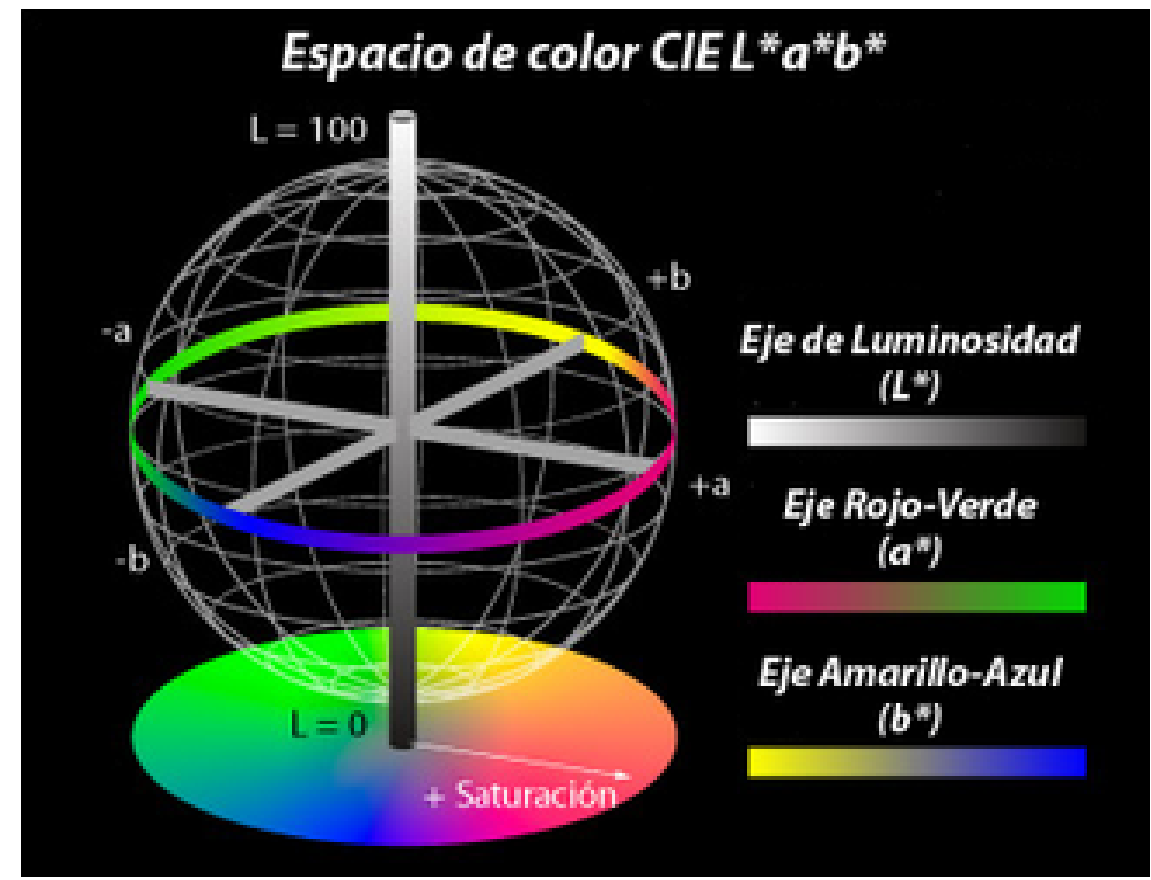

Figura 34. Diagrama de las coordenadas cromáticas, CIE-Lab, 1976.

\subsubsection{Análisis dilatométrico.}

Para la determinación de la dilatación térmica lineal de una arcilla o composición (basada en la Norma EN ISO 10545-8), se 
utiliza un dilatómetro, como el que se observa en la Figura 35, ubicado en los laboratorios de Grupo Tierra Atomizada [126].

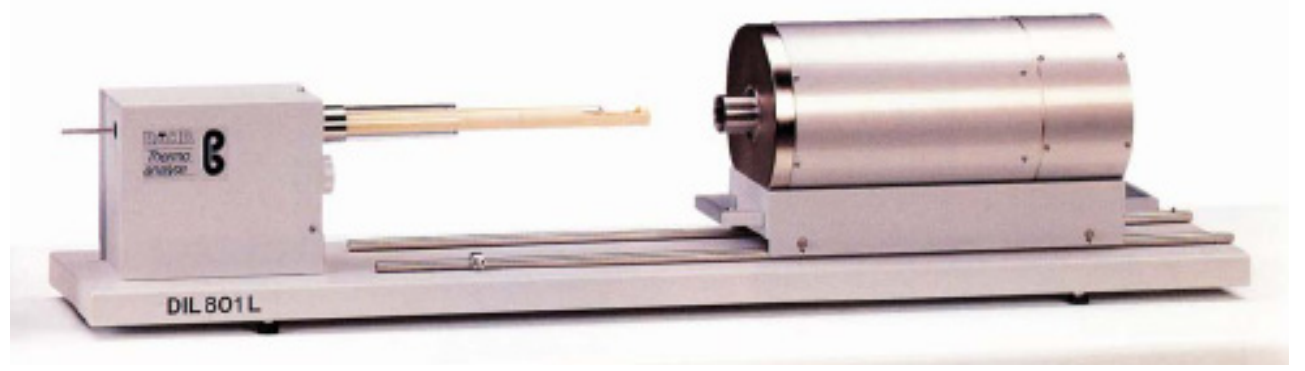

Figura 35. Dilatómetro Bähr modelo DIL 801L.

El resultado de la dilatación térmica lineal o "dilatometría" se obtiene a partir de la segunda cocción de la probeta cerámica (cocida previamente a $1185^{\circ} \mathrm{C}$ para gres porcelánico y a $1140^{\circ} \mathrm{C}$ para revestimiento de pasta blanca) al aplicarle un ciclo de cocción desde $30^{\circ} \mathrm{C}$ hasta $800^{\circ} \mathrm{C}$, con una velocidad de calentamiento de $5{ }^{\circ} \mathrm{C} / \mathrm{min}$. En cerámica, se expresa la dilatación térmica lineal en forma de coeficientes lineales obtenidos entre dos temperaturas, siendo sus unidades 1/K. El parámetro dilatométrico más relevante para una arcilla o una pasta es el coeficiente lineal obtenido entre $500^{\circ} \mathrm{C}$ y $650^{\circ} \mathrm{C}$, puesto que su valor refleja la cantidad de sílice libre que queda en la muestra sin reaccionar en la pieza ya cocida y que puede provocar defectos en el producto final.

\subsubsection{Ensayos cerámicos característicos en las arcillas y composiciones de pastas.}

En este apartado, se van a describir los ensayos cerámicos característicos, utilizados para conocer el comportamiento cerámico de las arcillas y de las composiciones de pastas. 


\section{a) DETERMINACIÓN DE LA RESISTENCIA MECÁNICA.}

Para la determinación de la resistencia mecánica de las piezas cerámicas, se utiliza el equipo mostrado en la Figura 36, que aplica una fuerza a una velocidad determinada en el centro de la pieza cerámica, estando el punto de aplicación en contacto con la superficie de la cara vista de la baldosa [127].

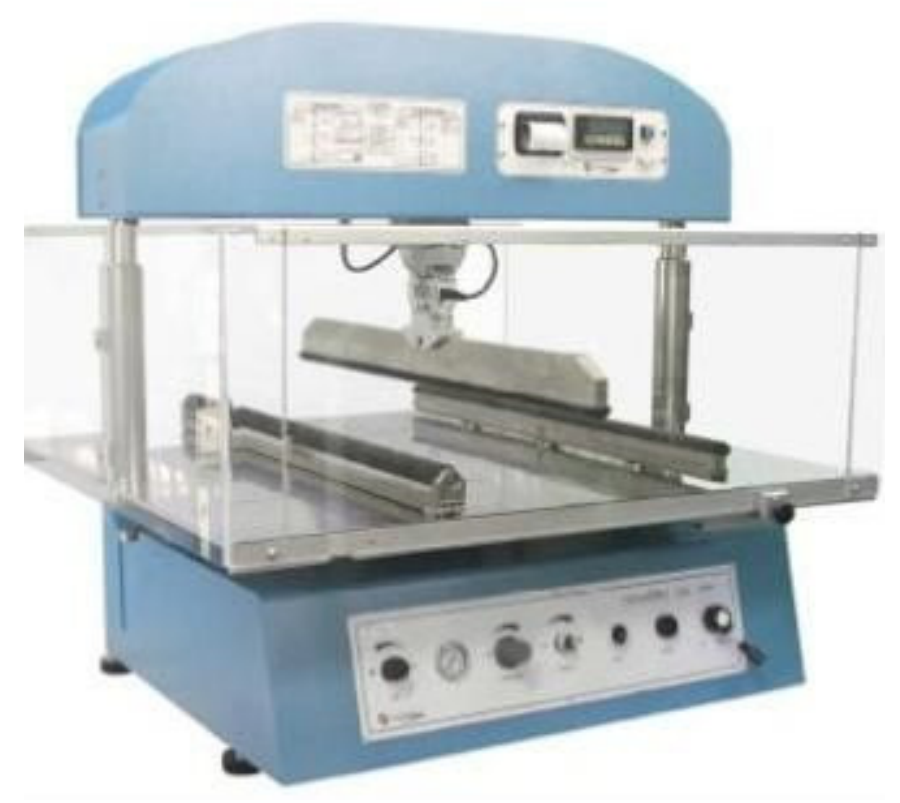

Figura 36. Flexímetro de Gabbrielli.

La resistencia mecánica (RMCA) de las piezas cerámicas, en seco o en cocido, se obtiene tras aplicar la fórmula siguiente con los valores recogidos a través del ensayo del método descrito en la Norma ISO 10545-4:1994.

$$
\operatorname{RMCA}\left(\mathrm{N} / \mathrm{mm}^{2}\right)=\frac{3}{2} \cdot \frac{\mathrm{F}_{\text {máx }}(\mathrm{N}) \cdot \mathrm{L}_{\text {apoyos }}(\mathrm{mm})}{\mathrm{E}_{\text {espesor }}^{2}(\mathrm{~mm}) \cdot \mathrm{a}_{\text {anchura }}(\mathrm{mm})}
$$


b) DETERMINACIÓN DEL RESIDUO MÁSICO A $63 \mu \mathrm{M}$ Y A $100 \mu \mathrm{M}$.

Para la determinación del residuo másico de una arcilla o una composición, se pesan $200 \mathrm{~g}$ secos de muestra y se dispersan en agua. A continuación, por vía húmeda, se vierte la dispersión de la muestra a través del tamiz, añadiendo agua al tiempo que se hace vibrar manualmente el éste, hasta que el agua que atraviesa el tamiz sale limpia y el residuo queda lavado. El residuo del tamiz se seca. Así, de este modo, se obtiene el porcentaje de residuo, correspondiente a la fracción de la muestra de arcilla o polvo atomizado que presenta un tamaño de partícula mayor que la luz de malla del tamiz utilizado. En la Figura 37, se muestran varios tamices normalizados, fabricados con malla metálica en acero inoxidable, que se utilizan en los controles habituales de los laboratorios de producción del sector cerámico.

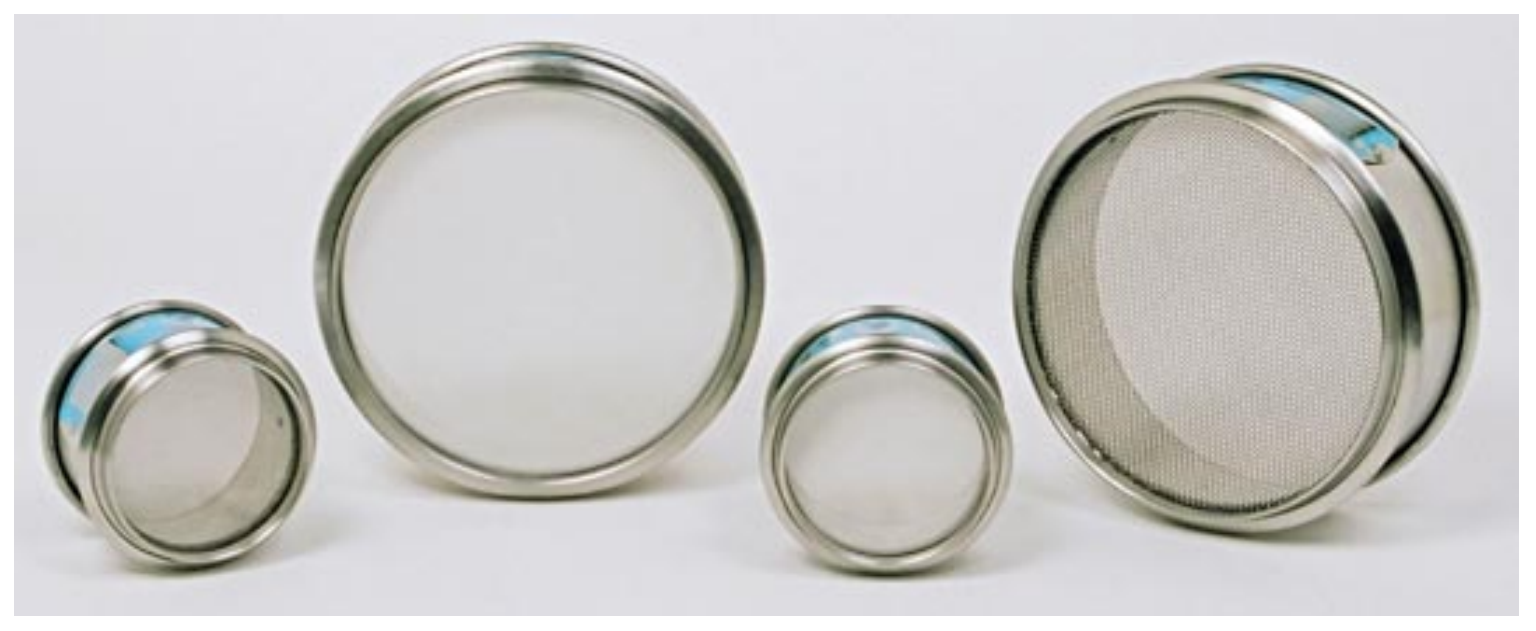

Figura 37. Tamices normalizados para el control del residuo de las arcillas. 
C) DETERMINACIÓN DEL PORCENTAJE DE CARBONATOS MEDIANTE $\quad$ EL CALCÍMETRO DE BERNARD.

Para determinar el porcentaje de carbonatos (generalmente carbonato cálcicol de las materias primas y de las composiciones cerámicas, se hace uso del Calcímetro de Bernard (Figura 38), según Norma UNE 103200:1993.

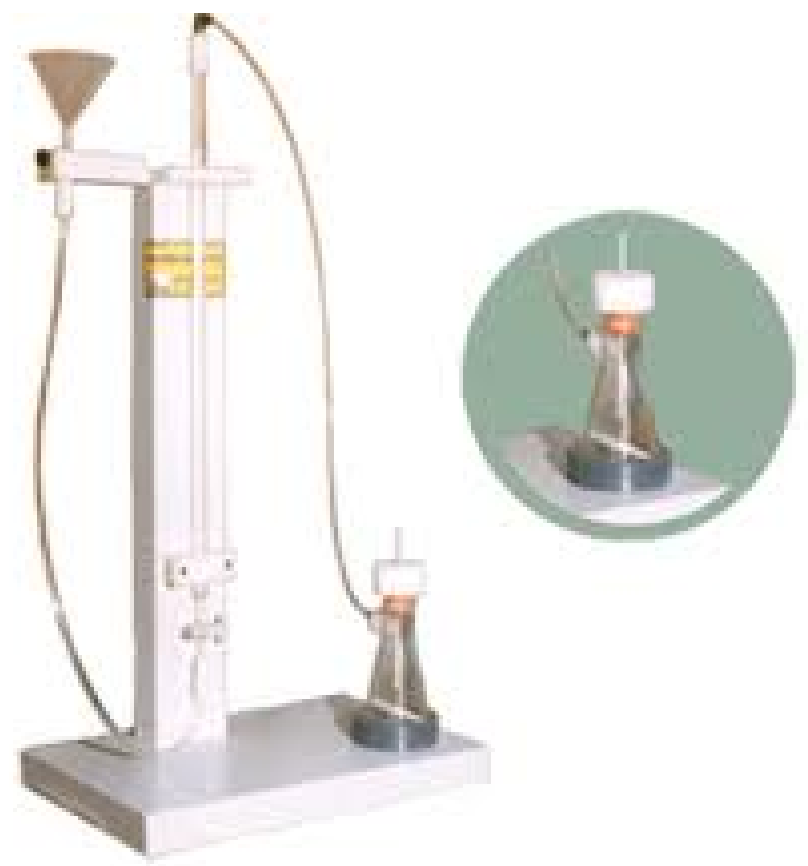

Figura 38. Calcímetro de Bernard.

Tras el ensayo, con los valores obtenidos, se utiliza la fórmula siguiente para obtener el porcentaje de carbonatos:

$$
\text { ○Carbonatos }=\frac{\mathrm{K} \cdot \mathrm{V}(\mathrm{ml})}{\mathrm{m}(\mathrm{g})}
$$

Donde :

\% Carbonatos $=$ porcentaje de $\mathrm{CaCO}_{3}$ presente

$\mathrm{V}=$ volumen de $\mathrm{CO}_{2}$ desprendido (ml) 


$$
\begin{aligned}
& \mathrm{m}=\text { peso del material }(\mathrm{g}) \\
& \mathrm{K}=\text { constante que varía con la temperatura. }
\end{aligned}
$$

Como K varía con la temperatura, mediante la fórmula siguiente se halla la constante "K" en función de la temperatura ambiente.

$$
\mathrm{K}=\frac{122}{\mathrm{~T}\left({ }^{\circ} \mathrm{C}\right)+273}
$$

d) DETERMINACIÓN DE LA PLASTICIDAD DE ARCILLAS Y PASTAS. MÉTODO DE PFEFFERKORN.

El método de Pfefferkorn considera que el Índice de Plasticidad de una arcilla es el porcentaje de contenido de agua para el que la muestra experimenta una compresión del 30\% respecto su altura inicial, tras aplicarle una fuerza constante. Así pues, el ensayo se realiza con distintos grados de humedad, de forma que se obtienen diferentes valores de compresión. La compresión de la probeta se determina como el cociente entre la altura inicial de la probeta y la altura de la probeta tras el ensayo ("a"). El parámetro "a" debe ser igual a 3,3, como se explica en la Norma IRAM $^{3}$ 165308:2000, [8]. La Figura 39 muestra el "Plasticinómetro" de Pfefferkorn [128].

\footnotetext{
3 Normas IRAM: Insdustrias del Vidrio y la Cerámica.
} 


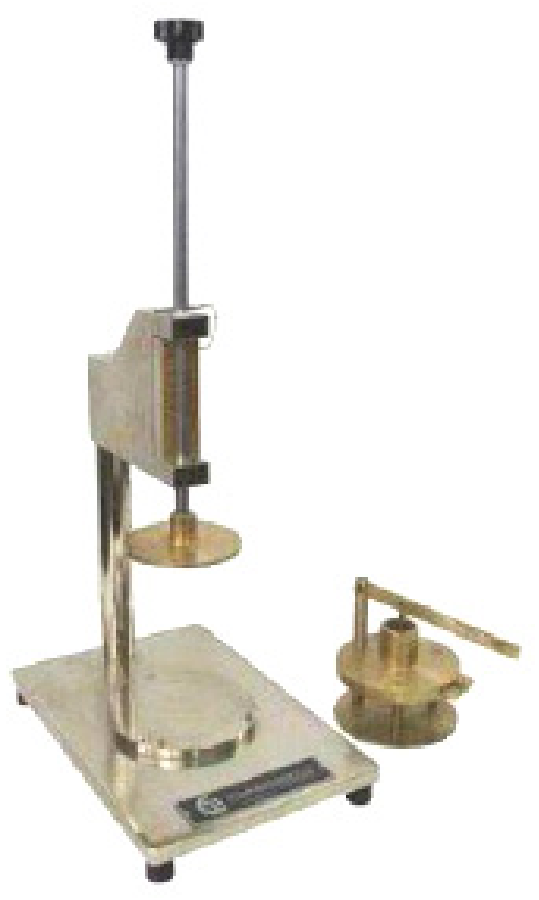

Figura 39. Plasticímetro de Pfefferkorn GT0675.

e) DETERMINACIÓN DE LA CONTRACCIÓN LINEAL Y DE LA ABSORCIÓN DE LAS PIEZAS CERÁMICAS.

La metodología utilizada para analizar la contracción lineal y la absorción de las piezas cerámicas, se basa en prensar las piezas a densidad aparente en seco constante (calculada por el método de inmersión en mercurio), medir la longitud inicial (L inicial) de las probetas secas y cocer a las distintas temperaturas que conforman el diagrama de gresificación, a través del horno eléctrico tipo mufla. Para obtener la contracción lineal en porcentaje (\%C.L.) de cocción a cada temperatura se mide la longitud de las probetas cocidas ( $L$ final) con un calibre y se aplica la fórmula siguiente: 


$$
\text { ○C.L. }=\frac{\mathrm{L}_{\text {inicial }}-\mathrm{L}_{\text {final }}}{\mathrm{L}_{\text {inicial }}} \cdot 100
$$

Para obtener la absorción de agua en porcentaje (\%A.a.), se pesan las probetas cocidas y secas (Masainicial) antes de introducirlas en el deprimómetro (Figura 40). Luego, se pesan las probetas húmedas (Masafinal) y se aplica la fórmula siguiente, según la Norma EN ISO 10545-3.

$$
\div \mathrm{A} \cdot \mathrm{a} \cdot=\frac{\text { Masa }_{\text {final }}-\text { Masa }_{\text {inicial }}}{\text { Masa }_{\text {inicial }}} \cdot 100
$$

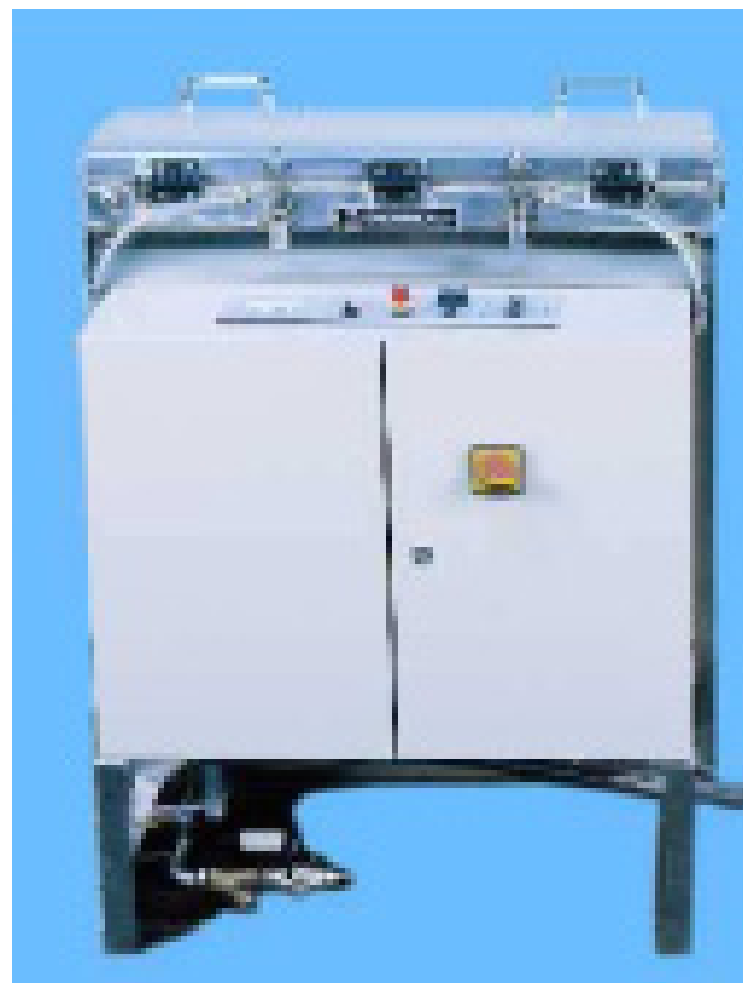

Figura 40. Deprimómetro DP600 de Gabbrielli. 
f) DETERMINACIÓN DE LA PÉRDIDA POR CALCINACIÓN A $1100^{\circ} \mathrm{C}$.

Para determinar el porcentaje de pérdida por calcinación de las muestras de cualquier materia primas cerámica o producto final atomizado, las muestras correspondientes se pesan secas, en polvo y sin mezclar con ningún aditivo. Para ello, se utilizan crisoles de alúmina y se obtiene la "masa inicial" de la muestra, antes de introducirlas en el horno eléctrico. A continuación, las muestras se someten a una temperatura de $1100^{\circ} \mathrm{C}$ durante 60 minutos en un horno eléctrico tipo mufla. Tras ser sometidas a dicho ciclo de calentamiento, se pesan de nuevo, con lo que se obtiene el "masa final".

Para el cálculo de la pérdida por calcinación (PPC), que completa el análisis químico (FRX), al ser la medida que indica el porcentaje de los componentes de la muestra que son más ligeros (como el azufre procedente de los sulfatos, el carbono que forma parte de la materia orgánica presente, el oxígeno y el hidrógeno que componen la molécula de agua de la deshidroxilación de las arcillas ...) y que el equipo de fluorescencia de Rayos-X no es capaz de medir, se hace uso de la fórmula siguiente:

$$
\operatorname{PPC}(\%)=\frac{\text { Masa }_{\text {inicial }}-\text { Masa }_{\text {final }}}{\text { Masa }_{\text {inicial }}} \cdot 100
$$

\subsection{Materias primas utilizadas.}

Las materias primas utilizadas para el desarrollo de esta Tesis Doctoral se especifican a continuación. 
- ARCILLAS DE IMPORTACIÓN DE ALTA ALÚMINA de origen de Ucrania, identificadas como (I-A), que marcarán la tendencia que se desea conseguir, es decir, son el punto de referencia. Se utilizan dos tipos de arcillas de alta alúmina, la referencia (A-I-1) y la referencia (A-I-2).

- ARCILLA DE CIUDAD REAL (ESPAÑA), con alto contenido en hematita y que no contiene materia orgánica. Se referencia como (N-A-Cr).

- ARCILLA DE TERUEL (ESPAÑA) de alta alúmina, ubicada dentro de la comarca de las Cuencas Mineras, con un contenido medio en materia orgánica y en compuestos de hierro, en forma de siderita. Se referencia como (N-Ate).

- ARCILLA DE TERUEL (ESPAÑA) de baja alúmina y con altos porcentajes de siderita. Se referencia como (N-B-te) .

Además, se han utilizado los siguientes materiales por la formulación de las correspondientes pastas cerámicas.

- cARBONATO.

- FELdespato Sódico procedente de Turquía (referenciado Fdto $\mathrm{Na}$ ).

- FELdESPATO SÓdICO-MAGNÉSiCO procedente de Cerdeña (referenciado Fdto $\mathrm{Na}-\mathrm{Mg}$ ). 
- SÍLICE O ARENA española.

- RESIDUO DE VIDRIO procedente del reciclado de vidrio hueco.

- RESIDUO DE VIDRIO procedente del reciclado de vidrio plano.

- DEFLOCULANTE utilizado: silicato sódico de Acrilatos, S.A., cuyas especificaciones técnicas aparecen en el apéndice.

La caracterización de las arcillas utilizadas ha consistido en los siguientes ensayos [129]:

- Determinación del análisis químico (FRX), completado con la pérdida por calcinación

- Determinación del análisis mineralógico (DRX) .

- Determinación del análisis dilatométrico.

- Determinación del contenido en materia orgánica (TOC).

- Determinación de la colorimetría según el sistema CIE-Lab de las piezas cocidas a distintas temperaturas.

- La caracterización cerámica típica que incluye los siguientes ensayos:

- El residuo a $63 \mu \mathrm{m}$ y $100 \mu \mathrm{m}$.

- La calcimetría con el calcímetro de Bernard.

- El cálculo del índice de plasticidad de Pfefferkorn.

- El diagrama de gresificación (porcentaje de contracción lineal (\%C.L.)y porcentaje de absorción de agua (\%A.a.) frente a la temperatura). 
- La compactación medida como densidad aparente de las piezas prensadas, mediante el método de inmersión en mercurio.

La caracterización de los feldespatos se ha basado también en el análisis químico (FRX) y el análisis mineralógico (DRX), completándose con el ensayo del microscopio de calentamiento.

En lo que se refiere a la arena y al carbonato, la caracterización se ha centrado en el análisis químico (FRX).

En cuanto a los residuos cocidos (chamota y vidrio reciclado), la caracterización se ha centrado en el análisis químico (FRX) y el ensayo en el microscopio de calentamiento.

\subsection{Técnicas utilizadas para la disminución de los compuestos de hierro en las arcillas españolas.}

\subsubsection{Técnica del hidrociclonado.}

El funcionamiento de un hidrociclón vía húmeda consiste en separar partículas de una barbotina muy diluida por gravedad. La barbotina de alimentación entra tangencialmente a la parte cilíndrica bajo una cierta presión, lo que genera su rotación alrededor del eje longitudinal del hidrociclón, formando un torbellino descendente hacia el vértice de la parte cónica. Las partículas más gruesas debido a la aceleración centrífuga giran cercanas a la pared, siendo evacuadas a través de la tobera inferior. Debido a las reducidas dimensiones de ésta, solamente se evacua una parte de la suspensión, creándose en el vértice del cono un segundo torbellino de trayectoria ascendente, el cual 
transporta las partículas finas junto con la mayor parte del líquido, abandonando el hidrociclón a través de un tubo central situado en la tapa superior del cuerpo cilíndrico. Regulando la aceleración del torbellino y variando la geometría y toberas del hidrociclón puede ajustarse el tamaño de separación entre 10 y 500 um. En la Figura 41 se muestra un esquema de un hidrociclón [130], $[131],[132],[133]$ y [134].

$$
\begin{aligned}
& \text { SALIDA } \\
& \text { PARTICULAS FINAS } \\
& \text { (FINOS) por la } \\
& \text { tobera de rebose }
\end{aligned}
$$

ENTRADA

TANGENCIAI

(ENTRADA)

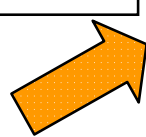

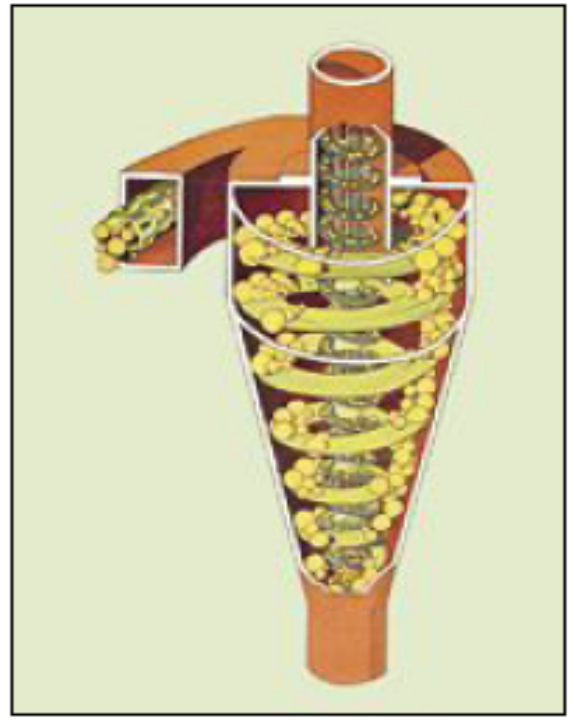

CUERPO CILÍNDRICO

CUERPO CONICO SUPERIOR

CUERPO CONICO INFERIOR

SALIDA PARTICULAS GRUESAS (GRUESOS)

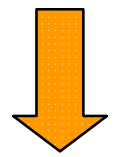

Figura 41. Esquema de funcionamiento de un hidrociclón. 
Para el estudio de este método gravimétrico se ha utilizado un hidrociclón de $40 \mathrm{~mm}$ de diámetro a escala de laboratorio de la marca ERAL y modelo PP004041, disponible en la planta piloto de Grupo Tierra Atomizada, que consta de las siguientes partes:

- Tobera de rebose, ("Overflow": salida de los "finos").

- Entrada tangencial.

- Cuerpo cilíndrico.

- Cuerpo cónico superior.

- Cuerpo cónico inferior.

- Boquilla "spigot", ("Underflow": salida de "gruesos").

Las variables que se han tenido en cuenta se indican a continuación:

- Caudal de entrada tangencial.

- Densidad de la barbotina.

En la Tabla VIII se han representado todas las combinaciones posibles según los accesorios disponibles, siendo en total hasta 24 combinaciones. Cada una de ellas se ha referenciado como "montaje $n^{\circ "}$. Se observa que el hidrociclón dispone de 4 toberas de rebose, 2 entradas tangenciales, 1 cuerpo cilíndrico, 1 cuerpo cónico superior, 2 cuerpos cónicos inferiores y 4 boquillas o "spigot". 
Tabla VIII. Combinaciones de accesorios para el montaje del hidrociclón.

\begin{tabular}{|c|c|c|c|c|c|c|c|c|c|c|c|c|c|c|c|c|c|c|c|c|c|c|c|c|c|c|}
\hline \multirow{2}{*}{\multicolumn{3}{|c|}{ HIDROCICLON PP004041 }} & \multicolumn{24}{|c|}{ MONTAJE $\mathrm{N}^{\circ}$} \\
\hline & & & 1 & 2 & 3 & 4 & 5 & 6 & 7 & 8 & 9 & 10 & 11 & 12 & 13 & 14 & 15 & 16 & 17 & 18 & 19 & 20 & 21 & 22 & 23 & 24 \\
\hline & & & \multicolumn{4}{|c|}{ I } & \multicolumn{4}{|c|}{ II } & \multicolumn{4}{|c|}{ III } & \multicolumn{4}{|c|}{ IV } & \multicolumn{4}{|c|}{ v } & \multicolumn{4}{|c|}{ VIII } \\
\hline Descripción & Referencia & $\begin{array}{c}\text { Diámetro } \\
(\mathrm{mm})\end{array}$ & I & A & B & C & II & A & B & $\mathrm{C}$ & III & A & B & C & IV & A & B & C & $\mathrm{v}$ & A & B & C & VIII & A & B & C \\
\hline \multirow{4}{*}{$\begin{array}{c}\text { Tobera de } \\
\text { rebose }\end{array}$} & $\mathrm{ZG} 2 \mathrm{~A}$ & 16 & $x$ & $\mathrm{x}$ & $\mathrm{x}$ & $\mathrm{x}$ & & & & & $x$ & $\mathrm{x}$ & $x$ & $x$ & & & & & & & & & & & & \\
\hline & ZG2B & 13 & & & & & $\mathrm{x}$ & $x$ & $x$ & $x$ & & & & & $x$ & $x$ & $x$ & $x$ & & & & & & & & \\
\hline & $\mathrm{ZG} 2 \mathrm{C}$ & 10 & & & & & & & & & & & & & & & & & $\mathrm{x}$ & $\mathrm{x}$ & $x$ & $x$ & & & & \\
\hline & ZG2D & 8 & & & & & & & & & & & & & & & & & & & & & $x$ & $x$ & $x$ & $x$ \\
\hline \multirow{2}{*}{$\begin{array}{c}\text { Entrada } \\
\text { tangencial }\end{array}$} & $\mathrm{ZH} 1 \mathrm{~A}$ & 40284 & $x$ & $x$ & $x$ & $x$ & $x$ & $x$ & $x$ & $x$ & & & & & & & & & & & & & & & & \\
\hline & ZH1B & 40253 & & & & & & & & & $x$ & $\mathrm{x}$ & $\mathrm{x}$ & $\mathrm{x}$ & $x$ & $x$ & $\mathrm{x}$ & $\mathrm{x}$ & $\mathrm{x}$ & $\mathrm{x}$ & $x$ & $x$ & $x$ & $\mathrm{x}$ & $x$ & $x$ \\
\hline $\begin{array}{l}\text { Cuerpo } \\
\text { cilíndrico }\end{array}$ & ZH91 & & & & & & & & & & & & & & & & & & & & & & & & & \\
\hline $\begin{array}{c}\text { Cuerpo } \\
\text { cónico } \\
\text { superior }\end{array}$ & ZH81 & & & & & & & & & & & & & & & & & & & & & & & & & \\
\hline \multirow{2}{*}{$\begin{array}{c}\text { Cuerpo } \\
\text { cónico } \\
\text { inferior }\end{array}$} & ZH82A & 7 & $\bar{x}$ & $x$ & $\mathrm{x}$ & & $x$ & $\bar{x}$ & $x$ & & $\bar{x}$ & $\mathrm{x}$ & $x$ & & $x$ & $x$ & $x$ & & $x$ & $\mathrm{x}$ & $x$ & & $x$ & $x$ & $x$ & \\
\hline & ZH82C & 5 & & & & $\mathrm{x}$ & & & & $\mathrm{x}$ & & & & $\mathrm{x}$ & & & & $\mathrm{x}$ & & & & $\mathrm{x}$ & & & & $\mathrm{x}$ \\
\hline \multirow{4}{*}{$\begin{array}{l}\text { Boquilla } \\
\text { "spigot" }\end{array}$} & ZG94A & 8 & & & & & & & & & & & & & & & & & & & & & & & & \\
\hline & ZG94B & 7 & $x$ & & & & $x$ & & & & $x$ & & & & $\mathrm{x}$ & & & & $\mathrm{x}$ & & & & $\mathrm{x}$ & & & \\
\hline & ZG94C & 6 & & $\mathrm{x}$ & & & & $\mathrm{x}$ & & & & $\mathrm{x}$ & & & & $\mathrm{x}$ & & & & $\mathrm{x}$ & & & & $\mathrm{x}$ & & \\
\hline & ZG94D & 5 & & & $x$ & $x$ & & & $x$ & $x$ & & & $x$ & $x$ & & & $x$ & $x$ & & & $x$ & $x$ & & & $x$ & $x$ \\
\hline
\end{tabular}


Se ha trabajado a densidades bajas de barbotina, alrededor de $1.25 \mathrm{~g} / \mathrm{cm}^{3}$. Se han tratado así todas las arcillas españolas referenciadas en esta Tesis, a saber, la arcilla (N-A-te), la arcilla (N-B-te) y la arcilla (N-A-Cr). Sin embargo, solamente se destacan los resultados obtenidos en la arcilla de Ciudad Real (N$A-c r)$, porque se ha visto, tras numerosas pruebas de planta piloto de Grupo Tierra Atomizada, que la concentración de los compuestos de hierro de las arcilla de Teruel (principalmente el carbonato férrico o siderita, como se observa en los difractogramas correspondientes en la Figura 42 y la Figura 43) no disminuye con esta técnica. Es por ello, que los resultados obtenidos con la arcilla de Ciudad Real (N-A-Cr), arcilla rica en hematita $\left(\mathrm{Fe}_{2} \mathrm{O}_{3}\right)$ se consideran los óptimos para presentar en esta Tesis. Esta arcilla presenta un alto contenido en hematita, tal y como indica el difractograma correspondiente ilustrado en la Figura 44.

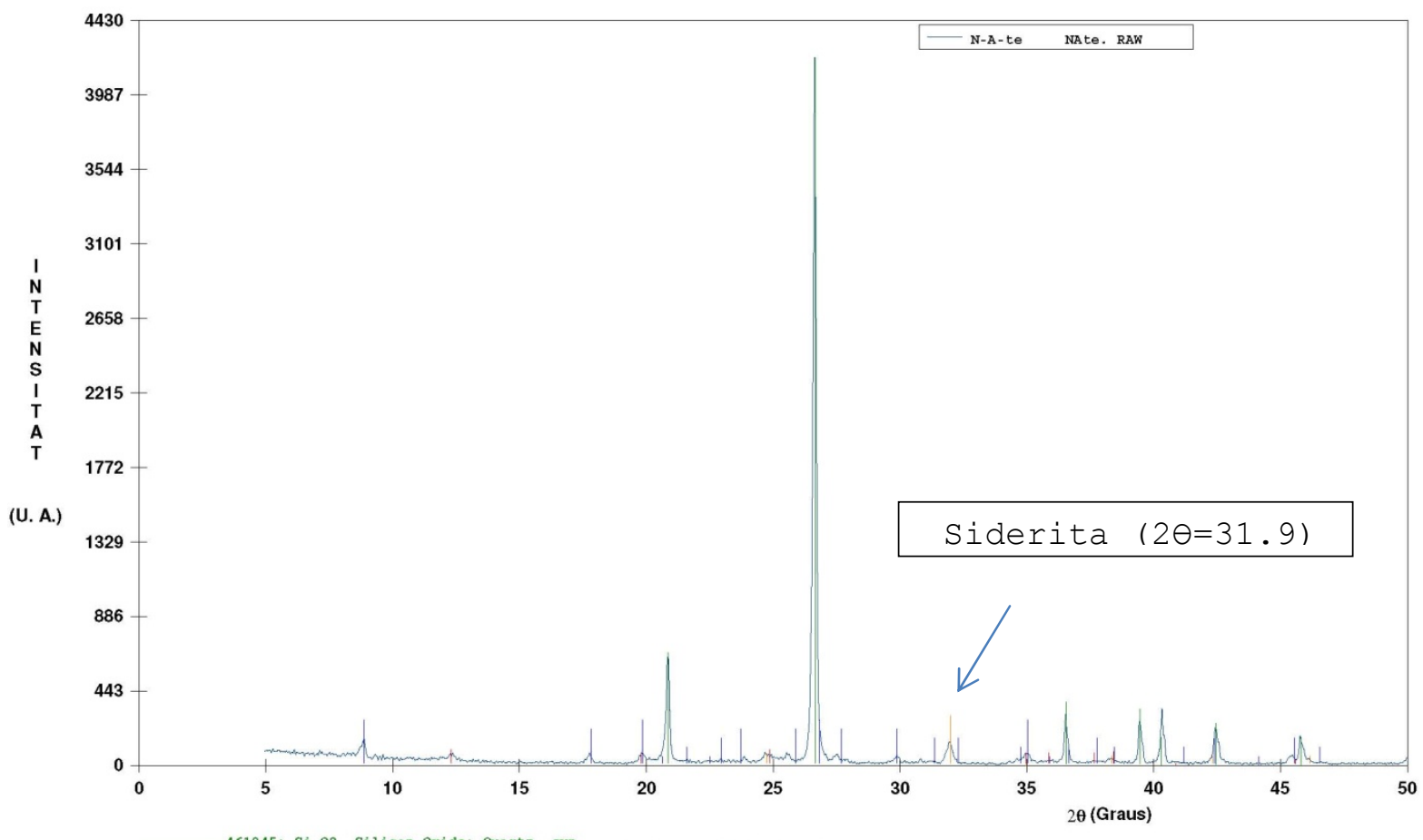

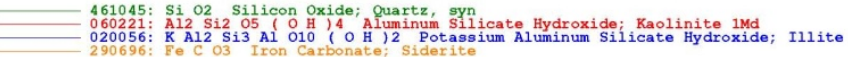

Figura 42. Difractograma de la arcilla (N-A-te) sin tratar. 


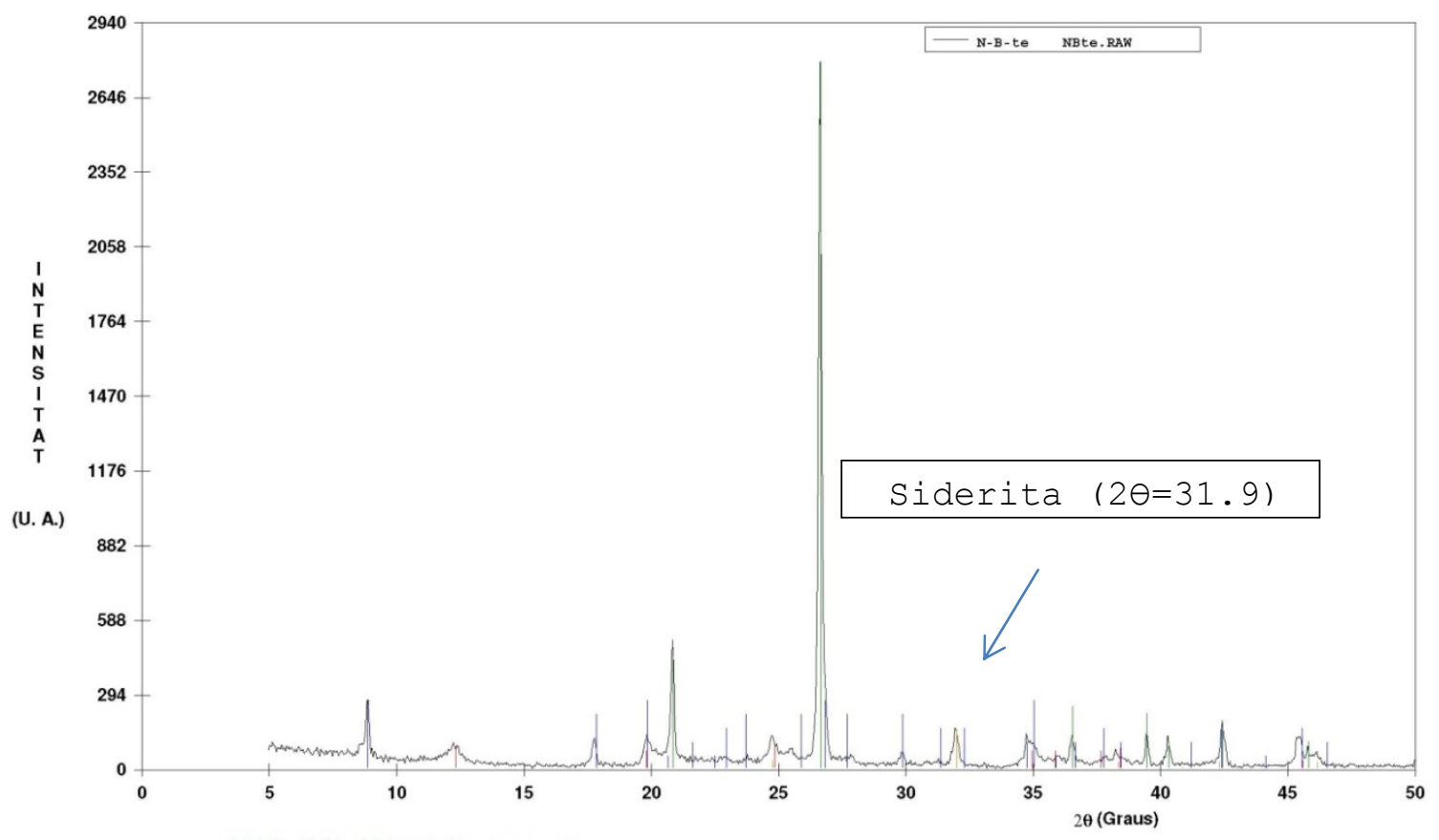

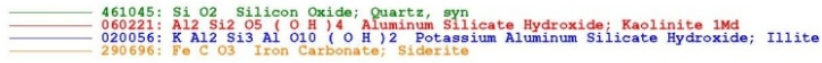

Figura 43. Difractograma de la arcilla (N-B-te) sin tratar.

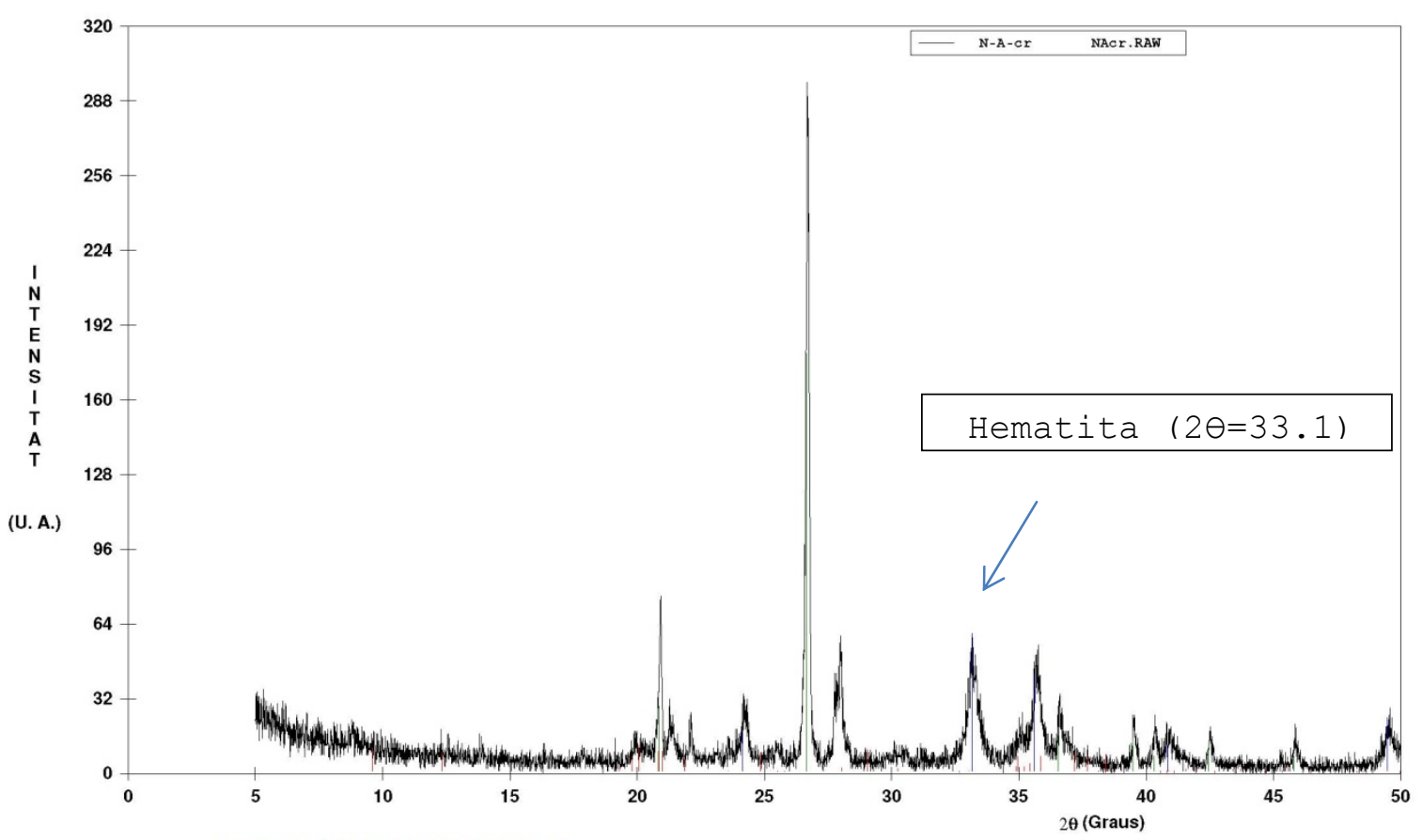

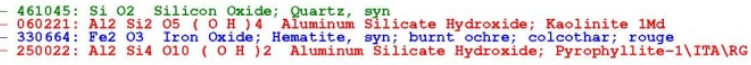

Figura 44. Difractograma de la arcilla (N-A-Cr) sin tratar 


\subsubsection{Técnica del separador magnético.}

En la Figura 45 se observa el filtro magnético inducido a escala de laboratorio de la marca Master Magnets [135].

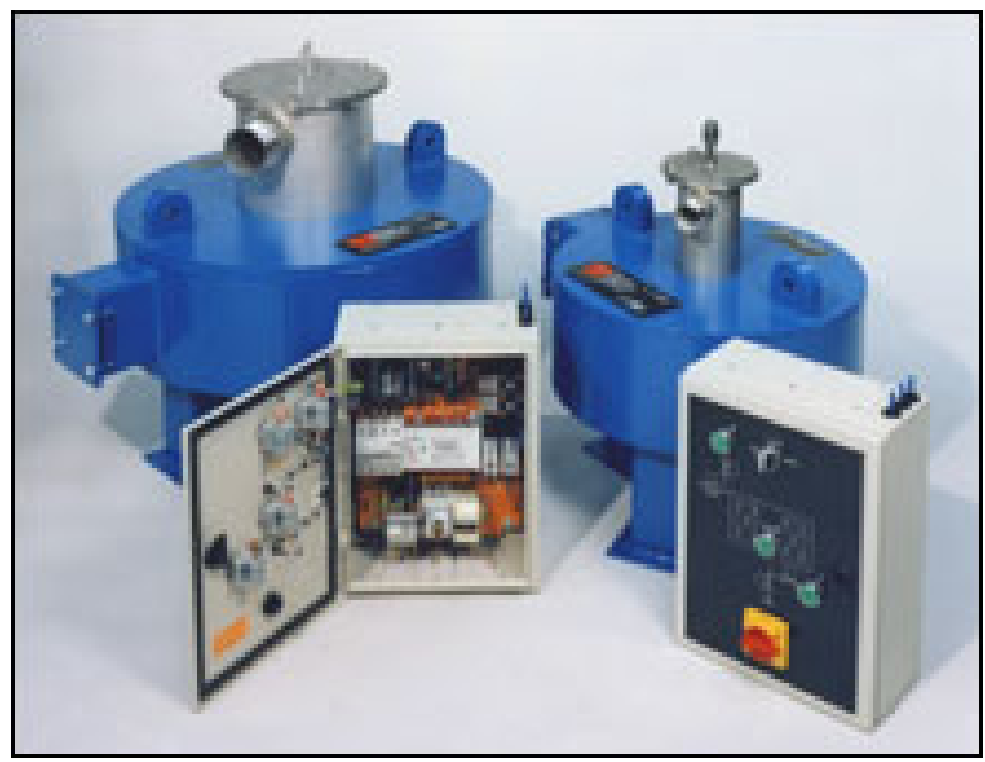

Figura 45. Filtro magnético inducido a escala piloto.

Este tipo de separador magnético consiste en un filtro o matriz al que se le ha aplicado un campo electromagnético, capaz de retener las partículas imantables. De esta manera, se aprovechan las distintas susceptibilidades magnéticas o conductividades eléctricas que presentan los compuestos de hierro, que, en este trabajo, pueden ser hematita o siderita. Los materiales ferromagnéticos se separan utilizando baja intensidad (500-1200 Oersted, medida de la reluctancia magnética), mediante un imán permanente o electroimán. Por el contrario, los materiales paramagnéticos, necesitan de una elevada intensidad para poder ser captados, hasta 22000 Oersted, mediante potentes electroimanes, [33], [136]. Los filtros electromagnéticos de alta intensidad están diseñados para la retirada continua de partículas 
ferrosas/magnéticas contenidas en una barbotina de baja densidad (alrededor de $1,4 \mathrm{~g} / \mathrm{cm}^{3}$ ). Este separador también es capaz de extraer un alto porcentaje de partículas paramagnéticas. Estos filtros electromagnéticos de alta intensidad se suministran con una sola entrada y salida de la matriz de acero inoxidable. El equipo consta de una bobina de alta eficiencia diseñada por ordenador en la que se inserta un recipiente que contiene la matriz de acero. La barbotina original entra por la parte inferior del separador a través de una válvula de mariposa que llega hasta la matriz, que es excitada usando una bobina electromagnética de intensidad variable por fuera. La matriz amplifica el campo magnético produciendo puntos de gradiente e intensidad magnética muy alta. La barbotina pasa a través de la matriz excitada, donde las partículas de hierro son capturadas por la matriz y el producto sin hierro sale de la parte superior del separador hacia las balsas de alimentación del molino continuo. Cuando la matriz está saturada con las partículas magnéticas las válvulas de entrada y salida se cierran, el electro imán se apaga y la matriz se limpia usando la secuencia automática de retro-lavado, permitiendo que el proceso empiece de nuevo. La matriz se desmonta manualmente de forma periódica.

En esta Tesis se ha utilizado un filtro electromagnético industrial de alta intensidad, modelo $25 \mathrm{HIF} \mathrm{75,} \mathrm{de} \mathrm{la} \mathrm{empresa}$ Master Magnets Ltd, cuyo esquema se representa en la Figura 46. 
Barbotina desferrizada

y filtrada

(FILTRADO)

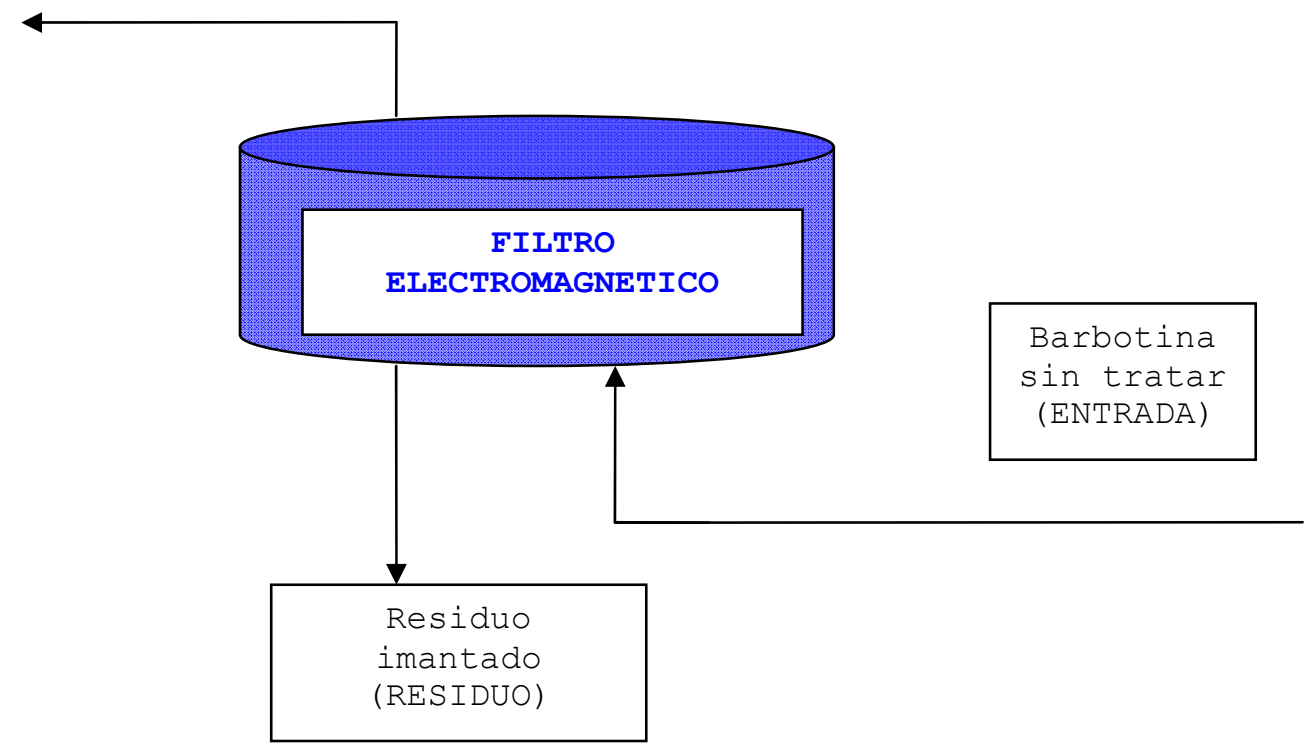

Figura 46. Esquema de funcionamiento del filtro electromagnético de Master Magnets.

El filtro utilizado en esta Tesis y suministrado a Tierra Atomizada, cuya imagen aparece en la

Figura 47, presenta los siguientes componentes:

- Unidad de filtro magnético

- Transformador de aceite para la refrigeración.

- Panel de control con 6 válvulas anti-retorno.

Los filtros electromagnéticos "MasterMag" están disponibles con potencias de 2500, 5000 y 10000 Gauss para adaptarse a las necesidades de distintas aplicaciones. 


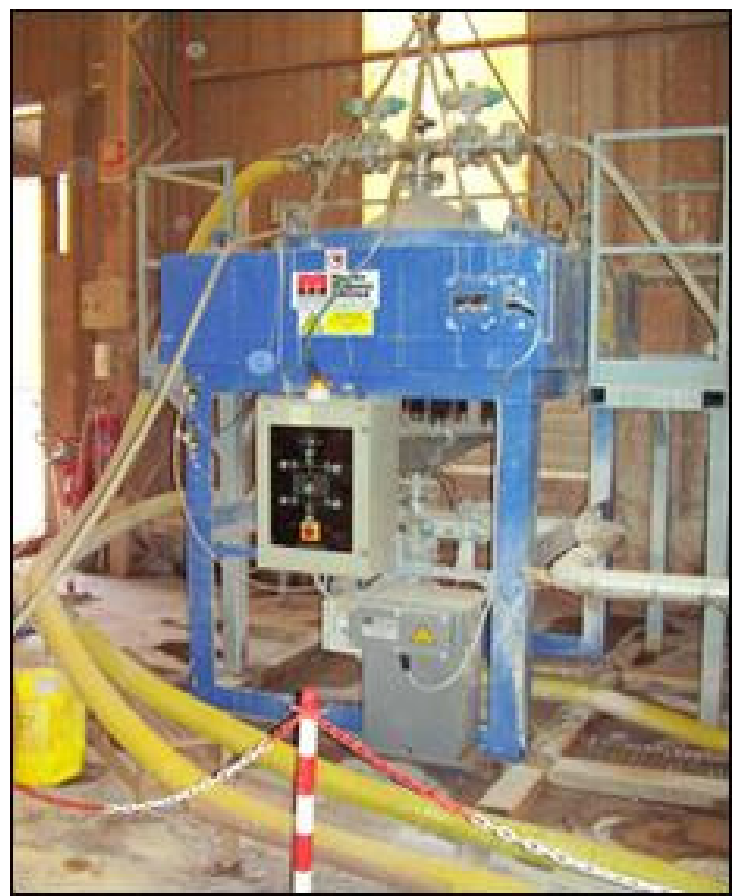

Figura 47. Filtro electromagnético industrial de Master Magnets adquirido por Tierra Atomizada y utilizado en la presente Tesis.

Inicialmente se proponen dos tipos de matrices o discos metálicos, una provista de armazón metálico rígido (matriz A) y otra sin armazón (matriz B). A través del estudio se ha observado que el armazón no influye en los resultados y se ha optado por la matriz B. A continuación, se han ensayado varios tipos de discos metálicos según el modelo de la matriz $B$, en función del tipo de hilo y de cómo está tejido, enumerándose los tipos de matrices probadas en la Tabla IX: 
Tabla IX. Características de las matrices tipo B1, B2 y B3.

\begin{tabular}{|c|c|c|c|c|c|c|c|}
\hline \multicolumn{4}{|c|}{ HILO de la MATRIZ } & \multicolumn{4}{|c|}{ MALLA } \\
\hline $\begin{array}{c}\text { PROCEDE } \\
\text { DE }\end{array}$ & $\begin{array}{c}\text { TEJIDO } \\
\text { EN }\end{array}$ & CARACTERISTICAS & $\begin{array}{c}\mathrm{RM}^{1} \\
\left(\mathrm{~N} / \mathrm{mm}^{2}\right)\end{array}$ & $\begin{array}{c}\varnothing^{2} \\
\text { hilo } \\
(\mathrm{mm})\end{array}$ & $\begin{array}{c}\varnothing^{2} \\
\text { externo } \\
(\mathrm{mm})\end{array}$ & $\begin{array}{c}\varnothing^{2} \\
\text { interno } \\
(\mathrm{mm})\end{array}$ & $\begin{array}{r}\text { Masa } \\
(g)\end{array}$ \\
\hline $\begin{array}{l}\text { FIDESA } \\
\text { MADRID }\end{array}$ & CODINA & $\begin{array}{c}\text { MATRIZ B1. } \\
\text { BGH-Feindraht } \\
\text { Gmbtt }\end{array}$ & $55-750$ & 0.11 & 160 & 23 & 803 \\
\hline $\begin{array}{l}\text { REINO } \\
\text { UNIDO }\end{array}$ & $\begin{array}{l}\text { MASTER } \\
\text { MAGNETS }\end{array}$ & $\begin{array}{l}\text { MATRIZ B2 } \\
\text { AISI-430 }\end{array}$ & $441-558$ & 0.18 & 160 & 23 & 849 \\
\hline ESPAÑA & CODINA & $\begin{array}{c}\text { MATRIZ B3 } \\
\text { AISI-430 } \\
\text { TRICOTADA X } 90\end{array}$ & $441-558$ & 0.18 & 160 & 23 & 867 \\
\hline
\end{tabular}

${ }^{1}$ Resistencia mecánica del hilo de la matriz.

${ }^{2}$ Diámetro del hilo.

Otro parámetro que también se ha analizado en las pruebas llevadas a cabo en el estudio, ha sido el caudal ( $\left.Q_{v}\right)$ del equipo, diseñado para trabajar a bajos caudales.

\subsection{Técnicas utilizadas para la disminución de la materia orgánica.}

\subsubsection{Calcinación en horno eléctrico tipo mufla.}

En el laboratorio de Grupo Tierra Atomizada se ha calcinado la arcilla (N-A-te) en un horno mufla de marca Pirometrol, serie "R" de $1300^{\circ} \mathrm{C}$ de temperatura máxima. Se han ensayado distintas temperaturas y tiempos, siguiendo los ciclos indicaciones en la Tabla X. 
Tabla x. Programa llevado a cabo en el horno eléctrico para el tratamiento de la materia orgánica de las arcillas.

\begin{tabular}{|c|c|}
\hline $\begin{array}{c}\text { TEMPERATURA } \\
\text { FINAL RAMPA }\left({ }^{\circ} \mathrm{C}\right)\end{array}$ & $\begin{array}{c}\text { TIEMPO } \\
(\mathrm{min})\end{array}$ \\
\hline 350 & 2 \\
\hline 350 & 60 \\
\hline 50 & 4 \\
\hline
\end{tabular}

En la Tabla X se halla indicado un ejemplo llevado a cabo para el tratamiento de las arcillas durante 60 minutos a $350^{\circ} \mathrm{C}$, de manera que en cada prueba se ha modificado la temperatura y el tiempo de las celdas sombreadas en rojo en la tabla. En cada experimento se han utilizado $500 \mathrm{~g}$ de muestra de arcilla de granulometría definida. El material calcinado se ha micronizado por debajo de 100 um, mediante un molino de anillos de la marca "Herzog". Para cuantificar la cantidad de materia orgánica que ha combustionado, se ha utilizado el analizador térmico, (ATD/TG) y el analizador de carbono (TOC) .

\subsubsection{Tratamiento en horno microondas.}

Para el tratamiento de las arcillas en horno microondas, se ha procedido a medir los parámetros dieléctricos de las arcillas a temperaturas inferiores a las deseadas, puesto no disponemos de otra opción. Para ello, se han seleccionado cuatro muestras, a saber:

- Arcilla (N-A-te) original.

- Fracción de la arcilla (N-A-te) rica en caolinita (blanca) .

- Fracción de la arcilla (N-A-te) rica en carbón (negra).

- Arcilla (I-A-1) rica en caolinita y sin impurezas. 
Se han preparado pastillas de $13 \mathrm{~mm}$ con las arcillas indicadas utilizando una presión de $8 \mathrm{Tm}$. Posteriormente, y sin ningún tratamiento adicional, se han recubrierto ambas caras de la pastilla con electrodos metálicos. Este electrodo únicamente puede alcanzar temperaturas hasta $260-280^{\circ} \mathrm{C}$. Cada muestra se ha micronizado a razón de $100 \%$ de las partículas menor de 100 micrómetros y, en el departamento de Química Inorgánica y Orgánica de la Universitat Jaume I de Castellón, se ha medido la permitividad relativa entre temperatura ambiente y $275^{\circ} \mathrm{C}$ a 100 $\mathrm{kHz}$.

Paralelamente, se ha establecido contacto con algunas empresas especialistas en la fabricación de microondas industriales para realizar las pruebas propuestas indicadas en la Tabla XI. La temperatura afecta a los parámetros dieléctricos, de forma que se ha pretendido investigar si existe una temperatura, en el intervalo de descomposición de la materia orgánica, donde los parámetros dieléctricos favorezcan la eliminación de carbono frente a la deshidroxilación de la arcilla. El propósito del estudio en el caso de la arcilla (N-A-te) ha sido el intentar realizar un tratamiento combinado con radiación infrarroja y microondas. De este modo, la radiación infrarroja calentaría previamente a la arcilla hasta una temperatura determinada y después, se aplicaría la radiación de microondas durante los tiempos especificados en la Tabla XI. Sin embargo, este ensayo no ha sido posible realizarlo, ya que no se ha encontrado un equipo mixto "infrarrojos-microondas" disponible en el mercado. 
Tabla XI. Programa de pruebas combinando la radiación infrarroja y la radiación de microondas.

\begin{tabular}{|c|c|}
\hline $\begin{array}{c}\text { Calentamiento en } \\
\text { infrarrojos }\end{array}$ & $\begin{array}{c}\text { Tiempo de } \\
\text { permanencia en } \\
\text { microondas (s) }\end{array}$ \\
\hline $250^{\circ} \mathrm{C}$ & $60-120-180 \mathrm{~S}$ \\
\hline $300^{\circ} \mathrm{C}$ & $60-120-180 \mathrm{~S}$ \\
\hline $350^{\circ} \mathrm{C}$ & $60-120-180 \mathrm{~S}$ \\
\hline $400^{\circ} \mathrm{C}$ & $60-120-180 \mathrm{~S}$ \\
\hline $450^{\circ} \mathrm{C}$ & $60-120-180 \mathrm{~S}$ \\
\hline
\end{tabular}

\subsection{Introducción de residuos cocidos en la composición de las pastas cerámicas para optimizar el ciclo de cocción.}

Con la intención de mejorar la competitividad del sector cerámico en los mercados, además de utilizar arcillas españolas tratadas, en esta Tesis se va a intentar llegar a la sinterización del gres porcelánico y del revestimiento, a temperaturas más bajas que las habituales, con el fin de ahorrar en costes energéticos durante la etapa de cocción industrial e incrementar el rendimiento productivo.

A continuación, en la Figura 48 se muestra la gráfica que representa la curva de cocción de los hornos cerámicos industriales. La cocción industrial de las baldosas cerámicas se inicia con el precalentamiento que culmina con el periodo de máxima temperatura, al que le sigue la etapa de enfriamiento, etapa suficientemente suave para evitar roturas y descuadres en las piezas [137]. 


\section{Ciclo de cocción}

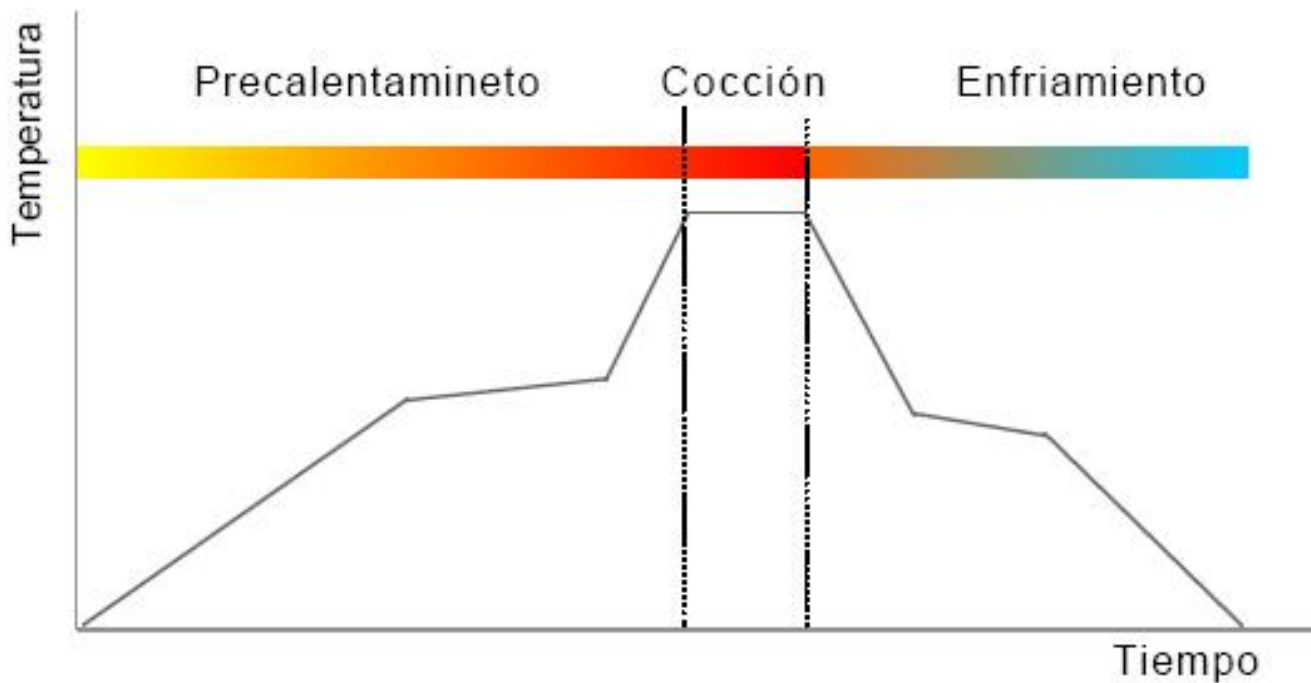

Figura 48. Gráfica esquemática del ciclo de cocción de un horno industrial de baldosas cerámicas.

Para ello, se ha estudiado la introducción como materias primas de los residuos cocidos procedentes de la fabricación de baldosas (chamotas) y del sector del vidrio reciclado. De cara a su introducción en el campo de la fabricación de baldosas cerámicas, el material reciclado tiene que presentar unas determinadas características [94].

- Abundancia, para garantizar el suministro industrial.

- Constancia en la composición y homogeneidad.

- Coste por tonelada asequible al sector cerámico. 


\subsubsection{Testillo cocido (chamota).}

El testillo cocido utilizado en este trabajo corresponde a restos de baldosas y azulejos desechados tras la cocción, por no cumplir con los requisitos mínimos de calidad para ser empaquetadas para la venta.

\subsubsection{Vidrio reciclado.}

El vidrio utilizado para el presente estudio procede de la empresa de reciclado de vidrio, Camacho Recycling, que lleva a cabo la recogida, clasificación, tratamientos y control de la calidad del vidrio para su posterior uso como materia prima en la industria cerámica, localizada en Caudete (Albacete) .

Se han ensayado los dos tipos principales de vidrio reciclado que existen: el vidrio plano y el vidrio hueco. Se han utilizado muestras molturadas, donde el 99.5\% está por debajo de $5 \mathrm{~mm}$, tal y como se introduce el feldespato en el molino de bolas industrial que fabrica pasta blanca.

\subsubsection{Composiciones de pastas cerámicas.}

Se han formulado las pastas cerámicas para gres porcelánico y para monoporosa de revestimiento, a nivel de laboratorio que se indican en la Tabla XII y la Tabla XIII. Se tiene que destacar que las composiciones (PORC-1A) y (PORC-1B), llevan más porcentaje en peso del feldespato sódico-magnésico para suplir la fundencia que les falta a las arcillas españolas. 
Tabla XII. Composiciones de gres porcelánico preparadas (\% en peso).

\begin{tabular}{|c|c|c|c|c|}
\hline Materias primas & PORC-STD & PORC-1A & PORC-1B & PORC-2 \\
\hline $\mathrm{N}-\mathrm{A}-\mathrm{te}$ & - & 10 & & - \\
\hline $\mathrm{N}-\mathrm{A}-\mathrm{Cr}$ & - & 10 & & - \\
\hline $\begin{array}{c}\text { N-A-te } \\
\text { calcinada }\end{array}$ & - & - & 10 & 15 \\
\hline $\begin{array}{c}\mathrm{N}-\mathrm{A}-\mathrm{Cr} \\
\text { desferritizada }\end{array}$ & - & - & 10 & 15 \\
\hline$I-A-1$ & 20 & 10 & 10 & 5 \\
\hline$I-A-2$ & 25 & 15 & 15 & 10 \\
\hline Fdto $\mathrm{Na}^{\mathrm{T}}$ & 35 & 30 & 30 & - \\
\hline Fdto $\mathrm{Na}-\mathrm{Mg}^{2}$ & 10 & 15 & 15 & 30 \\
\hline Arena & 10 & 10 & 10 & 5 \\
\hline Residuo cocido & - & - & - & 20 \\
\hline
\end{tabular}

Feldespato sódico.

Feldespato sódico-magnésico.

Tabla XIII. Composiciones de revestimiento preparadas ( $\%$ en peso) .

\begin{tabular}{|c|c|c|c|c|}
\hline Materias primas & REV-STD & REV-1A & REV-1B & REV-2 \\
\hline $\mathrm{N}-\mathrm{A}-\mathrm{te}$ & - & 15 & - & - \\
\hline $\mathrm{N}-\mathrm{A}-\mathrm{Cr}$ & - & 15 & - & - \\
\hline $\begin{array}{c}\text { N-A-te } \\
\text { calcinada }\end{array}$ & - & - & 15 & 20 \\
\hline $\begin{array}{c}\mathrm{N}-\mathrm{A}-\mathrm{Cr} \\
\text { desferritizada }\end{array}$ & - & - & 15 & 20 \\
\hline $\mathrm{I}-\mathrm{A}-1$ & 25 & 10 & 10 & 10 \\
\hline$I-A-2$ & 30 & 15 & 15 & 10 \\
\hline Fdto Na & 10 & 10 & 10 & - \\
\hline Arena & 25 & 25 & 25 & 15 \\
\hline Carbonato & 10 & 10 & 10 & 10 \\
\hline Residuo cocido & - & - & - & 15 \\
\hline
\end{tabular}


Las arcillas españolas tratadas utilizadas en las composiciones han sufrido los siguientes tratamientos: la arcilla de Teruel, (N-A-te), se ha calcinado en horno eléctrico tipo mufla a $400^{\circ} \mathrm{C}$ durante 30 minutos, para disminuir el contenido de materia orgánica $y$, la arcilla de Ciudad Real, (N-A-cr), se ha desferretizado mediante el filtro magnético, siendo tamizada previamente a $100 \mu \mathrm{m}$.

Los ensayos cerámicos característicos realizados a las composiciones de gres porcelánico y las de revestimiento han sido los indicados en el apartado 3.1.9. Además, se han realizado los siguientes ensayos.

- Análisis colorimétrico de las piezas cocidas de las distintas composiciones preparadas.

- Análisis químico de cada una de las composiciones preparadas, completado con la pérdida por calcinación.

- Análisis microestructural de las probetas cocidas a través del microscopio electrónico de barrido (MEB).

- Análisis dilatométrico de las composiciones preparadas.

- Determinación del contenido en carbono orgánico (TOC).

A través de los datos obtenidos de porcentajes de contracción lineal y de absorción de agua a las distintas temperaturas de cocción ensayadas, se ha obtenido el diagrama de gresificación (gráfica del porcentaje de contracción lineal y absorción de agua frente a la temperatura) para estudiar el comportamiento de cada composición de pasta preparada. Para ello, se ha utilizado un horno eléctrico tipo mufla de Pirometrol. Se han obtenido muestras 
en cada punto del diagrama de gresificación, siguiendo un ciclo como el indicado en la Figura 49, variando la temperatura máxima. En el caso de la Figura 49, la temperatura máxima es de $1200^{\circ} \mathrm{C}$.

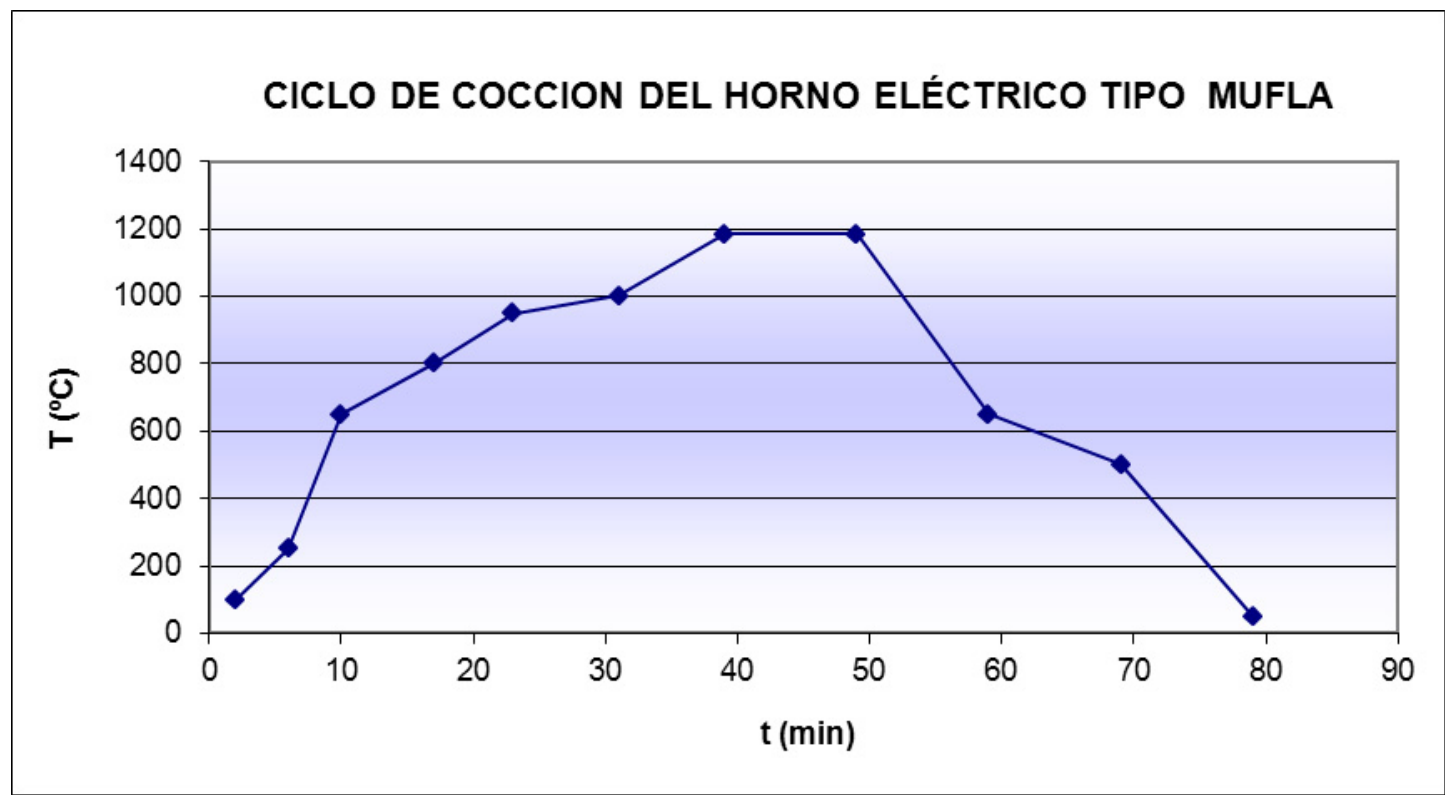

Figura 49. Gráfica del ciclo de cocción de las composiciones preparadas a $1200^{\circ} \mathrm{C}$ en horno eléctrico tipo mufla. 


\title{
Capítulo 4 .RESULTADOS Y DISCUSIÓN.
}

\subsection{Disminución del contenido de compuestos de hierro en las arcillas españolas.}

\begin{abstract}
Primeramente, se ha usado el método tradicional de "desleición" (dispersión de las arcillas en agua) y tamizado a 100 mu, para comparar estos resultados con los obtenidos mediante las técnicas del hidrociclonado y del separador magnético.
\end{abstract}

\subsubsection{Tamizado de las arcillas (N-B-te) y (N-A-Cr).}

Como se observa en la Tabla XIV, que representa los resultados de análisis químicos obtenidos tras tamizar a $100 \mathrm{~m} \mu$ la arcilla de Teruel ( $\mathrm{N}-\mathrm{B}-\mathrm{te})$ con altos contenidos en siderita $\left(\mathrm{FeCO}_{3}\right)$, el porcentaje de hierro correspondiente a la presencia del carbonato férrico en la arcilla, ha disminuido significativamente (por debajo de la mitad). Y, ésto tiene consecuencias también con la pérdida de calcinación, la cual disminuye, por la eliminación en el tamizado del $\mathrm{FeCO}_{3}$ (ya que descompone en la pérdida de calcinación, desprendiéndose $\mathrm{CO}_{2}$ (g)). Por otra parte, se observa que, tras el tamizado aumenta la alúmina, supuestamente porque en el rechazo del tamiz se retiene, además de la siderita, también granos de sílice libre. 
Tabla XIV. Análisis químico por FRX de la arcilla (N-B-te).

\begin{tabular}{|l|c|c|c|c|c|c|c|c|c|c|}
\hline MUESTRA & $\mathrm{Na}_{2} \mathrm{O}$ & $\mathbf{M g O}$ & $\mathrm{Al}_{2} \mathrm{O}_{3}$ & $\mathbf{S i O}_{2}$ & $\mathrm{~K}_{2} \mathrm{O}$ & $\mathbf{C a O}$ & $\mathbf{T i O}_{2}$ & $\mathbf{F e}_{2} \mathrm{O}_{3}$ & $\mathrm{PPC}^{1}$ & SUMA \\
\hline ORIGINAL & 0.29 & 0.89 & 21.09 & 59.42 & 3.34 & 0.32 & 0.91 & $\mathbf{5 . 3 9}$ & 8.51 & 99.99 \\
\hline TAM 100 & 0.52 & 0.69 & 23.21 & 61.25 & 3.46 & 0.24 & 0.87 & $\mathbf{2 . 2 1}$ & 7.32 & 99.79 \\
\hline
\end{tabular}

1 Pérdida por calcinación.

En cuanto a la arcilla española de Ciudad Real, referenciada como (N-A-Cr), el tamizado a $100 \mu m$ también ha posibilitado la disminución, esta vez, del contenido de hematita (64\%) y también de la sílice libre. Así, el resultado obtenido es una arcilla de alta alúmina con un porcentaje de $\mathrm{Fe}_{2} \mathrm{O}_{3}$ adecuado para ser tratada posteriormente con la técnica del hidrociclonado, tal y como se muestra en la Tabla XV.

Tabla XV. Análisis químico por FRX de la arcilla (N-A-Cr).

\begin{tabular}{|l|c|c|c|c|c|c|c|c|c|c|}
\hline MUESTRA & $\mathrm{Na}_{2} \mathrm{O}$ & $\mathbf{M g O}$ & $\mathrm{Al}_{2} \mathrm{O}_{3}$ & $\mathbf{S i O}_{2}$ & $\mathrm{~K}_{2} \mathrm{O}$ & $\mathrm{CaO}$ & $\mathbf{T i O}_{2}$ & $\mathbf{F e}_{2} \mathrm{O}_{3}$ & PPC & SUMA \\
\hline ORIGINAL & 0.82 & 0.07 & 23.45 & 59.77 & 2.72 & 0.01 & $\mathbf{1 . 1 4}$ & $\mathbf{6 . 0 5}$ & 5.76 & 99.90 \\
\hline TAM 100 & 0.80 & 0.17 & 26.71 & 59.50 & 3.39 & 0.05 & $\mathbf{1 . 1 5}$ & $\mathbf{2 . 1 7}$ & 5.85 & 99.88 \\
\hline
\end{tabular}

\subsubsection{Técnica del hidrociclonado de las arcillas españolas.}

Como se había comentado anteriormente (ver apartado 3.3.1), con las arcillas que contenían siderita en su composición, no se han conseguido resultados aceptables en la técnica del hidrociclonado, como han sido los casos de las arcillas de Teruel. Así pues, esta técnica se ha aplicado a la arcilla ce ciudad Real (N-A-Cr), tamizada a $100 \mu m$, de la forma que se ha explicado en el apartado $4 \cdot 1 \cdot 1$. 
Al comienzo de las pruebas, el hidrociclón se ha sometido a un test de prueba, con la propia arcilla (N-A-cr), cuyos resultados aparecen en la Tabla XVI.

Tabla XVI. Análisis químico (FRX) de la arcilla (N-A-cr) tamizada a $100 \mu \mathrm{m}$ e hidrociclonada a una densidad de la barbotina de $1.20 \mathrm{~g} / \mathrm{cm}^{3}$.

TEST DE PRUEBA

\begin{tabular}{|c|c|c|c|c|c|c|c|c|c|c|}
\hline Muestra & $\mathrm{Na}_{2} \mathrm{O}$ & $\mathrm{MgO}$ & $\mathrm{Al}_{2} \mathrm{O}_{3}$ & $\mathrm{SiO}_{2}$ & $\mathrm{~K}_{2} \mathrm{O}$ & $\mathrm{CaO}$ & $\mathrm{TiO}_{2}$ & $\mathrm{Fe}_{2} \mathrm{O}_{3}$ & $\mathrm{PPC}$ & SUMA \\
\hline ENTRADA $^{1}$ & 0.87 & 0.23 & 25.84 & 61.1 & 3.12 & 0.13 & 1.15 & 2.46 & 5.89 & 99.8 \\
\hline FINOS $^{1}$ & 0.91 & 0.24 & 26.79 & 58.6 & 3.22 & 0.13 & 1.19 & 2.24 & 6.50 & 99.9 \\
\hline GRUESOS $^{1}$ & 0.78 & 0.19 & 23.95 & 63.1 & 2.71 & 0.12 & 1.02 & 3.34 & 4.50 & 99.7 \\
\hline
\end{tabular}

RELACION FINOS/GRUESOS : $80 / 20^{2}$

\begin{tabular}{|l|l|l|l|l|l|l|l|l|l|l|}
\hline $\begin{array}{l}\text { ENTRADA } \\
\text { TEORICA }\end{array}$ & 0.88 & 0.23 & 26.22 & 59.5 & 3.12 & 0.13 & 1.15 & 2.46 & 6.10 & 99.9 \\
\hline
\end{tabular}

\% Eliminación de hematita: $8.90 \%$

1 Véase la Figura 41 donde están señaladas las partes del hidrociclón.

2 La relación "Finos/gruesos" se obtiene suponiendo que la "entrada" está compuesta por una corriente de "finos" y una de "gruesos". Se consideran "finos", las partículas que son capaces, por su baja densidad, de salir del hidrociclón por la salida superior llamada "finos", en unas condiciones de trabajo determinadas. Sin embargo, se denominan "gruesos" a las partículas más densas que las anteriores, que caen por gravedad por la apertura inferior del hidrociclón. Según el $\% \mathrm{Fe}_{2} \mathrm{O}_{3}$, por ser el compuesto a separar, se puede obtener esta relación, que permite controlar el rendimiento del proceso. En este caso, la entrada se bifurca en un 80\% de "finos" y un 20\% de "gruesos". La "entrada" teórica es la suma del $80 \%$ de "finos" y el 20\% de "gruesos."

Así pues, con el test de prueba se ha podido averiguar las condiciones de trabajo para poder eliminar el 8.90\% de hematita en la arcilla de Ciudad Real. A partir de aquí y ajustando las condiciones de montaje de los accesorios, se ha intentado optimizar el porcentaje de eliminación de la hematita. La siguiente prueba realizada ha sido el montaje $n^{\circ} 4$ (Tabla VIII) que 
utiliza la tobera de rebose de mayor diámetro, una de las dos entradas tangenciales y el cuerpo cónico y la boquilla de menor tamaño, referenciadas en dicha tabla. Se ha estudiado también la variable del caudal de entrada, modificando la presión de la bomba que alimenta el hidrociclón (véase Tabla XVII), obteniendo los resultados a tres caudales, mostrados en la Tabla XVIII, Tabla XIX y Tabla XX.

Tabla XVII. Relación de la presión de la bomba que alimenta al hidrociclón y el caudal volumétrico $\left(Q_{\mathrm{v}}\right)$.

\begin{tabular}{|c|c|c|}
\hline $\begin{array}{c}\text { Presión de la } \\
\text { bomba (bar) }\end{array}$ & $\begin{array}{c}\mathbf{Q}_{\mathrm{v}}\left(\mathrm{m}^{3} / \mathrm{h}\right) \\
\text { FINOS }\end{array}$ & $\begin{array}{c}\mathbf{Q}_{\mathrm{v}}\left(\mathrm{m}^{3} / \mathrm{h}\right) \\
\text { GRUESOS }\end{array}$ \\
\hline $\mathbf{1 . 5}$ & 1.80 & 0.40 \\
\hline $\mathbf{2 . 0}$ & 2.40 & 0.45 \\
\hline $\mathbf{2 . 5}$ & 3.60 & 0.51 \\
\hline
\end{tabular}

Tabla XVIII. Análisis químico (FRX) de la arcilla (N-A-Cr) hidrociclonada según el montaje $n^{\circ} 4$ a 1.5 bar de presión de bomba.

MONTAJE 4. BARBOTINA INICIAL $(1.27 \mathrm{~g} / \mathrm{cm} 3)$

Contenido en sólidos $=35 \%$ / Presión de la bomba $=1.5$ Bar

\begin{tabular}{|c|c|c|c|c|c|c|c|c|c|c|}
\hline muestra & $\mathrm{Na}_{2} \mathrm{O}$ & $\mathrm{MgO}$ & $\mathrm{Al}_{2} \mathrm{O}_{3}$ & $\mathrm{SiO}_{2}$ & $\mathrm{~K}_{2} \mathrm{O}$ & $\mathrm{CaO}$ & $\mathrm{TiO}_{2}$ & $\mathrm{Fe}_{2} \mathrm{O}_{3}$ & $\mathrm{PPC}$ & SUMA \\
\hline ENTRADA & 0.88 & $\mathbf{0 . 2 3}$ & $\mathbf{2 6 . 2}$ & $\mathbf{5 9 . 4}$ & $\mathbf{3 . 0 7}$ & $\mathbf{0 . 1 3}$ & $\mathbf{1 . 1 4}$ & 2.46 & 6.30 & 99.9 \\
\hline FINOS & 0.88 & $\mathbf{0 . 2 3}$ & $\mathbf{2 6 . 8}$ & $\mathbf{5 8 . 7}$ & $\mathbf{3 . 1 4}$ & $\mathbf{0 . 1 3}$ & $\mathbf{1 . 1 5}$ & 2.31 & 6.45 & 99.9 \\
\hline GRUESOS & 0.80 & $\mathbf{0 . 2 0}$ & $\mathbf{2 4 . 2}$ & $\mathbf{6 2 . 1}$ & $\mathbf{2 . 8 0}$ & $\mathbf{0 . 1 3}$ & $\mathbf{1 . 0 5}$ & 3.14 & 5.20 & $\mathbf{9 9 . 7}$ \\
\hline
\end{tabular}

RELACION FINOS/GRUESOS : $85 / 15$

\begin{tabular}{|l|l|l|l|l|l|l|l|l|l|l|}
\hline $\begin{array}{l}\text { ENTRADA } \\
\text { TEORICA }\end{array}$ & 0.87 & $\mathbf{0 . 2 3}$ & $\mathbf{2 6 . 4}$ & $\mathbf{5 9 . 2}$ & $\mathbf{3 . 0 9}$ & $\mathbf{0 . 1 3}$ & $\mathbf{1 . 1 3}$ & 2.44 & 6.26 & 99.9 \\
\hline
\end{tabular}

Eliminación de hematita: $5.94 \%$ 
Tabla XIX. Análisis químico (FRX) de la arcilla (N-A-cr) hidrociclonada según el montaje $n^{\circ} 4$ a 2.0 bar de presión de bomba.

\begin{tabular}{|c|c|c|c|c|c|c|c|c|c|c|}
\hline & Eenidc & $\begin{array}{l}\text { JNTAJ } \\
\text { en } s\end{array}$ & $\begin{array}{l}\text { 4. BI } \\
\text { Lidos }\end{array}$ & $\begin{array}{l}\text { RBOTI } \\
=35 \%\end{array}$ & $\begin{array}{l}\text { INI } \\
\text { Pre: }\end{array}$ & $\begin{array}{l}\text { CAL ( } \\
\text { ón de }\end{array}$ & $\begin{array}{l}27 \mathrm{~g} \\
1 \mathrm{a} b\end{array}$ & $\left.a m^{3}\right)$ & $.0 \mathrm{BC}$ & \\
\hline muestra & $\mathrm{Na}_{2} \mathrm{O}$ & MgO & $\mathrm{Al}_{2} \mathrm{O}_{3}$ & $\mathrm{SiO}_{2}$ & $\mathrm{~K}_{2} \mathrm{O}$ & $\mathrm{CaO}$ & $\mathrm{TiO}_{2}$ & $\mathrm{Fe}_{2} \mathrm{O}_{3}$ & PPC & SUMA \\
\hline ENTRADA & 0.88 & 0.23 & 26.3 & 59.2 & 3.07 & 0.13 & 1.14 & 2.46 & 6.14 & 99.7 \\
\hline FINOS & 0.90 & 0.25 & 27.5 & 58.2 & 3.20 & 0.14 & 1.17 & 2.26 & 6.23 & 99.9 \\
\hline GRUESOS & 0.81 & 0.20 & 24.2 & 61.9 & 2.78 & 0.13 & 1.03 & 3.25 & 5.41 & 99.9 \\
\hline & & & ELACIC & FIN & GRUI & OS : & $/ 20$ & & & \\
\hline $\begin{array}{l}\text { ENTRADA } \\
\text { TEORICA }\end{array}$ & 0.89 & 0.24 & 27.0 & 58.7 & 3.13 & 0.14 & 1.15 & 2.45 & 6.11 & 99.9 \\
\hline & & $\frac{0}{0}$ & & & 6 & & 12 & & & \\
\hline
\end{tabular}

Tabla XX. Análisis químico (FRX) de la arcilla (N-A-cr) hidrociclonada según el montaje $n^{\circ} 4$ a 2.5 bar de presión de bomba.

\begin{tabular}{|c|c|c|c|c|c|c|c|c|c|c|}
\hline$\% \mathrm{Co}$ & tenic & $\begin{array}{l}\text { ONTA } \\
\text { en } s\end{array}$ & $\begin{array}{r}4 . \mathrm{B} \\
\text { lidos }\end{array}$ & $\begin{array}{l}\text { RBOTI } \\
=35 \%\end{array}$ & $\begin{array}{l}\text { A INI } \\
\text { / Pre }\end{array}$ & $\begin{array}{l}\text { IAL ( } \\
\text { Lón d }\end{array}$ & $\begin{array}{r}.27 \mathrm{~g} \\
1 \mathrm{a} b\end{array}$ & $\begin{array}{l}\mathrm{cm}^{3} \text { ) } \\
\text { nba }=\end{array}$ & $.5 \mathrm{~B}$ & \\
\hline muestra & $\mathrm{Na}_{2} \mathrm{O}$ & MgO & $\mathrm{Al}_{2} \mathrm{O}_{3}$ & $\mathrm{SiO}_{2}$ & $\mathrm{~K}_{2} \mathrm{O}$ & $\mathrm{CaO}$ & $\mathrm{TiO}_{2}$ & $\mathrm{Fe}_{2} \mathrm{O}_{3}$ & PPC & SUMA \\
\hline ENTRADA & 0.89 & 0.25 & 27.4 & 58.5 & 3.11 & 0.14 & 1.14 & 2.42 & 6.02 & 99.9 \\
\hline FINOS & 0.92 & 0.25 & 27.9 & 57.2 & 3.21 & 0.14 & 1.17 & 2.20 & 6.51 & 99.7 \\
\hline GRUESOS & 0.78 & 0.20 & 24.9 & 60.8 & 2.73 & 0.13 & 1.03 & 3.32 & 5.87 & 99.9 \\
\hline & & & ELACI & $N$ FIN & S / GRU & SOS: & $0 / 20$ & & & \\
\hline $\begin{array}{l}\text { ENTRADA } \\
\text { TEORICA }\end{array}$ & 0.89 & 0.24 & 27.3 & 57.9 & 3.12 & 0.14 & 1.14 & 2.43 & 6.38 & 99.7 \\
\hline & & $\%$ & imi & ión & he & ita: & 8.89 & & & \\
\hline
\end{tabular}


Con el montaje $\mathrm{n}^{\circ} 4$ no se conseguido superar los porcentajes de eliminación de hematita alcanzados con el montaje de prueba (8.90\%) de la Tabla XVI. Por ello, se ha preparado el montaje n¹2, que sólo varía con respecto al montaje $n^{\circ} 4$, en la entrada tangencial. El resto de accesorios se han mantenido. En las tablas XXI, XXII, XXIII se presentan los resultados obtenidos del montaje $\mathrm{n}^{\circ} 12$.

Tabla XXI. Análisis químico (FRX) de la arcilla (N-A-cr) hidrociclonada según el montaje $n^{\circ} 12$ a 1.5 bar de presión de bomba.

\begin{tabular}{|c|c|c|c|c|c|c|c|c|c|c|}
\hline \multicolumn{11}{|c|}{$\begin{array}{l}\text { MONTAJE 12. BARBOTINA INICIAL }\left(1.30 \mathrm{~g} / \mathrm{cm}^{3}\right) \\
\text { Contenido en sólidos }=38 \% / \text { Presión de la bomba }=\end{array}$} \\
\hline muestra & $\mathrm{Na}_{2} \mathrm{O}$ & MgO & $\mathrm{Al}_{2} \mathrm{O}_{3}$ & $\mathrm{SiO}_{2}$ & $\mathrm{~K}_{2} \mathrm{O}$ & $\mathrm{CaO}$ & $\mathrm{TiO}_{2}$ & $\mathrm{Fe}_{2} \mathrm{O}_{3}$ & PPC & SUMA \\
\hline ENTRADA & 0.88 & 0.24 & 27.2 & 58.5 & 3.11 & 0.14 & 1.14 & 2.42 & 5.98 & 99.8 \\
\hline FINOS & 0.89 & 0.24 & 27.4 & 58.0 & 3.15 & 0.13 & 1.15 & 2.35 & 6.35 & 99.8 \\
\hline GRUESOS & 0.82 & 0.21 & 25.4 & 60.2 & 2.85 & 0.13 & 1.06 & 3.10 & 5.96 & 99.8 \\
\hline \multicolumn{11}{|c|}{ RELACION FINOS/GRUESOS: $90 / 10$} \\
\hline \begin{tabular}{|l|} 
ENTRADA \\
TEORICA
\end{tabular} & 0.88 & 0.23 & 27.2 & 58.2 & 3.12 & 0.13 & 1.14 & 2.42 & 6.31 & 99.8 \\
\hline
\end{tabular}


Tabla XXII. Análisis químico (FRX) de la arcilla (N-A-cr) hidrociclonada según el montaje $\mathrm{n}^{\circ} 12$ a 2.0 bar de presión de bomba.

\begin{tabular}{|c|c|c|c|c|c|c|c|c|c|c|}
\hline & $\begin{array}{r}M \\
\text { tenidc }\end{array}$ & $\begin{array}{l}\text { NTAJE } \\
\text { en Sc }\end{array}$ & $\begin{array}{l}12 . \mathrm{B} \\
\text { lidos }\end{array}$ & $\begin{array}{l}\text { ARBOTI } \\
=38 \%\end{array}$ & $\begin{array}{l}\text { NA INI } \\
\text { / Pres }\end{array}$ & $\begin{array}{l}\text { IALL ( } \\
\text { ión de }\end{array}$ & $\begin{array}{l}.30 \mathrm{~g} \\
1 \mathrm{a} \mathrm{bo}\end{array}$ & $\begin{array}{l}\left(\mathrm{cm}^{3}\right) \\
\mathrm{nba}=\end{array}$ & $2.0 \mathrm{BC}$ & \\
\hline muestra & $\mathrm{Na}_{2} \mathrm{O}$ & MgO & $\mathrm{Al}_{2} \mathrm{O}_{3}$ & $\mathrm{SiO}_{2}$ & $\mathrm{~K}_{2} \mathrm{O}$ & $\mathrm{CaO}$ & $\mathrm{TiO}_{2}$ & $\mathrm{Fe}_{2} \mathrm{O}_{3}$ & PPC & SUMA \\
\hline ENTRADA & 0.88 & 0.24 & 27.1 & 58.6 & 3.11 & 0.14 & 1.14 & 2.42 & 6.03 & 99.7 \\
\hline FINOS & 0.89 & 0.24 & 27.4 & 58.2 & 3.17 & 0.14 & 1.16 & 2.29 & 6.14 & 99.7 \\
\hline GRUESOS & 0.79 & 0.20 & 25.8 & 59.9 & 2.73 & 0.14 & 1.03 & 3.36 & 5.82 & 99.9 \\
\hline & & & ELACIC & FINC & /GRUE & os: & $5 / 15$ & & & \\
\hline $\begin{array}{l}\text { ENTRADA } \\
\text { TEORICA }\end{array}$ & 0.88 & 0.24 & 27.1 & 58.4 & 3.11 & 0.14 & 1.14 & 2.45 & 6.09 & 99.7 \\
\hline
\end{tabular}

Tabla XXIII. Análisis químico (FRX) de la arcilla (N-A-Cr) hidrociclonada según el montaje $\mathrm{n}^{\circ} 12$ a 2.5 bar de presión de bomba.

\begin{tabular}{|c|c|c|c|c|c|c|c|c|c|c|}
\hline$\div \mathrm{Co}$ & $\begin{array}{r}M C \\
\text { enido }\end{array}$ & $\begin{array}{l}\text { NTAJE } \\
\text { en sć }\end{array}$ & $\begin{array}{l}12 . \mathrm{B} \\
\text { idos }\end{array}$ & $\begin{array}{l}\text { RBOTI } \\
38 \%\end{array}$ & $\begin{array}{l}\text { A INI } \\
\text { Pres }\end{array}$ & $\begin{array}{l}\text { IAL ( } \\
\text { ón de }\end{array}$ & $\begin{array}{l}.30 \mathrm{~g} \\
1 \mathrm{abc}\end{array}$ & $\begin{array}{l}\left.\mathrm{cm}^{3}\right) \\
\mathrm{ba}=\end{array}$ & $.5 \mathrm{Ba}$ & \\
\hline muestra & $\mathrm{Na}_{2} \mathrm{O}$ & MgO & $\mathrm{Al}_{2} \mathrm{O}_{3}$ & $\mathrm{SiO}_{2}$ & $\mathrm{~K}_{2} \mathrm{O}$ & $\mathrm{CaO}$ & $\mathrm{TiO}_{2}$ & $\mathrm{Fe}_{2} \mathrm{O}_{3}$ & PPC & SUMA \\
\hline ENTRADA & 0.89 & 2.02 & 27.1 & 58.4 & 3.12 & 0.14 & 1.14 & 2.43 & 6.25 & 99.8 \\
\hline FINOS & 0.91 & 0.24 & 27.5 & 58.0 & 3.17 & 0.13 & 1.16 & 2.30 & 6.32 & 99.9 \\
\hline GRUESOS & 0.78 & 0.20 & 24.8 & 60.3 & 2.72 & 0.13 & 1.03 & 3.43 & 5.98 & 99.5 \\
\hline & & & ז & 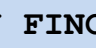 & ( & os : & $/ 12$ & & & \\
\hline $\begin{array}{l}\text { ENTRADA } \\
\text { TEORICA }\end{array}$ & 0.89 & 0.24 & 27.2 & 58.3 & 3.12 & 0.13 & 1.14 & 2.44 & 6.28 & 99.9 \\
\hline
\end{tabular}


Los resultados obtenidos de eliminación de la hematita con este montaje $n^{\circ} 12$, trabajando con una densidad de barbotina de $1.30 \mathrm{~g} / \mathrm{cm}^{3}$, han sido peores que los resultados correspondientes al montaje $\mathrm{n}^{\circ} 4$. A la vista de estos resultados, se ha decidido trabajar con menores contenidos en sólidos, a través del mismo montaje. En la Tabla XXIV, Tabla XXV y la Tabla XXVI se muestran los resultados obtenidos a menores porcentajes de contenido en sólidos.

Tabla XXIV. Análisis químico (FRX) de la arcilla (N-A-cr) hidrociclonada según el montaje $n^{\circ} 12$ a 1.5 bar de presión de bomba.

\begin{tabular}{|c|c|c|c|c|c|c|c|c|c|c|}
\hline \multicolumn{11}{|c|}{$\begin{array}{l}\text { MONTAJE 12. BARBOTINA INICIAL }\left(1.24 \mathrm{~g} / \mathrm{cm}^{3}\right) \\
\text { 。Contenido en sólidos }=32 \% / \text { Presión de la bomba }=\end{array}$} \\
\hline muestra & $\mathrm{Na}_{2} \mathrm{O}$ & Mgo & $\mathrm{Al}_{2} \mathrm{O}_{3}$ & $\mathrm{SiO}_{2}$ & $\mathrm{~K}_{2} \mathrm{O}$ & $\mathrm{CaO}$ & $\mathrm{TiO}_{2}$ & $\mathrm{Fe}_{2} \mathrm{O}_{3}$ & PPC & SUMA \\
\hline ENTRADA & 0.92 & 0.22 & 27.1 & 58.6 & 3.05 & 0.13 & 1.14 & 2.39 & 6.17 & 99.9 \\
\hline FINOS & 0.94 & 0.22 & 27.0 & 58.4 & 3.18 & 0.14 & 1.21 & 2.02 & 6.25 & 99.4 \\
\hline GRUESOS & 0.80 & 0.16 & 24.2 & 61.2 & 2.51 & 0.13 & 0.95 & 3.91 & 5.94 & 99.9 \\
\hline \multicolumn{11}{|c|}{ RELACION FINOS/GRUESOS: $80 / 20$} \\
\hline $\begin{array}{l}\text { ENTRADA } \\
\text { TEORICA }\end{array}$ & 0.91 & 0.21 & 26.4 & 59.0 & 3.04 & 0.14 & 1.15 & 2.40 & 6.19 & 99.5 \\
\hline
\end{tabular}


Tabla XXV. Análisis químico (FRX) de la arcilla (N-A-cr) hidrociclonada según el montaje $\mathrm{n}^{\circ} 12$ a 2.0 bar de presión de bomba.

MONTAJE 12. BARBOTINA INICIAL $\left(1.24 \mathrm{~g} / \mathrm{cm}^{3}\right)$

\%Contenido en sólidos $=32 \% /$ Presión de la bomba $=2.0$ Bar

\begin{tabular}{|c|c|c|c|c|c|c|c|c|c|c|}
\hline muestra & $\mathrm{Na}_{2} \mathrm{O}$ & $\mathrm{MgO}$ & $\mathrm{Al}_{2} \mathrm{O}_{3}$ & $\mathrm{SiO}_{2}$ & $\mathrm{~K}_{2} \mathrm{O}$ & $\mathrm{CaO}$ & $\mathrm{TiO}_{2}$ & $\mathrm{Fe}_{2} \mathrm{O}_{3}$ & $\mathrm{PPC}$ & $\mathrm{SUMA}$ \\
\hline ENTRADA & 0.89 & 0.20 & 27.0 & 58.1 & 2.96 & 0.13 & 1.11 & 2.52 & 6.23 & 99.2 \\
\hline FINOS & 0.96 & 0.22 & 27.5 & 58.2 & 3.19 & 0.13 & 1.18 & 2.06 & 6.31 & 99.9 \\
\hline GRUESOS & 0.76 & 0.15 & 25.3 & 60.2 & 2.50 & 0.12 & 0.95 & 3.81 & 5.84 & 99.7 \\
\hline
\end{tabular}

RELACION FINOS/GRUESOS : $80 / 20$

\begin{tabular}{|c|c|c|c|c|c|c|c|c|c|c|}
\hline $\begin{array}{l}\text { ENTRADA } \\
\text { TEORICA }\end{array}$ & 0.92 & 0.21 & 27.1 & 58.6 & 3.05 & 0.13 & 1.13 & 2.41 & 6.22 & 99.9 \\
\hline
\end{tabular}

Tabla XXVI. Análisis químico (FRX) de la arcilla (N-A-cr) hidrociclonada según el montaje $\mathrm{n}^{\circ} 12$ a 2.5 bar de presión de bomba.

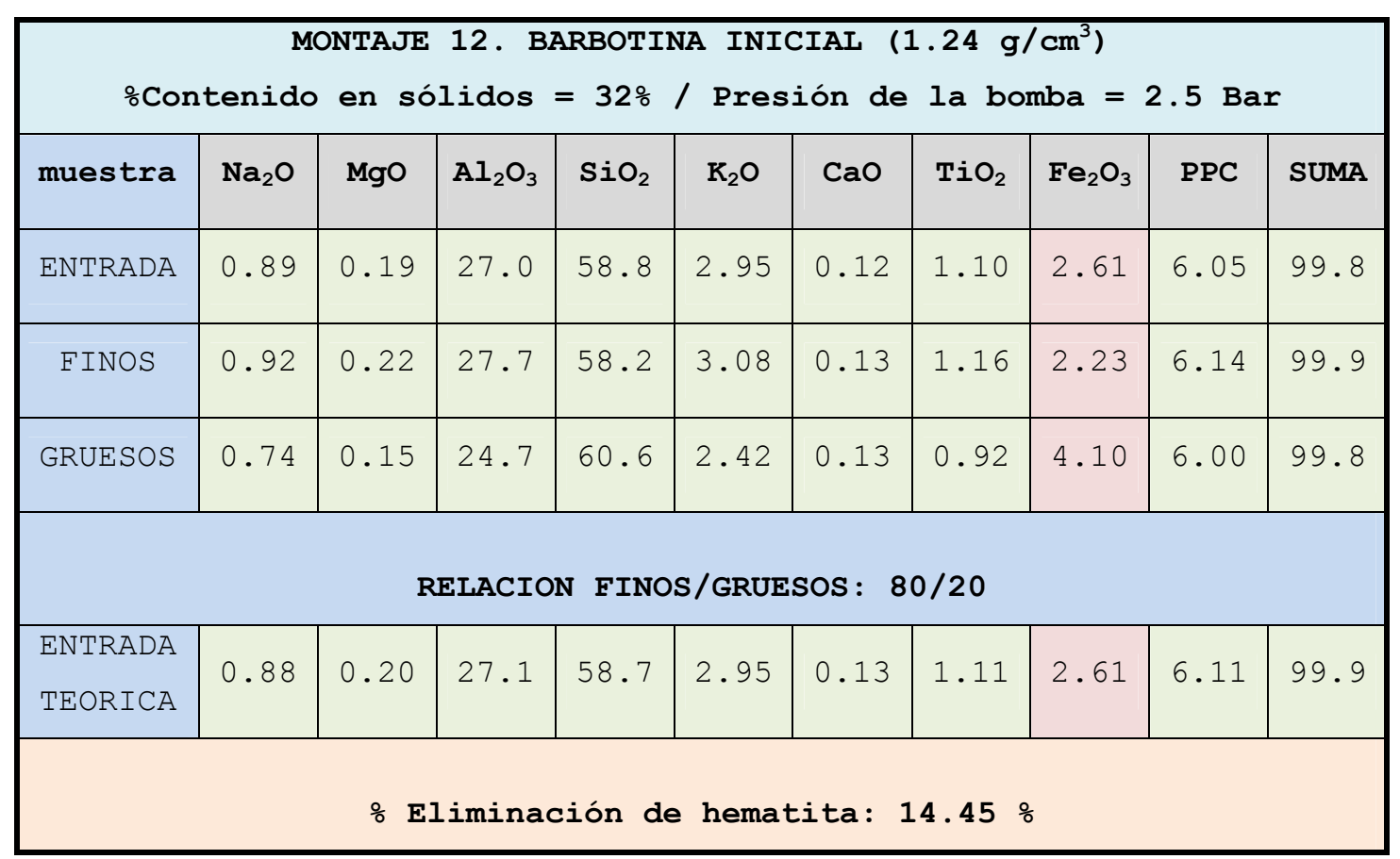


Con este montaje $\mathrm{n}^{\circ} 12 \mathrm{y}$, trabajando a menor densidad de barbotina de entrada, se ha conseguido mejorar bastante los resultados, puesto que con 2 bares de presión, casi se elimina cerca de un 20\% de hierro. Con esta prueba se descartan los caudales extremos, de forma que en las siguientes pruebas el caudal será constante, correspondiente a la presión de bomba de 2 bares. Además, también se ha fijado la densidad de la barbotina a $1.24 \mathrm{~g} / \mathrm{cm}^{3}$.

A continuación se presenta un resumen de todas las pruebas más interesantes obtenidas, de cara a optimizar la eliminación de hematita, las cuales han sido diseñadas eligiendo distintos montajes de accesorios (Tabla XXVII, Tabla XXVIII, Tabla XXIV y Tabla XXX) .

Tabla XXVII. Análisis químico (FRX) de la arcilla (N-A-Cr) hidrociclonada según el montaje $n^{\circ} 11$ a 2.0 bar de presión de bomba.

\begin{tabular}{|c|c|c|c|c|c|c|c|c|c|c|}
\hline$\% \mathrm{Con}$ & $\begin{array}{r}M \\
\text { enido }\end{array}$ & $\begin{array}{l}\text { NTAJE } \\
\text { en só }\end{array}$ & $\begin{array}{l}\text { 11. B } \\
\text { Lidos }\end{array}$ & $\begin{array}{l}\overline{R B O T I} \\
=32 \%\end{array}$ & $\begin{array}{l}\text { A INI } \\
\text { Pres }\end{array}$ & $\begin{array}{l}\text { IAAL } \\
\text { ión de }\end{array}$ & $\begin{array}{l}.24 \mathrm{c} \\
1 \mathrm{ab}\end{array}$ & $\begin{array}{l}\left(\mathrm{cm}^{3}\right) \\
m b a=\end{array}$ & $2.0 \mathrm{~B}$ & \\
\hline muestra & $\mathrm{Na}_{2} \mathrm{O}$ & MgO & $\mathrm{Al}_{2} \mathrm{O}_{3}$ & $\mathrm{SiO}_{2}$ & $\mathrm{~K}_{2} \mathrm{O}$ & $\mathrm{CaO}$ & $\mathrm{TiO}_{2}$ & $\mathrm{Fe}_{2} \mathrm{O}_{3}$ & PPC & SUMA \\
\hline ENTRADA & 0.88 & 0.21 & 27.1 & 58.7 & 3.01 & 0.15 & 1.12 & 2.51 & 6.03 & 99.9 \\
\hline FINOS & 0.94 & 0.24 & 27.4 & 58.3 & 3.12 & 0.18 & 1.16 & 2.22 & 6.25 & 99.9 \\
\hline GRUESOS & 0.76 & 0.17 & 25.4 & 59.9 & 2.53 & 0.14 & 0.98 & 3.79 & 5.95 & 99.7 \\
\hline & & REL & ACION & EINOS/ & GRUES & S: 81 & $5 / 18$ & & & \\
\hline $\begin{array}{l}\text { ENTRADA } \\
\text { TEORICA }\end{array}$ & 0.91 & 0.22 & 27.0 & 58.6 & 3.01 & 0.17 & 1.12 & 2.51 & 6.19 & 99.9 \\
\hline
\end{tabular}


Tabla XXVIII. Análisis químico (FRX) de la arcilla (N-A-cr) hidrociclonada según el montaje $n^{\circ} 24$ a 2.0 bar de presión de bomba.

\begin{tabular}{|c|c|c|c|c|c|c|c|c|c|c|}
\hline \multicolumn{11}{|c|}{$\begin{array}{l}\text { MONTAJE 24. BARBOTINA INICIAL }\left(1.24 \mathrm{~g} / \mathrm{cm}^{3}\right) \\
\text { do en sólidos }=32 \% / \text { Presión de la bomba }=\end{array}$} \\
\hline muestra & $\mathrm{Na}_{2} \mathrm{O}$ & MgO & $\mathrm{Al}_{2} \mathrm{O}_{3}$ & $\mathrm{SiO}_{2}$ & $\mathrm{~K}_{2} \mathrm{O}$ & $\mathrm{CaO}$ & $\mathrm{TiO}_{2}$ & $\mathrm{Fe}_{2} \mathrm{O}_{3}$ & PPC & SUMA \\
\hline ENTRADA & 0.95 & 0.20 & 27.0 & 58.4 & 3.02 & 0.13 & 1.13 & 2.47 & 6.13 & 99.6 \\
\hline FINOS & 0.98 & 0.21 & 27.7 & 57.9 & 3.15 & 0.14 & 1.17 & 2.15 & 6.46 & 99.9 \\
\hline GRUESOS & 0.84 & 0.16 & 25.4 & 59.6 & 2.63 & 0.13 & 1.01 & 3.51 & 6.00 & 99.3 \\
\hline \multicolumn{11}{|c|}{ RELACION F } \\
\hline $\begin{array}{l}\text { ENTRADA } \\
\text { TEORICA }\end{array}$ & 0.95 & 0.20 & 27.1 & 58.3 & 3.03 & 0.14 & 1.13 & 2.47 & 6.35 & 99.8 \\
\hline
\end{tabular}

Tabla XXIX. Análisis químico (FRX) de la arcilla (N-A-cr) hidrociclonada según el montaje $n^{\circ} 4$ a 2.0 bar de presión de bomba.

\begin{tabular}{|c|c|c|c|c|c|c|c|c|c|c|}
\hline$\% \mathrm{Co}$ & $\begin{array}{r}1 \\
\text { tenidc }\end{array}$ & $\begin{array}{l}\overline{\text { ONTAJF }} \\
\text { en sć }\end{array}$ & $\begin{array}{l}4 . \mathrm{BF} \\
\text { lidos }\end{array}$ & $\begin{array}{l}\text { ARBOTII } \\
=32 \%\end{array}$ & $\begin{array}{l}\text { A INIC } \\
\text { / Pres }\end{array}$ & $\begin{array}{l}\text { IAL (1 } \\
\text { Lón de }\end{array}$ & $\begin{array}{l}.24 \mathrm{~g} / \\
1 \mathrm{a} \mathrm{bo}\end{array}$ & $\begin{array}{l}\left.\mathrm{cm}^{3}\right) \\
\mathrm{nba}=\end{array}$ & $.0 \mathrm{Ba}$ & \\
\hline muestra & $\mathrm{Na}_{2} \mathrm{O}$ & MgO & $\mathrm{Al}_{2} \mathrm{O}_{3}$ & $\mathrm{SiO}_{2}$ & $\mathrm{~K}_{2} \mathrm{O}$ & $\mathrm{CaO}$ & $\mathrm{TiO}_{2}$ & $\mathrm{Fe}_{2} \mathrm{O}_{3}$ & PPC & SUMA \\
\hline ENTRADA & 0.92 & 0.20 & 27.1 & 58.4 & 3.00 & 0.15 & 1.11 & 2.49 & 6.25 & 99.7 \\
\hline FINOS & 0.98 & 0.21 & 27.7 & 57.7 & 3.17 & 0.15 & 1.17 & 2.07 & 6.28 & 99.5 \\
\hline GRUESOS & 0.79 & 0.14 & 25.2 & 59.7 & 2.36 & 0.15 & 0.91 & 4.25 & 5.97 & 99.6 \\
\hline & & REI & ACION & FINOS/ & GRUESC & : 80. & $5 / 19.5$ & & & \\
\hline $\begin{array}{l}\text { ENTRADA } \\
\text { TEORICA }\end{array}$ & 0.94 & 0.20 & 27.2 & 58.1 & 3.01 & 0.15 & 1.12 & 2.49 & 6.22 & 99.6 \\
\hline
\end{tabular}


Tabla XXX. Análisis químico (FRX) de la arcilla (N-A-cr) hidrociclonada según el montaje $\mathrm{n}^{\circ} 9$ a 2.0 bar de presión de bomba.

\begin{tabular}{|c|c|c|c|c|c|c|c|c|c|c|}
\hline \multicolumn{11}{|c|}{$\begin{array}{c}\text { MONTAJE 9. BARBOTINA INICIAL }\left(1.24 \mathrm{~g} / \mathrm{cm}^{3}\right) \text { \%ontenido en sólidos }= \\
32 \% / \text { Presión de la bomba }=2.0 \mathrm{Bar}\end{array}$} \\
\hline muestra & $\mathrm{Na}_{2} \mathrm{O}$ & MgO & $\mathrm{Al}_{2} \mathrm{O}_{3}$ & $\mathrm{SiO}_{2}$ & $\mathrm{~K}_{2} \mathrm{O}$ & $\mathrm{CaO}$ & $\mathrm{TiO}_{2}$ & $\mathrm{Fe}_{2} \mathrm{O}_{3}$ & PPC & SUMA \\
\hline ENTRADA & 0.89 & 0.21 & 27.0 & 58.8 & 3.02 & 0.14 & 1.13 & 2.51 & 6.14 & 99.9 \\
\hline FINOS & 0.93 & 0.22 & 27.2 & 58.2 & 3.20 & 0.13 & 1.19 & 1.99 & 6.68 & 99.9 \\
\hline GRUESOS & 0.75 & 0.16 & 25.5 & 60.6 & 2.50 & 0.13 & 0.97 & 3.83 & 5.41 & 99.9 \\
\hline \multicolumn{11}{|c|}{ RELACION } \\
\hline $\begin{array}{l}\text { ENTRADA } \\
\text { TEORICA }\end{array}$ & 0.88 & 0.20 & 26.7 & 58.9 & 3.00 & 0.13 & 1.13 & 2.51 & 6.32 & 99.9 \\
\hline
\end{tabular}

Según el equipo utilizado y las condiciones de trabajo seleccionadas, la técnica del hidrociclonado permite eliminar hasta un 20\% de hematita de la barbotina inicial ("entrada") trabajando a densidades bajas de contenidos en sólidos (próximos al 30\% en pesol. Se observa cómo, además, la alúmina correspondiente a los "Finos" se incrementa ligeramente, puesto que las partículas arcillosas corresponden a las fracciones más finas. Se indican, a través de la Figura 50, los resultados obtenidos en cada una de las pruebas ensayadas. Como se observa en esta gráfica, el montaje $n^{\circ} 9$ presenta el porcentaje de hematita eliminado más alto, en las condiciones de trabajo fijadas (densidad de barbotina inicial a $1.24 \mathrm{~g} / \mathrm{cm}^{3}$ y caudal de $2.4 \mathrm{~m}^{3} / \mathrm{h}$ ), si bien el porcentaje de "Finos" obtenido es el valor más bajo. Los resultados obtenidos en el montaje $\mathrm{n}^{\circ} 4$ y $\mathrm{n}^{\circ} 12$, permiten eliminar cerca del 20\% de hematita y, a la vez obtener un 
porcentaje de "Finos" elevado, cerca del 80\%. Sin embargo, con el montaje $n^{\circ} 11$, se obtiene un porcentaje elevado de "Finos", pero el porcentaje de hematita eliminado se reduce a la mitad. En el caso del montaje n²4, se consiguen resultados más bajos, tanto de porcentaje de hematita eliminada como de "Finos" obtenidos.

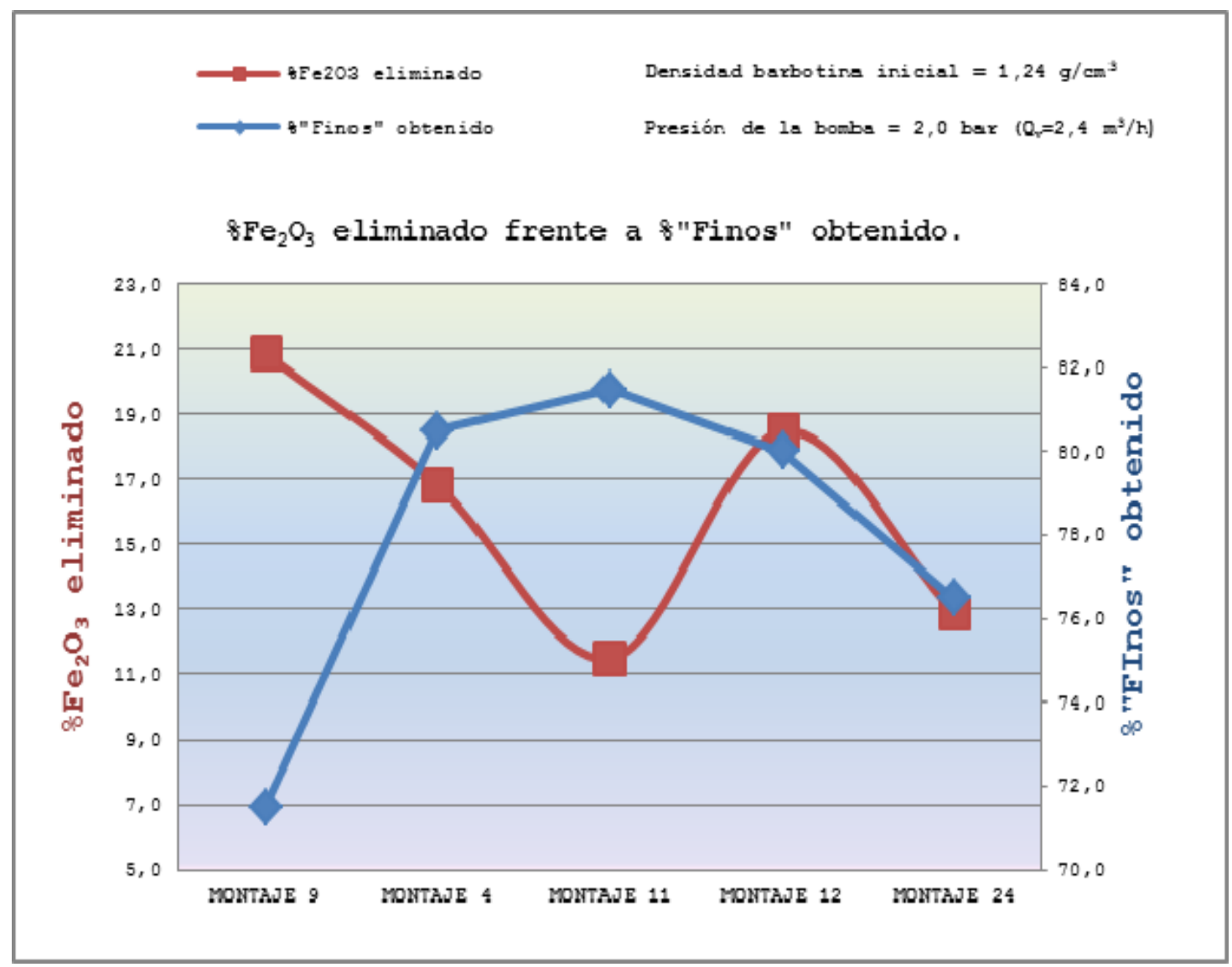

Figura 50. Gráfica de los montajes ensayados a las mismas condiciones de trabajo.

Otro experimento que se ha diseñado ha consistido en "hidrociclonar" la barbotina de "gruesos", obtenidos a través del montaje n9 (Tabla XXX), cuyos resultados se indican en la Tabla XXXI : 
Tabla XXXI. Análisis químico (FRX) de los "gruesos" (N-A-cr) hidrociclonados según el montaje $n^{\circ} 9$ a 2.0 bar de presión de bomba.

\begin{tabular}{|c|c|c|c|c|c|c|c|c|c|c|}
\hline$\% \mathrm{Co}$ & $\begin{array}{l}\text { MONTA } \\
\text { tenid }\end{array}$ & $\begin{array}{l}\mathrm{E} 9 \\
\text { en } \mathrm{s}\end{array}$ & $\begin{array}{l}\text { ARBOT } \\
\text { lidos }\end{array}$ & $\begin{array}{l}\text { NA IN } \\
=43 \%\end{array}$ & $\begin{array}{l}\text { SIAL: } \\
\text { / Pres }\end{array}$ & $\begin{array}{l}\text { 'GRUE: } \\
\text { ión d }\end{array}$ & $\begin{array}{l}S^{\prime \prime} \\
1 a b\end{array}$ & $\begin{array}{l}35 \mathrm{~g} / \\
\mathrm{nba}=\end{array}$ & $\begin{array}{l}\left.\mathrm{m}^{3}\right) \\
.0\end{array}$ & \\
\hline muestra & $\mathrm{Na}_{2} \mathrm{O}$ & MgO & $\mathrm{Al}_{2} \mathrm{O}_{3}$ & $\mathrm{SiO}_{2}$ & $\mathrm{~K}_{2} \mathrm{O}$ & $\mathrm{CaO}$ & $\mathrm{TiO}_{2}$ & $\mathrm{Fe}_{2} \mathrm{O}_{3}$ & PPC & SUMA \\
\hline ENTRADA & 0.75 & 0.16 & 25.5 & 60.6 & 2.50 & 0.13 & 0.97 & 3.83 & 5.41 & 99.9 \\
\hline FINOS & 0.79 & 0.19 & 26.5 & 59.8 & 2.70 & 0.15 & 1.01 & 2.66 & 5.91 & 99.8 \\
\hline GRUESOS & 0.66 & 0.10 & 23.7 & 61.0 & 1.69 & 0.17 & 0.68 & 6.18 & 5.34 & 99.6 \\
\hline & & $\mathrm{RE}$ & ACION & FINOS & GRUES & s: 71 & $5 / 28$ & & & \\
\hline $\begin{array}{l}\text { ENTRADA } \\
\text { TEORICA }\end{array}$ & 0.75 & 0.16 & 25.5 & 60.2 & 2.35 & 0.16 & 0.90 & 3.89 & 5.71 & 99.7 \\
\hline
\end{tabular}

El tratamiento realizado a la barbotina de "gruesos" del montaje n॰9 (Tabla XXX) supone una eliminación de hematita hasta el 30\%. Sin embargo, la barbotina de "Finos" conseguida no tiene la suficiente blancura como para introducirla en el proceso directamente $\left(2.66 \% \mathrm{Fe}_{2} \mathrm{O}_{3}\right.$ en peso) .

Con las arcillas de Teruel, no se ha podido realizar el estudio, ya que no se separaba la siderita, como se ha explicado en el apartado 3.3.1.

\subsubsection{Separador magnético.}

Para aplicar esta técnica al estudio de la eliminación del hierro en las arcillas españolas, se ha elegido la arcilla (N-Acr) tamizada a $100 \mu \mathrm{m}$ (Tabla XV), rica en hierro en forma de 
hematita, preparando una barbotina cuyo contenido en sólidos está alrededor del 42\% en peso. Se han preparado 1000 litros de barbotina en estas condiciones para utilizar 50 litros en cada ensayo. El esquema de funcionamiento del equipo ya se ha indicado en la figura anteriormente descrita (véase apartado 3.3.2, Figura 46). Para la realización de las pruebas, se dispone de tres tipos de matrices o filtros magnéticos inducidos (véase Tabla IX) que, son en realidad el lugar donde se queda retenida la hematita procedente de la barbotina. Se prepara para ello, una barbotina de densidad constante $\left(1.38 \mathrm{~g} / \mathrm{cm}^{3}\right)$ que se alimenta al filtro a caudal constante $(2.0 \mathrm{l} / \mathrm{min})$. En la Tabla XXXII, se muestran los resultados obtenidos con cada tipo de matriz.

Tabla XXXII. Comparación de los análisis químicos de las 3 matrices.

\begin{tabular}{|c|c|c|c|c|c|c|c|c|c|c|}
\hline Muestra & $\mathrm{Na}_{2} \mathrm{O}$ & $\mathrm{MgO}$ & $\mathrm{Al}_{2} \mathrm{O}_{3}$ & $\mathrm{SiO}_{2}$ & $\mathrm{~K}_{2} \mathrm{O}$ & $\mathrm{CaO}$ & $\mathrm{TiO}_{2}$ & $\mathbf{F e}_{2} \mathrm{O}_{3}$ & $\mathrm{PPC}$ & $\mathrm{TOTAL}$ \\
\hline $\mathbf{N - A - c r}$ & 0.82 & 0.07 & 23.45 & 59.77 & 2.72 & 0.01 & 1.14 & $\mathbf{6 . 0 5}$ & 5.76 & 99.90 \\
\hline TAM $100^{1}$ & 0.80 & 0.17 & 26.71 & 59.50 & 3.39 & 0.05 & 1.15 & $\mathbf{2 . 1 7}$ & 5.85 & 99.88 \\
\hline $\mathrm{B} 1^{2}$ & 0.93 & 0.15 & 27.89 & 58.34 & 3.36 & 0.05 & 1.00 & $\mathbf{1 . 8 9}$ & 5.86 & 99.75 \\
\hline $\mathrm{B} 2$ & 0.98 & 0.16 & 27.15 & 59.04 & 3.31 & 0.11 & 1.26 & $\mathbf{1 . 7 6}$ & 6.03 & 99.82 \\
\hline B3 & 0.94 & 0.17 & 27.85 & 59.01 & 3.32 & 0.07 & 1.19 & $\mathbf{1 . 4 8}$ & 5.91 & 99.97 \\
\hline
\end{tabular}

${ }^{1}$ Barbotina tamizada a $100 \mu \mathrm{m}$.

${ }^{2}$ Tipo de matriz (B1, B2 y B3).

En la Tabla XXXII se muestra el porcentaje de $\frac{\circ}{\mathrm{Fe}_{2} \mathrm{O}_{3}}$ eliminado en función de la matriz ensayada y se desprende que la matriz que más hematita retiene es la B3, ya que es capaz de reducir hasta un $30 \%$ el porcentaje de $\mathrm{Fe}_{2} \mathrm{O}_{3}$ presente en la barbotina sin tratar y tamizada a $100 \mu m$. 
Tabla XXXIII. Comparación del $\frac{\circ}{\mathrm{Fe}_{2} \mathrm{O}_{3}}$ eliminado en cada matriz.

\begin{tabular}{|c|c|}
\hline MATRIz & $\begin{array}{c}\% \mathrm{Fe}_{2} \mathrm{O}_{3} \\
\text { eliminado }\end{array}$ \\
\hline Matriz B1 & 12.90 \\
\hline Matriz B2 & 18.89 \\
\hline Matriz B3 & 31.80 \\
\hline
\end{tabular}

El caudal que alimenta al equipo de separación magnética ha sido otro parámetro a estudiar. Para ello, se han probado tres caudales distintos, cuyos resultados a través del análisis químico se presentan en la Tabla XXXIV, comparativamente entre las muestras tratadas y sin tratar.

Tabla XXXIV. Comparación de los análisis químicos (FRX) obtenidos a diferentes caudales.

\begin{tabular}{|c|c|c|c|c|c|c|c|c|c|c|c|}
\hline \multicolumn{2}{|c|}{ Muestra } & $\mathrm{Na}_{2} \mathrm{O}$ & MgO & $\mathrm{Al}_{2} \mathrm{O}_{3}$ & $\mathrm{SiO}_{2}$ & $\mathrm{~K}_{2} \mathrm{O}$ & $\mathrm{CaO}$ & $\mathrm{TiO}_{2}$ & $\mathrm{Fe}_{2} \mathrm{O}_{3}$ & PPC & TOTAL \\
\hline \multirow{2}{*}{ S } & $\mathrm{N}-\mathrm{A}-\mathrm{Cr}$ & 0.82 & 0.07 & 23.45 & 59.77 & 2.72 & 0.01 & 1.14 & 6.05 & 5.76 & 99.90 \\
\hline & TAM 100 & 0.80 & 0.17 & 26.71 & 59.50 & 3.39 & 0.05 & 1.15 & 2.17 & 5.85 & 99.88 \\
\hline \multirow{3}{*}{ 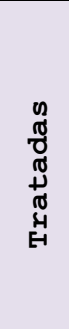 } & $\begin{array}{c}1.5 \\
1 / \mathrm{min}\end{array}$ & 0.85 & 0.20 & 27.15 & 59.23 & 3.27 & 0.09 & 1.15 & 1.46 & 6.09 & 99.58 \\
\hline & $\begin{array}{c}2.0 \\
1 / \mathrm{min}\end{array}$ & 0.95 & 0.22 & 27.96 & 59.07 & 3.29 & 0.08 & 1.14 & 1.51 & 5.54 & 99.84 \\
\hline & $\begin{array}{c}2.5 \\
1 / \mathrm{min}\end{array}$ & 0.93 & 0.21 & 27.17 & 59.06 & 3.24 & 0.09 & 1.15 & 1.59 & 6.17 & 99.69 \\
\hline
\end{tabular}


A la vista de los resultados de la Tabla XXXIV, de los tres caudales ensayados, se elige el caudal menor (1.5 l/min), por ser el que más contenido de $\mathrm{Fe}_{2} \mathrm{O}_{3}$ ha eliminado, como se muestra en la Tabla XXXV.

Tabla XXXV. Comparación del $\frac{\circ}{\circ} \mathrm{Fe}_{2} \mathrm{O}_{3}$ eliminado para cada caudal empleado.

\begin{tabular}{|c|c|}
\hline CAUDAL (Qv) & $\begin{array}{c}\text { e203 } \\
\text { eliminado }\end{array}$ \\
\hline $1.51 / \mathrm{min}$ & 32.72 \\
\hline $2.01 / \mathrm{min}$ & 30.41 \\
\hline $2.51 / \mathrm{min}$ & 26.73 \\
\hline
\end{tabular}

Otra variable importante a tener en cuenta en esta técnica de separación magnética de partículas, es la intensidad del campo magnético. Para ello, se han probado tres intensidades del campo magnético medidas en Gauss. En la Tabla XXXVI se muestran los resultados de análisis químico de la arcilla (N-A-cr) ensayada a diferentes intensidades de campo y en la Tabla XXXVII se expresan

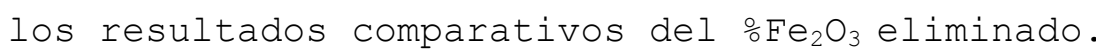

Tabla XXXVI. Análisis químico (FRX) para comparación del $\% \mathrm{Fe}_{2} \mathrm{O}_{3}$ eliminado a diferentes intensidades de campo magnético.

\begin{tabular}{|c|c|c|c|c|c|c|c|c|c|c|c|}
\hline & Muestra & $\mathrm{Na}_{2} \mathrm{O}$ & MgO & $\mathrm{Al}_{2} \mathrm{O}_{3}$ & $\mathrm{SiO}_{2}$ & $\mathrm{~K}_{2} \mathrm{O}$ & $\mathrm{CaO}$ & $\mathrm{TiO}_{2}$ & $\mathrm{Fe}_{2} \mathrm{O}_{3}$ & PPC & TOTAL \\
\hline \multirow{2}{*}{ 点 } & $\mathrm{N}-\mathrm{A}-\mathrm{Cr}$ & 0.82 & 0.07 & 23.45 & 59.77 & 2.72 & 0.01 & 1.14 & 6.05 & 5.76 & 99.90 \\
\hline & TAM 100 & 0.80 & 0.17 & 26.71 & 59.50 & 3.39 & 0.05 & 1.15 & 2.17 & 5.85 & 99.88 \\
\hline \multirow{3}{*}{ 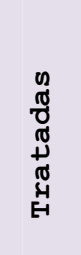 } & $2500 \mathrm{G}$ & 0.85 & 0.20 & 27.15 & 59.23 & 3.27 & 0.09 & 1.15 & 1.46 & 6.09 & 99.58 \\
\hline & $5000 \mathrm{G}$ & 0.81 & 0.21 & 26.72 & 59.81 & 3.27 & 0.13 & 1.14 & 1.38 & 6.03 & 99.60 \\
\hline & $10000 \mathrm{G}$ & 0.82 & 0.22 & 26.63 & 59.74 & 3.32 & 0.10 & 1.15 & 1.42 & 6.39 & 99.88 \\
\hline
\end{tabular}


Tabla XXXVII. Comparación del $\frac{\circ}{\circ} \mathrm{Fe}_{2} \mathrm{O}_{3}$ eliminado para cada intensidad de campo magnético.

\begin{tabular}{|c|c|}
\hline $\begin{array}{c}\text { INTENSIDAD } \\
(\mathrm{G})\end{array}$ & $\begin{array}{c}\frac{\circ \mathrm{Fe}_{2} \mathrm{O}_{3}}{\text { eliminado }} \\
2500 \text { Gauss }\end{array}$ \\
\hline 5000 Gauss & 36.41 \\
\hline 10000 Gauss & 34.56 \\
\hline
\end{tabular}

En cuanto a los resultados obtenidos en la Tabla XXXVII, se ha observado que la intensidad no influye de una forma determinante, de manera que los tres resultados son bastante similares. No obstante, vistos estos resultados, se ha decidido usar los 2500 Gauss, para disminuir el coste energético y también el riesgo de exposición magnética de los técnicos que manipulan el equipo magnético.

Finalmente, si el equipo de separación magnética se pone en modo automático, es decir, mediante el cual realiza automáticamente ciclos de limpieza (lavado) de los filtros cada 10 minutos, es posible obtener los resultados que aparecen en la Tabla XXXVIII. Así, esta tabla muestra el análisis químico de la arcilla (N-A-Cr) tratada con el separador magnético. Tras la desferritización de la barbotina filtrada ("Filtrado") con respecto a la arcilla tamizada a 100 um, sin filtrar, el contenido de $\mathrm{Fe}_{2} \mathrm{O}_{3}$ eliminado ha sido del $45.62 \%$. 


\section{Tabla XXXVIII. Análisis químico (FRX) de (N-A-Cr) desferritizada trabajando en} modo automático.

\begin{tabular}{|c|l|l|l|l|l|l|l|l|l|l|}
\hline Muestra & $\mathrm{Na}_{2} \mathrm{O}$ & $\mathrm{MgO}$ & $\mathrm{Al}_{2} \mathrm{O}_{3}$ & $\mathrm{SiO}_{2}$ & $\mathrm{~K}_{2} \mathrm{O}$ & $\mathrm{CaO}$ & $\mathrm{TiO}_{2}$ & $\mathrm{Fe}_{2} \mathrm{O}_{3}$ & PPC & TOTAL \\
\hline N-A-cr & 0.82 & 0.07 & 23.45 & 59.77 & 2.72 & 0.01 & 1.14 & 6.05 & 5.76 & 99.90 \\
\hline TAM 100 & 0.80 & 0.17 & 26.71 & 59.50 & 3.39 & 0.05 & 1.15 & 2.17 & 5.85 & 99.88 \\
\hline FILTRADO & 0.93 & 0.24 & 26.91 & 59.84 & 2.81 & 0.09 & 1.06 & 1.18 & 6.52 & 99.66 \\
\hline RESIDUO & 0.98 & 0.05 & 12.17 & 60.43 & 1.48 & 0.12 & 0.62 & 19.5 & 3.84 & 99.35 \\
\hline
\end{tabular}

Con esta prueba, la cantidad de hematita en la barbotina se ha reducido casi a la mitad, transfiriéndose a la fracción del residuo, el cual corresponde a un 20\% en peso. En la Figura 51, se observan los difractogramas de las cuatro muestras de la arcilla $(\mathrm{N}-\mathrm{A}-\mathrm{Cr})$, rica en hematita, obtenidas tras la aplicación de las técnicas descritas. 


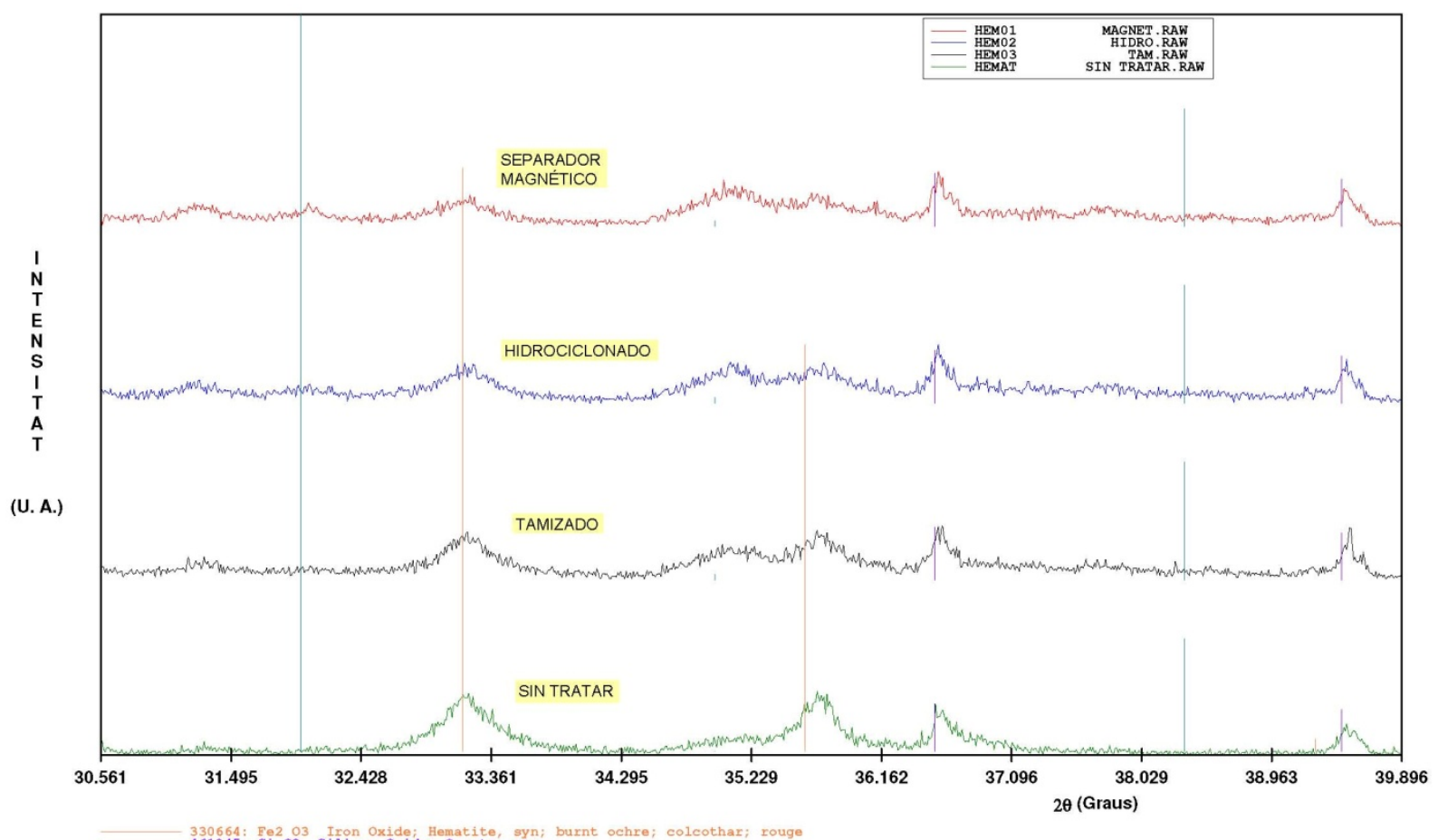

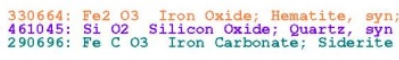

Figura 51. Detalle del pico de la hematita correspondiente a los difractogramas de las muestras de arcilla (N-A-Cr) tratadas.

La intensidad del pico principal de difracción de rayos-X correspondiente a la hematita $(2 \theta=33.1)$, disminuye conforme se consigue reducir el porcentaje de $\mathrm{Fe}_{2} \mathrm{O}_{3}$, el cual se ha medido por fluorescencia de rayos-X. Además, se puede ver claramente que la arcilla (N-A-Cr) contiene una cantidad minúscula de carbonato de hierro o siderita $(2 \theta=31.9)$, comparado con la señal de la hematita.

Por último, se indica en la Tabla XXXIX se muestra un resumen de los mejores resultados obtenidos en las tres técnicas ensayadas para la eliminación del contenido en hierro de la arcilla de Ciudad Real, (N-A-Cr), rica en hematita. 
Tabla XXXIX. Resumen de los resultados obtenidos en la arcilla (N-A-cr) tras la aplicación de las técnicas para disminuir el porcentaje de hematita.

\begin{tabular}{|c|c|c|c|}
\hline TÉCNICA & $\begin{array}{c}\% \mathrm{Fe}_{2} \mathrm{O}_{3} \\
\text { de partida }\end{array}$ & $\begin{array}{c}\% \mathrm{Fe}_{2} \mathrm{O}_{3} \\
\text { resultante }\end{array}$ & $\begin{array}{c}\% \mathrm{Fe}_{2} \mathrm{O}_{3} \\
\text { eliminado }\end{array}$ \\
\hline TAMIZADO & 6.05 & 2.17 & 64 \\
\hline HIDROCICLÓN & 2.51 & 1.99 & 46 \\
\hline SEPARADOR & 2.17 & 1.18 & 41 \\
\hline
\end{tabular}

Como puede observarse en Tabla XXXIX, el mayor porcentaje eliminado ha sido a través del tamizado (64\% en peso). Sin embargo, éste no ha sido suficiente, ya que el contenido de la hematita en la arcilla todavía es muy alto (2.17\% $\mathrm{Fe}_{2} \mathrm{O}_{3}$ ). Así pues, con el separador magnético, se consigue eliminar un 46\% de $\mathrm{Fe}_{2} \mathrm{O}_{3} \mathrm{Y}$ queda en la arcilla el valor del $1.18 \%$ del mismo.

\subsection{Disminución del contenido en materia orgánica.}

\subsubsection{Tratamiento de las arcillas españolas con horno eléctrico tipo mufla.}

De cara a disminuir el contenido de materia orgánica que presentan las arcillas españolas de Teruel, con vistas a su posible aplicación, se ha tratado la arcilla (N-A-te) con un horno mufla de Pirometrol perteneciente al laboratorio de Grupo Tierra Atomizada. Para ello, se ha calcinado la arcilla en diferentes pruebas, modificando tres variables consideradas: granulometría de la muestra, temperatura de cocción y tiempo de permanencia en el 
interior del horno. Las muestras calcinadas se han analizado con el análisis térmico ATD/TG y con el analizador de carbono, (TOC).

Se ha realizado un estudio de tratamiento térmico con el propósito de eliminar la materia orgánica de la arcilla de Teruel, de referencia, (N-A-te), por ser ésta la que más contenido de materia orgánica dispone, llevando a cabo los análisis correspondientes a través del ATD/TG. Se ha programado el ATD/TG con un ciclo de calentamiento de la muestra original entre $50^{\circ} \mathrm{C}$ y $1150^{\circ} \mathrm{C}$, con una velocidad de calentamiento de $10^{\circ} \mathrm{C} / \mathrm{minuto}$.

Con el fin de obtener información sobre las pérdidas de masa debidas a la combustión de materia orgánica, intentando no alterar la estructura de la caolinita, se han ensayado tratamientos previos a la muestra original entre los rangos de temperatura comprendidos entre $250^{\circ} \mathrm{C}$ y $600^{\circ} \mathrm{C}$, variando los tiempos de retención a dichas temperaturas desde 30 minutos hasta 240 minutos. La granulometría que presenta la arcilla original (N-Ate), el 100\% del tamaño de grano por debajo de $1 \mathrm{~cm}$ de diámetro, ha permanecido constante durante la realización de estas pruebas.

Así, se ha podido observar en el ATD/TG (Figura 52) de la muestra original (sin tratar) que aparece un pico exotérmico entre $349^{\circ} \mathrm{C}$ y $417^{\circ} \mathrm{C}$. Dicho pico estaría relacionado con la combustión de la materia orgánica presente en la muestra. Aparece también un pico endotérmico entre $448^{\circ} \mathrm{C}$ y $558^{\circ} \mathrm{C}$ (máximo a $516^{\circ} \mathrm{C}$ ), el cual se puede relacionar con la deshidroxilación de la caolinita. Por último, aparece un pico exotérmico, sin cambio de masa en el TG, en el rango de temperaturas entre $934{ }^{\circ} \mathrm{C}$ y $976^{\circ} \mathrm{C}$ (máximo a $953^{\circ} \mathrm{C}$ ), que está relacionado con la formación de la fase mullita (véase apartado 1.4.4). 


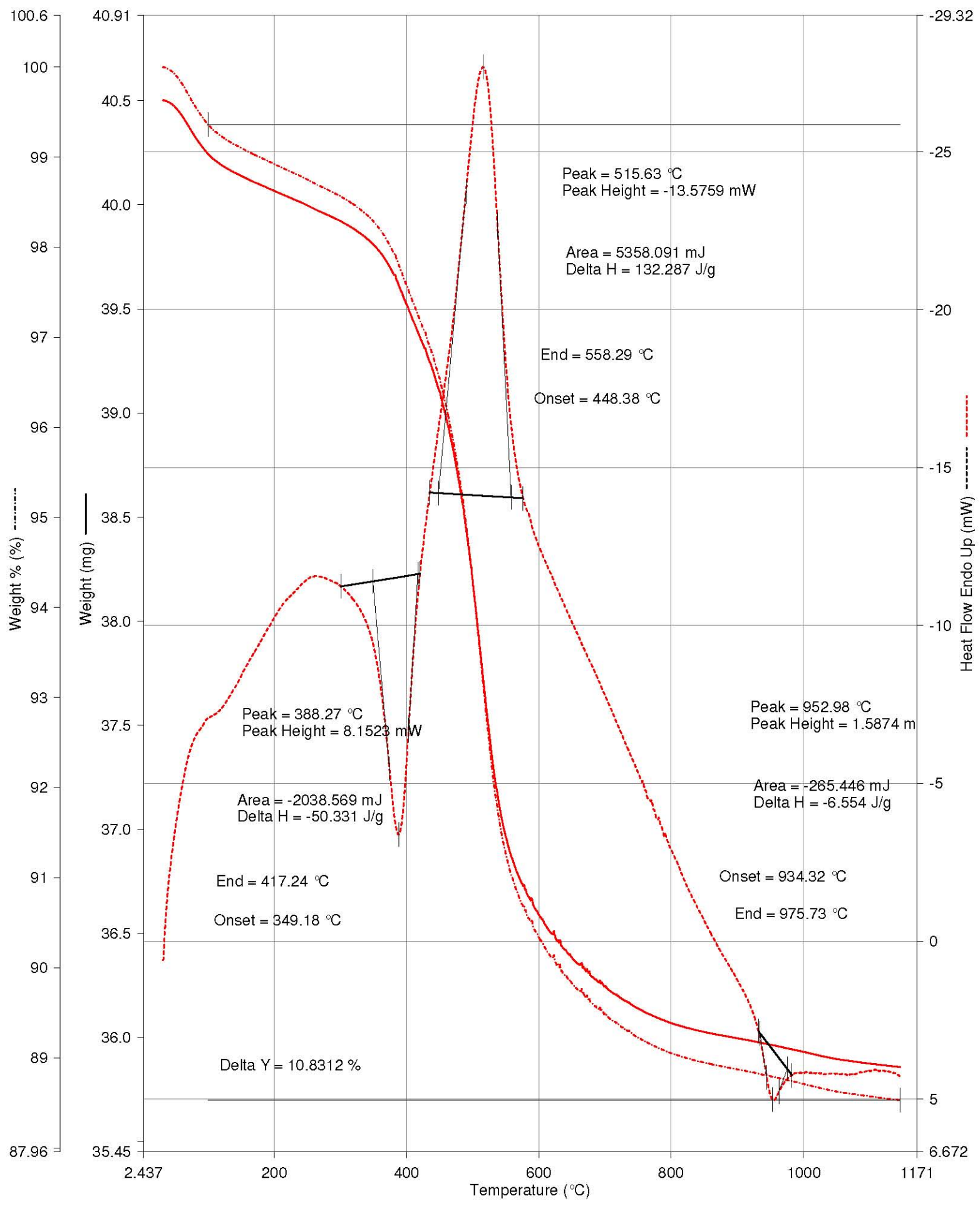

Figura 52. Análisis ATD/TG de la muestra original de referencia (N-A-te), sin tratar. 
Para obtener información acerca de la cantidad de materia orgánica combustionada, sin que se altere la estructura de la caolinita, la arcilla original se ha tratado térmicamente en un horno tipo mufla, antes de ser sometida al análisis del ATD/TG. Todos los resultados obtenidos se recogen en las tablas del apartado 8.14 y 8.15 del apéndice. Se destaca en los valores que aparecen en estas tablas que la muestra original presenta una pérdida total de masa en el TG del 10.83\%. Así, se han ensayado diferentes pruebas, referenciadas en la Tabla XL. En dicha tabla se puede observar que la presencia de materia orgánica (reflejada a través de los picos del ATD, entre $340^{\circ} \mathrm{C}$ y $\left.420^{\circ} \mathrm{C}\right)$, desaparece ya en el tratamiento previo de la arcilla de $350^{\circ} \mathrm{C}$, durante 90 minutos. Al mismo tiempo, el pico endotérmico del ATD correspondiente a la deshidroxilación de la caolinita (intervalo de temperaturas que aparece entre $450^{\circ} \mathrm{C}$ y $560^{\circ} \mathrm{C}$ ), se ha alterado sólo ligeramente, por el tratamiento térmico previo en el horno tipo mufla. No obstante esto, de cara a un posible tratamiento industrial y a fin de acortar los tiempos, se han estudiado temperaturas más altas, como a $400^{\circ} \mathrm{C}$ durante 30 minutos, donde el área del pico correspondiente a la deshidroxilación de la caolinita se mantiene en valores similares a los obtenidos a temperaturas inferiores, a la vista de los datos del ATD. En la Tabla XLI se indican las pérdidas de masa (TG) obtenidas para cada uno de los picos analizados. 
Tabla XI. Pruebas realizadas con la arcilla de referencia (N-A-te), en un horno eléctrico tipo mufla, con los correspondientes resultados obtenidos con el ATD/TG.

\begin{tabular}{|c|c|c|c|c|c|}
\hline \multicolumn{3}{|c|}{ HORNO ELÉCTRICO } & \multicolumn{3}{|c|}{ RESULTADDOS OBTENIDOS CON EL ATD/TG } \\
\hline PRUEBA & $\begin{array}{c}\text { TEMPERATURA } \\
\text { MÁXIMA } \\
\left({ }^{\circ} \mathrm{C}\right)\end{array}$ & $\begin{array}{c}\text { TIEMPO } \\
\text { (MIN) }\end{array}$ & $\begin{array}{l}\text { PÉRDIDA } \\
\text { DE MASA } \\
\text { TG (\%) }\end{array}$ & $\begin{array}{c}\text { Área pico (mJ) } \\
\left(340^{\circ} \mathrm{C}-420^{\circ} \mathrm{C}\right) \\
\text { Exotérmico }\end{array}$ & $\begin{array}{c}\text { Área pico (mJ) } \\
\left(450^{\circ} \mathrm{C}-560^{\circ} \mathrm{C}\right) \\
\text { Endotérmico }\end{array}$ \\
\hline 0 & - & - & 10,83 & -2038 & 5358 \\
\hline 1 & 250 & 120 & 10,78 & -2083 & 5284 \\
\hline 2 & 250 & 240 & 10,77 & -1914 & 5156 \\
\hline 3 & 300 & 120 & 10,56 & -546 & 5283 \\
\hline 4 & 300 & 240 & 10,36 & -194 & 5109 \\
\hline 5 & 350 & 30 & 9,82 & -685 & 5128 \\
\hline 6 & 350 & 60 & 9,71 & -542 & 5042 \\
\hline 7 & 350 & 90 & 9,55 & - & 4854 \\
\hline 8 & 350 & 120 & 9,35 & - & 4850 \\
\hline 9 & 350 & 240 & 9,41 & - & 4746 \\
\hline 10 & 400 & 30 & 9,42 & - & 4944 \\
\hline 11 & 400 & 60 & 9,14 & - & 4881 \\
\hline 12 & 400 & 120 & 9,13 & - & 4706 \\
\hline 13 & 400 & 240 & 9,22 & - & 4675 \\
\hline 14 & 500 & 30 & 8,10 & - & 4172 \\
\hline 15 & 500 & 60 & 7,39 & - & 3776 \\
\hline 16 & 500 & 120 & 5,39 & - & 640 \\
\hline 17 & 600 & 30 & 3,11 & - & 688 \\
\hline 18 & 600 & 60 & 3,43 & - & 141 \\
\hline 19 & 600 & 120 & 3,12 & - & 87 \\
\hline
\end{tabular}

${ }^{1}$ Pico exotérmico de combustión de la materia orgánica presente en la muestra.

${ }^{2} \mathrm{Pico}$ endotérmico de deshidroxilación de la caolinita presente en la muestra 
Tabla XII. Pérdidas de masa (TG) referentes al área del pico exotérmico en el ATD correspondientes a la combustión de la materia orgánica y a la deshidroxilación de la caolinita.

\begin{tabular}{|c|c|c|c|c|}
\hline \multicolumn{3}{|c|}{ HORNO ELÉCTRICO } & \multicolumn{2}{|c|}{ PÉRDIDA DE MASA TG (\%) } \\
\hline PRUEBA & $\begin{array}{c}\text { TEMPERATURA } \\
\text { MÁXIMA } \\
\left({ }^{\circ} \mathrm{C}\right)\end{array}$ & $\begin{array}{c}\text { TIEMPO } \\
\text { (MIN) }\end{array}$ & $\begin{array}{c}\text { Pico (mJ) } \\
\left(340^{\circ} \mathrm{C}-420^{\circ} \mathrm{C}\right) \\
\text { Exotérmico }\end{array}$ & $\begin{array}{c}\text { Pico (mJ) } \\
\left(450^{\circ} \mathrm{C}-560^{\circ} \mathrm{C}\right) \\
\text { Endotérmico }{ }^{1}\end{array}$ \\
\hline 0 & - & - & 2,1078 & 8,7234 \\
\hline 1 & 250 & 120 & 2,0987 & 8,6841 \\
\hline 2 & 250 & 240 & 2,0561 & 8,7174 \\
\hline 3 & 300 & 120 & 1,8420 & 8,7157 \\
\hline 4 & 300 & 240 & 1,8391 & 8,5216 \\
\hline 5 & 350 & 30 & 1,8262 & 7,9954 \\
\hline 6 & 350 & 60 & 1,7263 & 7,9841 \\
\hline 7 & 350 & 90 & 1,5770 & 7,9748 \\
\hline 8 & 350 & 120 & 1,5452 & 7,8066 \\
\hline 9 & 350 & 240 & 1,5347 & 7,8713 \\
\hline 10 & 400 & 30 & 1,5174 & 7,8987 \\
\hline 11 & 400 & 60 & 1,3313 & 7,8071 \\
\hline 12 & 400 & 120 & 1,2446 & 7,8826 \\
\hline 13 & 400 & 240 & 1,2833 & 7,9337 \\
\hline 14 & 500 & 30 & 1,1696 & 6,9324 \\
\hline 15 & 500 & 60 & 1,1570 & 6,2344 \\
\hline 16 & 500 & 120 & 1,1533 & 4,2353 \\
\hline 17 & 600 & 30 & 0,9832 & 2,1266 \\
\hline 18 & 600 & 60 & 0,9828 & 2,4492 \\
\hline 19 & 600 & 120 & 0,9972 & 2,1251 \\
\hline
\end{tabular}

${ }^{1}$ Pico endotérmico de deshidroxilación de la caolinita presente en la muestra.

En la Tabla XLII, se muestran los porcentajes de pérdidas de masa (TG) en cada una de las pruebas realizadas, respecto de la muestra sin tratar, para el pico exotérmico correspondiente a la 
combustión de la materia orgánica y para el pico endotérmico que representa la deshidroxilación de la caolinita. Como se puede observar en la tabla, a la temperatura de $400^{\circ} \mathrm{C}$ y 30 minutos, se consigue reducir sobre el $28 \%$ de materia orgánica, respecto a la de la arcilla sin tratar, mientras que la deshidroxilación de la caolinita ha disminuido el 9\%. Estos mismos resultados, como se indica en la propia Tabla XLII, se pueden obtener a temperaturas más bajas, pero prolongando mucho más los tiempos de tratamiento. Por contrario, si el tratamiento térmico a la arcilla (N-A-te) se realiza a temperaturas superiores a $400^{\circ} \mathrm{C}$, el porcentaje de materia orgánica eliminado es más alto, pero también ocurre que el porcentaje de agua procedente de la deshidroxilación de la caolinita disminuye en mayor medida. Así pues, parece ser que el tratamiento a $400^{\circ} \mathrm{C}$ y 30 minutos serían las condiciones más óptimas del tratamiento.

Para una mayor claridad, en la Figura 53, aparecen indicadas las transformaciones que ocurren en cada uno de los rangos de temperatura ensayados, durante los tratamientos previos realizados a la arcilla de referencia ( $\mathrm{N}-\mathrm{A}$-te) para 30 minutos de permanencia a cada una de las temperaturas indicadas. 
Tabla XIII. Porcentaje de pérdidas de masa (TG) respecto de la muestra sin tratar.

\begin{tabular}{|c|c|c|c|c|}
\hline \multicolumn{3}{|c|}{ HORNO ELÉCTRICO } & \multicolumn{2}{|c|}{$\begin{array}{l}\text { \%PÉRDIDA DE MASA TG RESPECTO DE } \\
\text { LA MUESTRA SIN TRATAR， (ATD/TG) }\end{array}$} \\
\hline PRUEBA & $\begin{array}{c}\text { TEMPERATURA } \\
\text { MÁXIMA } \\
\left({ }^{\circ} \mathrm{C}\right)\end{array}$ & $\begin{array}{l}\text { TIEMPO } \\
\text { (MIN) }\end{array}$ & $\begin{array}{c}\text { Pico } \\
\left(340^{\circ} \mathrm{C}-420^{\circ} \mathrm{C}\right) \\
\text { Exotérmico }\end{array}$ & $\begin{array}{c}\text { Pico (mJ) } \\
\left(450^{\circ} \mathrm{C}-560^{\circ} \mathrm{C}\right) \\
\text { Endotérmico }\end{array}$ \\
\hline 0 & - & - & - & - \\
\hline 1 & 250 & 120 & 0 & 0 \\
\hline 2 & 250 & 240 & 2 & 0 \\
\hline 3 & 300 & 120 & 13 & 0 \\
\hline 4 & 300 & 240 & 13 & 2 \\
\hline 5 & 350 & 30 & 13 & 8 \\
\hline 6 & 350 & 60 & 18 & 8 \\
\hline 7 & 350 & 90 & 25 & 9 \\
\hline 8 & 350 & 120 & 27 & 11 \\
\hline 9 & 350 & 240 & 27 & 10 \\
\hline 10 & 400 & 30 & 28 & 9 \\
\hline 11 & 400 & 60 & 37 & 11 \\
\hline 12 & 400 & 120 & 41 & 10 \\
\hline 13 & 400 & 240 & 39 & 9 \\
\hline 14 & 500 & 30 & 45 & 21 \\
\hline 15 & 500 & 60 & 45 & 29 \\
\hline 16 & 500 & 120 & 45 & 51 \\
\hline 17 & 600 & 30 & 53 & 76 \\
\hline 18 & 600 & 60 & 53 & 72 \\
\hline 19 & 600 & 120 & 53 & 76 \\
\hline
\end{tabular}

${ }^{1}$ Referentes al área del pico exotérmico en el ATD correspondientes a la combustión de la materia orgánica y a la deshidroxilación de la caolinita. 


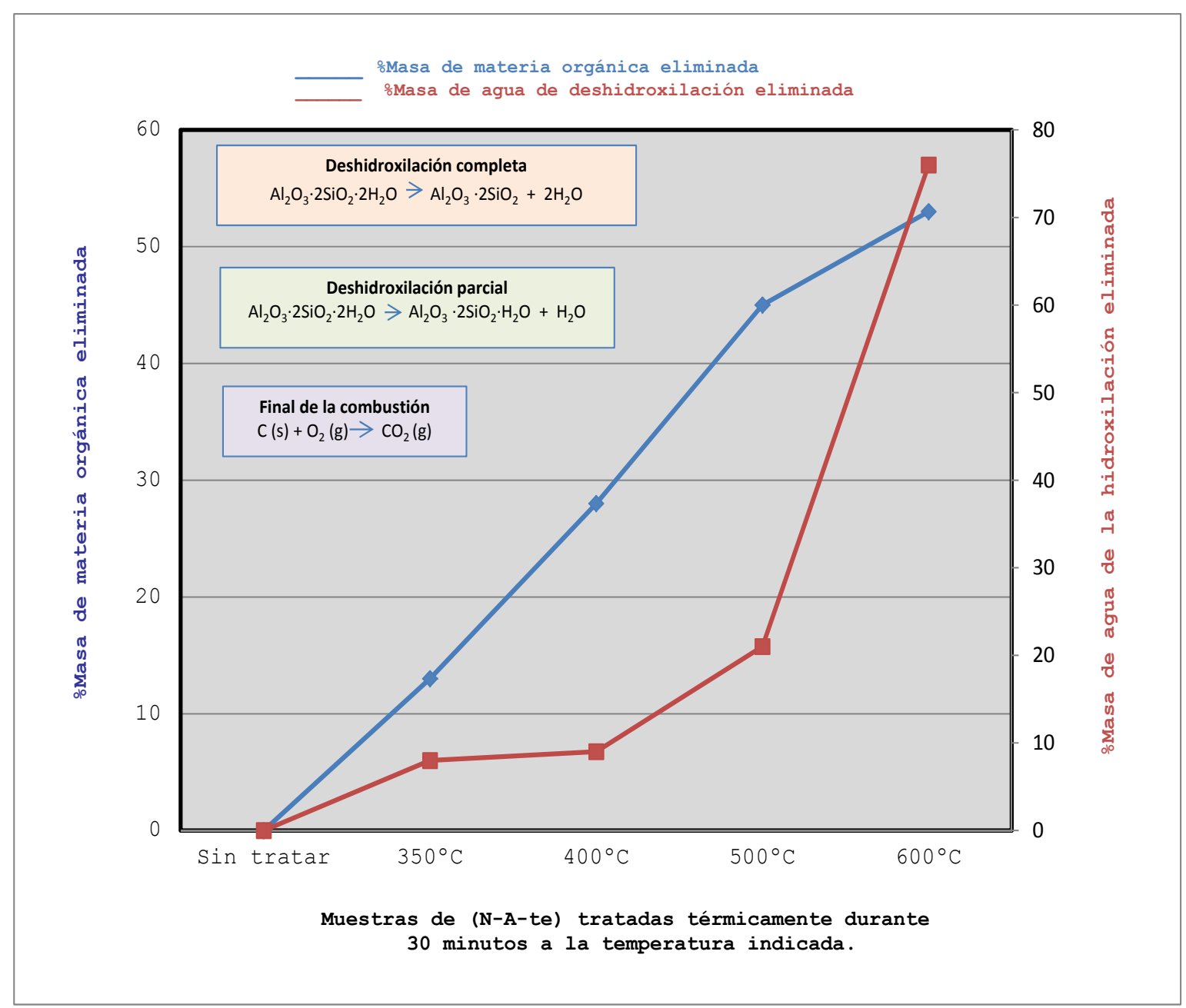

Figura 53. Procesos que ocurren durante el tratamiento térmico de la arcilla (N-A-te), durante 30 minutos de permanencia.

Con el objeto de poder evaluar la posibilidad de utilizar la arcilla (N-A-te) tratada a $400^{\circ} \mathrm{C} / 30$ minutos, para su uso en las pastas cerámicas, se ha hecho un estudio comparativo con la misma arcilla sin tratar y con dos tipos de arcillas de importación: arcillas $(A-I-1)$ y $(A-I-2)$, procedentes de Ucrania.

El estudio se ha centrado en poder analizar el contenido de carbono orgánico (carbono unido a estructuras orgánicas), presente en las muestras arcillosas, y que podría derivar en la formación 
de defectos en las piezas cerámicas prensadas como es la formación del "corazón negro" (véase apartado 1.4.3). También se ha medido el índice de plasticidad para poder comparar esta propiedad con respecto a las arcillas tratadas y sin tratar térmicamente y también con respecto a las arcillas de importación. En cuanto a la compacidad y prensabilidad de la arcilla de Teruel (N-A-te), comparándolas con respecto a las arcillas de Ucrania, se ha realizado la confección de probetas en forma de pastillas prensadas a diferentes presiones de prensado para que todas ellas presentasen una compactación similar, medida a través de la densidad aparente en seco. Dichas pastillas han sido calcinadas a $1185^{\circ} \mathrm{C}$ con un ciclo similar al del gres porcelánico ya indicado anteriormente (véase apartado 3.5.3, Figura 49). Con las pastillas cocidas, se ha estudiado el porcentaje de contracción lineal y el porcentaje de absorción de agua, obteniendo los correspondientes diagramas de gresificación que aparecen en el apéndice (apartado $8.2,8.3,8.5$ y 8.10). También se han analizado las coordenadas cromáticas que presentan las diferentes arcillas cocidas, utilizando para ello el espectrofotómetro y parametrizando las coordenadas a través del sistema CIE-Lab (véase el apartado 3.1.8.). Todos los resultados obtenidos se reflejan en la Tabla XLIII. 
Tabla XIIII. Comparación cerámica de la arcilla (N-A-te) calcinada con la misma arcilla sin tratar y con arcillas de importación.

\begin{tabular}{|c|c|c|c|c|c|c|c|c|c|}
\hline ARCILLAS & $\begin{array}{l}\text { \%CARBONO } \\
\text { ORGÁNICO }{ }^{1}\end{array}$ & $\begin{array}{l}\text { I. P. } \\
\left(\frac{\circ}{0}\right)^{2}\end{array}$ & $\begin{array}{c}\mathrm{P} \\
\left(\mathrm{kg} / \mathrm{cm}^{2}\right)\end{array}$ & $\begin{array}{c}\text { Dap. }^{3} \\
\text { seco } \\
\left(\mathrm{g} / \mathrm{cm}^{3}\right)\end{array}$ & $\begin{array}{c}\text { C.I. } \\
\left(\frac{\circ}{0}\right)\end{array}$ & $\begin{array}{l}\text { A. a. } \\
\text { (\%) }\end{array}$ & $\mathrm{L} *$ & $a *$ & $b *$ \\
\hline$(A-I-1)$ & 0,08 & 28,74 & 551 & 1,83 & 9,23 & 2,64 & 82,82 & 2,27 & 13,91 \\
\hline$(A-I-2)$ & 0,05 & 27,22 & 235 & 1,88 & 8,22 & 1,43 & 75,27 & 2,74 & 12,54 \\
\hline $\begin{array}{c}(\mathrm{N}-\mathrm{A}-\mathrm{te}) \\
\text { sin tratar }\end{array}$ & 0,52 & 28,55 & 553 & 1,86 & 10,11 & 0,61 & 65,4 & 4,15 & 17,54 \\
\hline $\begin{array}{c}\text { (N-A-te) } \\
\text { calcinada } \\
400^{\circ} \mathrm{C}-30 \mathrm{~min}\end{array}$ & 0,10 & 23,86 & 553 & 1,81 & 11,33 & 0,55 & 69,41 & 4,18 & 18,89 \\
\hline
\end{tabular}

${ }^{1}$ Indice de plasticidad de Pfefferkorn.

${ }^{2}$ Densidad aparente de las probetas secas (método de inmersión en mercurio).

${ }^{3}$ Medido a través del analizador de carbono (TOC).

A la vista de los resultados obtenidos en la Tabla XLIII, se puede indicar lo siguiente. En primer lugar, la presencia de materia orgánica, reflejada a través del análisis del carbono orgánico, muestra que las arcillas de Ucrania presentan menos materia orgánica que la arcilla española de Teruel (N-A-te). Se observa también que la reducción de materia orgánica durante el tratamiento térmico ha sido significativamente eliminado (del orden de cinco veces menos). Aun así, el contenido de materia orgánica de la arcilla (N-A-te) tratada es ligeramente mayor que el de las arcillas de importación. También el índice de plasticidad de la arcilla (N-A-te) tratada, se ha visto ligeramente afectado. Esto estaría de acuerdo con que durante el tratamiento térmico a que ha sido sometida la arcilla, se haya afectado parcialmente a la estructura de la caolinita, la cual influye directamente en la plasticidad de la misma. 
Es interesante observar en los valores reflejados en la Tabla XLIII, que la arcilla (N-A-te) tratada se compacta algo menos que el resto de las arcillas que se comparan, lo cual puede influir en el ligero aumento de los valores de contracción lineal (11.33\%). El grado de sinterización, medido mediante la absorción de agua (A.a.) de la arcilla de Teruel es mayor que la arcilla de importación de Ucrania y se acentúa en el caso de la arcilla (N-Ate) tratada. Por último, los valores de las coordenadas cromáticas señalan un mayor grado de blancura en las arcillas de importación (coordenada L* mayor), frente a las arcillas de Teruel, si bien en el caso de la arcilla tratada presenta una mayor blancura que la arcilla sin tratar (la coordenada $L^{*}$ varía de 69.41, tratada a 65.40, sin tratar).

El siguiente objetivo llevado a cabo de cara a la utilización industrial de la arcilla (N-A-te) tratada a $400^{\circ} \mathrm{C}$ durante 30 minutos, ha sido estudiar la influencia de la distribución granulométrica (tamaño de los granos) en la combustión de la materia orgánica presente en la misma. Para ello, se ha ensayado la variación de tres distribuciones granulométricas. De este modo, se ha procedido a molturar mediante un molino desmenuzador, cortando a tres cortes distintos, con lo cual se modifica el tamaño de corte, de menor a mayor (de M1 a M3). La distribución granulométrica para cada muestra, se indica en la Figura 54. En los tres casos la fracción mayor de $6 \mathrm{~mm}$ contiene gránulos o aglomerados de un tamaño medio que oscila entre 20 y 90 mm. 


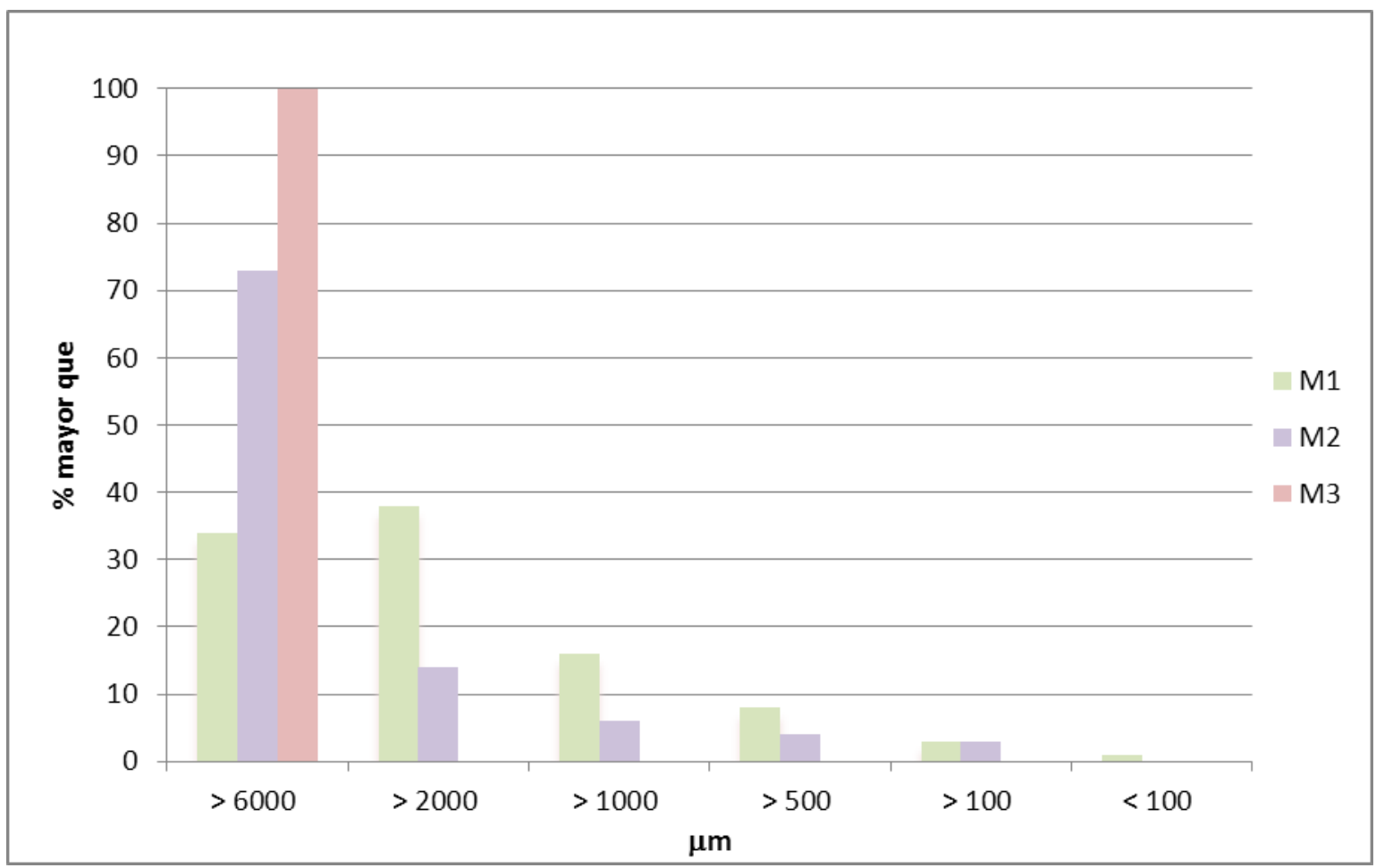

Figura 54. Distribución granulométrica de la arcilla (N-A-te) para su tratamiento a $400^{\circ} \mathrm{C}$ y 30 minutos.

A continuación, las muestras de la arcilla (N-A-te) a diferentes distribuciones granulométricas (M1, M2 y M3) y tratadas a $400^{\circ} \mathrm{C}$ y 30 minutos, han sido estudiadas a través del análisis térmico (ATD/TG), cuyos resultados se muestran en la Tabla XLIV. Según los datos mostrados en esta tabla, sí que parece observarse una influencia entre el tamaño de los granos y la combustión de la materia orgánica, ya que a medida que aumenta el tamaño de los granos (muestra M1 a M3), el área del pico exotérmico asignado a la combustión de la materia orgánica, es mayor. 
Tabla XLIV. Análisis térmico ATD/TG (entre $50^{\circ} \mathrm{C}$ y $1150^{\circ} \mathrm{C}$ ) de las muestras de (N-A-te), tratadas a $400^{\circ} \mathrm{C}$ y 30 minutos, preparadas a diferentes granulometrías (M1 a M3).

\begin{tabular}{|c|c|c|c|c|c|c|c|c|c|c|c|c|c|}
\hline \multicolumn{2}{|c|}{$\begin{array}{l}\text { Calentamiento } \\
\text { de } 50^{\circ} \mathrm{C}-1150^{\circ} \mathrm{C} \\
\text { a } 10^{\circ} \mathrm{C} / \mathrm{min}\end{array}$} & \multicolumn{4}{|c|}{$\begin{array}{l}\text { Pico exotérmico } \\
\text { de la combustión } \\
\text { de la materia } \\
\text { orgánica }\end{array}$} & \multicolumn{4}{|c|}{$\begin{array}{l}\text { Pico endotérmico de } \\
\text { deshidroxilación } \\
\text { de la caolinita }\end{array}$} & \multicolumn{4}{|c|}{$\begin{array}{l}\text { Pico exotérmico de } \\
\text { formación de mullita }\end{array}$} \\
\hline $\begin{array}{l}\text { ATD-TG de } \\
(\mathrm{N}-\mathrm{A}-\mathrm{te})\end{array}$ & $\begin{array}{l}\text { PÉRDIDA } \\
\text { DE MASA } \\
\text { TOTAL } \\
\text { TGA (\%) }\end{array}$ & $\begin{array}{l}\text { ONSET } \\
\left({ }^{\circ} \mathrm{C}\right)\end{array}$ & $\begin{array}{c}\mathrm{T} \\
\mathrm{MAX} \\
\left({ }^{\circ} \mathrm{C}\right)\end{array}$ & $\begin{array}{c}\text { T END } \\
\left({ }^{\circ} \mathrm{C}\right)\end{array}$ & $\begin{array}{l}\text { AREA } \\
\text { PICO } \\
(\mathrm{mJ})\end{array}$ & $\begin{array}{c}\text { ONSET } \\
\left({ }^{\circ} \mathrm{C}\right)\end{array}$ & $\left|\begin{array}{cc}\mathrm{T} & \mathrm{MAX} \\
\left({ }^{\circ} \mathrm{C}\right)\end{array}\right|$ & $\begin{array}{l}\mathrm{T} \text { END } \\
\left({ }^{\circ} \mathrm{C}\right)\end{array}$ & $\begin{array}{l}\text { AREA } \\
\text { PICO } \\
(\mathrm{mJ})\end{array}$ & $\begin{array}{c}\text { ONSET } \\
\left({ }^{\circ} \mathrm{C}\right)\end{array}$ & $\mid \begin{array}{cc}\mathrm{T} & \mathrm{MAX} \\
\left({ }^{\circ} \mathrm{C}\right)\end{array}$ & $\mid \begin{array}{cc}\mathrm{T} & \mathrm{END} \\
\left({ }^{\circ} \mathrm{C}\right)\end{array}$ & $\begin{array}{l}\text { AREA } \\
\text { PICO } \\
(\mathrm{mJ})\end{array}$ \\
\hline $\mathrm{M} 1$ & 9.45 & & & & & 446 & 515 & 557 & 5157 & 933 & 955 & 979 & -432 \\
\hline M2 & 9.74 & 382 & 426 & 365 & -390 & 464 & 520 & 557 & 5128 & 933 & 954 & 976 & -404 \\
\hline M3 & 9.93 & 359 & 433 & 355 & -440 & 466 & 515 & 555 & 5689 & 939 & 956 & 980 & -245 \\
\hline
\end{tabular}


También se ha analizado la presencia de materia orgánica en las arcillas a través del analizador de carbono orgánico (TOC), cuyos resultados se muestran en la Tabla XLV.

Tabla XLV. Variación del porcentaje de eliminación de carbono orgánico (TOC) con la granulometría de las muestras de (N-A-te) tratadas a $400^{\circ} \mathrm{C}$ y 30 minutos.

\begin{tabular}{|c|c|c|}
\hline MUESTRA & $\begin{array}{c}\text { \% carbono } \\
\text { orgánico presente }\end{array}$ & $\begin{array}{c}\text { \% Disminución } \\
\text { carbono orgánico }\end{array}$ \\
\hline M1 & 0.15 & 71 \\
\hline M2 & 0.26 & 35 \\
\hline M3 & 0.34 & \\
\hline
\end{tabular}

Como se puede observar, el tamaño de grano de la arcilla experimentada, la arcilla española (N-A-te), influye bastante en la proceso de calcinación. Para las condiciones ensayadas, se elimina hasta un 71\% del carbono orgánico en la muestra (M1) que presenta una granulometría más pequeña (cerca de un 88\% por debajo de $1000 \mathrm{\mu m})$. Esto podría explicarse ya que, conforme aumentan los tamaños de los granos, es más dificil que la energía térmica llegue al interior de las partículas y las etapas de transferencia de materia y de energía son más lentas.

Otra variable que puede influir en la eliminación de la materia orgánica, en orden a disminuir su temperatura, es la atmósfera del horno. Para ello, se ha ensayado una muestra de la arcilla (N-A-te) en el propio equipo de análisis térmico ATD/TG, variando para tal propósito, la naturaleza de la atmósfera de la combustión. Así, se ha introducido oxígeno puro en lugar de trabajar con la atmósfera ambiental y también se ha modificado el caudal de éste. Los resultados obtenidos aparecen en la Tabla XLVI. 
Tabla XLVI. Análisis térmico, ATD-TG, de $50^{\circ} \mathrm{C}$ a $1150^{\circ} \mathrm{C}$, de la arcilla (N-A-te) modificando la concentración y el caudal de oxígeno.

\begin{tabular}{|c|c|c|c|c|}
\hline \multirow{2}{*}{$\begin{array}{c}\text { ATD/TG } \\
\text { de la arcilla } \\
(\mathrm{N}-\mathrm{A}-\mathrm{te})\end{array}$} & \multicolumn{3}{|c|}{$\begin{array}{c}\text { Pico exotérmico de la combustión } \\
\text { de la materia orgánica }\end{array}$} \\
\cline { 2 - 5 } & $\begin{array}{c}\text { (ATD) } \\
\left({ }^{\circ} \mathrm{C}\right)\end{array}$ & $\begin{array}{c}\text { T MAX } \\
\left({ }^{\circ} \mathrm{C}\right)\end{array}$ & $\begin{array}{c}\text { T END } \\
\left({ }^{\circ} \mathrm{C}\right)\end{array}$ & $\begin{array}{c}\text { AREA } \\
\text { PICO } \\
(\mathrm{mJ})\end{array}$ \\
\hline AIRE $\left(21 \% \mathrm{O}_{2}-200 \mathrm{ml} / \mathrm{min}\right)$ & 362 & 392 & 413 & -918 \\
\hline $100 \% \mathrm{O}_{2}-200 \mathrm{ml} / \mathrm{min}$ & 352 & 376 & 394 & -724 \\
\hline $\mathbf{1 0 0} \mathrm{O}_{2}-\mathbf{4 0 0} \mathrm{ml} / \mathrm{min}$ & 349 & 374 & 393 & -862 \\
\hline
\end{tabular}

Parece observarse, a partir de los valores que aparecen en la Tabla XLVI, un avance en el inicio de la temperatura de combustión de la materia orgánica, en el caso de utilizar una atmósfera de $100 \%$ de oxígeno frente a una atmósfera de aire $\left(349^{\circ} \mathrm{C}\right.$ y $352^{\circ} \mathrm{C}$ frente a $362^{\circ} \mathrm{C}$ ). También se refleja esto, en el final de la combustión $\left(394^{\circ} \mathrm{C}\right.$ frente a $413^{\circ} \mathrm{C}$ en aire). La Figura 55 muestra gráficamente los resultados de la Tabla XLVI. Estos valores energéticos van a ser de interés para un proceso industrial, por el ahorro económico que supone. 


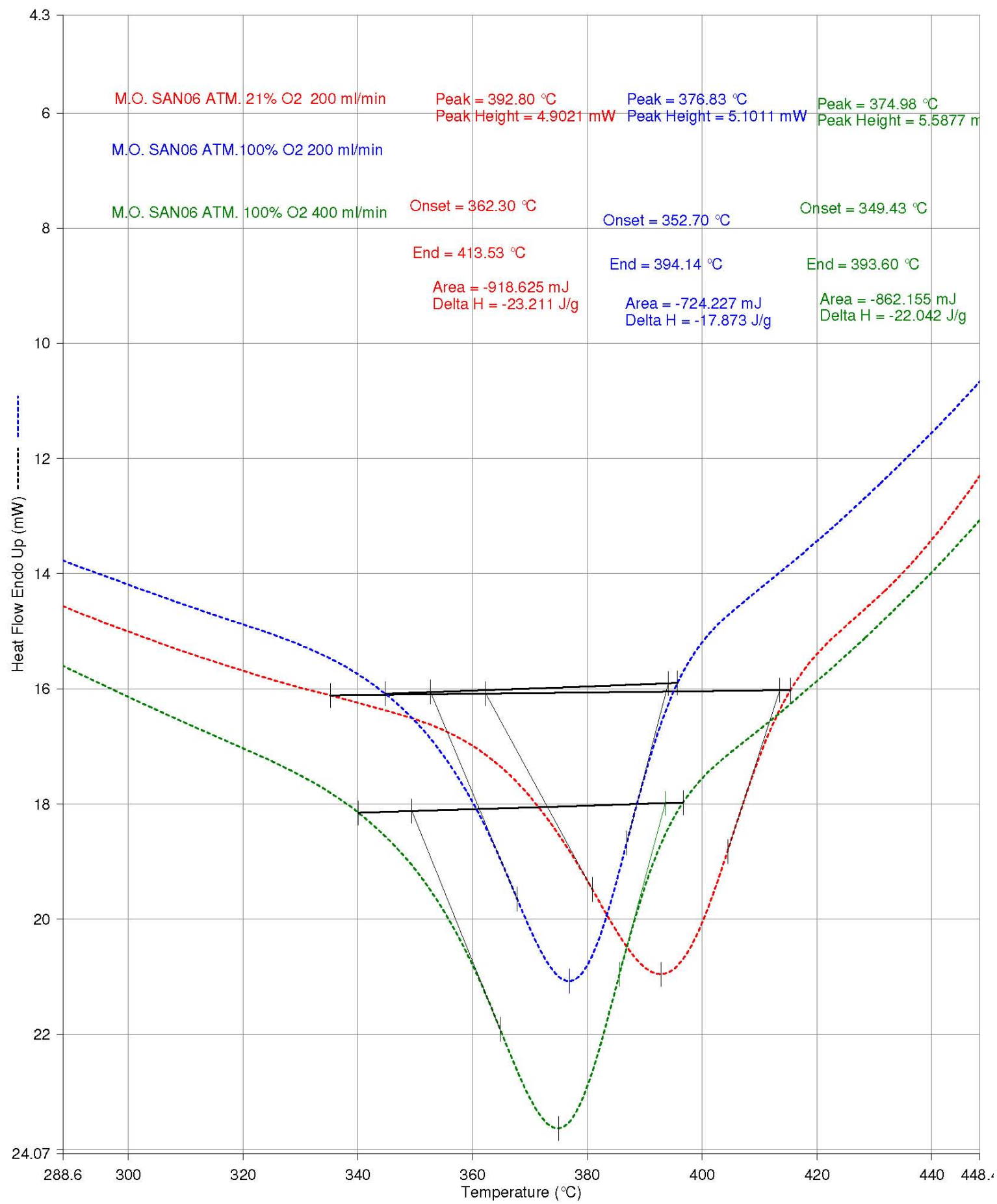

Figura 55. Análisis térmico, ATD/TG, correspondiente a la combustión de la materia orgánica de la arcilla (N-A-te), modificando la concentración de oxígeno de la atmósfera. 
Finalmente, se ha observado que las muestras de arcillas (N-Ate) calcinadas tienen una ligera tendencia a imantarse [86], [138], seguramente porque la siderita empieza a oxidarse a las temperaturas de calcinación sometidas. Para comprobar este hecho, se ha preparado una barbotina con la arcilla (N-A-te) calcinada a $400^{\circ} \mathrm{C}$ y durante 30 minutos, con un contenido en sólidos en masa del 30\% y se ha tamizado a $63 \mu \mathrm{m}$. El imán permanente utilizado consiste en una barra magnética de acero inoxidable con pastillas de neodimio en su interior, fabricada por la empresa italiana Bitecnology. Es de geometría cilíndrica (20mm diámetro y 150mm de altura) y, presenta una densidad de flujo de campo magnético nominal de $0.6 \mathrm{~T}$. La barra de imán se ha introducido en el interior de un litro de barbotina de la arcilla calcinada, unido al agitador mecánico de marca Heidolph, a mínima velocidad, durante unos 30 minutos. Transcurrido este tiempo, se ha recogido el rechazo de arcilla imantado sobre la barra magnética. Tras el secado de la muestra se ha procedido a realizar el análisis químico (FRX), indicando en la Tabla XLVII los resultados obtenidos.

Tabla XLVII. Análisis químico (FRX) de la muestra (N-A-te) tratada a $400^{\circ} \mathrm{C}$ y 30 minutos $y$ desferretizada.

\begin{tabular}{|c|c|c|c|c|c|c|c|c|c|c|}
\hline MUESTRAS & $\mathrm{Na}_{2} \mathrm{O}$ & $\mathbf{M g O}$ & $\mathrm{Al}_{2} \mathrm{O}_{3}$ & $\mathrm{SiO}_{2}$ & $\mathrm{~K}_{2} \mathrm{O}$ & $\mathrm{CaO}$ & $\mathrm{TiO}_{2}$ & $\mathbf{F e}_{2} \mathrm{O}_{3}$ & PPC & TOTAL \\
\hline $\begin{array}{r}(\mathrm{N}-\mathrm{A}-\mathrm{te}) \mathrm{calC} \\
400^{\circ} \mathrm{C}-30 \mathrm{~min}\end{array}$ & 0.21 & 0.66 & 30.5 & 51.1 & 2.74 & 0.25 & 0.82 & 3.19 & 9.34 & 99.6 \\
\hline $\begin{array}{c}(\mathrm{N}-\mathrm{A}-\mathrm{te}) \mathrm{calC} \\
400{ }^{\circ} \mathrm{C}-30 \mathrm{~min} \\
\text { desferretizada }\end{array}$ & 0.15 & 0.56 & 31.0 & 51.0 & 2.85 & 0.25 & 0.86 & 2.51 & 9.18 & 99.2 \\
\hline
\end{tabular}


Como puede observarse a partir de los datos de la Tabla XLVII, después del proceso de desferritización de la arcilla (N-A-te) tratada previamente a $400^{\circ} \mathrm{C}$ durante 30 minutos, se ha conseguido eliminar hasta un $21.6 \%$ de óxido de hierro.

\subsubsection{Tratamiento de las arcillas españolas con radiación de microondas.}

Con el objetivo de seguir en el estudio de la eliminación de la materia orgánica que presenta la arcilla española de Teruel (NA-te), se ha procedido a tratar de eliminar ésta a través de la radiación de microondas. Para ello, ha sido necesario estudiar el comportamiento dieléctrico de la misma.

Previamente al estudio, se ha llevado a cabo la selección de muestras correspondientes a la arcilla (N-A-te) o arcilla "total", desde el punto de vista de separar de la misma, las fracciones que presentan materia orgánica (fracción negra) de aquéllas otras que no la contienen (fracción blanca). Además, se ha comparado con una muestra de arcilla procedente de importación (arcilla A-I-1).

Las medidas de permeabilidad relativa se han realizado en los laboratorios del Departamento de Química Inorgánica y Orgánica de la Universitat Jaume $I$, en el rango de temperaturas, entre temperatura ambiente y $275^{\circ} \mathrm{C}$, a varias frecuencias: 50 y $100 \mathrm{kHz}$, tanto de la arcilla española, (N-A-te) "total" como de las fracciones, y de la arcilla de importación (A-I-1). La frecuencia utilizada va a cambiar el valor de la permitividad relativa pero no el perfil de la curva, por ello, sólo se muestran los valores obtenidos a una frecuencia de $100 \mathrm{kHz}$ en la Figura 56. Sin embargo, con el equipo disponible en el Departamento de Química Inorgánica y Orgánica de la Universitat Jaume I, no se puede alcanzar las frecuencias de trabajo del equipo de microondas. 
Los resultados indican que a la frecuencia utilizada, no se observan variaciones apreciables de la permitividad relativa, en el intervalo de temperaturas ensayado.

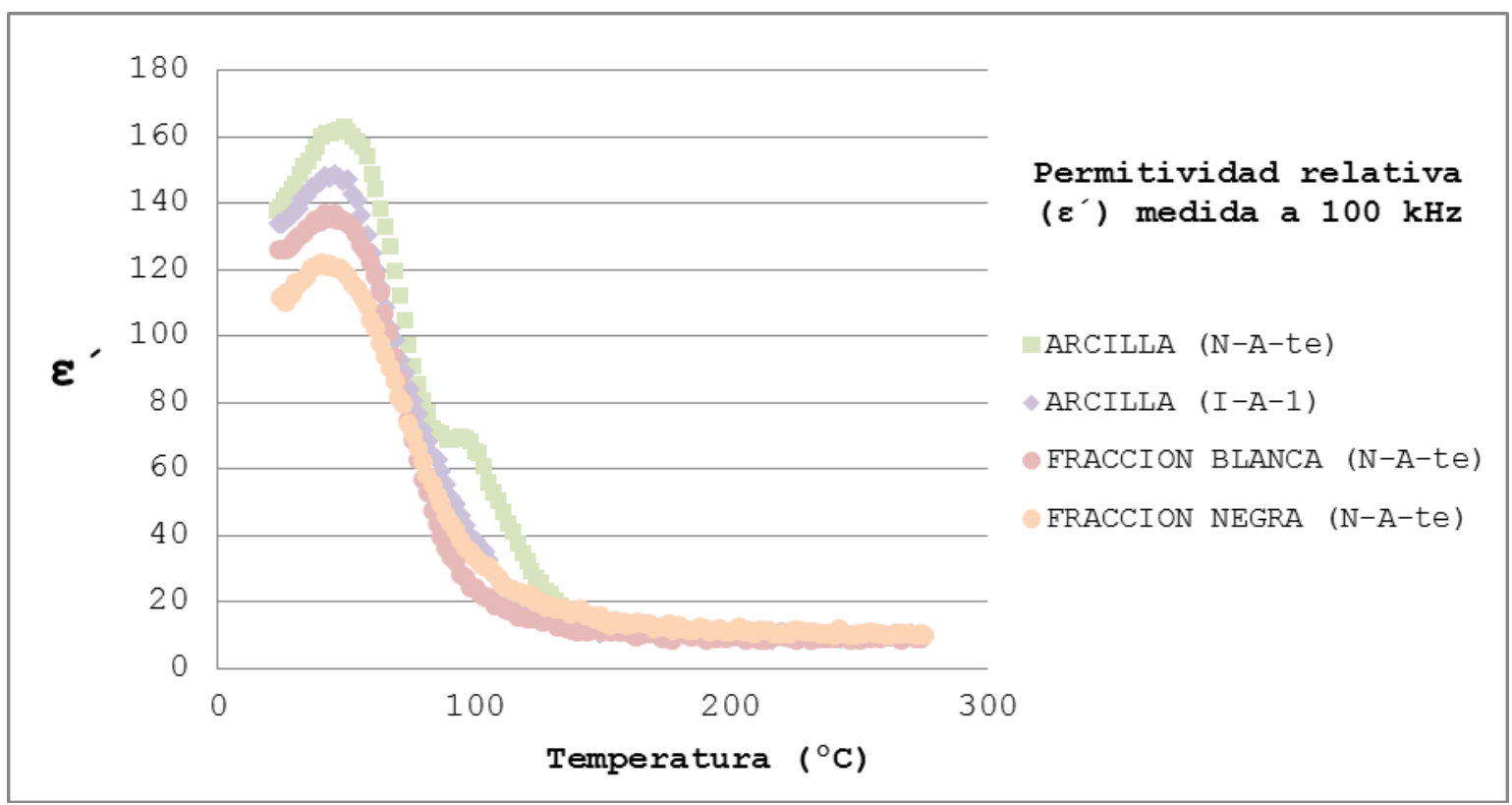

Figura 56. Comparación de permitividad relativa de diferentes arcillas españolas $y$ de importación ensayadas, medida a $100 \mathrm{kHz}$.

A la vista de estos resultados, se ha considerado continuar el trabajo en un futuro, mediante la colaboración con alguna empresa experta en la fabricación de hornos microondas.

\subsection{Introducción de residuos cocidos en la pasta}

\section{cerámica.}

En este apartado, se presentan los resultados de las composiciones de gres porcelánico y revestimiento indicadas anteriormente (Tabla XII y Tabla XIII). Así pues, en primer lugar, se presenta en la Tabla XLVIII, el análisis químico de las materias primas utilizadas en la formulación de las composiciones 
(las arcillas de importación, las arcillas españolas, el carbonato, los feldespatos y la arena).

Tabla XLVIII. Análisis químico (FRX) de las materias primas utilizadas.

\begin{tabular}{|c|c|c|c|c|c|c|c|c|c|c|}
\hline ARCILLA & $\mathrm{Na20}$ & $\mathrm{MgO}$ & $\mathrm{Al}_{2} \mathrm{O}_{3}$ & $\mathrm{SiO}_{2}$ & $\mathrm{~K}_{2} \mathrm{O}$ & $\mathrm{CaO}$ & $\mathrm{TiO}_{2}$ & $\mathrm{Fe}_{2} \mathrm{O}_{3}$ & PPC & TOTAL \\
\hline I-A-1 & 0,42 & 0,49 & 28,00 & 57,09 & 1,72 & 0,31 & 1,24 & 1,22 & 8,98 & 99,50 \\
\hline I-A-2 & 0.46 & 0.49 & 25.63 & 60.85 & 2.38 & 0.36 & 1.30 & 1.22 & 7.16 & 99.91 \\
\hline N-A-te & 0.22 & 0.71 & 26.01 & 57.86 & 3.00 & 0.24 & 0.95 & 2.70 & 8.00 & 99.72 \\
\hline N-B-te & 0.31 & 0.69 & 21.49 & 59.02 & 3.34 & 0.32 & 0.91 & 5.39 & 8.51 & 99.99 \\
\hline N-A-Cr & 0.82 & 0.07 & 23.45 & 59.77 & 2.72 & 0.01 & 1.14 & 6.05 & 5.76 & 99.90 \\
\hline CARBONATO & 0.04 & 0.19 & 0.25 & 1.00 & 0.05 & 54.0 & 0.02 & 0.10 & 42.67 & 99.55 \\
\hline \begin{tabular}{c} 
Fdto Na \\
\hline $\begin{array}{c}\text { Fdto } \\
\text { Na-Mg }\end{array}$
\end{tabular} & 9.64 & 0.13 & 17.69 & 70.62 & 0.04 & 0.86 & 0.0 & 0.09 & 0.15 & 99.72 \\
\hline \begin{tabular}{c} 
ARENA \\
\hline
\end{tabular} & 0.09 & 0.05 & 5.20 & 91.93 & 1.67 & 0.11 & 0.05 & 0.10 & 0.79 & 100.00 \\
\hline
\end{tabular}

Seguidamente, en la Tabla XLIX, se muestran los análisis químicos de los residuos cocidos (chamotas) procedentes de la producción de baldosas de pavimento y revestimiento de pasta blanca utilizados en este trabajo. Como se puede observar, los dos tipos de testillo cocido tienen composiciones muy similares a la pasta original, con un poco más de hierro, debido seguramente a la contaminación adquirida durante la manipulación del material. El testillo procedente de la fabricación de gres porcelánico presenta un contenido en sodio menor que el original y, de la misma manera, el testillo de porosa presenta una cantidad menor de óxido de calcio que la pasta de porosa original, puesto que durante el 
proceso de reciclado se altera ligeramente la composición original, ya que éste contiene además del soporte de la pasta, una capa de engobe y otra de esmalte.

Tabla XLIX. Análisis químico (FRX) del testillo cocido.

\begin{tabular}{|c|c|c|c|c|c|c|c|c|c|c|}
\hline Muestra & $\mathrm{Na}_{2} \mathrm{O}$ & $\mathrm{MgO}$ & $\mathrm{Al}_{2} \mathrm{O}_{3}$ & $\mathrm{SiO}_{2}$ & $\mathrm{~K}_{2} \mathrm{O}$ & $\mathrm{CaO}$ & $\mathrm{TiO}_{2}$ & $\mathrm{Fe}_{2} \mathrm{O}_{3}$ & $\mathrm{PPC}$ & $\mathrm{TOTAL}$ \\
\hline $\begin{array}{c}\text { TESTILLO } \\
\text { PORCELANICO }\end{array}$ & 2.94 & 1.35 & 19.6 & 69.5 & 3.34 & 0.65 & 0.64 & 1.24 & 0.27 & 99.6 \\
\hline $\begin{array}{c}\text { PASTA } \\
\text { PORCELÁNICO }\end{array}$ & 4.71 & 0.70 & 19.3 & 67.5 & 1.24 & 0.79 & 0.77 & 0.73 & 3.63 & 99.5 \\
\hline $\begin{array}{c}\text { TESTILLO } \\
\text { POROSA }\end{array}$ & 1.28 & 1.23 & 17.0 & 70.6 & 2.56 & 4.40 & 0.87 & 1.38 & 0.56 & 99.9 \\
\hline $\begin{array}{c}\text { PASTA } \\
\text { POROSA }\end{array}$ & 1.26 & 0.20 & 16.9 & 62.2 & 1.62 & 6.76 & 0.62 & 1.04 & 9.20 & 99.9 \\
\hline
\end{tabular}

En la Tabla L se muestra el análisis químico (FRX) realizado a las muestras de vidrio hueco y vidrio plano reciclados, utilizados para la formulación de las pastas.

Tabla L. Análisis químico del vidrio plano y del vidrio hueco procedente del reciclado del vidrio.

\begin{tabular}{|c|c|c|c|c|c|c|c|c|c|c|}
\hline Muestra & $\mathrm{Na}_{2} \mathrm{O}$ & $\mathbf{M g O}$ & $\mathrm{Al}_{2} \mathrm{O}_{3}$ & $\mathbf{S i O}_{2}$ & $\mathrm{~K}_{2} \mathrm{O}$ & $\mathbf{C a O}$ & $\mathbf{T i O}_{2}$ & $\mathbf{F e}_{2} \mathrm{O}_{3}$ & $\mathrm{PPC}$ & $\mathrm{TOTAL}$ \\
\hline $\begin{array}{c}\text { Vidrio } \\
\text { plano }\end{array}$ & 13.30 & 3.47 & 0.92 & 64.57 & 0.24 & 8.76 & 0.05 & 0.10 & 1.0 & 99.4 \\
\hline $\begin{array}{c}\text { Vidrio } \\
\text { hueco }\end{array}$ & 12.90 & 2.13 & 1.55 & 65.19 & 0.21 & 9.62 & 0.05 & 0.20 & 1.1 & 99.9 \\
\hline
\end{tabular}

Los resultados obtenidos indican que la composición de los dos tipos de vidrio ensayados es muy similar, destacando la alta concentración de óxido de sodio y de calcio que presentan, por lo que se consideran materiales portadores de agentes alcalinos y alcalinotérreos. 
Con vistas a estudiar el comportamiento fundente de los vidrios, éstos se han caracterizado a través de la microscopía de calentamiento, comparando con los feldespatos utilizados a lo largo del trabajo: feldespato sódico (Fdto $\mathrm{Na}$ ) y feldespato sódico-magnésico (Fdto Na-Mg). En la Tabla LI se muestran los resultados alcanzados. Según los resultados de la microscopía de calentamiento observada en dicha tabla, se observa que los vidrios alcanzan todas las fases a temperaturas inferiores a las de los feldespatos, por tratarse de material ya cocido y de naturaleza amorfa. Comparando los dos vidrios, el vidrio plano es más fundente, alcanzando las formas de media esfera y de fusión unos $60^{\circ} \mathrm{C}$ antes. Sin embargo, en este trabajo y con vistas a su posterior utilización industrial, se va a utilizar el vidrio hueco por ser más económico que el vidrio plano, para su posible utilización en la formulación de las pastas cerámicas. 
Tabla LI. Microscopía de calentamiento del vidrio plano y del vidrio hueco comparada con la de los feldespatos ensayados.

\begin{tabular}{|c|c|c|c|c|}
\hline Etapa & Vidrio & $\mathrm{T}\left({ }^{\circ} \mathrm{C}\right)$ & \% Area & Angulo $\left({ }^{\circ}\right)$ \\
\hline \multirow{4}{*}{ Sinterización } & Plano & 705 & 94 & 123 \\
\hline & Hueco & 695 & 95 & 125 \\
\hline & $\begin{array}{c}\text { Fdto } \mathrm{Na}- \\
\mathrm{Mg}^{1}\end{array}$ & 1165 & 93 & 131 \\
\hline & Fdto $\mathrm{Na}^{2}$ & 1180 & 94 & 106 \\
\hline \multirow{4}{*}{ Ablandamiento } & Plano & & & \\
\hline & Hueco & 735 & 88 & 122 \\
\hline & Fdto $\mathrm{Na}-\mathrm{Mg}$ & 1195 & 85 & 190 \\
\hline & Fdto Na & 1256 & 86 & 99 \\
\hline \multirow{4}{*}{ Esfera } & Plano & 980 & 55 & 90 \\
\hline & Hueco & & & \\
\hline & Fdto $\mathrm{Na}-\mathrm{Mg}$ & & & \\
\hline & Fdto $\mathrm{Na}$ & & & \\
\hline \multirow{4}{*}{ Media Esfera } & Plano & 1020 & 44 & 111 \\
\hline & Hueco & 1080 & 55 & 109 \\
\hline & Fdto $\mathrm{Na}-\mathrm{Mg}$ & 1300 & 50 & 120 \\
\hline & Fdto $\mathrm{Na}$ & 1436 & 49 & 94 \\
\hline \multirow{4}{*}{ Fusión } & Plano & 1080 & 33 & 133 \\
\hline & Hueco & 1140 & 42 & 126 \\
\hline & Fdto $\mathrm{Na}-\mathrm{Mg}$ & 1339 & 39 & 124 \\
\hline & Fdto $\mathrm{Na}$ & 1440 & 47 & 121 \\
\hline
\end{tabular}

${ }^{1}$ Feldespato sódico-magnésico.

${ }^{2}$ Eeldespato sódico. 


\subsubsection{Composiciones de gres porcelánico.}

Continuando con lo expuesto en el apartado 3.5, los resultados de las composiciones de pasta de gres porcelánico preparadas se indican en el apéndice (véase apartado 8.16 a 8.19). En la Tabla LII se presentan los parámetros cerámicos más importantes obtenidos antes de la cocción de las muestras.

Tabla LII. Parámetros cerámicos de las composiciones de porcelánico antes de la cocción.

\begin{tabular}{|c|c|c|c|c|c|}
\hline $\begin{array}{c}\text { Composiciones } \\
\text { de } \\
\text { Porcelánico }\end{array}$ & $\begin{array}{l}\text { \% CARBONO } \\
\text { ORGÁNICO }\end{array}$ & I.P. ${ }^{2}(\%)$ & $\mathrm{P}\left(\mathrm{kg} / \mathrm{cm}^{2}\right)$ & $\begin{array}{l}\text { Dap. }^{3} \\
\text { seco } \\
\left(\mathrm{g} / \mathrm{cm}^{3}\right)\end{array}$ & $\begin{array}{c}\text { RMCA } \\
\text { SECO } \\
\left(\mathrm{N} / \mathrm{mm}^{2}\right)\end{array}$ \\
\hline PORC-STD & 0,00 & 21,23 & 331 & 1,93 & 3,67 \\
\hline PORC-1A & 0,20 & 20,56 & 250 & 1,93 & 3,51 \\
\hline PORC-1B & 0,05 & 20,92 & 250 & 1,93 & 3,45 \\
\hline PORC-2 & 0,01 & 21,20 & 250 & 1,93 & 3,89 \\
\hline
\end{tabular}

\footnotetext{
${ }^{1}$ Carbono orgánico (\%) medido con el TOC.

${ }^{2}$ Indice de plasticidad de Pfefferkorn.

${ }^{3}$ Densidad aparente en seco.

${ }^{4}$ Resistencia mecánica en seco.
}

Se puede observar que el carbono orgánico se reduce tras el tratamiento térmico realizado a la arcilla (N-A-te) y, además, con la introducción del resto de componentes de la formulación de la pasta, aún disminuye un poco más, por la dilución que se consigue en la mezcla. En cuanto a la plasticidad, se mantiene en valores similares en todos los casos, a pesar de la presencia de agentes desgrasantes como la chamota, el vidrio reciclado y la arcilla tratada térmicamente. Además, la prensabilidad mejora respecto de la composición de referencia (PORC-STD), al introducir arcillas españolas y/o residuos cocidos a la composición de gres porcelánico. La resistencia mecánica en seco, parámetro muy importante a la hora de evitar roturas de piezas industriales 
desde la salida de la prensa hasta la entrada al horno, se reduce ligeramente en las composiciones que contienen arcillas españolas sin tratar (PORC-1A) y tratadas (PORC-1B). Sin embargo, el residuo cocido (chamota y vidrio reciclado) contribuye al aumento de resistencia mecánica en seco, debido presumiblemente a que éste mejora el empaquetado de partículas, como se puede observar en el valor de resistencia mecánica alcanzado en la muestra (PORC-2).

En la Tabla LIII, aparecen las coordenadas colorimétricas según el sistema CIE-Lab a dos temperaturas de cocción, $1165^{\circ} \mathrm{C}$ y $1185^{\circ} \mathrm{C}$, donde se sitúa el final del ciclo de gresificación, con absorciones de agua cercanas a cero y densidades aparentes en cocido máximas, correspondientes a las probetas prensadas con las formulaciones de gres porcelánico. Se observa en esta tabla que, al sustituir parte de arcillas de importación por arcillas españolas, se reduce la luminosidad (L*), incrementándose a su vez el parámetro a* (eje rojo-verde), lo que se traduce en una pérdida de blancura de la pasta. También ocurre lo mismo con la composición (PORC-2), que contiene residuo cocido.

Tabla LIII. Análisis colorimétrico de las composiciones de gres porcelánico tratadas térmicamente.

\begin{tabular}{|c|c|c|c|c|}
\hline COMPOS ICION & T $\left({ }^{\circ} \mathbf{C}\right)$ & L* & a* & b* \\
\hline PORC-STD & 1165 & 74,76 & 2,01 & 11,08 \\
\hline PORC-1A & 1165 & 66,73 & 3,39 & 12,84 \\
\hline PORC-1B & 1165 & 71,58 & 3,20 & 12,26 \\
\hline PORC-2 & 1165 & 64,12 & 2,25 & 12,87 \\
\hline PORC-STD & $\mathbf{1 1 8 5}$ & $\mathbf{7 0 , 6 7}$ & $\mathbf{2 , 2 6}$ & $\mathbf{1 2 , 2 3}$ \\
\hline PORC-1A & 1185 & 64,88 & 2,71 & 11,79 \\
\hline PORC-1B & 1185 & 69,19 & 2,72 & 11,79 \\
\hline PORC-2 & $\mathbf{1 1 4 0}$ & $\mathbf{6 6 , 8 5}$ & $\mathbf{2 , 9 5}$ & $\mathbf{1 3 , 2 6}$ \\
\hline PORC-2 & 1165 & 64,12 & 2,25 & 12,87 \\
\hline
\end{tabular}


En cuanto al análisis dilatométrico obtenido de las composiciones de gres porcelánico preparadas, los datos se presentan en la Tabla LIV:

Tabla LIV. Análisis dilatométrico de las composiciones de gres porcelánico preparadas.

\begin{tabular}{|c|c|c|c|}
\hline \multirow{2}{*}{ COMPOSICION } & \multicolumn{3}{|c|}{ ALFA $10^{\wedge} 7 \mathrm{1} / \mathrm{K}$} \\
\cline { 2 - 4 } & $30^{\circ} \mathrm{C}-300^{\circ} \mathrm{C}$ & $300^{\circ} \mathrm{C}-500^{\circ} \mathrm{C}$ & $500^{\circ} \mathrm{C}-650^{\circ} \mathrm{C}$ \\
\hline PORC-STD & 69.16 & 83.82 & 101.51 \\
\hline PORC-1A & 68.50 & 85.12 & 105.82 \\
\hline PORC-1B & 69.72 & 85.90 & 103.69 \\
\hline PORC-2 & 68.10 & 82.58 & 100.52 \\
\hline
\end{tabular}

Como se puede observar en dicha tabla, los valores dilatométricos aumentan ligeramente en las composiciones que presentan arcillas españolas (PORC-1A) y (PORC-1B), seguramente porque estas arcillas contienen más cantidad de sílice libre como impureza (véase que las intensidades de la fase cuarzo que aparece en los difractogramas de las arcillas de importación (véase apartado 8.7 del apéndice) son menores que las intensidades correspondientes a las arcillas de Teruel, (véase el apartado 3.3.1). Por otra parte, en cuanto a la composición (PORC-2), que contiene un 20\% de residuo cocido, ésta presenta los valores dilatométricos más bajos. Esto puede ser debido a que el residuo cocido, especialmente el vidrio reciclado, ya no presenta sílice libre, pues ésta se puede encontrar formando parte de nuevas estructuras cristalinas (residuo cocido) o amorfas (vidrio reciclado). No obstante, las dilatometrías obtenidas en las cuatro composiciones ensayadas están dentro de los valores habituales que se utilizan en el proceso industrial de fabricación cerámico. 
Por lo que respecta al análisis químico (FRX), en la Tabla LV se representan los valores obtenidos para cada una de las composiciones.

Tabla LV. Análisis químico (FRX) de las composiciones de gres porcelánico preparadas.

\begin{tabular}{|c|c|c|c|c|c|c|c|c|c|c|}
\hline Muestra & $\mathrm{Na}_{2} \mathrm{O}$ & $\mathbf{M g O}$ & $\mathrm{Al}_{2} \mathrm{O}_{3}$ & $\mathrm{SiO}_{2}$ & $\mathrm{~K}_{2} \mathrm{O}$ & $\mathrm{CaO}$ & $\mathrm{TiO}_{2}$ & $\mathbf{F e}_{2} \mathrm{O}_{3}$ & PPC & TOTAL \\
\hline PORC-STD & 4,31 & 0,70 & 19,7 & 67,5 & 1,24 & 0,79 & 0,77 & 0,73 & 3,63 & 99,4 \\
\hline PORC-1A & 3,94 & 0,87 & 18,5 & 68,2 & 1,62 & 0,81 & 0,59 & 1,19 & 4,06 & 99,8 \\
\hline PORC-1B & 3,89 & 0,84 & 19,2 & 67,8 & 1,64 & 0,66 & 0,68 & 1,05 & 3,48 & 99,2 \\
\hline PORC-2 & 4,78 & 0,97 & 17,5 & 68,5 & 1,40 & 1,20 & 0,85 & 1,10 & 3,19 & 99,5 \\
\hline
\end{tabular}

A la vista de los resultados obtenidos en la tabla, se aprecia que si se sustituye parte de las arcillas de importación por arcillas españolas, (PORC-1A), aumenta el porcentaje de $\mathrm{Fe}_{2} \mathrm{O}_{3}$, como era de esperar, ya que éstas presentan impurezas de hierro (siderita y hematita). Si las arcillas españolas se someten a tratamientos desferrizadores y a tratamientos térmicos para eliminar la materia orgánica (PORC-1B), se consigue un valor intermedio de $\mathrm{Fe}_{2} \mathrm{O}_{3}$ entre (PORC-1A) y (PORC-STD). Si, además de utilizar arcillas españolas tratadas, se incorporan residuos cocidos en la composición (PORC-2), el valor de $\mathrm{Fe}_{2} \mathrm{O}_{3}$ se sitúa por debajo del de la composición (PORC-1A). Además, la composición (PORC-2) presenta un contenido en $\mathrm{Na}_{2} \mathrm{O}$ y en CaO más alto que el resto de formulaciones, porque procede del 13\% de $\mathrm{Na}_{2} \mathrm{O}$ y un 9\% de CaO que contiene el vidrio reciclado, como se aprecia en los análisis químicos correspondientes (Tabla XLIX, Tabla L).

En la Figura 57 se reflejan los correspondientes diagramas de gresificación de las composiciones de gres porcelánico preparadas (PORC-STD, PORC-1A, PORC-1B y PORC-2). 


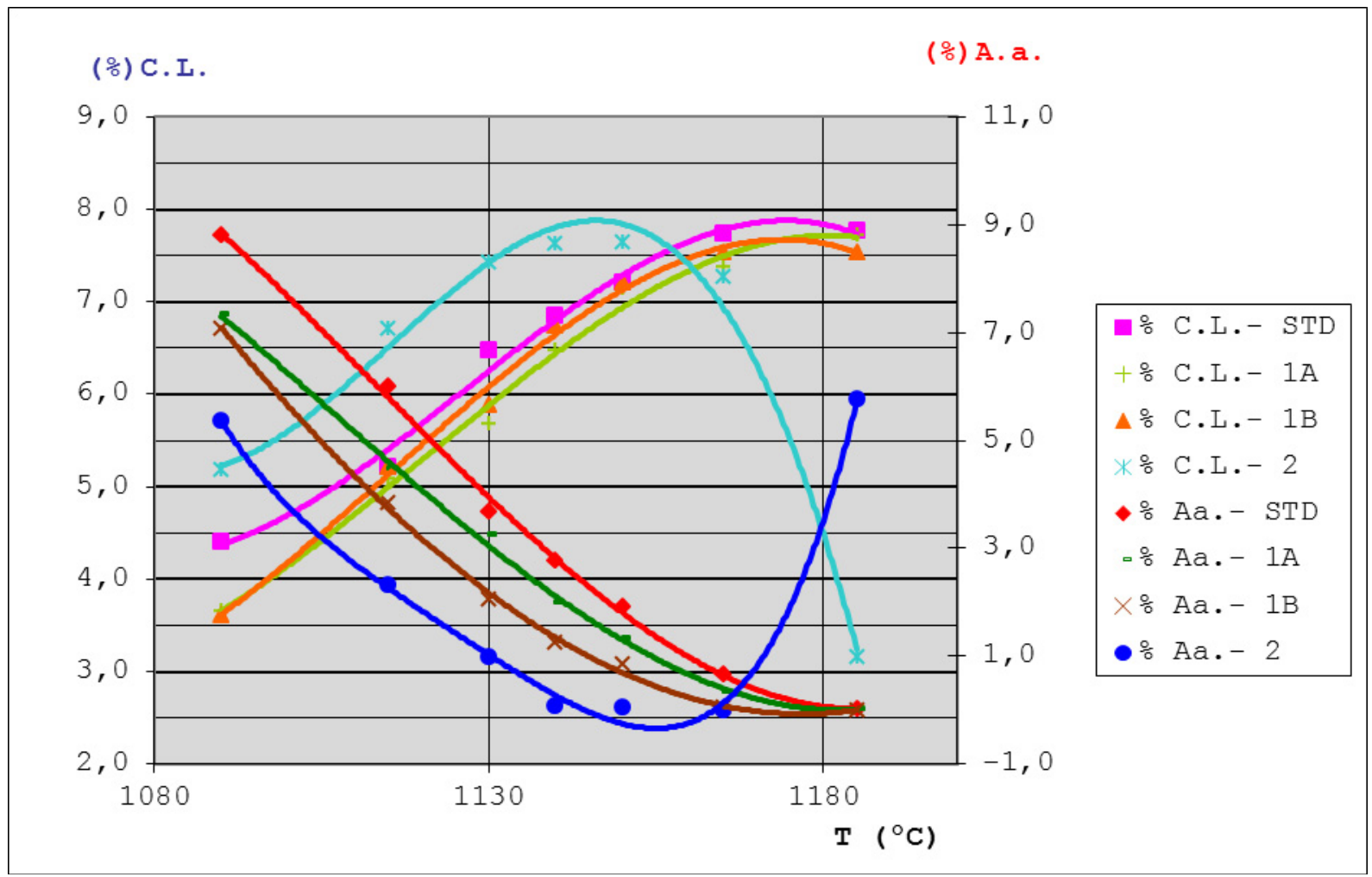

Figura 57. Diagrama de gresificación de las composiciones de gres porcelánico.

Las composiciones que no contienen residuos cocidos (chamota y vidrio reciclado) en su formulación (PORC-1A y PORC-1B), presentan un comportamiento similar, en cuanto a contracción lineal se refiere y una porcentaje de absorción de agua menor. Cuando se añaden las arcillas españolas a la formulación, tras la corrección mediante la sustitución de parte del feldespato sódico por el sódico-magnésico, también presentan una contracción lineal dentro de los límites aceptables que se utilizan en la actual producción industrial, por debajo del 8\%.

Por lo que respecta a la composición (PORC-2), en la que se ha introducido un $20 \%$ en peso de residuo cocido y se ha sustituido totalmente el porcentaje en peso del feldespato sódico por el sódico-magnésico, para asegurar la fundencia de la pasta, se observa que la etapa de sinterización se ha desplazado desde 
$1185^{\circ} \mathrm{C}$, donde la composición PORC-STD presenta una absorción de agua del $0.01 \%$ y una densidad aparente en cocido de $2.38 \mathrm{~g} / \mathrm{cm}^{3}$, hasta $1140^{\circ} \mathrm{C}$, temperatura a la que la composición (PORC-2) presenta una absorción de agua del 0.07\% y una densidad aparente en cocido de $2.41 \mathrm{~g} / \mathrm{cm}^{3}$. De este modo, hay una disminución importante de temperatura de gresificación $\left(45^{\circ} \mathrm{C}\right)$ para los ciclos de cocción cerámicos de calcinación extrema. Esto supone un importante ahorro energético para la etapa de cocción en el horno industrial. Por otra parte, el color de la composición (PORC-2) a $1140^{\circ} \mathrm{C}$ (absorción de agua del 0.07\%) comparado con el color de la composición (PORC-STD) a $1185^{\circ} \mathrm{C}$ (absorción de agua del 0.01\%) disminuye cerca de 4 puntos de $L^{*}$, probablemente por la mayor fundencia que presenta esta pasta, como se observa en la tabla Tabla LIII.

Por otra parte, en la Figura 58, se observa la variación de la densidad aparente en cocido de con la temperatura, correspondiente a las probetas de las composiciones de porcelánico estudiadas. Se observa cómo la composición de porcelánico (PORC-2) alcanza densidades aparentes en cocido superiores a menor temperatura (alrededor de $45^{\circ} \mathrm{C}$ menos), puesto que llega a valores de densidad aparente en cocido del orden de $2.40 \mathrm{~g} / \mathrm{cm}^{3}$ a unos $1140^{\circ} \mathrm{C}$, mientras que el resto de composiciones alcanza este nivel de sinterización a temperaturas cercanas a $1185^{\circ} \mathrm{C}$. La composición (PORC-2) también destaca porque presenta deformación piroplástica en las piezas cocidas por encima de $1165^{\circ} \mathrm{C}$, provocada por la presencia del $20 \%$ de residuo cocido [139], [140], [141], [142], [143]. 


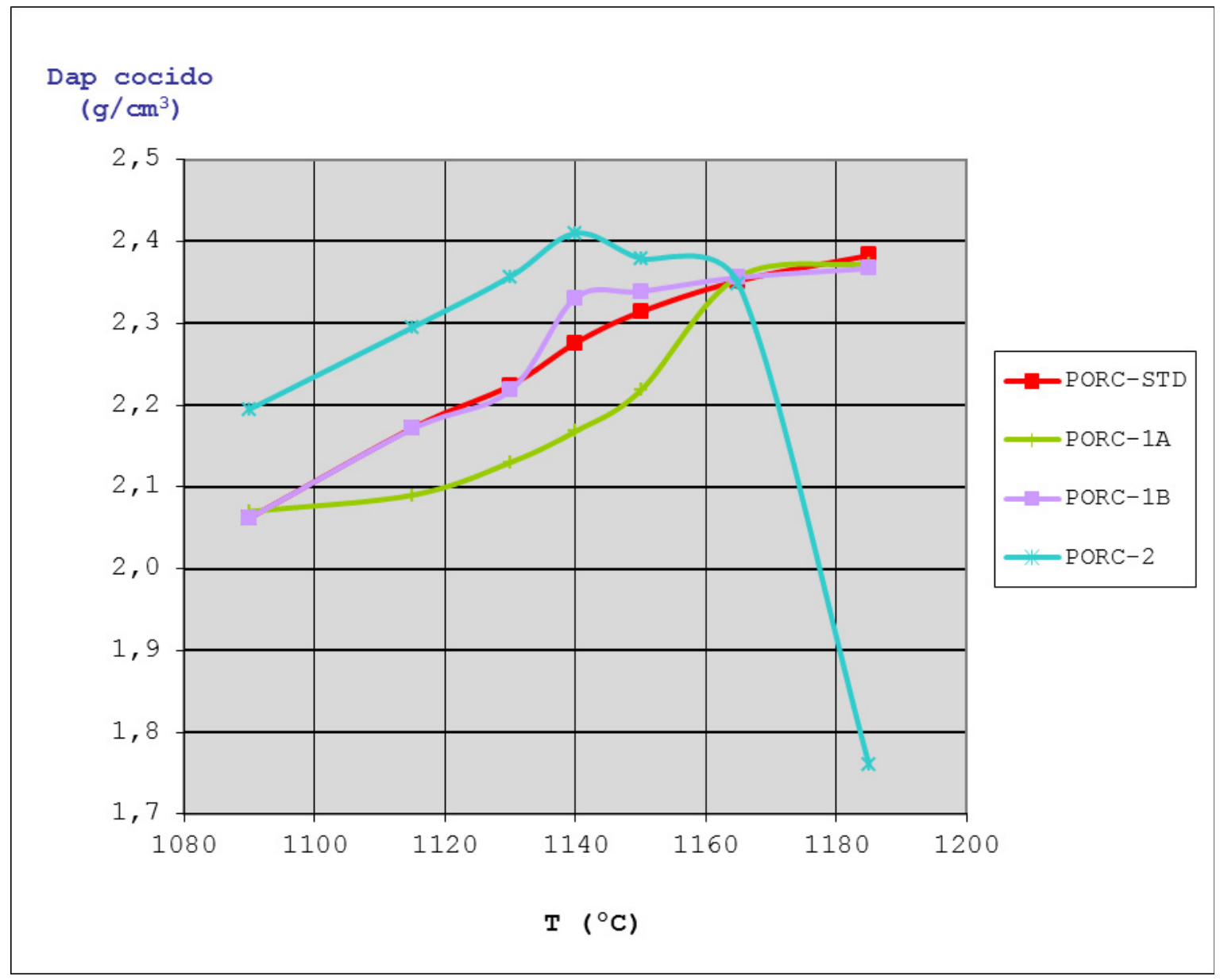

Figura 58. Variación de la densidad aparente en cocido (medida con el método de inmersión en mercurio) con la temperatura en las composiciones de gres porcelánico.

Mediante la técnica de microscopía electrónica de barrido (MEB), se ha estudiado la presencia de porosidad interna para las cuatro composiciones cocidas a $1185^{\circ} \mathrm{C}$, excepto en la composición (PORC-2), que se ha realizado a $1140^{\circ} \mathrm{C}$, su temperatura de máxima densificación. Las micrografías correspondientes aparecen en la Figura 59 y, en la Figura 60, se representa el análisis estadístico de las composiciones y de la porosidad interna. 


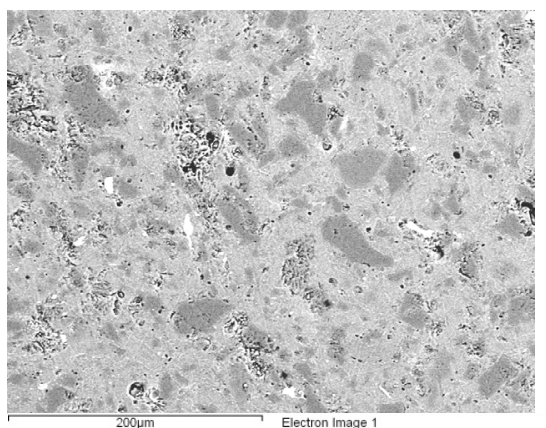

Micrografía (PORC-STD)

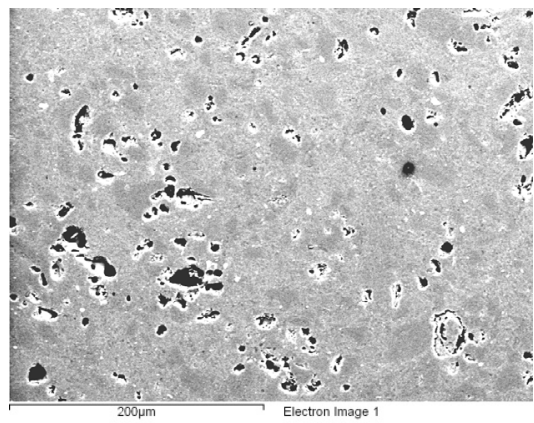

Micrografía (PORC-1B)

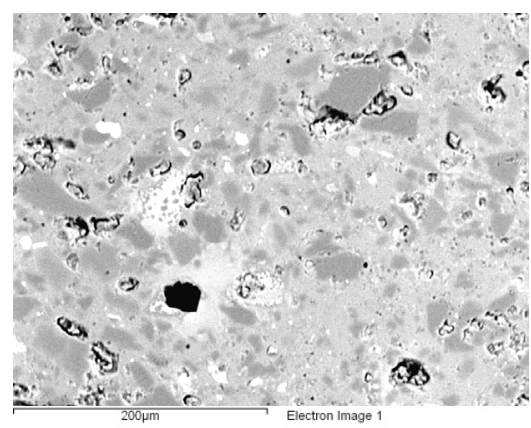

Micrografía (PORC-1A)

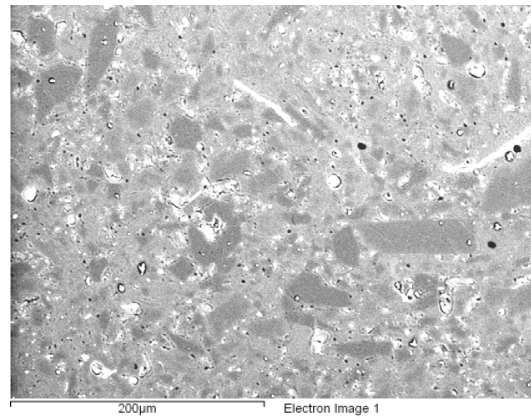

Micrografía (PORC-2)

Figura 59. Micrografías ( $\times 300$ aumentos) de las composiciones de gres porcelánico ensayadas, utilizando el detector de electrones retrodispersados. 


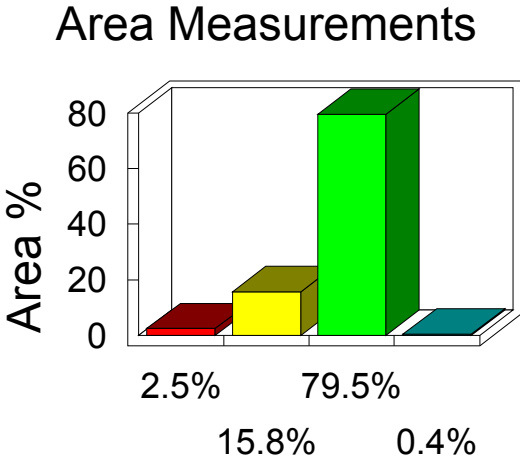

Análisis de imagen (PORC-STD)

Area Measurements

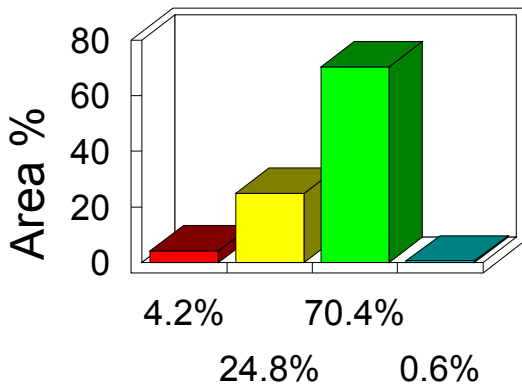

Análisis de imagen (PORC-1B)
Area Measurements

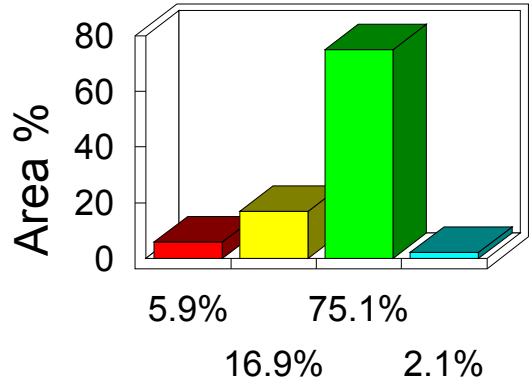

Análisis de imagen (PORC-1A)

\section{Area Measurements}

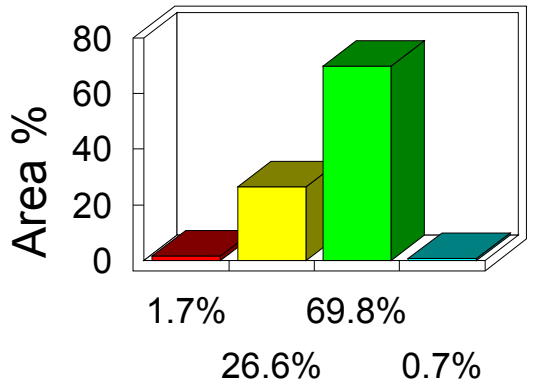

Análisis de imagen $\left(\right.$ PORC-2) ${ }^{1}$

Figura 60. Valores estadísticos correspondientes a los análisis de imagen de las micrografías de las composiciones de gres porcelánico estudiadas, en la Figura 59.

${ }^{1}$ El color rojo representa la porosidad interna. El amarillo, el cuarzo cristalino. El verde, la matriz sinterizada (mezcla de filosilicatos amorfos y feldespatos). El azul, los óxidos colorantes de hierro y titanio presentes en la pasta. 
A partir de la observación de las micrografías que aparecen en la Figura 59 y de los análisis que se reflejan en la Figura 60, la micrografía del gres porcelánico de referencia (PORC-STD) destaca por la escasa porosidad interna que presenta, junto con las fases de cuarzo libre embebidas en la matriz sinterizada. La composición (PORC-1A), con arcillas españolas sin tratar, presenta más porosidad interna y más cantidad de óxidos colorantes (hierro y titanio), que al ser metales más pesados, aparecen como zonas más claras en las micrografías de la Figura 59 (por el tipo de señal en que son recogidas las imágenes de electrones retrodispersados). En cuanto a la siguiente composición (PORC-1B), su porosidad interna es similar a la de la composición (PORC-1A), aunque se observa menor cantidad de óxidos colorantes, lo que podría ser debido al proceso de desferritización aplicado a la arcilla (N-Acr), introducida en la formulación. Finalmente, la composición (PORC-2B), que contiene un 20\% de residuo cocido, presenta la porosidad interna más baja, siendo mínima también la presencia de óxidos colorantes, aunque ligeramente mayor que la composición de referencia (PORC-STD) .

Por tanto, esta composición (PORC-2), puede ser muy interesante para formular composiciones de gres porcelánico esmaltado, pasta que no requiere una excesiva blancura, como se ha comentado en el apartado 1.1.4. Además, la importancia de esta composición (PORC-2) se fundamenta en el ahorro energético producido durante la etapa de cocción que tiene lugar actualmente a través del horno cerámico industrial de rodillos, ya que la reacción de sinterización se puede avanzar en $45^{\circ} \mathrm{C}$. 


\subsubsection{Composiciones de revestimiento.}

Siguiendo con las composiciones preparadas para revestimiento, de monoporosa, indicado en el apartado 3.5, los resultados obtenidos mediante los ensayos del comportamiento cerámico se adjuntan en el apéndice (véase apartados desde 8.20 a 8.23). En la Tabla LVI se presentan los resultados del análisis de los parámetros que más importancia tienen en el proceso en las etapas previas a la cocción de las pastas. Así pues, se observa que, aunque el porcentaje de carbono orgánico se incrementa si se sustituye parte de las arcillas de importación por arcillas españolas sin tratar (REV-1A), como era de esperar, éste vuelve a disminuir si se tratan las arcillas (REV-1B) y/o se introduce residuo cocido en la pasta (REV-2). El índice de plasticidad según Pfefferkorn disminuye ligeramente en la composición que contiene residuo cocido (REV-2), por contener material poco plástico o desgrasante, si bien su valor se mantiene dentro del rango habitual de trabajo a nivel industrial [17]. Por otra parte, en la

Tabla LVI, destacan significativamente los valores de la resistencia mecánica en seco, puesto que el residuo cocido confiere a la pasta un incremento de resistencia en seco, como ya se ha visto en las composiciones preparadas de gres porcelánico. Parece ser que el empaquetamiento conseguido de las partículas en las pastas cerámicas que contienen residuo cocido, está más cercano al óptimo, por lo que la resistencia mecánica en seco de las probetas es mayor. 
Tabla LVI. Parámetros cerámicos de las composiciones de revestimiento antes de la cocción.

\begin{tabular}{|c|c|c|c|c|c|}
\hline $\begin{array}{c}\text { Composiciones } \\
\text { de } \\
\text { Revestimiento }\end{array}$ & $\begin{array}{l}\text { \% CARBONO } \\
\text { ORGÁNICO }\end{array}$ & I.P. ${ }^{2}\left(\frac{\circ}{0}\right)$ & $\mathrm{P}\left(\mathrm{kg} / \mathrm{cm}^{2}\right)$ & $\begin{array}{c}\text { Dap. }^{3} \\
\text { seco } \\
\left(\mathrm{g} / \mathrm{cm}^{3}\right)\end{array}$ & $\begin{array}{c}\mathrm{RMCA} \\
\mathrm{SECO}^{4} \\
\left(\mathrm{~N} / \mathrm{mm}^{2}\right)\end{array}$ \\
\hline REV-STD & 0,00 & 20,96 & 213 & 1,93 & 3,10 \\
\hline REV-1A & 0,05 & 20,52 & 191 & 1,93 & 2,90 \\
\hline REV-1B & 0,01 & 20,47 & 191 & 1,93 & 2,95 \\
\hline REV-2 & 0,01 & 19,68 & 250 & 1,93 & 3,35 \\
\hline
\end{tabular}

${ }^{1}$ Carbono orgánico (\%) medido con el TOC.

${ }^{2}$ Indice de plasticidad de Pfefferkorn.

${ }^{3}$ Densidad aparente en seco.

${ }^{4}$ Resistencia mecánica en seco.

En el caso del revestimiento, como este tipo de pasta cerámica debe presentar una porosidad elevada (sobre 16\% de absorción de agua, A.a.) y, por tanto, sinterizar menos que la pasta de gres porcelánico, conforme se explica en el apartado 1.1.4, el color de la pasta (referido al grado de blancura) no es un parámetro tan crítico como en el caso del gres porcelánico. Como se muestra en la Tabla LVII, cuando parte de las arcillas de importación (REVSTD) se sustituyen por las arcillas españolas sin tratar ( $(\mathrm{N}-\mathrm{A}-\mathrm{Cr}$ ) y (N-A-te)), la blancura disminuye a $1140^{\circ} \mathrm{C}$, aunque sólo unos 4 puntos del parámetro L*. Sin embargo, cuando parte de las arcillas de importación se sustituyen por las arcillas españolas tratadas en la composición (REV-1B), ( $(\mathrm{N}-\mathrm{A}-\mathrm{Cr})$ desferretizada con separador magnético y la (N-A-te) calcinada en horno eléctrico tipo mufla a $400^{\circ} \mathrm{C}$ y durante 30 minutos) se obtienen resultados intermedios entre la composición (REV-STD) y la composición (REV-1A). En cuanto a la composición (REV-2), los valores de los parámetros de color a $1140^{\circ} \mathrm{C}$, disminuyen significativamente ((REV-STD); $\left.L^{\star}=80.07\right)$ frente a $\left((R E V-2) ; L^{\star}=69.45\right)$. 
Tabla LVII. Análisis colorimétrico de las composiciones de revestimiento tratadas térmicamente.

\begin{tabular}{|c|c|c|c|c|}
\hline COMPOSICIONES & T $\left({ }^{\circ} \mathbf{C}\right)$ & $\mathbf{L}^{*}$ & $\mathbf{a}^{*}$ & b* \\
\hline REV-STD & 1115 & 81.24 & 5.05 & 14.94 \\
\hline REV-1A & 1115 & 77.02 & 6.75 & 15.67 \\
\hline REV-1B & 1115 & 78.95 & 5.32 & 14.28 \\
\hline REV-2 & 1115 & 76.56 & 4.52 & 13.58 \\
\hline REV-STD & $\mathbf{1 1 4 0}$ & $\mathbf{8 0 . 0 7}$ & $\mathbf{4 . 6 8}$ & $\mathbf{1 5 . 0 0}$ \\
\hline REV-1A & 1140 & 75.80 & 5.17 & 14.57 \\
\hline REV-1B & 1140 & 76.97 & 4.21 & 14.32 \\
\hline REV-2 & 1140 & 76.05 & 4.54 & 13.69 \\
\hline REV-2 & 1090 & 77.24 & 4.48 & 13.74 \\
\hline REV-2 & $\mathbf{1 0 0 0}$ & $\mathbf{7 8 . 5 0}$ & $\mathbf{4 . 5 9}$ & $\mathbf{1 3 . 8 5}$ \\
\hline
\end{tabular}

En cuanto a los resultados de dilatometría obtenidos de las composiciones de revestimiento diseñadas, en la Tabla LVIII aparecen los valores correspondientes.

Tabla LVIII. Análisis dilatométrico de las composiciones de revestimiento preparadas.

\begin{tabular}{|c|c|c|c|}
\hline \multirow{2}{*}{ COMPOSICION } & \multicolumn{3}{|c|}{ ALFA $10^{\wedge} 71 / \mathrm{K}$} \\
\cline { 2 - 4 } & $30^{\circ} \mathrm{C}-300^{\circ} \mathrm{C}$ & $300^{\circ} \mathrm{C}-500^{\circ} \mathrm{C}$ & $500^{\circ} \mathrm{C}-650^{\circ} \mathrm{C}$ \\
\hline REV-STD & 68.6 & 81.5 & 97.0 \\
\hline REV-1A & 69.2 & 83.8 & 101.5 \\
\hline REV-1B & 68.1 & 82.6 & 100.5 \\
\hline REV-2 & 67.1 & 82.6 & 98.7 \\
\hline
\end{tabular}

Se puede observar, como en el caso de las composiciones de gres porcelánico, la tendencia a incrementarse los valores de dilatometría si se utilizan arcillas españolas en la composición, sin tratar (REV-1A) y tratadas (REV-1B), puesto que estas arcillas contienen más sílice libre que las arcillas de importación a las que sustituyen en parte. Por otro lado, la composición que lleva 
en su formulación residuo cocido (REV-2), presenta un ligero descenso de los valores dilatométricos, favorecido por la presencia del residuo.

Por lo que respecta a los análisis químicos (FRX), en la Tabla LIX se muestras los resultados obtenidos de las composiciones de revestimiento preparadas.

Tabla LIX. Análisis químicos (FRX) de las composiciones de revestimiento preparadas.

\begin{tabular}{|c|c|c|c|c|c|c|c|c|c|c|}
\hline Muestra & $\mathrm{Na}_{2} \mathrm{O}$ & $\mathbf{M g O}$ & $\mathrm{Al}_{2} \mathrm{O}_{3}$ & $\mathbf{S i O}_{2}$ & $\mathrm{~K}_{2} \mathrm{O}$ & $\mathrm{CaO}$ & $\mathbf{T i O}_{2}$ & $\mathbf{F e}_{2} \mathrm{O}_{3}$ & PPC & TOTAL \\
\hline REV-STD & 0,96 & 0,14 & 18,5 & 60,7 & 1,71 & 6,45 & 0,68 & 0,99 & 9,63 & 99,7 \\
\hline REV-1A & 1,01 & 0,16 & 17,9 & 61,1 & 1,93 & 6,42 & 0,63 & 1,14 & 9,57 & 99,8 \\
\hline REV-1B & 1,07 & 0,28 & 18,1 & 60,8 & 1,78 & 6,34 & 0,60 & 1,07 & 9,55 & 99,5 \\
\hline REV-2 & 1,35 & 0,34 & 17,2 & 61.5 & 1,70 & 6,89 & 0,53 & 0,99 & 9.38 & 99,9 \\
\hline
\end{tabular}

Según la Tabla LIX, se puede ver cómo, la incorporación de arcillas españolas a la pasta de revestimiento (REV-1A) Y (REV1B), provoca un ligero aumento del porcentaje de $\mathrm{Fe}_{2} \mathrm{O}_{3}$, mientras que el resto de componentes que definen el análisis químico, permanecen dentro de valores similares. La composición (REV-2), que contiene un 15\% de residuo cocido, presenta más porcentaje de $\mathrm{Na}_{2} \mathrm{O}$ y de $\mathrm{CaO}$ que las otras composiciones, aunque lleve el mismo porcentaje de carbonato cálcico que éstas. Sin embargo, la pérdida por calcinación ( $\mathrm{PPC}$ ) se ha reducido ligeramente, a pesar del incremento de CaO. Esto se debe a que el residuo cocido es portador de CaO, procedente de la descomposición del carbonato cálcico contenido en la pasta de la que procede la chamota y, también del CaO proveniente del vidrio reciclado. Así, en la Tabla LX se indican los porcentajes de carbonatos y de pérdidas por calcinación (PPC) obtenidos en cada caso. 
Tabla LX. Comparativa entre el porcentaje de carbonato cálcico y de pérdida por calcinación (PPC) de las composiciones de revestimiento estudiadas.

\begin{tabular}{|c|c|c|c|}
\hline COMPOSICIÓN & $\begin{array}{c}\text { \%Carbonato } \\
\text { cálcico }^{1}\end{array}$ & \%CaO & PPC \\
\hline REV-STD & 11.43 & 6,45 & 9,63 \\
\hline REV-1A & 11.01 & 6,42 & 9,57 \\
\hline REV-1B & 11.53 & 6,34 & 9,55 \\
\hline REV-2 & 11.20 & 6,89 & 9.38 \\
\hline
\end{tabular}

1 Medido con el calcímetro de Bernard.

Además, se han obtenido también, los diferentes diagramas de gresificación de las composiciones de revestimiento preparadas (REV-STD, REV-1A, REV-1B y REV-2), que aparecen el apartado del apéndice (de 8.20 a 8.23). En la Figura 61 se muestran en una misma gráfica todos los diagramas de gresificación de las composiciones preparadas. Puede observarse que las composiciones que no contienen residuo cocido (vidrio y chamota) en su formulación ((REV-1A) y (REV-1B)), presentan unos valores muy similares a los de la pasta de referencia (REV-STD). En cuanto a la composición (REV-2), que contiene un 15\% de residuo cocido en su formulación, presenta una contracción lineal mayor (del orden de $0.39 \%$ de C.L. a $1000^{\circ} \mathrm{C}$ ) que el resto de composiciones (del orden de 0.20-0.30\% de C.L. a $1140^{\circ} \mathrm{C}$ ). A nivel industrial los valores de tolerancia de los porcentajes de C.L. están comprendidos entre $0.2 \%$ y $0.4 \%$ [17]. En la Tabla LVII se puede ver que los parámetros de color de la composición (REV-2) a $1000^{\circ} \mathrm{C}(\mathrm{L} *$ =78.50) son comparables a los de la composición de referencia $(\mathrm{REV}-\mathrm{STD})$ a $1140^{\circ} \mathrm{C}(\mathrm{L} *=80.07)$. 


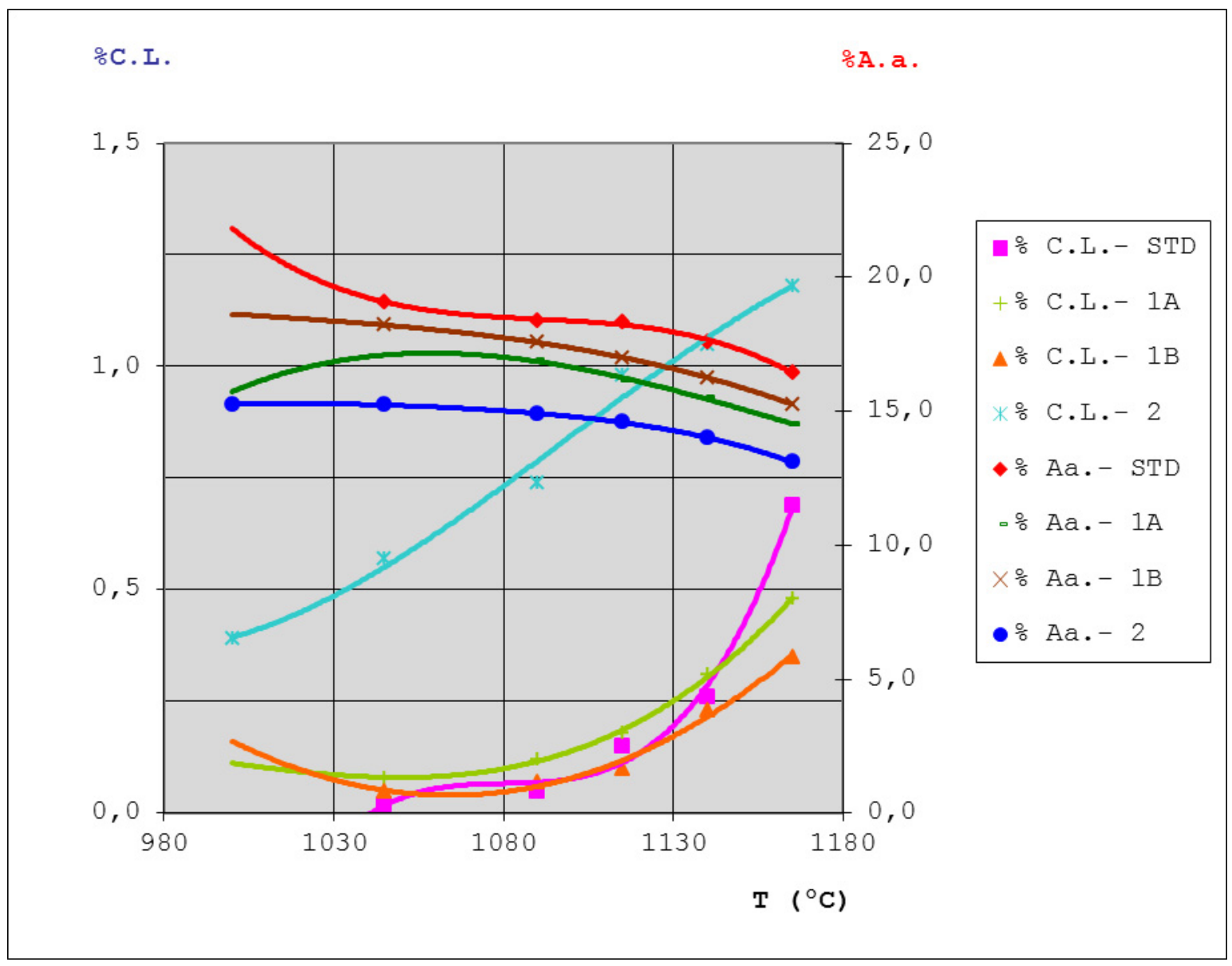

Figura 61. Diagrama de gresificación de las composiciones de revestimiento.

En orden de estudiar el grado de sinterización alcanzado en las composiciones de revestimiento gresificadas, se han obtenido los difractogramas de rayos-X que se muestran en la Figura 62. Destaca en dicha figura, la variación del pico correspondiente a la fase anortita $\left(\mathrm{CaAl}_{2} \mathrm{Si}_{2} \mathrm{O}_{8}, 2 \theta=27.9\right)$, en función del tipo de pasta y de la temperatura a la que se ha cocido ésta. Se observa que a $1000^{\circ} \mathrm{C}$, en la muestra $(\mathrm{REV}-2)$, aparece ya el pico de la fase anortita, mientras que para la muestra (REV-STD), éste no aparece hasta los $1140^{\circ} \mathrm{C}$. 


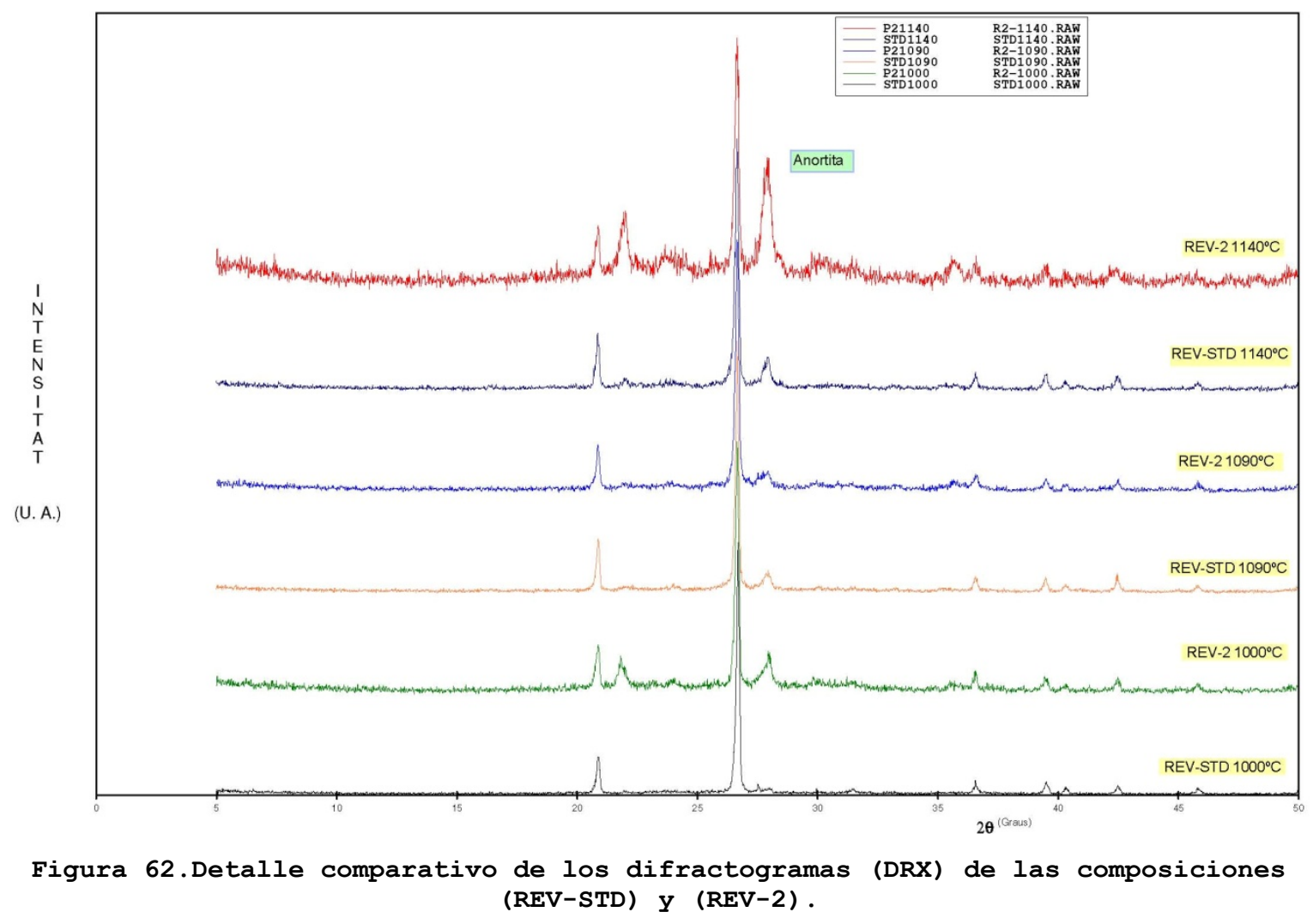

Así pues, a la vista de los porcentajes de contracción lineal, y a los resultados de los difractogramas, se confirma que la introducción de un 15\% de residuo cocido en las pastas de revestimiento de pasta blanca permite disminuir $140^{\circ} \mathrm{C}$ la temperatura máxima de sinterización en dichas pastas. Esto va a suponer un cambio muy importante para el sector productivo, ya que va a posibilitar el adelantar los ciclos de cocción y, por lo tanto, el obtener un ahorro energético muy importante. Sin embargo, esto también supone la reformulación de nuevas composiciones de esmaltes y engobes, para adaptarlos a los nuevos ciclos productivos menos energéticos. 


\subsubsection{Ahorro energético en el consumo de energía térmica de un horno industrial de rodillos.}

Con el fin de cuantificar el ahorro energético que se produce en las composiciones preparadas que contienen residuo cocido, debido a que los resultados obtenidos indican una disminución de la temperatura de máxima densificación de las piezas, (reducción de $45^{\circ} \mathrm{C}$ en la composición de gre porcelánico, (PORC-2) y de $140^{\circ} \mathrm{C}$ en la composición de revestimiento ( $\mathrm{REV}-2))$, se ha realizado un cálculo estimativo del consumo energético en la etapa de la cocción industrial en horno de rodillos [144], [145], [146].

Para ello, se ha hecho uso de los datos sobre consumo energético de hornos de rodillos encontrados en la bibliografía [energia], que se ilustran en la Tabla LXI.

Tabla LXI. Producción ( $\mathrm{m}^{2} /$ día), temperatura máxima y consumo de energía térmica en la etapa de cocción, referido al $\mathrm{PCS}^{1}$.

\begin{tabular}{|c|c|c|c|c|}
\hline CONCEPTO & $\begin{array}{c}\text { GRES } \\
\text { PORCELANICO }\end{array}$ & $\begin{array}{l}\text { GRES } \\
\text { ROJO }\end{array}$ & $\begin{array}{c}\text { REVESTIMIENTO } \\
\text { BLANCO }\end{array}$ & $\begin{array}{c}\text { REVESTIMIENTO } \\
\text { ROJO }\end{array}$ \\
\hline $\begin{array}{l}\text { Producción } \\
\text { (m²/día) }\end{array}$ & 4390 & 5620 & 4590 & 5550 \\
\hline $\begin{array}{l}\text { Temperatura } \\
\text { máxima }\left({ }^{\circ} \mathrm{C}\right)\end{array}$ & 1192 & 1147 & 1144 & 1126 \\
\hline $\begin{array}{c}\text { Consumo } \\
\text { específico } \\
\left(\mathrm{KWh} / \mathrm{m}^{2} \text { cocido) }\right.\end{array}$ & 17.4 & 14.3 & 16.0 & 13.4 \\
\hline
\end{tabular}

1 Poder calorífico superior del combustible.

En la Tabla LxI se indica la producción diaria, la temperatura máxima y el consumo específico de energía térmica (referido al PCS), de los productos cerámicos que se fabrican en la actualidad: 
gres porcelánico, gres rojo, revestimiento blanco y revestimiento rojo. Se observa que los productos de pasta blanca (gres porcelánico y revestimiento blancol consumen más energía que los productos de pasta roja (gres y revestimiento de monoporosa), debido a la distinta naturaleza que presentan las materias primas de cocción blanca respecto a las de cocción roja, siendo éstas fundamentalmente arcillas, cuya fundencia se potencia gracias al alto contenido en óxidos colorantes (principalmente $\mathrm{Fe}_{2} \mathrm{O}_{3}$ ) que contienen.

Para estimar el consumo energético aproximado de las baldosas de gres porcelánico, utilizando la composición (PORC-2), que densifica unos $45^{\circ} \mathrm{C}$ antes que la pasta de porcelánico de referencia (PORC-STD), se puede suponer que el consumo energético está alrededor del consumo energético de la fabricación de revestimiento blanco, ya que la temperatura de cocción del revestimiento blanco está unos $45^{\circ} \mathrm{C}$ por debajo de la del porcelánico de referencia. De esta forma, se puede hacer la aproximación en el cálculo del ahorro energético conseguido en la formulación (PORC-2), con respecto a la pasta de gres porcelánico de referencia (PORC-STD), del 8\%.

Como no se disponen de datos sobre el consumo energético para la composición (REV-2), cocida a $1000^{\circ} \mathrm{C}$, a la hora de estimar el ahorro energético que puede suponer la fabricación de baldosas con dicha composición (donde la sinterización se ha producido a $140^{\circ} \mathrm{C}$ menos, valores reflejados en el apartado 4.3.2), se puede comparar con el consumo energético utilizado para la fabricación de revestimiento rojo (13.4 $\mathrm{Kwh} / \mathrm{m}^{2}$ cocido, indicado en la Tabla LXI), ya que aunque éste último sinteriza a $1126^{\circ} \mathrm{C}$, el tiempo de permanencia es menor que en el caso de la pasta blanca. De este modo, el ahorro energético aproximado, entre la composición de 
revestimiento (REV-2) y la de referencia (REV-STD) estaría sobre el $16 \%$

Sin embargo, como ya se ha comentado, estos datos de ahorro energético, se han estimado a partir de datos obtenidos de forma estadística recogidos en la literatura, que no reflejan las variables propias de la etapa de cocción específica de cada horno industrial: el tipo de ciclo, las corrientes del aire de combustión, el sistema de recuperación utilizado, etc.). Habría que comparar el consumo energético real de las composiciones que contienen residuo cocido en su formulación, (PORC-2) y (REV-2), utilizando el mismo tipo de horno de rodillos industrial que se utiliza para cocer las composiciones de referencia (PORC-STD) y $(\mathrm{REV}-\mathrm{STD})$. 


\section{Capítulo 5.CONCLUSIONES.}

Esta Tesis Doctoral se ha basado en la valorización de las arcillas españolas, de Ciudad Real y de Teruel, junto con la incorporación, además de lodos, aguas de limpieza y testillos crudos, de residuos cocidos procedentes del sector cerámico y del vidrio reciclado. Las conclusiones más destacadas que se desprenden de este trabajo se enumeran a continuación:

1. La arcilla española de Ciudad Real (N-A-Cr), estudiada en este proyecto, que contiene cantidades importantes de hematita, $\mathrm{Fe}_{2} \mathrm{O}_{3}$, se ha tratado mediante distintas técnicas de desferritización. El procedimiento más óptimo ha sido el tamizado de la arcilla a 100 um seguido de la desferritización magnética. Con ello, se ha conseguido reducir más de 45\% del contenido de hierro en la misma.

2. La arcilla española de Teruel (N-B-te) con altos contenidos en siderita, $\mathrm{FeCO}_{3}$, estudiada, ha sido tamizada en un tamiz de 100 um, reduciendo así, la concentración de esta impureza en un 50\%.

3. La arcilla española de Teruel con altos contenidos en materia orgánica y presencia de siderita ( $\mathrm{N}-\mathrm{A}-\mathrm{te}$ ) ha sido valorizada mediante tratamientos térmicos para la eliminación de la materia orgánica $y$, posteriormente, ha sido tratada para la eliminación magnética del contenido de hierro. De esta forma, se ha obtenido una arcilla española de mayor calidad, puesto que la materia orgánica se ha reducido alrededor de un 70\% y el contenido en hierro de la arcilla calcinada ha disminuido hasta un $21 \%$. 
4. La sustitución de parte de las arcillas de importación por arcillas españolas tratadas, ha permitido formular composiciones de gres porcelánico de calidad técnica similar a la del gres porcelánico de referencia (formulado con arcillas de importación), permitiendo competir con los proveedores de arcillas de otros países. Así, se ha mejorado la prensabilidad y el porcentaje de absorción de agua, mientras que la resistencia mecánica y los parámetros de color han disminuido ligeramente.

5. Las arcillas españolas tratadas se han incorporado en la formulación de pasta blanca para revestimiento, con resultados muy positivos, puesto que, respecto a la composición de referencia, se mantienen los valores correspondientes a la gresificación, sin incrementar el porcentaje de materia orgánica, si bien la resistencia mecánica en seco y los parámetros de color disminuyen sólo ligeramente.

6. La incorporación de residuos cocidos, procedentes del sector cerámico y del reciclado del vidrio, en la formulación de pasta de gres porcelánico ha permitido fabricar baldosas de gres porcelánico de calidad elevada, obteniéndose un grado de sinterización, medido como densidad aparente en cocido a máxima gresificación, de $2.38 \mathrm{~g} / \mathrm{cm}^{3}$, y una resistencia mecánica en seco sobre $3.90 \mathrm{~N} / \mathrm{mm}^{2}$, superando incluso a la composición de referencia, lo que facilita su manipulación industrial desde la salida de la prensa hasta su entrada al horno de rodillos. Esto permite el poder manipular formatos más grandes y el poder aplicar decoraciones serigráficas, etc., si bien el grado de blancura (medido a través de las coordenadas cromáticas) disminuye ligeramente.

7. También con la incorporación de residuos cocidos, procedentes del sector cerámico y del reciclado del vidrio, se han obtenido formulaciones para baldosas de revestimiento de la misma 
calidad que las baldosas fabricadas con la composición de referencia, tanto a nivel de gresificación como de resistencia mecánica, quedando sin embargo, el grado de blancura ligeramente inferior al de la composición de referencia.

8. La incorporación de residuos cocidos para la formulación de la pasta blanca de gres porcelánico ha adelantado la etapa de sinterización en $45^{\circ} \mathrm{C}$ menos que la temperatura actual, de $1185^{\circ} \mathrm{C}$.

9. Como se ha evidenciado en los correspondientes diagramas de gresificación, la introducción de residuos cocidos ha reducido hasta $140^{\circ} \mathrm{C}$ de temperatura de cocción (de $1140^{\circ} \mathrm{C}$ a $1000^{\circ} \mathrm{C}$ ), la etapa de sinterización de las baldosas de revestimiento, al mismo tiempo que ha mejorado la resistencia mecánica en seco de las baldosas.

10. Se ha conseguido un importante ahorro energético gracias al uso de material reciclado, permitiendo la disminución de la temperatura de cocción, tanto en pastas de gres porcelánico (estimado en un 8\%) como en las de revestimiento (estimado en un $16 \%)$

11. Por último, se ha posibilitado un beneficio medioambiental al consumir residuos, tanto del propio sector cerámico (lodos, testillo crudo y chamota, aguas sucias) como de otros sectores como el del vidrio reciclado, permitiendo disminuir el consumo de recursos naturales y el impacto medioambiental, al no derivar estos residuos a vertederos y, también, la reducción de emisiones de $\mathrm{CO}_{2}$ por la incorporación de residuos ya cocidos (chamota y vidrio) . 



\section{Capítulo 6.RECOMENDACIONES Y PROYECTOS FUTUROS}

Como se ha comentado en algunos apartados de este trabajo, quedan abiertos los proyectos que a continuación se resumen:

- Proyecto de tratamiento gravimétrico de la arcilla de Ciudad Real, a través de hidrociclones en serie para refinar las corrientes de "Finos" y "Gruesos", aumentando así el rendimiento de la operación de separación. Este estudio se va a desarrollar más adelante en las instalaciones de Grupo Tierra Atomizada, con el fin de reducir las mermas a nivel industrial y optimizar el proceso del hidrociclonado.

- Proyecto de tratamiento térmico de arcillas con alto contenido en materia orgánica en horno eléctrico tipo mufla con posibilidad de modificar la atmósfera interior, ya que se ha visto que el aumento de concentración de oxígeno en la atmósfera del horno, reduce la temperatura de descomposición de la materia orgánica.

- Proyecto de tratamiento por radiación en horno microondas (apartado 4.2.2), siguiendo las pruebas indicadas en la Tabla X. El tratamiento por microondas de las arcillas precalentadas mediante infrarrojos a temperaturas que no superen los $450^{\circ} \mathrm{C}$, para mantener lo más intacta posible la estructura illítico-caolinítica, es interesante desarrollarlo porque, teóricamente, supone un ahorro importante de energía y tiempo. 
- Proyecto de producción a escala industrial de composiciones de gres porcelánico tipo (PORC-2) y de revestimiento tipo (REV-2), que incorporen residuos cocidos para optimizar el proceso y calcular el ahorro energético real. La utilización de residuos cocidos supone una mejora importante a nivel medioambiental, además de producir un ahorro energético, no sólo por la reducción de $\mathrm{CO}_{2}$, sino por la disminución de la temperatura de sinterización, tanto en porcelánico como en revestimiento.

- Proyecto de fabricación de baldosas de gres porcelánico y de revestimiento con pastas que incorporen residuos cocidos, tras la reformulación de esmaltes y engobes adecuados a las nuevas curvas de cocción. Para engobar y esmaltar baldosas que sinterizan a temperaturas inferiores es necesario que los engobes y los esmaltes anticipen también su ciclo de cocción.

- El adelanto de la etapa de gresificación de las composiciones que contienen residuo cocido, obliga a fabricar engobes y esmaltes que se acoplen a menor temperatura. En consecuencia, esto abre camino hacia otro proyecto de gran envergadura que se debería estar formado por un fabricante de polvo atomizado, un fabricante de baldosas de pasta blanca, un fabricante de esmalte y engobes y por una entidad universitaria que coordinase todo el proyecto, que está en estudio. 


\section{Capítulo 7 .BIBLIOGRAFIA.}

[1] D. Náger, "El azulejo se vuelca en la pasta blanca para preservar ventas". El Periódico Mediterráneo, 12/06/2006: Tema del día.

[2] E. Criado, "Reflexiones sobre el futuro de la Industria Europea de la Cerámica", Boletín de la Sociedad Española de Cerámica y Vidrio, 46 (1), $39-43,(2007)$.

[3] E. Sánchez, J. García-Ten, M. Regueiro, "Materias para la industria cerámica española. Situación actual y perspectivas", Boletín de la Sociedad Española de Cerámica y Vidrio, 45 (1), 1-12, (2006).

[4] M.D. Notari, J. Llop, I. Nebot, E. Barrachina, S. Ferrer, J.B. Carda, "Estudio y caracterización de materias primas para la formulación de pastas cerámicas de gres porcelánico", Cerámica Información, 356, 41-57, $(2008)$.

[5] J. Llop, M.D. Notari, I. Nebot-Díaz, E. Barrachina, I. Núñez, J.B. Carda, "Estudios de gresificación a composiciones de gres porcelánico con la introducción de nuevos fundentes y materias primas nacionales", Qualicer, Ed. Cámara de Comercio de Castellón, Castellón, 2010.

[6] L. Sánchez-Muñoz, I.T. Marinova, G. F. de la Fuente, I. Núñez, M.A. Rodríguez, J. Sánz, J.B. Carda," $I+D+i$ para las baldosas cerámicas del siglo XXI: competencia, diversidad y funcionalidad", Qualicer, Ed. Cámara de Comercio de Castellón, Castellón, 2010.

[7] "Guía de mejores técnicas disponibles para el sector de fabricación de baldosas cerámicas en la Comunitat Valenciana", Ed. Instituto de Tecnología Cerámica y Comisión de Trabajo, Castellón, 2009. 
[8] A. Barba, V. Beltrán, C. Feliu, J. García, F. Ginnés, E. Sánchez, V. Sánz, "Materias primas para la fabricación de soportes de baldosas cerámicas", Ed. Instituto de Tecnología Cerámica, Castellón, 1997.

[9] Sacmi Ibérica, "Tecnología Cerámica Aplicada", vol. II, Ed. Faenza Editrice Ibérica, S.L., Castellón, 2004.

[10] Expert Cerámica, Solución de gestión para el sector de la cerámica, http://www.erp-expert-ceramica.es/, [Consulta: 25-11-2010].

[11] J. Albors, J. I. Hervás, "La industria cerámica europea en el siglo XXI. Retos tecnológicos y desafíos de la próxima década", Boletín de la Sociedad Española de Cerámica y Vidrio, 45 (1), 13-21, (2006).

[12] V. Cantavella, E. Sánchez, G. Mallol, E. Monfort, L. Miralles, E. Cuesta, M.C. García, "Control de la operación de molienda en contínuo", Qualicer, Ed. Cámara de Comercio de Castellón, Castellón, 2002.

[13] Minera Sabater, S.I., http://www.minerasabater.es, [Consulta: 21-012009].

[14] M. Bhappu, Diseño de plantas de proceso de minerales, Editorial Rocas y minerales, Madrid, 1982.

[15] Gervasio Belda, S.L., http://www.gervasiobelda.com, [Consulta: 2-22010].

[16] Sacmi, Molinos continuos, http://www.sacmi.com/System/00/01/03/10356/633562908054062500_1.pdf, [Consulta: el 5-4-2009].

[17] Tierra Atomizada, S.A., "Estudios propios", L’Alcora, Castellón, 2010. 


\section{[18] Sacmi, Atomizadores,}

http://www.sacmi.it/System/00/01/06/10601/633568390894062500_1.pdf,

[Consulta 5-4-2009].

[19] Ch. Agrafiotis, Th.Tsoutsos, "Energy saving technologies in the European ceramic sector: a systematic review", Applied Thermal Engineering, 21, 1231-1249, (2001).

[20] J. Llop, M.D. Notari, E.Barrachina, I. Nebot, I. Núñez, J.B. Carda, "Tratamientos en arcillas con vistas a mejorar sus coordenadas cromáticas para el sector de fabricación de gres porcelánico", Boletín de la Sociedad Española de Cerámica y Vidrio, 49 (6), 413-422, (2010).

[21] G. Biffi, "Fine porcelain stoneware tiles", Editorial Faenza Editrice, Faenza, 1998 .

[22] J.L. Amorós, A.Barba, V. Beltrán, "Estructuras cristalinas de los silicatos y óxidos de las materias primas cerámicas", Ed. Instituto de Tecnología Cerámica, Castellón, 1994.

[23] L. Sánchez, J. B. Carda, "Enciclopedia Cerámica", Vol.II, Ed. Faenza Editrice Ibérica S.L., Castellón, 2001.

[24] Arciblansa, S.A., http://www.arciblansa.com, [Consulta 8-5-2010].

[25] C. Leonelli, F. Bondioli, P. Veronesi, M. Romagnoli, T. Manfredini, G. C. Pellacani, v. Canillo, "Enhancing the mechanical properties of porcelain stoneware tiles: a microstructural approach", Journal of the European Ceramic Society, 21, 785-793, (2001).

[26] E. Sánchez, M.J. Orts, J. García-Ten, V. Cantavella, "Porcelain tile composition effect on phase formation and end products", American Ceramic Society Bulletin, 80 (6), 43-49, (2001).

[27] J. A. Cabezas, J.C. Galiano, J.B. Carda, C. Gil, E. Navarro, J. Pascual, "Estudio comparativo de los parámetros determinantes del 
comportamiento químico-físico y mecánico de diferentes gres porcelánicos", Qualicer, Ed. Cámara de Castellón, Castellón, 2006.

[28] J.L. Amorós, A. Escardino, E. Sánchez, F. Zaera, "Estabilidad dimensional en piezas de monococción porosa", Ed. Instituto de Tecnología Cerámica, Castellón, (1990).

[29] Universidad Politécnica de Madrid, "Control, desmuestre y protección",

http://ww2.minas.upm.es/catedra-anefa/nunez-6/contro desmuestre5 m6.PPT, [Consulta 12-3-2010].

[30] Minera Sabater, S.L., "Estudios propios", Crivillén, Teruel, 2000.

[31] A. Ballester, L.F. Verdeja, J.P. Sancho, "Metalurgia extractiva", vol. I, Ed. Síntesis, 2000 .

[32] Electromagnestismo,

http://materias.fi.uba.ar/6209/download/4-Materiales\%20Magneticos.pdf, [Consulta: 11-12-2010].

[33] R.D. Ambashta, M. Sillanpää, "Water purification using magnetic assistance: A review", Journal of Hazardous Materials, 180, 38-49, (2010).

[34] R. Juan, C. Ruiz, X. Querol, J.L. Fernández; A. López, "Caracterización y clasificación de los carbones cretácicos de Teruel. Relaciones entre sus características y el entorno geológico". Cuadernos de Geología Ibérica, n¹7, 109-13 5, Editorial Complutense, Madrid, 1993.

[35] Mindat.org, wWw.mindat.org/min-3647.html, [14-05-2009].

[36] J. Capel, "Estudio mineralógico y geoquímico de sedimentos y cerámicas arqueológicas de algunos yacimientos de la Mancha". http://biblioteca2.uclm.es/biblioteca/CECLM/ARTREVISTAS/oretum/Oretum_II_ estudio_capel.pdf, [Consulta 25-4-2010].

[37] J. García Guinea, J. Martínez Frías, "Recursos Minerales de España", Ed. Centro Superior de Investigaciones Científicas (CSIC), 1992. 
[38] F. Negre, "Mecanismo de la formación y cinética de la oxidación del "corazón negro" durante la cocción de las piezas cerámicas", Tesis Doctoral, Facultad de Químicas, Universitat de València, 1989.

[39] A. Barba, "Oxidación del "corazón negro" durante la cocción de piezas cerámicas. Influencia de la estructura del sólido y de su contenido en materia orgánica y óxidos de hierro sobre la cinética del proceso", Tesis Doctoral, Universitat de València, 1989.

[40] A. Escardino, "Reacciones y procesos a alta temperatura", Departamento de Ingeniería Química, Universitat Jaume I, 1999.

[41] P.S. Nicholson, W.A. Ross, "Kinetics of Oxidation of Natural Organic Material in Clays". Journal of the American Ceramic Society, 53, 154-158, (1970).

[42] X. Querol, J.S. Chichón, A. López, "Distribución del azufre en los carbones albienses de la cuenca del Maestrazgo". Acta geológica hispánica, vol. 24, n¹, 21-32, 1989.

[43] M. A. Albéniz, "Perspectiva de la minería del carbón en Teruel", Cuadernos de Geología Ibérica, $n^{\circ}$ 17, 39-56. Editorial Complutense, Madrid, 1993.

[44] S. Qinglei, L. Wen, C. Haokan, L. Baoqing, "The variation of structural characteristics of macerals during pyrolysis", Fuel, 82, 669$676,(2003)$.

[45] O. Gómez, I. Carmona, O. Bustamante, "Análisis de liberación de los grupos de macerales del carbón: carbones colombianos", Boletín de Ciencias de la Tierra, 75-85, (2007).

[46] A. Scott, "Coal petrology and the origin of coal macerals: a way ahead?" International Journal of Geology, 50, 119-134, (2002). 
[47] R.M. Bustin, y col., "Coal Petrology its principles, Methods and Aplications", Short Courses Notes, Geological Association of Canada, $n^{\circ}$ 3. 1983 .

[48] C. Ward, L.W Gurba, "Chemical composition of macerals in bituminous coals of the Gunnedah Basin, Australia, using electron microprobe analysis techniques", International Journal of Geology 39, 279-300, (1999).

[49] M. Khandelwal, T.N. Singh, "Prediction of macerals contents of Indian coals from proximate and ultimate analyses using artificial neural networks", Fuel, 89, 1101-1109, (2010).

[50] L. Kozdrowska, B.Pilawa, A.B. Wieckowski, "Influence of thermal decomposition on paramagnetic centres in vitrinite". Fuel Processing Technology, 85, 1585-1593, (2004).

[51] J.L. Amorós, V. Beltrán, A. Blasco y col., "Defectos de fabricación de pavimentos y revestimientos cerámicos", Ed. Instituto de Tecnología Cerámica, Castellón, 1991.

[52] J. Velasco, "Patologías de las piezas cerámicas para la construcción", Ed. Asociación para la Investigación y Desarrollo Industrial de Recursos Naturales (Aitemin), 2005.

[53] W.E. Brownell, Journal of the American Ceramic Society, 40 (6), 179$187,(1957)$.

[54] V.P. Kareev, P.I. Berenshtein, Steklo Keramik, 11, 27-30, (1970).

[55] W.E. Lee, G.P. Souza, C.J. McConville, T. Tarvornpanich, Y. Iqbal, "Mullite formation in clays and clay-derived vitreous ceramics", Journal of the European Ceramic Society, 28, 465-471, (2008).

[56] H. Schneider, S. Komarneni, "Mullite", Ed. Wiley-Vch, New York, 2005. 
[57] J. Bastida, "Procedimiento para la eliminación de la materia orgánica presente en las arcillas cerámicas y en materiales arcillosos en general", Valencia, España, núm. 2126 488, (30-09-1999).

[58] Ingetecsa, http://www.ingetecsa.com/pdf_prod/TamboresRotativos.pdf, [Consulta 16-4-2011].

[59] R. Saidur, M.S. Hossaina, M.R. Islam, H. Fayaz, H.A. Mohammed, " $A$ review on kiln system modeling", Renewable and Sustainable Energy Reviews, 15, 2487-2500, (2011).

[60] X. Yan Liu, E. Specht, "Temperature distribution within the moving bed of rotary kilns: Measurement and analysis", Chemical Engineering and Processing: Process Intensification, 49, 147-150, (2010).

[61] K.S. Hatzilyberis, "Design of an indirect heat rotary kiln gasifier", Fuel Processing Technology, 92 (12), 2429-2454, (2011).

[62] P. R. Davies, M. J.S. Norton, D. Ian Wilson, John F. Davidson, D. M. scott, "Gas flow in rotary kilns" Particuology 8, 613-616, (2010).

[63] A. Boateng, "Transport Phenomena and Transport Processes", Rotary Kilns, Butterworth Heinemann, 2008.

[64] S.w. Kingman, "A method of microwave treatment of multiphase materials", Nottingham (Gran Bretaña), núm. 1490525 B1, (12-12-2007).

[65] C.Y. Yue, H.C. Looi, "Influence of thermal and microwave processing on the mechanical and interfacial properties of a glass/epoxy composite", Composites, 26, 767-773, (1995).

[66] J. Berlan, "Microwaves in chemistry: another way of heating reaction mixtures", Radiation Physics and Chemistry, 45 (4), 581-599, (1995).

[67] J.M. Hill, T.R. Marchant, "Modelling microwave heating", Applied Mathematics and Computation, 20, 3-15, (1996). 
[68] S. Bodman, P. Monsef-Mirzai, H. Manak, W.R. Mcwhinnie, "Does microwave heating have a role in functional group reactions of coal?", Fuel, 76 (13), 1315-1318, (1997).

[69] S.W. Kingman, N.A. Rowson, "Microwave treatment of minerals-a review", Mineral Engineering, 11, 1081-1087, (1998).

[70] H.S. Tai, C.G. Jou, "Application of granular activated carbon packed-bed reactor in microwave radiation field to treat phenol". Chemosphere 38, 2667-2680, (1999).

[71] E.T. Thostenson, T.W. Chou, "Microwave processing: fundamentals and applications", Composites, 30 (A), 1055-1071, (1999).

[72] D.E. Clark, D.C. Folz, J.K. West, "Processing materials with microwave energy", Materials Science and Engineering, A287, 153-158, $(2000)$.

[73] T.J. Appleton, R.I. Colder, S.W. Kingman, I.S. Lowndes, A.G. Read, "Microwave technology for energy-efficient processing of waste", Applied Energy ,81, 85-113, (2005).

[74] E. Lester, S. Kingman, "Effect of microwave heating on the physical and petrographic characteristics of a U.K. Coal", Energy \& Fuels, 18, $140-147,(2004)$.

[75] E. Lester, S. Kingman, "The effect of microwave pre-heating on five different coals", Fuel, 83, 1941-1947, (2004).

[76] S.W. Kingman, K. Jackson, S.M.Bradshaw, N.A. Rowson, R. Greenwood, "An investigation into the influence of microwave treatment on mineral ore comminution", Powder technology, 146, 176-184, (2004).

[77] J.L. Pedreño-Molina, J. Monzó-Cabrera, M. Pinzolas, "A new procedure for power efficiency optimization in microwave ovens based on thermographic measurements and load location search", International Communications in Heat and Mass Transfer, 34, 564-569, (2007). 
[78] Y. Zhao, J. Chen, "Applications of microwaves on nuclear chemistry and engineering", Process in Nuclear Energy, 50, 1-6, (2008).

[79] S. Vongpradubchai, P. Rattanadecho, "The microwave processing of wood using a continuous microwave belt drier" Chemical Engineering and Processing, 48, 997-1003, (2009).

[80] S.J. Ma, X.W. Zhou, X.J. Su, W. Mo, J.L. Yang, P. Liu, "A new practical method to determine the microwave energy absorption ability of materials", Minerals Engineering, 22, 1154-1159, (2009).

[81] N. Serpone, S. Horikoshi, A.V. Emeline, "Microwaves in advanced oxidation processes for environmental applications. A brief review", Journal of Photochemistry and Photobiology C: Photochemistry Reviews, 11, $110-117,(2010)$.

[82] F.L. Liu, X. Qian, X. Wu, C. Guo, Y. Lei, J. Zhang, "The response of carbon black filled high-density polyethylene to microwave processing", Journal of Materials Processing Technology, 210, 1991-1996, (2010).

[83] C. Leonelli, T.J. Mason, "Microwave and ultrasonic processing: Now a realistic option for industry", Chemical Engineering and Processing, 2010 .

\section{[84] Industrial Microwave Heating Technology,}

http://www.amtmicrowave.com, [Consulta 2-7-2008].

[85] BI. Elle. Srl. Microwaves.it. Engineering company, http://www.microwaves.it/spa/microondas.html, [Consulta 11-9-2009].

[86] Y. Pan, R. Zhu, Q. Liu, M. Jackson, "Low-temperature magnetic behavior related to thermal alteration of siderite". Geophysical research letters, 29 (23), 2087, (2002). 
[87] I. Znamenackova, M. Lovas, A. Mockovciaková, S. Jakabsky, J. Briancin, "Modification of magnetic properties of siderite ore by microwave energy", Separation and Purification Technology, 43, 169-174, $(2005)$.

[88] T. Uslu, ü. Atalay, "Microwave heating of coal for enhanced magnetic removal of pyrite", Fuel Processing Technology, 85, 21-29, (2003).

[89] T. Uslu, Ü. Atalay, A.I. Arol, "Effect of microwave heating on magnetic separation of pyrite", Colloids and Surfaces A: Physicochemical and Engineering Aspects, 225, 161-167, (2003).

[90] D.D. Bluhm, G.E. Fanslow, S.O. Nelson, "Enhanced magnetic separation of pyrite from coal after microwave heating", IEEE Transactions on Magnetics, 22 (6), (1986).

[91] F. Andreola, L. Babieri, I. Lancellotti, T. Manfredini, "Piezas de gres porcelánico: efecto del reciclado de las aguas residuales sobre las propiedades reológicas, térmicas y estética", Qualicer, Ed. Cámara de Castellón, Castellón, 2004.

[92] "Tratamiento de emisiones gaseosas, efluentes líquidos y residuos sólidos de la industria cerámica", Ed. Instituto de Tecnología Cerámica, Castellón, 1992.

[93] "Cuestiones sobre medio ambiente para un técnico del sector cerámico", Ed. Instituto de Tecnología Cerámica, Castellón, 1999.

[94] Azulejos Plaza, "Estudio de la incorporación de residuos derivados de la fabricación cerámica y del vidrio reciclado en el proceso cerámico". Premio Alfa de Oro, Cevisama 2011.

[95] Chamota, S.L., http://www.chamota.es/productos.php, [Consulta 7-92009].

[96] E. Monfort, J. García-Ten, M. Monzó, E.Bou, "Viabilidad del reciclado de residuos cocidos de baldosas", Qualicer, Ed. Cámara de Comercio de Castellón, Castellón, 2002. 
[97] W.D Callister, "Introducción a la ciencia e ingeniería de los materiales", 2a edición, Ed. Reverté, Barcelona, 2009.

[98] P. Escribano, J.B. Carda, E. Cordoncillo, "Enciclopedia Cerámica", Vol. I, Ed. Faenza Editrice Ibérica S.L., Castellón, 2001.

[99] G. Tammann, w. Hesse, "Die Abháugigkeit dar visksitlt von dar temperatur bei unterkahlten flússigkeiten", Zeitschrift für anorganische und allgemeine Chemie, 156, 245-257, (1926).

[100] A. Dietzel, "Relations between surfasse tension and structure of molten glass", Kolloid-Zeitschrift und Zeitschrift für Polymere, 100, 368-380, (1942).

[101] J.M. Fernández, "El Vidrio", Ed. Centro Superior de Investigaciones Científicas-Sociedad Española de Cerámica y Vidrio, $2^{a}$ Edición, Madrid, 2009.

[102] M. Dondi, G. Guarini, M. Raimonndo, C. Zanelli, "Recycling PC and TV waste glass in clay bricks and roof tiles", Waste Management, 29, 1945-1951, (2009).

[103] V. Loryuenyong, T. Panyachai, K. Kaewsimorka, C. Siritai, "Effects of recycled glass substitution on the physical and mechanical properties of clay bricks", Waste Management 29 2717-2721, (2009).

[104] F. Andreola, L. Barbieri, E. Karamanova, I. Lancellotti, M. Pelino, "Recycling of CRT panel glass as fluxing agent in the porcelain stoneware tile production", Ceramics International, 34, 1289-1295, (2008).

[105] A. Tucci, E. Rambladi, L. Esposito, "Use of scrap glass as raw material for porcelain stoneware tiles", Advances in Applied Ceramics, 105 (1), 40-45, (2006). 
[106] A.P. Luz, S. Ribeiro, "Use of glass waste as a raw material in porcelain stoneware tile mixtures", Ceramic International, 33 (5), 761$765,(2007)$.

[107] P. Torres, R.S. Manjate, S. Quaresma, H.R. Fernandes, J.M.F. Ferreira, "Development of ceramic floor tile compositions based on quartzite and granite sludges" Journal of the European Ceramic Society, $27,4649-4655,(2007)$.

[108] P. Torres, H.R. Fernandes, S. Oliveiro, J.M.F. Ferreira, "Incorporation of wastes from granite rock cutting and polishing industries to produce roof tiles", Journal of the European Ceramic Society, 29, 23-30, (2009).

[109] R. Alonso-Santurde, A. Coz, J.R. Viguri, A. Andrés, "Recycling of foundry by-products in the ceramic industry: Green and core sand in clay bricks", Construction and Building Materials, (2011).

[110] R. Alonso-Santurde, A. Coz, N. Quijorna, J.R. Viguri and A. Andrés, "Valorization of foundry sand in clay bricks at industrial scale: environmental behavior of clay-sand mixtures", Journal of Industrial Ecology, 14, 217-230, (2010).

[111] T.K. Mukhopadhyay, S. Ghosh, J. Ghosh, S. Ghatak, H.S. Maiti, "Effect of fly ash on the physico-chemical and mechanical properties of a porcelain composition", Ceramics International, 36, 1055-1062, (2010).

[112] S. Yürüyen, H. O. Toplan, "The sintering kinetics of porcelain bodies made from waste glass and fly ash", Ceramics International, 35, 2427-2433, (2009).

[113] V. Melnick, S.A. Pianaro, S. Cava, S.M. Tebcherani, "Application of oil shale mining by-products as raw materials in the determination of the vitrification curve of red porcelain stoneware tiles by dilatometric method", Applied Clay Science, 50, 311-314 (2010). 
[114] N. Romero, A. Andrés, R. Alonso, J.R. Viguri and J.M. Rincón, "Sintering behaviour of ceramic bodies from contaminated marine sediments", Ceramic International, 334, 1917-1924, (2008).

[115] A. Shui, X. Xi, Y. Wang, X. Cheng, "Effect of silicon carbide additive on microstructure and properties of porcelain ceramics", Ceramics International, 37, 1557-1562, (2011).

[116] C. Zanelli, G. Baldi, M. Dondi, G. Ercolani, G. Guarini, M. Raimondo, "Glass-ceramic frits for porcelain stoneware bodies: Effects on sintering, phase composition and technological properties", Ceramics International, 34 455-465, (2008).

[117] E. Rambaldi, I. Esposito, F. Andreola, L. Barbieri, I. Lancellotti, I. Vassura, "The recycling of MSWI bottom ash in silicate based ceramic", Ceramics International, 36, 2469-2476, (2010).

\section{[118] Desarrollo sostenible.}

http://www.sostenibilidad.com, [Consulta 31-08-2010].

\section{[119] Portal de sostenibilidad.}

http://portalsostenibilidad.upc.edu, [Consulta: 29-08-2010].

[120] Ecovidrio, WWw.ecovidrio.es, [Consulta: 29-08-2010].

\section{[121] Asociación Española de Reciclado de Vidrio.}

http://www.anarevi.com/presentacion.htm, [Consulta 29-08-2010].

[122] Universidad Nacional de Educación a Distancia (UNED), http://www. uned.es/cristamine/mineral/metodos/bragg.htm, [Consulta: 2205-2009].

\section{[123] Expert System Solutions,}

http://www.expertsystemsolutions.com/SPAGNOLO/strumenti/HSM.html, [Consulta: 07-03-2011].

\section{[124] Leco, Delivering the Right Results,}


http://www.leco.com/products/organic/sc144/SC144DR.html, [Consulta: 1405-2011].

[125] F.G. Ortiz, "Procesamiento morfológico de imágenes en color. Aplicación a la reconstrucción geodésica", Tesis Doctoral, Alicante, 2002 .

[126] Serviquimia S.L.,

http://www.serviquimia.com/upload/documentos/20110311134158.dilatometros. pdf, [Consulta: 20-01-2010].

[127] Gabbrielli Technology, s.r.1.

http: //www.gab-tec.com/upload_pdf/FLEXI201000\%20LX.CCC.pdf,

[Consulta: 27-03-2010]

\section{[128] Labotronic, aparatos para laboratorio,}

http: //www. labotronic.es/librerias/ver_pdf.php?tab=productos\&nc_cod=codig o\&cod=36\&nc_pdf=documento, [Consulta: 15-06-2011].

[129] "Manual para el control de la calidad de materias primas arcillosas", 2a edición, Ed. Instituto de Tecnología Cerámica, Castellón, 2004

[130] ERAL, Equipos y procesos, S.A.,

http://www.eralgroup.com/pdf/prog_16.pdf, [Consulta: 25-05-2010].

[131] B. Wang, K.W. Chu, A.B. Yu, A. Vince, G.D. Barnett, P.J. Barnett, "Computational study of the multiphase flow and performance of dense medium cyclones: Effect of body dimensions", Minerals Engineering, 24, 19-34, (2011). 
[132] V. Golyk, S. Huber, M.G. Farghaly, G. Prölss, E. Endres, T. Neesse, M.A. Hararah, "Higher kaolin recovery with a water-injection cyclone", Minerals Engineering, 24, 98-101,(2011).

[133] J. Dueck, E. Pikushchak, L. Minkov, M. Farghaly, Th. Neesse, "Mechanism of hydrocyclone separation with water injection", Minerals Engineering 23, 289-294, (2010).

[134] M.J. Janse van Vuuren, C. Aldrich, L. Auret, "Detecting changes in the operational states of hydrocyclones", Minerals Engineering", 24,15321544, (2011).

\section{[135] Master Magnets Itd.}

http://www.mastermagnets.com, [Consulta: 25-02-2009].

[136] S. Mohanty, B. Das, B.K. Mishra, "A preliminary investigation into magnetic separation process using CFD", Minerals Engineering xxx, $x x x-$ xxx, (2011).

[137] Construmática "Proceso de Fabricación de baldosas cerâmicas", http://www.construmatica.com/construpedia/Proceso_de_FabricacioC3\%B3n_de_ Baldosas_CeroC3Almicas, [Consulta: 22-04-2011].

[138] Y. Pan, R. Zhu, Q. Liu, M. Jackson, "Low-temperature magnetic behaviour related to thermal alteration of siderite", Geophysical Research Letters, vol. 29 (23), 2087, (2002).

[139] J. Márquez-Márquez, J. Ma. Rincón, M. Romero, "Effect of firing temperature on sintering of porcelain stoneware tiles", Ceramics International, 34, 1867-1873, (2008).

[140] M.J. Orts, A. Escardino, J.L. Amorós, F. Negre, "Microestructual changes during the firing of stoneware floor tiles", Applied Clay Science, 8, (2-3), 193-205, (1993). 
[141] E. Sánchez, M.J. Ibañez, J. García-Ten, M.F. Quereda, I.M. Hutchings, Y.M. Xu, "Porcelain tile microstructure: Implications for polished tile properties", Journal of the European Ceramic Society, 26, 2533-2540, (2006).

[142] C. Zanelli, M. Raimondo, G. Guarini, M. Dondi, "The vitreous phase of porcelain stoneware: Composition, evolution during sintering and physical properties", Journal of Non-Crystalline Solids, 357, 3251-3260, (2011).

[143] E. Suvaci, N. Tamsua, "The role of viscosity on microstructure development and stain resistance in porcelain stoneware tiles", Journal of the European Ceramic Society, 30, 3071-3077, (2010).

[144] E. Monfort, A. Mezquita, R. Granel, E. Váquer, A. Escrig, A. Miralles, v. Zaera, "Análisis de consumos energéticos y emisiones de dióxido de carbono en la fabricación de baldosas cerámicas", Boletín de la Sociedad Española de Cerámica y Vidrio, 49 (4), 303-310 (2010).

[145] H.J. Alves, F.G. Melchiades, A.O. Boschi, "Brazilian ceramic tiles industry: thermal energy consumption and CO2 emissions", Ed. Cámara de Comercio de Castellón, Castellón, 2012.

[146] G. Nassetti et al. "Piastrelle ceramiche \& energía: banca dati dei consumi energetici nell'industria della piastrelle di ceramica". Bologna: Assopiastrelle, 1998 . 
Capítulo 8.APÉNDICE.

8.1. Listado de materias primas utilizadas.

Tabla LXII. Listado de las materias primas utilizadas.

\begin{tabular}{|c|c|}
\hline MATERIAS PRIMAS & NOMENCLATURA \\
\hline Arcilla de importación alta alúmina 1 & I-A-A \\
\hline Arcilla de importación alta alúmina 2 \\
\hline Arcilla española alta alúmina de Teruel & N-A-te \\
\hline Arcilla española baja alúmina de Teruel & N-B-te \\
\hline Arcilla española alta alúmina de Ciudad Real & N-A \\
\hline Carbonato cálcico & Fdto Na \\
\hline Feldespato sódico & Fdto Na-Mg \\
\hline Feldespato sódico-magnésico & \\
\hline Residuo cocido (vidrio, chamota) & \\
\hline
\end{tabular}


8.2. Caracterización cerámica de la arcilla (A-I-1).

ARCILLA DE IMPORTACION (A-I-1)

$\begin{array}{lr}\text { CALCIMETRIA. } & 0,25 \% \\ \text { PLASTICIDAD. } & 28,74 \% \\ \text { RESIDUO MASICO }(63 \mu \mathrm{m}) . & 7,60 \% \\ \text { RESIDUO MASICO }(63 \mathrm{~mm}) . & 3,12 \% \\ \therefore \text { CARBONO ORGANICO } & 0,01 \%\end{array}$

HUMEDAD

$6,14 \%$

DENSIDAD VERDE

DENSIDAD SECO

$1,94 \mathrm{~g} / \mathrm{cm}^{3}$

PRESION ESPECIFICA

$1,83 \mathrm{~g} / \mathrm{cm}^{3}$

$551 \mathrm{Kg} / \mathrm{cm}^{2}$

CARACTERISTICAS DE COCCION/

DILATOMETRIA

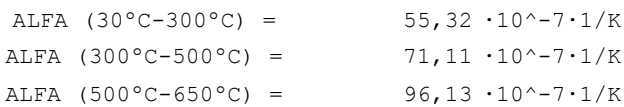

DIAGRAMA DE GRESIFICACIÓN

\begin{tabular}{|c|c|c|c|c|c|c|}
\hline $\mathrm{T}^{\mathbf{a}} \max .\left({ }^{\circ} \mathrm{C}\right)$ & 1090 & 1115 & 1140 & 1165 & 1185 & 1200 \\
\hline$\% \mathrm{C} . \mathrm{L}$. & 4,07 & 6,10 & 7,63 & 8,57 & 9,23 & 9,56 \\
\hline \% $\mathrm{Aa}$. & 11,82 & 8,97 & 6,47 & 4,05 & 2,64 & 2,21 \\
\hline $\mathrm{L}^{*}$ & - & - & - & 84,24 & 82,82 & 81,74 \\
\hline $\mathbf{a}^{*}$ & - & - & - & 2,77 & 2,27 & 1,86 \\
\hline $\mathrm{b} *$ & - & - & - & 13,33 & 13,91 & 14,86 \\
\hline
\end{tabular}

(\%) C.I

12,

10 ,

8,0

6,0

4,0

2,0

0,0

1060
DIAGRAMA DE GRESIFICACION

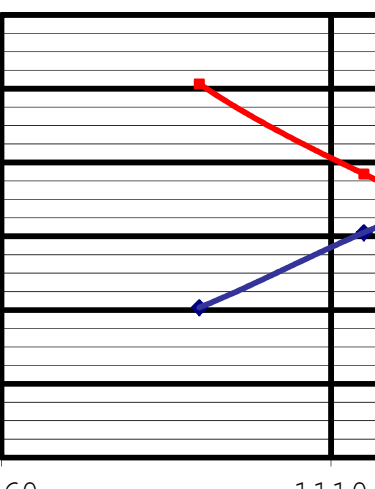

(응 A. a .

14,0

12,0

10,0

8,0

6,0

4,0

2,0

0,0

1210

T $\left({ }^{\circ} \mathrm{C}\right)$ 
8.3. Caracterización cerámica de la arcilla (A-I-2).

ARCILLA DE IMPORTACION (A-I-2)

CALCIMETRIA.

PLASTICIDAD.

RESIDUO MASICO $(63 \mu \mathrm{m})$.

RESIDUO MÁSICO $(100 \mu \mathrm{m})$.

\% CARBONO ORGANICO
$0,42 \%$

3,40

$2,20 \div$

$0,05 \div$
HUMEDAD

DENSIDAD VERDE

DENSIDAD SECO

PRESION ESPECIFICA
$6,59 \div$

CARACTERISTICAS DH COCCION

DILATOMETRIA

DIAGRAMA DE GRESIFICACIÓN

\begin{tabular}{|c|c|c|c|c|c|c|}
\hline $\mathrm{T}^{\mathbf{a}} \max .\left({ }^{\circ} \mathrm{C}\right)$ & 1090 & 1115 & 1140 & 1165 & 1185 & 1200 \\
\hline$\%$ C.L. & 4,73 & 5,82 & 7,26 & 7,66 & 8,22 & 8,62 \\
\hline$\% \mathrm{Aa}$. & 7,90 & 5,82 & 3,58 & 2,59 & 1,43 & 0,47 \\
\hline $\mathrm{L}^{*}$ & - & - & - & 77,56 & 75,27 & 71,77 \\
\hline $\mathbf{a} *$ & - & - & - & 3,69 & 2,74 & 2,70 \\
\hline $\mathrm{b} *$ & - & - & - & 12,48 & 12,54 & 13,18 \\
\hline
\end{tabular}

(\%) C.L.

$$
\begin{array}{r}
10,0 \\
9,0 \\
8,0 \\
7,0 \\
6,0 \\
5,0 \\
4,0 \\
3,0 \\
2,0 \\
1,0 \\
0,0
\end{array}
$$

1060
DIAGRAMA DE GRESIFICACION

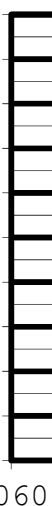

\section{DIAGRAMA DE GRESIFICACION}

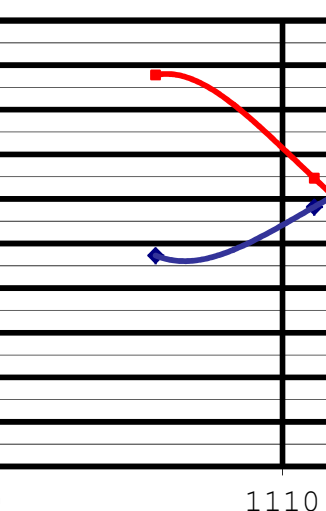

(응 A. a.

\section{9,0}

8,0

7,0

6,0

5,0

4,0

3,0

2,0

1,0

0,0

$\mathrm{T}\left({ }^{\circ} \mathrm{C}\right)$ 
8.4. Caracterización cerámica de la arcilla (N-A-Cr).

ARCILLA ESPAÑOLA (N-A-Cr)

CALCIMETRIA .

PLASTICIDAD.

RESIDUO MASICO $(63 \mu \mathrm{m})$.

RESIDUO MÁSICO $(100 \mu \mathrm{m})$.

\% CARBONO ORGANICO
$0,21 \%$

$24,79 \%$

$0,40 \%$

$0,04 \div$

$0,00 \div$
HUMEDAD

DENSIDAD VERDE

DENSIDAD SECO

PRESION ESPECIFICA
$6,52 \div$

$2,01 \mathrm{~g} / \mathrm{cm}^{3}$

$1,89 \mathrm{~g} / \mathrm{cm}^{3}$

$330 \mathrm{Kg} / \mathrm{cm}^{2}$

\section{CARCTERISTICAS DE CQCCION}

DILATOMETRIA

ALFA $\left(30^{\circ} \mathrm{C}-300^{\circ} \mathrm{C}\right)=$
ALFA $\left(300^{\circ} \mathrm{C}-500^{\circ} \mathrm{C}\right)=$
ALFA $\left(500^{\circ} \mathrm{C}-650^{\circ} \mathrm{C}\right)=$

DIAGRAMA DE GRESIFICACIÓN

\begin{tabular}{|c|c|c|c|c|c|c|}
\hline $\mathrm{T}^{\mathrm{a}} \max .\left({ }^{\circ} \mathrm{C}\right)$ & 1090 & 1115 & 1140 & 1165 & 1185 & 1200 \\
\hline$\because$ C.L. & 0,86 & 1,85 & 2,71 & 3,64 & 4,50 & 5,03 \\
\hline ㅇa. & 13,29 & 11,75 & 9,38 & 7,59 & 6,16 & 5,06 \\
\hline$L^{*}$ & - & - & - & 68,56 & 65,13 & 62,48 \\
\hline$a *$ & - & - & - & 5,43 & 4,81 & 4,15 \\
\hline$b^{*}$ & - & - & - & 8,87 & 8,30 & 7,94 \\
\hline
\end{tabular}

$51,91 \cdot 10^{\wedge}-7 \cdot 1 / \mathrm{K}$

$65,34 \cdot 10^{\wedge}-7 \cdot 1 / \mathrm{K}$

$79,18 \cdot 10^{\wedge}-7 \cdot 1 / \mathrm{K}$
() C.I.

DIAGRAMA DE GRESIFICACION

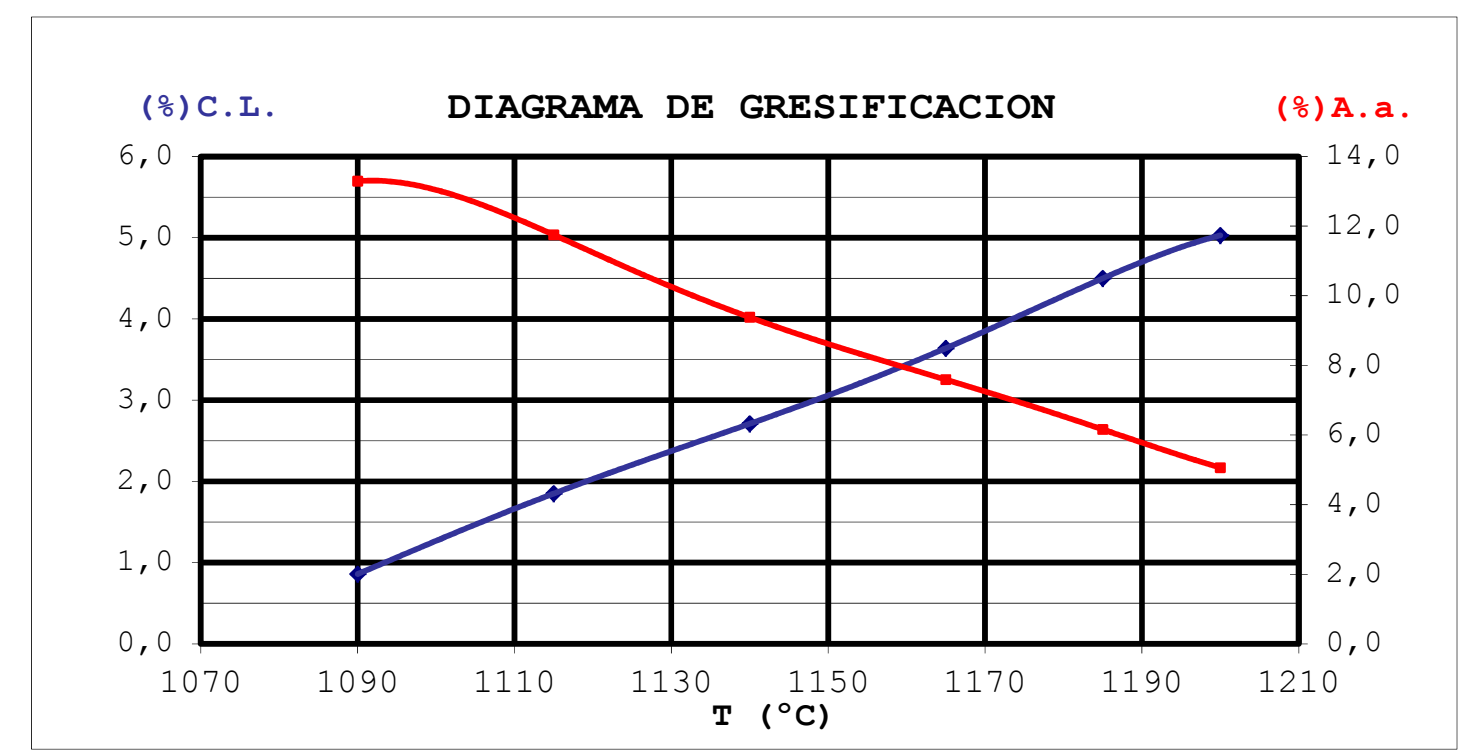




\subsection{Caracterización cerámica de la arcilla (N-A-te) .}

\begin{tabular}{|c|}
\hline \multicolumn{2}{|c|}{ ARCILLA ESPAÑOLA (N-A-te) } \\
\hline
\end{tabular}

CALCIMETRIA.

PLASTICIDAD

RESIDUO MASICO $(63 \mu \mathrm{m})$.

RESIDUO MÁSICO $(100 \mu \mathrm{m})$.

\% CARBONO ORGANICO

\section{$0,61 \%$}

$28,55 \%$

$1,00 \%$

$0,10 \%$

$0,52 \%$
HUMEDAD

DENSIDAD VERDE

DENSIDAD SECO

PRESION ESPECIFICA
$6,49 \%$

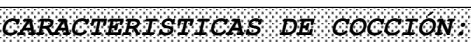

DILATOMETRIA

ALFA $\left(30^{\circ} \mathrm{C}-300^{\circ} \mathrm{C}\right)=$

ALFA $\left(300^{\circ} \mathrm{C}-500^{\circ} \mathrm{C}\right)=$

ALFA $\left(500^{\circ} \mathrm{C}-650^{\circ} \mathrm{C}\right)=$

DIAGRAMA DE GRESIFICACIÓN

\begin{tabular}{|c|c|c|c|c|c|c|}
\hline $\mathrm{T}^{\mathrm{a}} \max \left({ }^{\circ} \mathrm{C}\right)$ & 1090 & 1115 & 1140 & 1165 & 1185 & 1200 \\
\hline \% C.L. & 8,07 & 9,66 & 10,02 & 10,06 & 10,11 & 10,45 \\
\hline$\frac{\mathrm{Aa}}{\mathrm{O}}$. & 5,15 & 2,06 & 0,97 & 0,87 & 0,61 & 0,69 \\
\hline$L^{*}$ & 77,830 & 72,83 & 71,13 & 66,27 & 65,40 & 61,65 \\
\hline$a *$ & 6,840 & 7,54 & 7,18 & 5,05 & 4,15 & 3,40 \\
\hline$b *$ & 16,790 & 19,57 & 19,90 & 17,48 & 17,54 & 16,30 \\
\hline
\end{tabular}

$54,68 \cdot 10^{\wedge}-7 \cdot 1 / \mathrm{K}$

$67,07 \cdot 10^{\wedge}-7 \cdot 1 / \mathrm{K}$

$88,11 \cdot 10^{\wedge}-7 \cdot 1 / \mathrm{K}$ 16,790

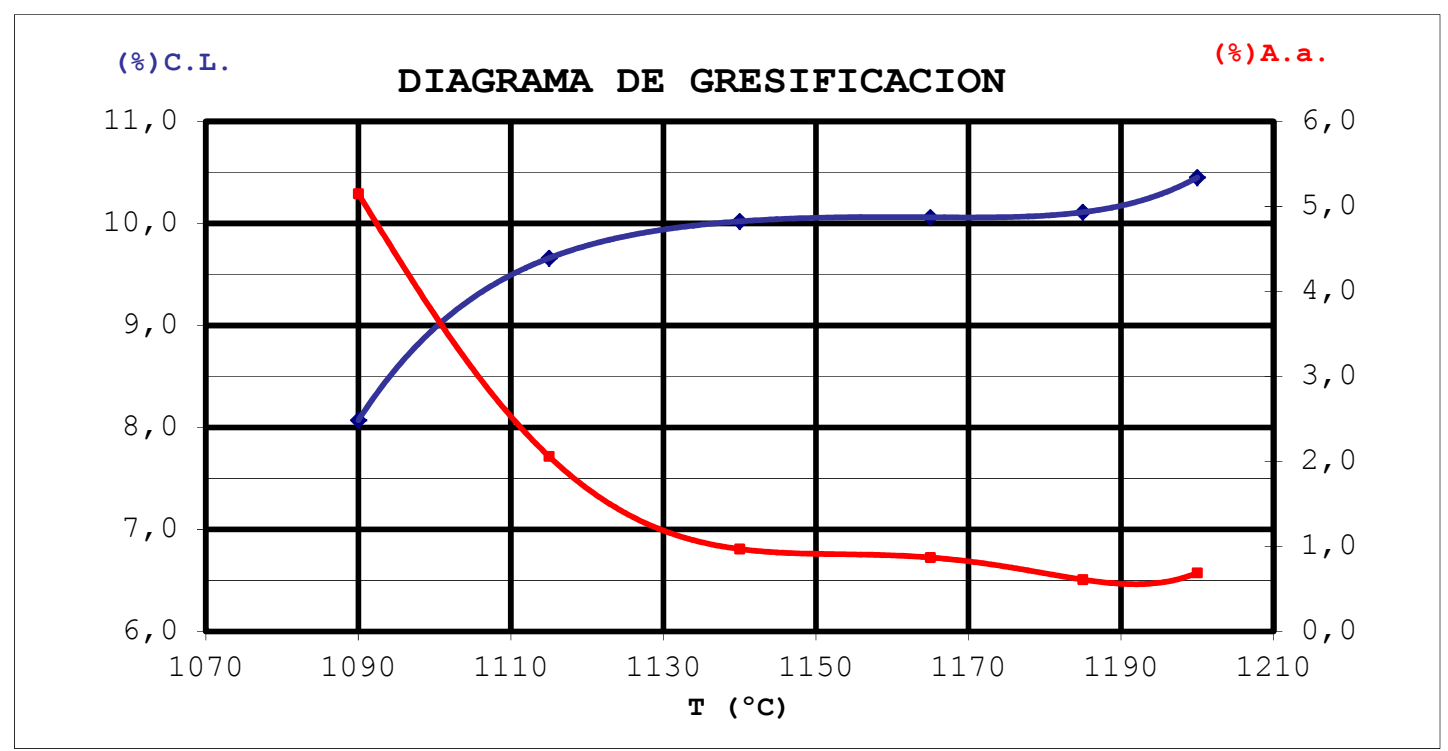


8.6. Caracterización cerámica de la arcilla (N-B-te) sin tratar.

ARCILLA ESPAÑOLA (N-B-te)

$\begin{array}{lr}\text { CALCIMETRIA. } & 0,31 \% \\ \text { PLASTICIDAD. } & 21,63 \% \\ \text { RESIDUO MASICO }(63 \mu \mathrm{m}) . & 2,88 \% \\ \text { RESIDUO MÁSICO }(100 \mu \mathrm{m}) . & 0,46 \% \\ \% \text { CARBONO ORGANICO } & 0,10 \%\end{array}$

HUMEDAD

DENSIDAD VERDE

DENSIDAD SECO

PRESION ESPECIFICA

\section{CARACTERISTICAS DE COCCION:}

DILATOMETRIA

DIAGRAMA DE GRESIFICACIÓN

\begin{tabular}{|c|c|c|c|c|c|c|}
\hline $\mathrm{T}^{\mathbf{a}} \max .\left({ }^{\circ} \mathrm{C}\right)$ & 1090 & 1115 & 1140 & 1165 & 1185 & 1200 \\
\hline$\% \mathrm{C} . \mathrm{L}$. & 2,69 & 3,44 & 3,97 & 4,45 & 4,96 & 5,28 \\
\hline$\% \mathrm{Aa}$. & 10,08 & 8,84 & 7,82 & 6,81 & 5,65 & 5,08 \\
\hline $\mathrm{L} *$ & - & - & - & 77,88 & 76,33 & 75,64 \\
\hline $\mathrm{a} *$ & - & - & - & 4,68 & 4,19 & 3,70 \\
\hline $\mathrm{b} *$ & - & - & - & 19,57 & 19,41 & 18,72 \\
\hline
\end{tabular}

(응 C. I

DIAGRAMA DE GRESIFICACION

(응 A. a .

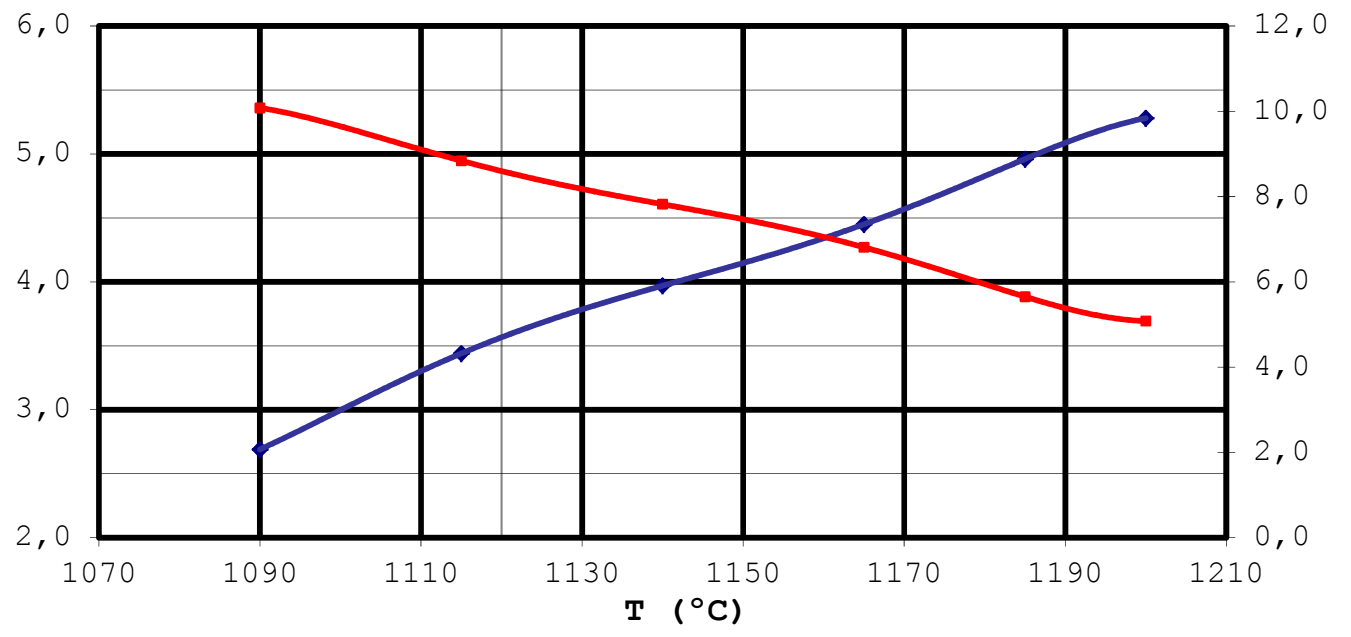


8.7. Difractogramas de las arcillas de importación.

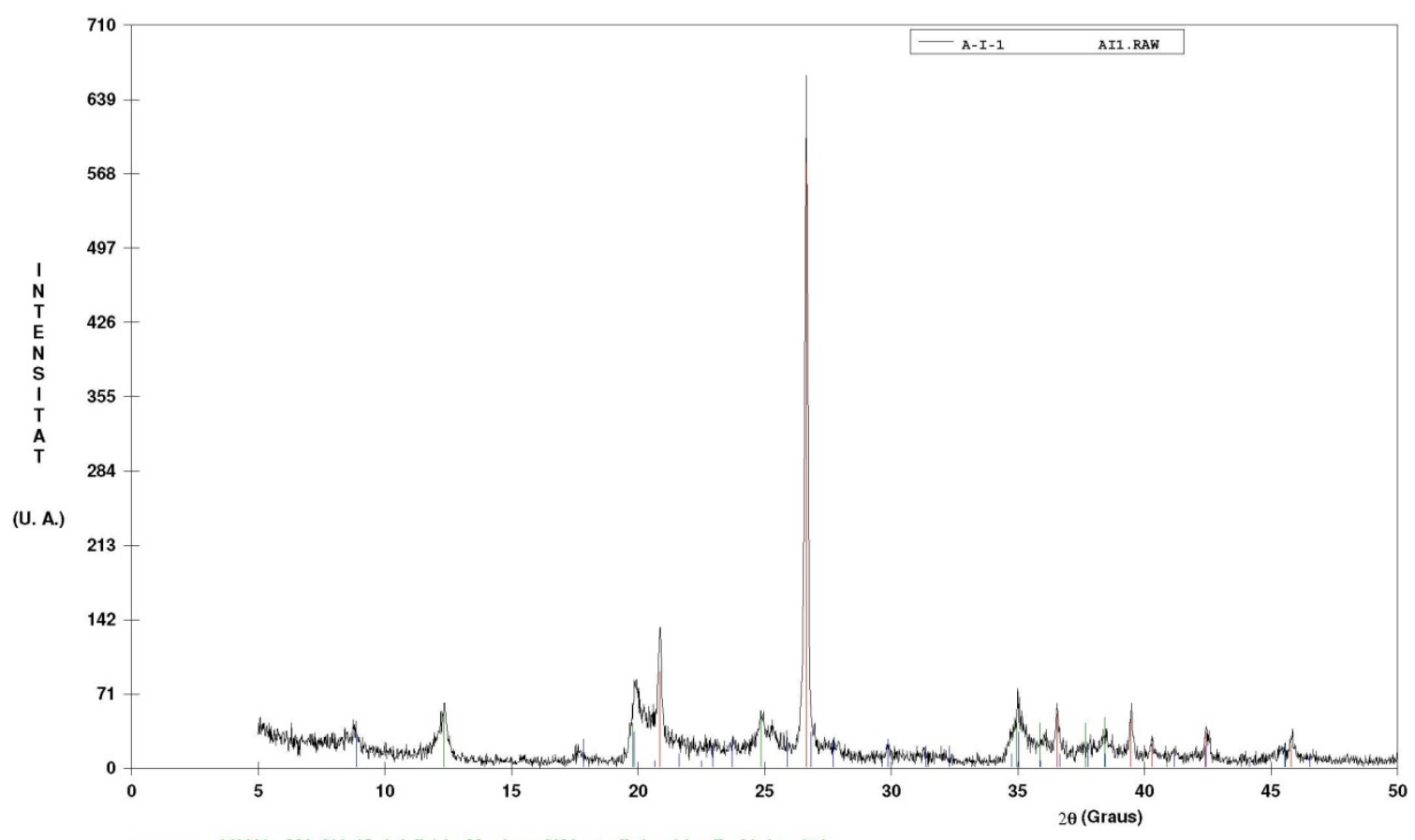

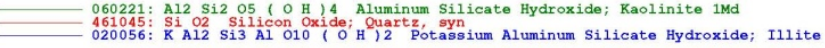

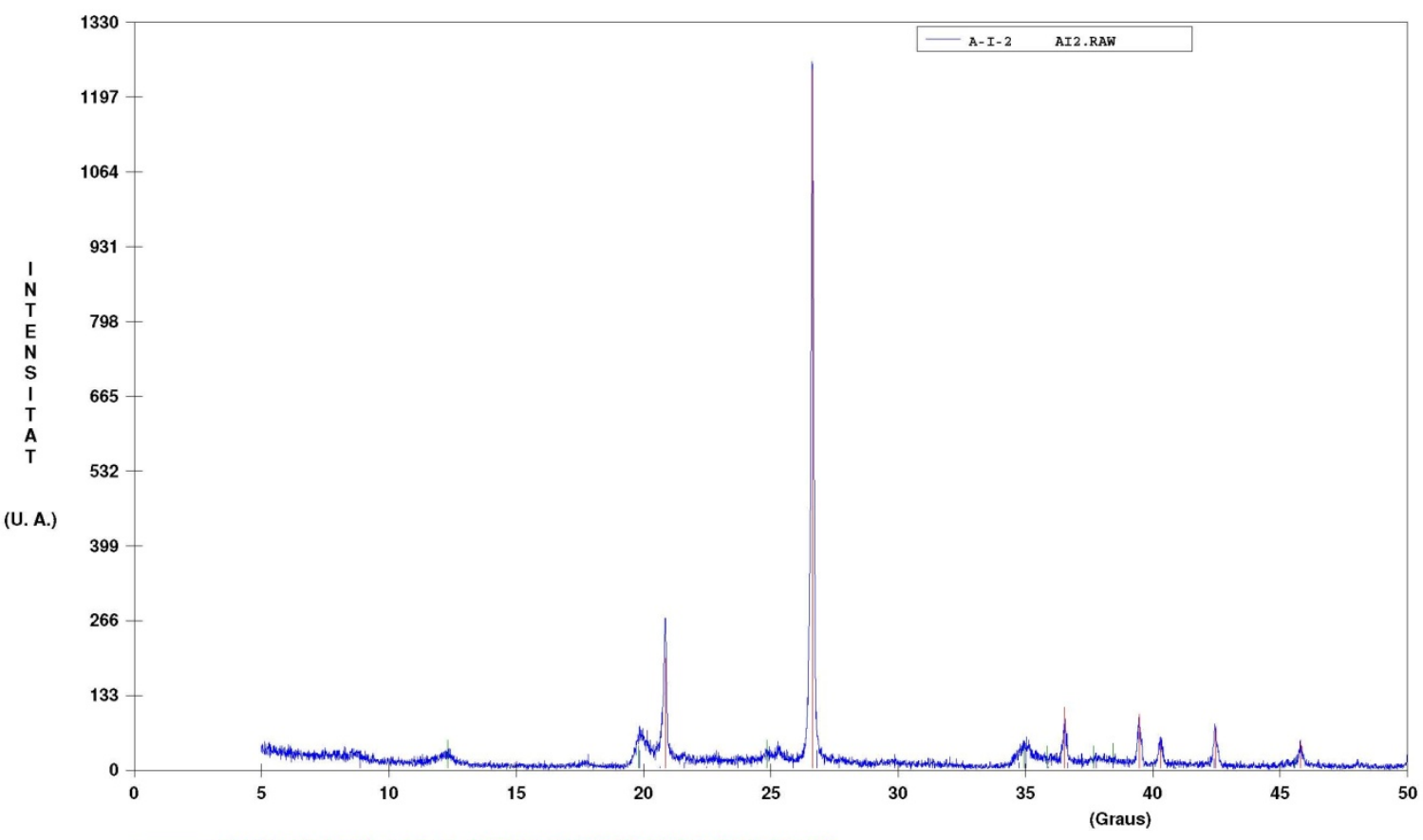

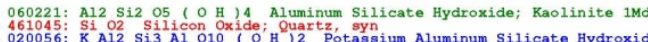


8.8.Difractogramas de los feldespatos.

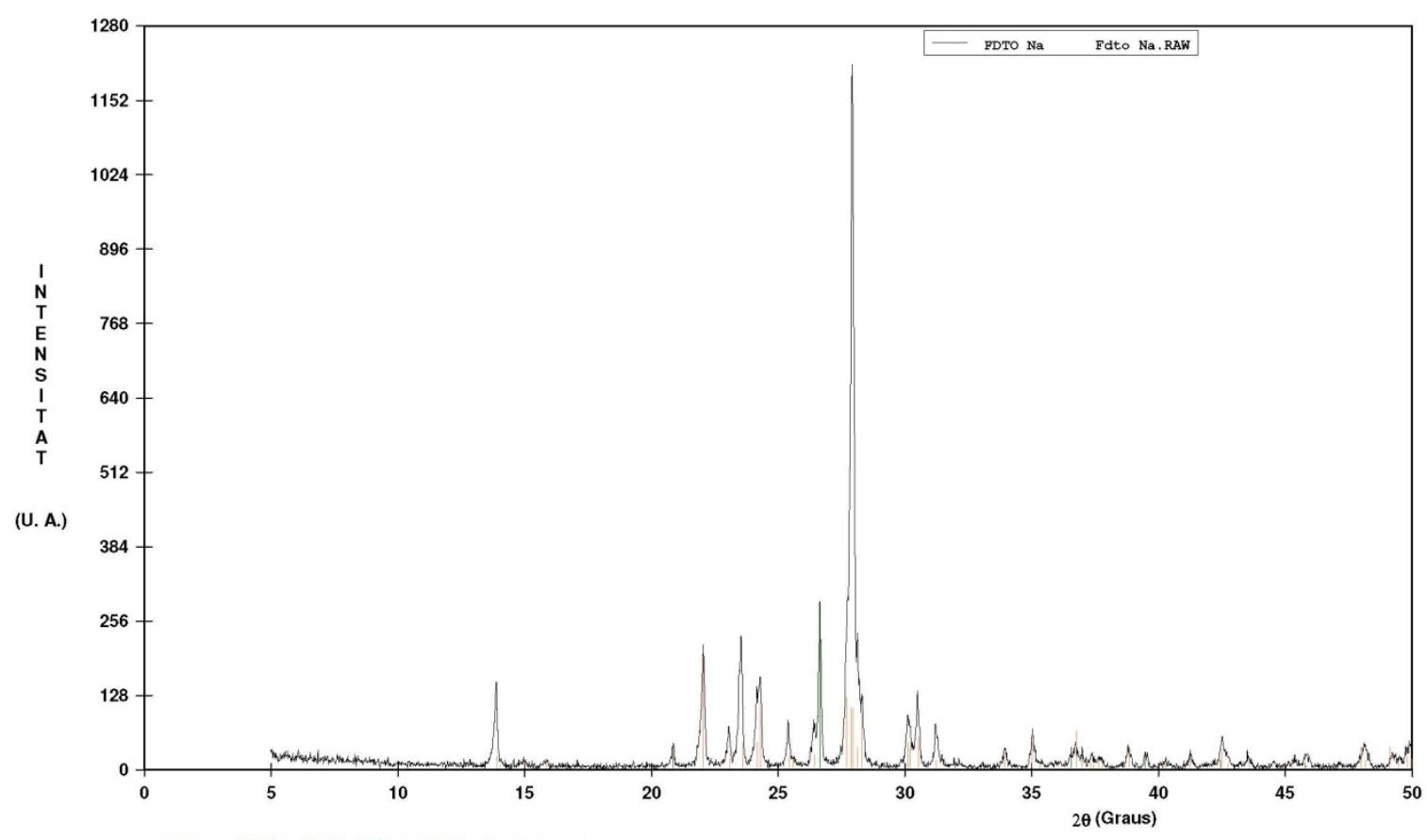

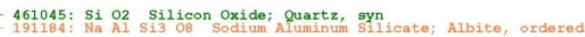

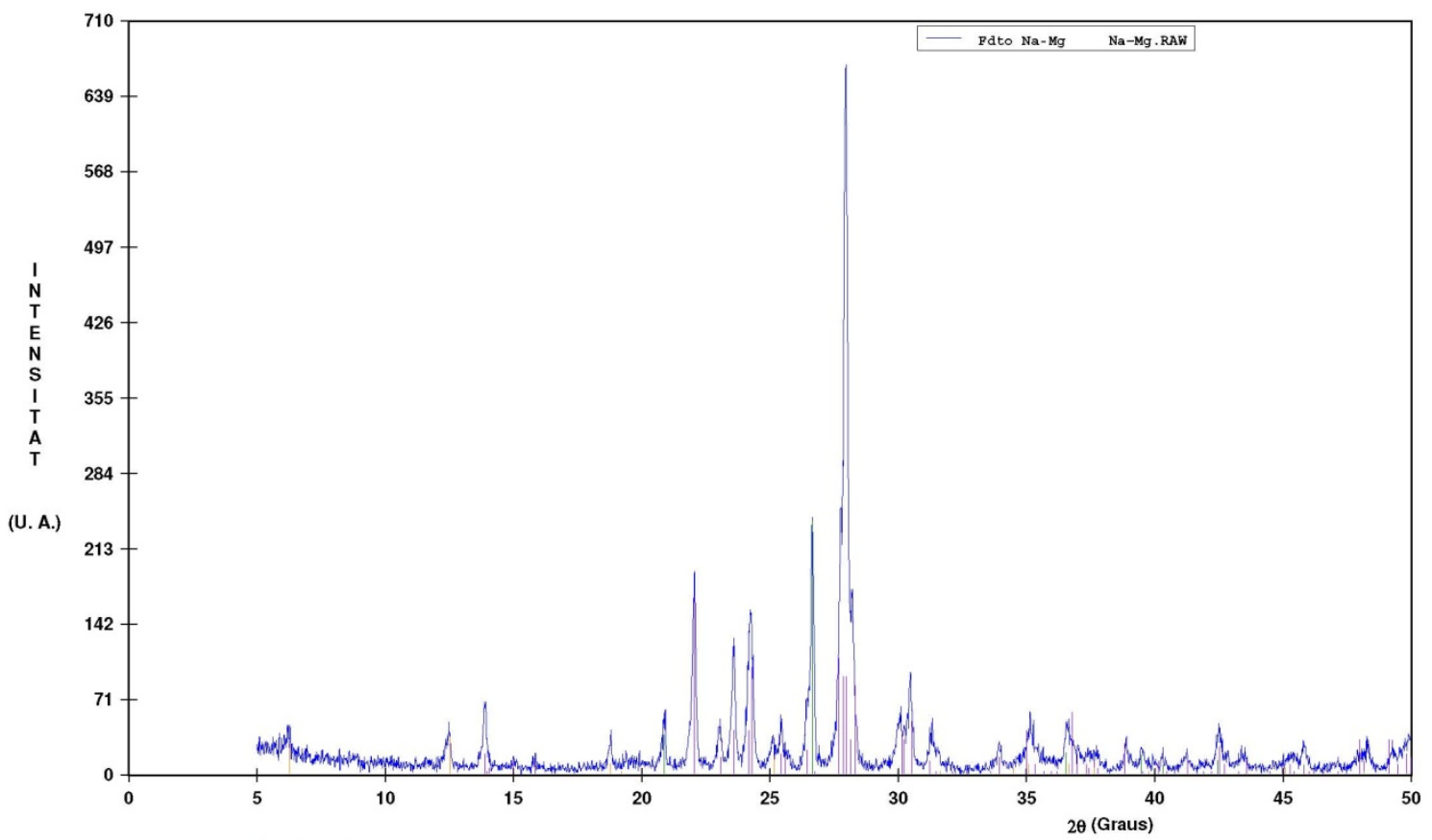

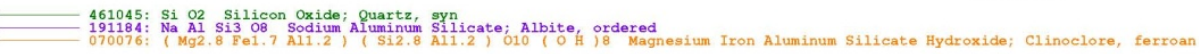




\subsection{Ficha técnica del silicato sódico.}

\section{SILIFLUX AR}

Composición química: Silicato de Sodio en solución acuosa

\begin{tabular}{|c|c|c|}
\hline PARÁMETRO & VALOR & UNIDADES \\
\hline Aspecto & $\begin{array}{c}\text { Líquido límpido } \\
\text { incoloro }\end{array}$ & $\begin{array}{l}-- \\
--\end{array}$ \\
\hline Baume & $50.22-52.64$ & $\circ \mathrm{Be}$ \\
\hline Densidad a $25{ }^{\circ} \mathrm{C}$ & $1.550 \pm 20$ & $\mathrm{~g} / \mathrm{ml}$ \\
\hline Relación ponderal & $2 \pm 0.10$ & -- \\
\hline $\mathrm{SiO}_{2}$ & $30 \pm 0,50$ & $\%$ \\
\hline $\mathrm{Na}_{2} \mathrm{O}$ & $15 \pm 0,50$ & $\%$ \\
\hline Contenido en seco & $45 \pm 1$ & 응 \\
\hline $\mathrm{pH}$ & $12.80 \pm 0.50$ & -- \\
\hline Viscosidad a $25^{\circ} \mathrm{C}$ & $300-800$ & cpoises \\
\hline
\end{tabular}

Fecha de emisión: 31 / 02 / 10

ACRILATOS, S.A. 
8.10. Caracterización cerámica de la arcilla ( $N$-A-te) calcinada $400^{\circ} \mathrm{C}-30$ minutos en horno eléctrico mufla.

$\begin{array}{lr}\text { CALCIMETRIA. } & 0,62 \% \\ \text { PLASTICIDAD. } & 23,86 \% \\ \text { RESIDUO MASICO }(63 \mu \mathrm{m}) . & 5,50 \% \\ \text { RESIDUO MÁSICO }(100 \mu \mathrm{m}) . & 0,86 \% \\ \therefore \text { CARBONO ORGANICO } & 0,10 \%\end{array}$

\begin{tabular}{|c|c|c|c|c|c|c|}
\hline $\mathrm{T}^{\mathbf{a}} \max \cdot\left({ }^{\circ} \mathrm{C}\right)$ & 1090 & 1115 & 1140 & 1165 & 1185 & 1200 \\
\hline$\because$ C.L. & 7,69 & 9,86 & 10,47 & 10,87 & 11,33 & 11,13 \\
\hline$\%$ Aa. & 7,40 & 3,56 & 2,09 & 1,09 & 0,55 & 0,21 \\
\hline $\mathrm{L}^{*}$ & 78,910 & 75,31 & 72,54 & 70,44 & 69,41 & 64,71 \\
\hline $\mathbf{a}^{*}$ & 4,980 & 5,46 & 5,80 & 5,13 & 4,18 & 2,99 \\
\hline $\mathbf{b}^{*}$ & 17,410 & 18,46 & 19,91 & 19,53 & 18,89 & 16,98 \\
\hline
\end{tabular}

() C.I. DIAGRAMA DE GRESIFICACION (응) A. a .

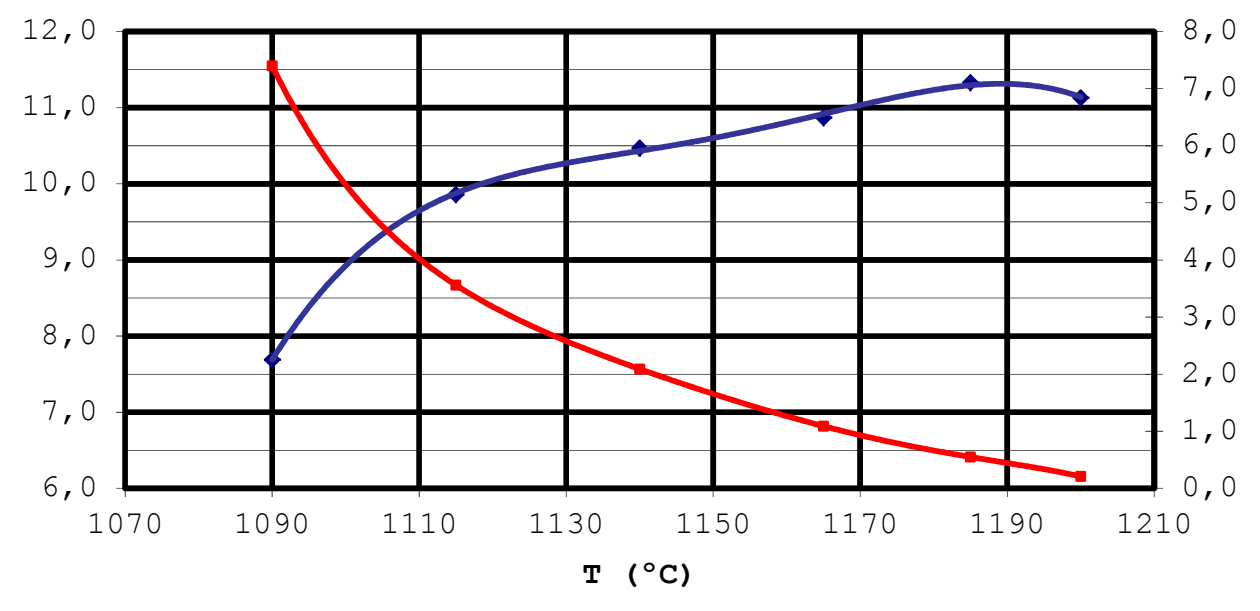


8.11. Caracterización cerámica de la arcilla ( $N$-A-te) calcinada. Granulometría M1.

ARCILLA ESPANOLA $\mathrm{N}-\mathrm{A}-\mathrm{te}$ calc $400^{\circ} \mathrm{C}-30 \mathrm{~min}$.

GRANULOMETRIA M1

CARACTERTSTICAS EN SECO

CARACTERISTICAS DE PRENSADO

$\begin{array}{lr}\text { CALCIMETRIA. } & 0,43 \% \\ \text { PLASTICIDAD. } & 23,80 \% \\ \text { RESIDUO MASICO }(63 \mu \mathrm{m}) . & 6,23 \% \\ \text { RESIDUO MÁSICO }(100 \mu \mathrm{m}) . & 0,54 \% \\ \text { \% CARBONO ORGANICO } & 0,15 \%\end{array}$

HUMEDAD

DENSIDAD VERDE

PRESION ESPECIFICA

$1,910 \mathrm{~g} / \mathrm{cm}^{3}$

$553 \mathrm{Kg} / \mathrm{cm}^{2}$

\% CARBONO ORGANICO

DIAGRAMA DE GRESIFICACIÓN

\begin{tabular}{|c|c|c|c|c|c|c|}
\hline $\mathrm{T}^{\mathbf{a}} \max .\left({ }^{\circ} \mathrm{C}\right)$ & 1090 & 1115 & 1140 & 1165 & 1185 & 1200 \\
\hline$\% \mathrm{C} . \mathrm{L}$. & 7,49 & 9,10 & 9,76 & 10,39 & 10,89 & 10,67 \\
\hline$\circ \mathrm{Aa}$. & 7,31 & 3,64 & 1,89 & 0,65 & 0,13 & 0,13 \\
\hline $\mathrm{L}^{\star}$ & - & - & - & - & - & - \\
\hline $\mathrm{a} *$ & - & - & - & - & - & - \\
\hline $\mathrm{b} *$ & - & - & - & - & - & - \\
\hline
\end{tabular}

(응 ) C. L . DIAGRAMA DE GRESIFICACION

(응 A. a .

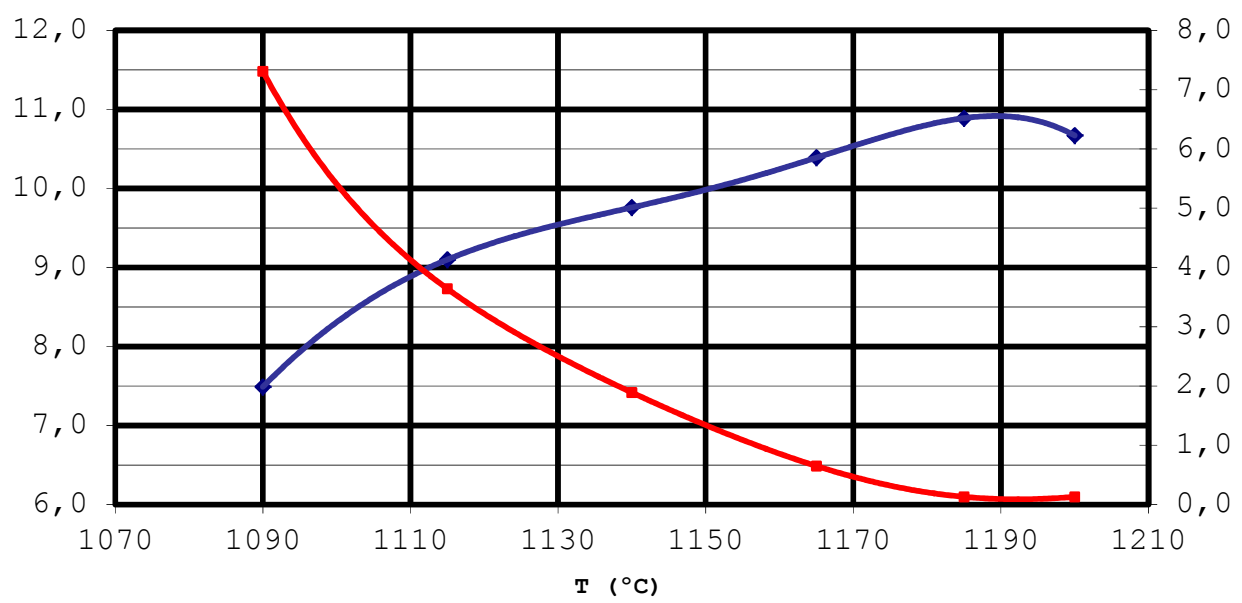


8.12. Caracterización cerámica de la arcilla ( $N-A-t e)$ calcinada. Granulometría M2.

ARCILLA ESPANOLA (N-A-te) CaIC $400^{\circ} \mathrm{C}-30 \mathrm{~min}$.

$\begin{array}{lr}\text { CALCIMETRIA. } & 0,39 \% \\ \text { PLASTICIDAD. } & 24,00 \% \\ \text { RESIDUO MASICO }(63 \mu \mathrm{m}) . & 7,20 \% \\ \text { RESIDUO MÁSICO }(100 \mu \mathrm{m}) . & 0,58 \% \\ \frac{\circ}{0} \text { CARBONO ORGANICO } & 0,26 \%\end{array}$

DIAGRAMA DE GRESIFICACIÓN

\begin{tabular}{|c|c|c|c|c|c|c|}
\hline T $^{\mathbf{a}} \max .\left({ }^{\circ} \mathrm{C}\right)$ & 1090 & 1115 & 1140 & 1165 & 1185 & 1200 \\
\hline$\circ \mathrm{C} . \mathrm{L}$. & 8,09 & 10,12 & 10,65 & 11,08 & 11,53 & 11,23 \\
\hline$\circ \mathrm{Aa}$. & 6,76 & 2,67 & 1,91 & 0,63 & 0,19 & 0,11 \\
\hline $\mathrm{L}^{*}$ & - & - & - & - & - & - \\
\hline $\mathrm{a}^{*}$ & - & - & - & - & - & - \\
\hline $\mathrm{b*}$ & - & - & - & - & - & - \\
\hline
\end{tabular}

(응) C.I.

DIAGRAMA DE GRESIFICACION

(응 A. a .

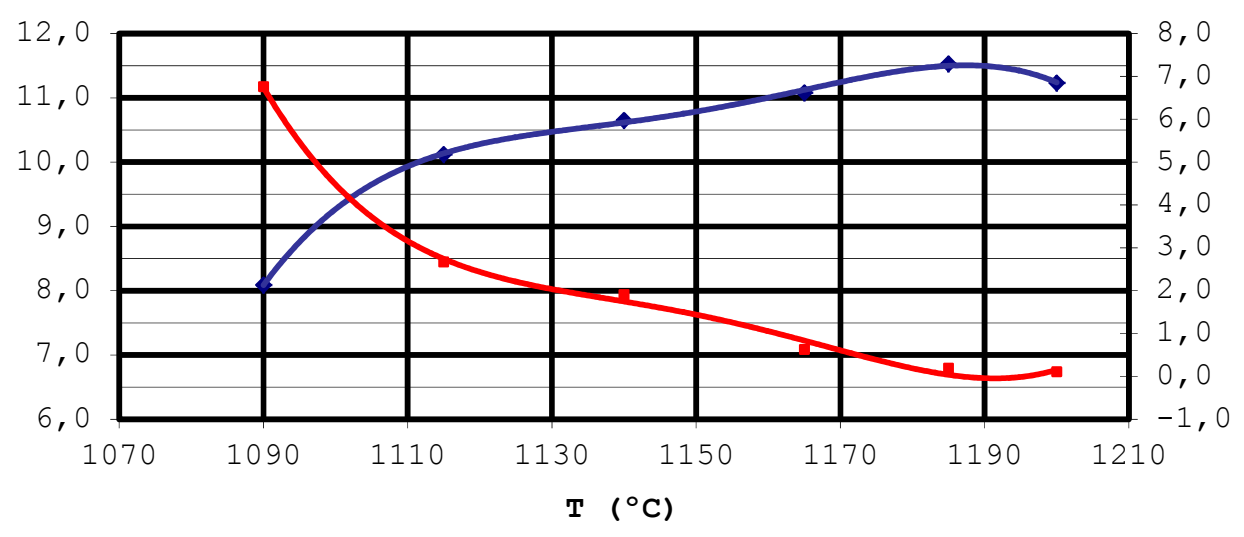




\subsection{Caracterización cerámica de la arcilla ( $N$-A-te)} calcinada. Granulometría M3.

ARCILLA ESPANOLA (N-A-te) CaIC $400^{\circ} \mathrm{C}-30$ min .

GRANULOMETRIA M3

\section{CALCIMETRIA.}

PLASTICIDAD

RESIDUO MASICO (63mm).

RESIDUO MÁSICO (100 mm)

\% CARBONO ORGANICO

$0,43 \%$
$22,62 \%$
$6,01 \%$
$0,23 \%$
$0,34 \%$

$0,43 \%$

$2,62 \div$

$0,34 \div$

\section{HUMEDAD}

DENSIDAD VERDE

DENSIDAD SECO

PRESION ESPECIFICA
$6,45 \%$

$1,97 \mathrm{~g} / \mathrm{cm}^{3}$

$1,85 \mathrm{~g} / \mathrm{cm}^{3}$

$553 \mathrm{Kg} / \mathrm{cm}^{2}$

DIAGRAMA DE GRESIFICACIÓN

\begin{tabular}{|c|c|c|c|c|c|c|}
\hline $\mathrm{T}^{\mathrm{a}} \max \cdot\left({ }^{\circ} \mathrm{C}\right)$ & 1090 & 1115 & 1140 & 1165 & 1185 & 1200 \\
\hline$\because$ C.L. & 6,83 & 8,17 & 9,03 & 9,66 & 9,83 & 8,90 \\
\hline$\because \mathrm{Aa}$. & 6,86 & 4,55 & 2,76 & 1,13 & 1,00 & 1,85 \\
\hline$L^{\star}$ & - & - & - & - & - & - \\
\hline$a *$ & - & - & - & - & - & - \\
\hline$b^{*}$ & - & - & - & - & - & - \\
\hline
\end{tabular}

(응) C.L.

DIAGRAMA DE GRESIFICACION

(응 A.a .

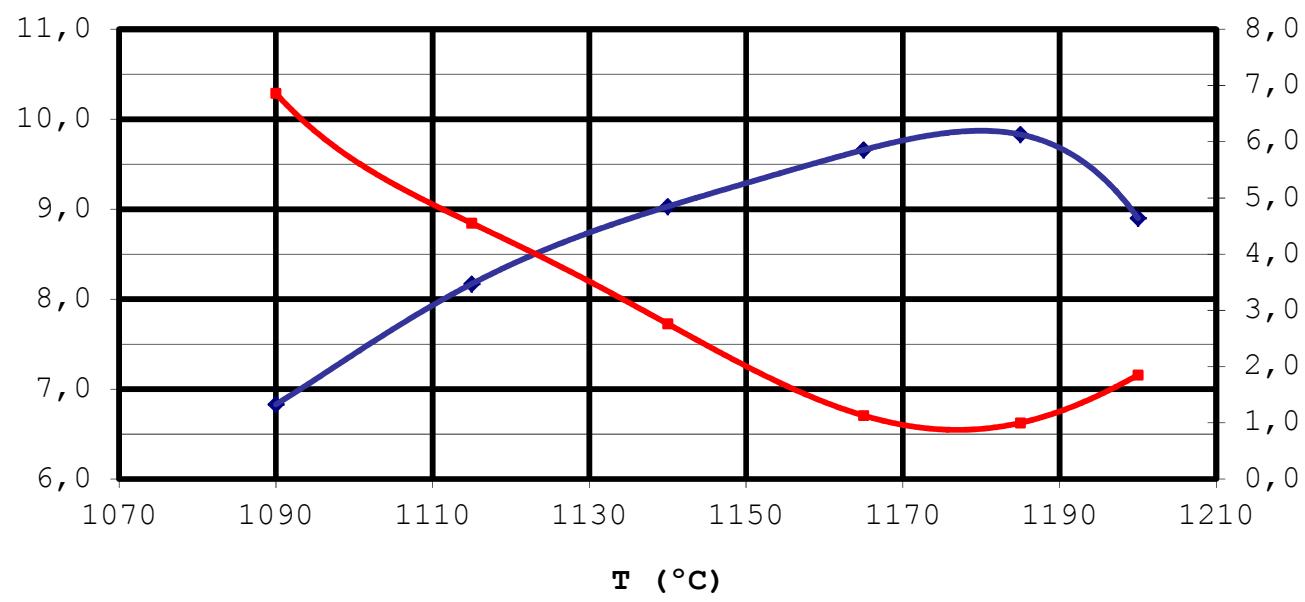




\subsection{Análisis térmico ATD/TG de las muestras preparadas I.}

\begin{tabular}{|c|c|c|c|c|c|c|c|c|c|c|c|c|c|}
\hline \multicolumn{2}{|c|}{$\begin{array}{l}\text { Calentamiento } \\
\text { de } 50^{\circ} \mathrm{C}-1150^{\circ} \mathrm{C} \\
\text { a } 10^{\circ} \mathrm{C} / \mathrm{min}\end{array}$} & \multicolumn{4}{|c|}{$\begin{array}{c}\text { Pico exotérmico } \\
\text { de la combustión } \\
\text { de la materia } \\
\text { orgánica }^{1}\end{array}$} & \multicolumn{4}{|c|}{$\begin{array}{c}\text { Pico endotérmico de } \\
\text { deshidroxilación } \\
\text { de la caolinita }\end{array}$} & \multicolumn{4}{|c|}{$\begin{array}{l}\text { Pico exotérmico de } \\
\text { formación de mullita }\end{array}$} \\
\hline $\begin{array}{l}\text { ATD-TG de } \\
(\mathrm{N}-\mathrm{A}-\mathrm{te})\end{array}$ & $\begin{array}{|cc|}\text { PÉRDIDA } \\
\text { DE } & \text { MASA } \\
\text { TOTAL } \\
\text { TGA } & \text { (\%) }\end{array}$ & $\begin{array}{l}\text { ONSET } \\
\left({ }^{\circ} \mathrm{C}\right)\end{array}$ & $\mid \begin{array}{cc}\mathrm{T} & \mathrm{MAX} \\
\left({ }^{\circ} \mathrm{C}\right)\end{array}$ & $\begin{array}{cc}T & \text { END } \\
& \left({ }^{\circ} \mathrm{C}\right)\end{array}$ & $\begin{array}{l}\text { AREA } \\
\text { PICO } \\
(\mathrm{mJ})\end{array}$ & $\begin{array}{c}\text { ONSET } \\
\left({ }^{\circ} \mathrm{C}\right)\end{array}$ & $\begin{array}{c}\mathrm{T} \text { MAX } \\
\left({ }^{\circ} \mathrm{C}\right)\end{array}$ & $\left|\begin{array}{c}T \\
\left({ }^{\circ} \mathrm{C}\right)\end{array}\right|$ & $\begin{array}{l}\text { AREA } \\
\text { PICO } \\
(\mathrm{mJ})\end{array}$ & $\begin{array}{c}\text { ONSET } \\
\left({ }^{\circ} \mathrm{C}\right)\end{array}$ & $\left|\begin{array}{cc}\mathrm{T} & \mathrm{MAX} \\
\left({ }^{\circ} \mathrm{C}\right)\end{array}\right|$ & $\left|\begin{array}{cc}T & \text { END } \\
\left({ }^{\circ} \mathrm{C}\right)\end{array}\right|$ & \begin{tabular}{|l} 
AREA \\
PICO \\
$(\mathrm{mJ})$
\end{tabular} \\
\hline ORIGINAL $^{2}$ & 10.83 & 349 & 388 & 417 & -2038 & 448 & 515 & 558 & 5358 & 934 & 953 & 976 & -265 \\
\hline $350^{\circ} \mathrm{C}-30 \mathrm{MIN}^{3}$ & 9.82 & 348 & 385 & 409 & -685 & 452 & 516 & 555 & 5128 & 931 & 952 & 974 & -308 \\
\hline $350^{\circ} \mathrm{C}-60$ MIN & 9.71 & 346 & 383 & 414 & -542 & 453 & 516 & 557 & 5042 & 930 & 952 & 971 & -407 \\
\hline $350^{\circ} \mathrm{C}-90$ MIN & 9.55 & & & & & 456 & 516 & 556 & 4854 & 929 & 953 & 984 & -399 \\
\hline $400^{\circ} \mathrm{C}-30$ MIN & 9.42 & & & & & 450 & 516 & 557 & 4944 & 933 & 952 & 978 & -286 \\
\hline $500^{\circ} \mathrm{C}-30$ MIN & 8.10 & & & & & 450 & 516 & 557 & 4172 & 934 & 953 & 973 & -339 \\
\hline $600^{\circ} \mathrm{C}-30 \mathrm{MIN}$ & 3.11 & & & & & 419 & 455 & 486 & 688 & 926 & 950 & 976 & -372 \\
\hline $400^{\circ} \mathrm{C}-60$ MIN & 9.14 & & & & & 457 & 515 & 557 & 4881 & 929 & 952 & 929 & -403 \\
\hline $500^{\circ} \mathrm{C}-60$ MIN & 7.39 & & & & & 446 & 512 & 559 & 3776 & 927 & 952 & 977 & -339 \\
\hline $600^{\circ} \mathrm{C}-60$ MIN & 3.43 & & & & & 352 & 425 & 494 & 141 & 936 & 951 & 973 & -163 \\
\hline
\end{tabular}

Pico exotérmico asignado a la combustión de la materia orgánica presente en la muestra.

2 Arcilla sin tratamiento térmico.

${ }^{3}$ MIN $=$ minutos. 


\subsection{Análisis térmico ATD/TG de las muestras preparadas II.}

\begin{tabular}{|c|c|c|c|c|c|c|c|c|c|c|c|c|c|}
\hline \multicolumn{2}{|c|}{$\begin{array}{l}\text { Calentamiento } \\
\text { de } 50^{\circ} \mathrm{C}-1150^{\circ} \mathrm{C} \\
\text { a } 10^{\circ} \mathrm{C} / \mathrm{min}\end{array}$} & \multicolumn{4}{|c|}{$\begin{array}{c}\text { Pico exotérmico } \\
\text { de la combustión } \\
\text { de la materia } \\
\text { orgánica }\end{array}$} & \multicolumn{4}{|c|}{$\begin{array}{l}\text { Pico endotérmico de } \\
\text { deshidroxilación } \\
\text { de la caolinita }\end{array}$} & \multicolumn{4}{|c|}{$\begin{array}{l}\text { Pico exotérmico de } \\
\text { formación de mullita }\end{array}$} \\
\hline $\begin{array}{l}\text { ATD-TG de } \\
(\mathrm{N}-\mathrm{A}-\mathrm{te})\end{array}$ & $\begin{array}{l}\text { PÉRDIDA } \\
\text { DE MASA } \\
\text { TOTAL } \\
\text { TGA (\%) }\end{array}$ & $\begin{array}{c}\text { ONSET } \\
\left({ }^{\circ} \mathrm{C}\right)\end{array}$ & $\begin{array}{l}\mathrm{T} \operatorname{MAX} \\
\left({ }^{\circ} \mathrm{C}\right)\end{array}$ & $\begin{array}{l}\mathrm{T} \text { END } \\
\left({ }^{\circ} \mathrm{C}\right)\end{array}$ & $\begin{array}{c}\text { AREA } \\
\text { PICO } \\
(\mathrm{mJ})\end{array}$ & $\begin{array}{c}\text { ONSET } \\
\left({ }^{\circ} \mathrm{C}\right)\end{array}$ & $\begin{array}{c}\text { T } \mathrm{MAX} \\
\left({ }^{\circ} \mathrm{C}\right)\end{array}$ & $\left|\begin{array}{cc}T & \text { END } \\
\left({ }^{\circ} \mathrm{C}\right)\end{array}\right|$ & $\begin{array}{l}\text { AREA } \\
\text { PICO } \\
(\mathrm{mJ})\end{array}$ & $\begin{array}{c}\text { ONSET } \\
\left({ }^{\circ} \mathrm{C}\right)\end{array}$ & $\left|\begin{array}{cc}T & M A X \\
\left({ }^{\circ} \mathrm{C}\right)\end{array}\right|$ & $\begin{array}{c}T \\
\end{array}$ & $\begin{array}{l}\text { AREA } \\
\text { PICO } \\
(\mathrm{mJ})\end{array}$ \\
\hline ORIGINAL & 10.83 & 349 & 388 & 417 & -2038 & 448 & 515 & 558 & 5358 & 934 & 953 & 976 & -265 \\
\hline $250^{\circ} \mathrm{C}-120 \mathrm{MIN}$ & 10.78 & 349 & 387 & 416 & -2083 & 447 & 513 & 556 & 5284 & 928 & 954 & 981 & -458 \\
\hline $300^{\circ} \mathrm{C}-120 \mathrm{MIN}$ & 10.56 & 346 & 383 & 407 & -546 & 453 & 516 & 558 & 5283 & 929 & 953 & 982 & -450 \\
\hline $350^{\circ} \mathrm{C}-120 \mathrm{MIN}$ & 9.35 & & & & & 446 & 515 & 558 & 4850 & 929 & 952 & 984 & -475 \\
\hline $400^{\circ} \mathrm{C}-120 \mathrm{MIN}$ & 9.13 & & & & & 449 & 519 & 560 & 4706 & 933 & 954 & 980 & -320 \\
\hline $500^{\circ} \mathrm{C}-120 \mathrm{MIN}$ & 5.39 & & & & & 469 & 509 & 555 & 640 & 931 & 952 & 979 & -277 \\
\hline $600^{\circ} \mathrm{C}-120 \mathrm{MIN}$ & 3.12 & & & & & 419 & 460 & 500 & 87 & 932 & 950 & 976 & -236 \\
\hline $250^{\circ} \mathrm{C}-240 \mathrm{MIN}$ & 10.77 & 352 & 388 & 414 & -1914 & 462 & 517 & 557 & 5156 & 931 & 954 & 979 & -374 \\
\hline $300^{\circ} \mathrm{C}-240 \mathrm{MIN}$ & 10.36 & 344 & 381 & 398 & -194 & 451 & 512 & 553 & 5109 & 933 & 953 & 978 & -257 \\
\hline $350^{\circ} \mathrm{C}-240$ MIN & 9.41 & & & & & 449 & 513 & 555 & 4746 & 935 & 954 & 978 & -255 \\
\hline $400^{\circ} \mathrm{C}-240$ MIN & 9.22 & & & & & 449 & 515 & 558 & 4675 & 929 & 952 & 981 & -448 \\
\hline
\end{tabular}


8.16. Caracterización cerámica de la composición PORC-STD.

PORC-STD

SÓLO ARCILLAS DE IMPORTACION

CARACTERTSTTCAS EN SECO

$\begin{array}{lrr}\text { CALCIMETRIA. } & 0,48 \% & \text { RESISTENCIA MECÁNICA EN SECO } \\ \text { PLASTICIDAD. } & 21,23 \% & 3,67 \mathrm{~N} / \mathrm{mm}^{2} \\ \text { RESIDUO MASICO }(63 \mu \mathrm{m}) . & 1,50 \% \\ \text { RESIDUO MÁSICO }(100 \mu \mathrm{m}) . & 0,30 \% \\ \therefore \text { CARBONO ORGANICO } & 0,00 \% & \end{array}$

\section{CARACTERTSTICAS DO PRENSADO}

HUMEDAD (base humeda)

$6,60 \%$

Densidad aparente verde

$2,056 \mathrm{~g} / \mathrm{cm}^{3}$

P.esp.

$331 \mathrm{Kg} / \mathrm{cm}^{2}$

CARACTERISTICAS DE COCCION

\begin{tabular}{|c|c|c|c|c|c|c|c|}
\hline $\mathrm{T}^{\mathbf{a}} \max \cdot\left({ }^{\circ} \mathbf{C}\right)$ & 1090 & 1115 & 1130 & 1140 & 1150 & 1165 & 1185 \\
\hline$\%$ C.I. & 4,41 & 5,22 & 6,47 & 6,85 & 7,21 & 7,73 & 7,76 \\
\hline$\%$ Aa. & 8,80 & 6,01 & 3,67 & 2,77 & 1,93 & 0,67 & 0,01 \\
\hline Dap. (seco) & 1,92 & 1,93 & 1,93 & 1,93 & 1,93 & 1,93 & 1,93 \\
\hline Dap. (cocido) & 2,06 & 2,17 & 2,22 & 2,28 & 2,31 & 2,35 & 2,38 \\
\hline $\mathrm{L}^{*}$ & - & - & - & - & - & 74,76 & 70,67 \\
\hline $\mathbf{a}^{*}$ & - & - & - & - & - & 2,01 & 2,26 \\
\hline $\mathbf{b}^{*}$ & - & - & - & - & - & 11,08 & 12,23 \\
\hline
\end{tabular}

(응) C.L.

DIAGRAMA DE GRESIFICACION

(응 A. a .

8,5

8,0

7,5

7,0

6,5

6,0

5,5

5,0

4,5

4,0 1080

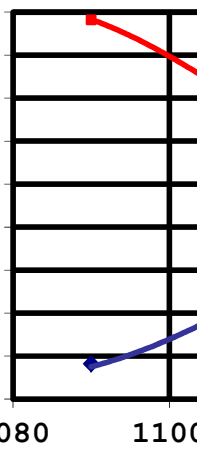

9,0

8,0

7,0

6,0

5,0

4,0

3,0

2,0

1,0

0,0

$\left({ }^{\circ} \mathrm{C}\right)$ 


\subsection{Caracterización cerámica de la composición (PORC-1A).}

\section{PORC-1A}

\section{CARACTERTSTICAS EN SECO}

$\begin{array}{lr}\text { CALCIMETRIA. } & 0,40 \% \\ \text { PLASTICIDAD. } & 20,56 \% \\ \text { RESIDUO MASICO }(63 \mu \mathrm{m}) . & 1,55 \% \\ \text { RESIDUO MÁSICO }(100 \mu \mathrm{m}) . & 0,28 \% \\ \% \text { CARBONO ORGANICO } & 0,20 \%\end{array}$

RESISTENCIA MECÁNICA EN SECO

$3,51 \mathrm{~N} / \mathrm{mm}^{2}$

$\therefore$ CARBONO ORGANICO

$0,20 \%$

$C A R A C T E R T S T C A S$ DE PRHNSADQ

HUMEDAD (base humeda)

Densidad aparente verde
$6,10 \div$

$2,047 \mathrm{~g} / \mathrm{cm}^{3}$
$250 \mathrm{Kg} / \mathrm{cm}^{2}$

$C A R A C T E R T S T I C A S$ DE COCCION

\begin{tabular}{|c|c|c|c|c|c|c|c|}
\hline$T^{a} \max .\left({ }^{\circ} \mathrm{C}\right)$ & 1090 & 1115 & 1130 & 1140 & 1150 & 1165 & 1185 \\
\hline$\because$ C.L. & 3,65 & 5,09 & 5,68 & 6,47 & 7,14 & 7,37 & 7,72 \\
\hline ㅇ $\mathrm{Aa}$. & 7,33 & 4,48 & 3,25 & 2,01 & 1,34 & 0,35 & 0,03 \\
\hline Dap. (seco) & 1,93 & 1,93 & 1,93 & 1,92 & 1,93 & 1,92 & 1,92 \\
\hline Dap. (cocido) & 2,07 & 2,09 & 2,13 & 2,17 & 2,22 & 2,36 & 2,37 \\
\hline$L^{*}$ & - & - & - & - & - & 66,73 & 64,88 \\
\hline$a *$ & - & - & - & - & - & 3,39 & 2,71 \\
\hline$b^{*}$ & - & - & - & - & - & 12,84 & 11,79 \\
\hline
\end{tabular}

(응 C.L.

DIAGRAMA DE GRESIFICACION

(응 A. a .

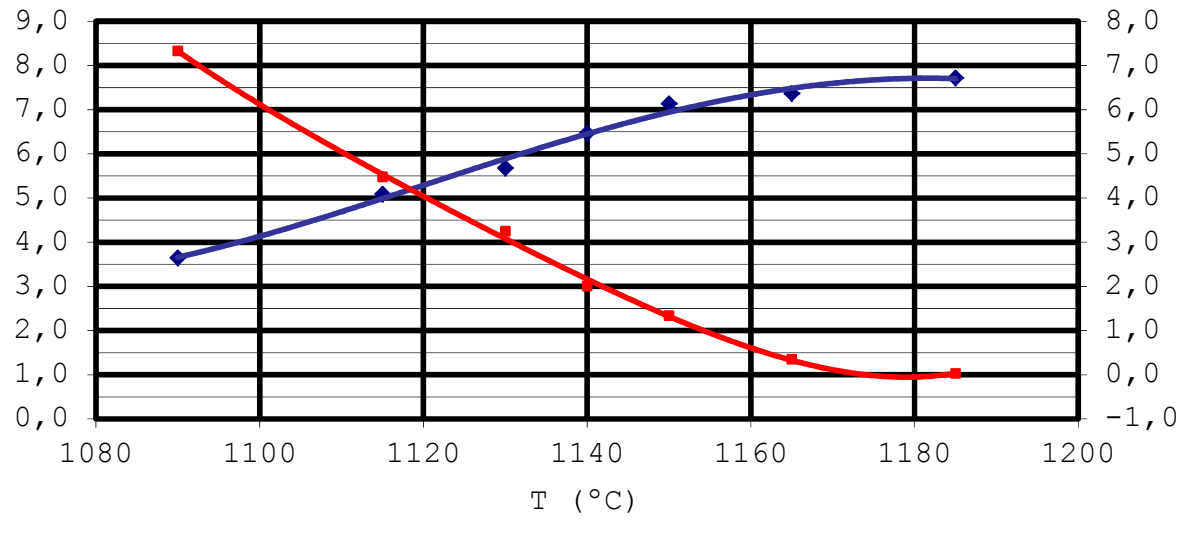


8.18. Caracterización cerámica de la composición (PORC-1B).

\begin{tabular}{|c|}
\hline \multicolumn{2}{|c|}{ PORC-1B } \\
\hline ARCILLAS ESPAÑOLAS TRATADAS \\
\hline
\end{tabular}

\section{CARACTERISTICAS EN SECO:}

$\begin{array}{lrr}\text { CALCIMETRIA. } & 0,41 \% & \text { RESISTENCIA MECÁNICA EN SECO } \\ \text { PLASTICIDAD. } & 20,92 \% & 3,45 \mathrm{~N} / \mathrm{mm}^{2} \\ \text { RESIDUO MASICO }(63 \mu \mathrm{m}) . & 1,76 \% \\ \text { RESIDUO MÁSICO }(100 \mu \mathrm{m}) . & 0,30 \% \\ \therefore \text { CARBONO ORGANICO } & 0,05 \% & \end{array}$

\section{CARACTERTSTICAS DE PRENSADO:}

HUMEDAD (base humeda)

Densidad aparente verde
$6,47 \%$

$2,055 \mathrm{~g} / \mathrm{cm}^{3}$
$250 \mathrm{Kg} / \mathrm{cm}^{2}$

CARACTERTSTTCAS DE COCCTON

\begin{tabular}{|c|c|c|c|c|c|c|c|}
\hline $\mathrm{T}^{\mathbf{a}}$ máx. $\left({ }^{\circ} \mathbf{C}\right)$ & 1090 & 1115 & 1130 & 1140 & 1150 & 1165 & 1185 \\
\hline ○ C.L. & 3,61 & 5,22 & 5,89 & 6,74 & 7,21 & 7,53 & 7,54 \\
\hline$\because$ Aa. & 7,07 & 3,84 & 2,06 & 1,24 & 0,85 & 0,05 & 0,00 \\
\hline Dap. (seco) & 1,92 & 1,92 & 1,92 & 1,92 & 1,93 & 1,92 & 1,92 \\
\hline Dap. (cocido) & 2,06 & 2,17 & 2,22 & 2,33 & 2,34 & 2,36 & 2,37 \\
\hline $\mathrm{L}^{\star}$ & - & - & - & - & - & 71,58 & 69,19 \\
\hline $\mathbf{a}^{*}$ & - & - & - & - & - & 3,20 & 2,72 \\
\hline $\mathbf{b}^{*}$ & - & - & - & - & - & 12,26 & 11,79 \\
\hline
\end{tabular}

(\%) C.L.

DIAGRAMA DE GRESIFICACION

(

9,0
8,0
7,0
6,0
5,0
4,0
3,0
2,0
1,0
0,0
108
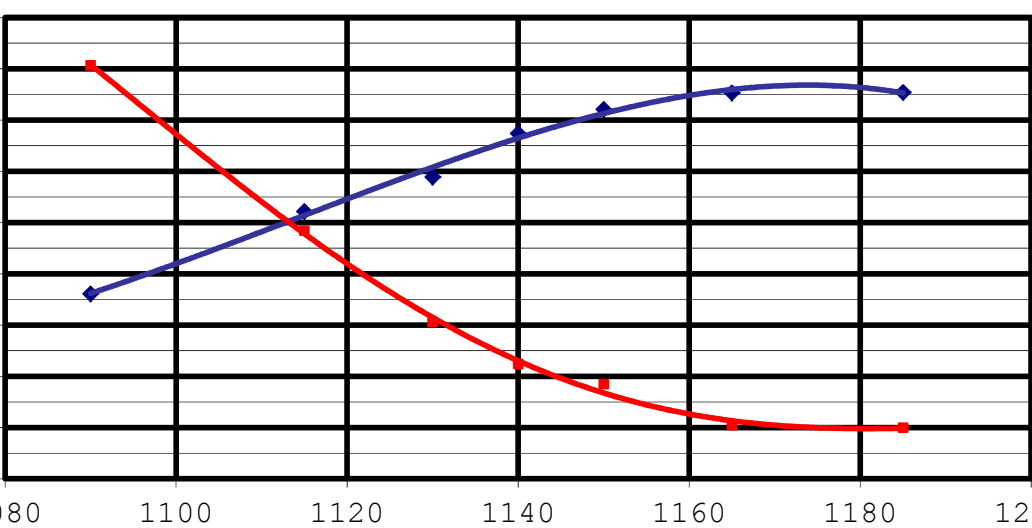

8,0

7,0

6,0

5,0

4,0

3,0

2,0

1,0

0,0

T $\left({ }^{\circ} \mathrm{C}\right)$ 
8.19. Caracterización cerámica de la composición (PORC-2).

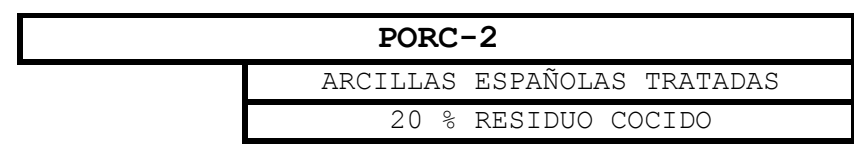

CARACTERTSTICAS ENSECO

$\begin{array}{lr}\text { CALCIMETRIA. } & 0,31 \% \\ \text { PLASTICIDAD. } & 21,20 \% \\ \text { RESIDUO MASICO }(63 \mu \mathrm{m}) . & 0,65 \% \\ \text { RESIDUO MÁSICO }(100 \mu \mathrm{m}) . & 0,09 \% \\ \% \text { CARBONO ORGANICO } & 0,01 \%\end{array}$

RESISTENCIA MECÁNICA EN SECO

$3,89 \mathrm{~N} / \mathrm{mm}^{2}$

\% CARBONO ORGANICO

$0,01 \%$

CARACTERTSTTICAS DE PRENSADO

HUMEDAD (base humeda)

$6,53 \%$

Densidad aparente verde

$2,056 \mathrm{~g} / \mathrm{cm}^{3}$

P.esp.

$250 \mathrm{Kg} / \mathrm{cm}^{2}$

CARACTERISTICAS DE COCCIÓN

\begin{tabular}{|c|c|c|c|c|c|c|c|}
\hline $\mathrm{T}^{\mathrm{a}}$ máx. $\left({ }^{\circ} \mathrm{C}\right)$ & 1090 & 1115 & 1130 & 1140 & 1150 & 1165 & 1185 \\
\hline$\because$ C.I. & 5,18 & 6,70 & 7,43 & 7,62 & 7,65 & 7,27 & 3,15 \\
\hline$\%$ Aa. & 5,35 & 2,32 & 0,98 & 0,07 & 0,05 & 0,00 & 5,76 \\
\hline Dap. $(\sec 0)$ & 1,93 & 1,93 & 1,92 & 1,93 & 1,93 & 1,92 & 1,92 \\
\hline Dap. (cocido) & 2,20 & 2,33 & 2,36 & 2,41 & 2,38 & 2,35 & 1,76 \\
\hline $\mathrm{L}^{*}$ & - & 69,18 & 68,45 & 66,85 & 64,90 & 64,12 & - \\
\hline$a^{*}$ & - & 3,85 & 3,16 & 2,95 & 2,74 & 2,25 & - \\
\hline$b^{*}$ & - & 14,83 & 13,96 & 13,26 & 13,02 & 12,87 & - \\
\hline
\end{tabular}

(\%) C.I.

DIAGRAMA DE GRESIFICACION

(응 A. a .

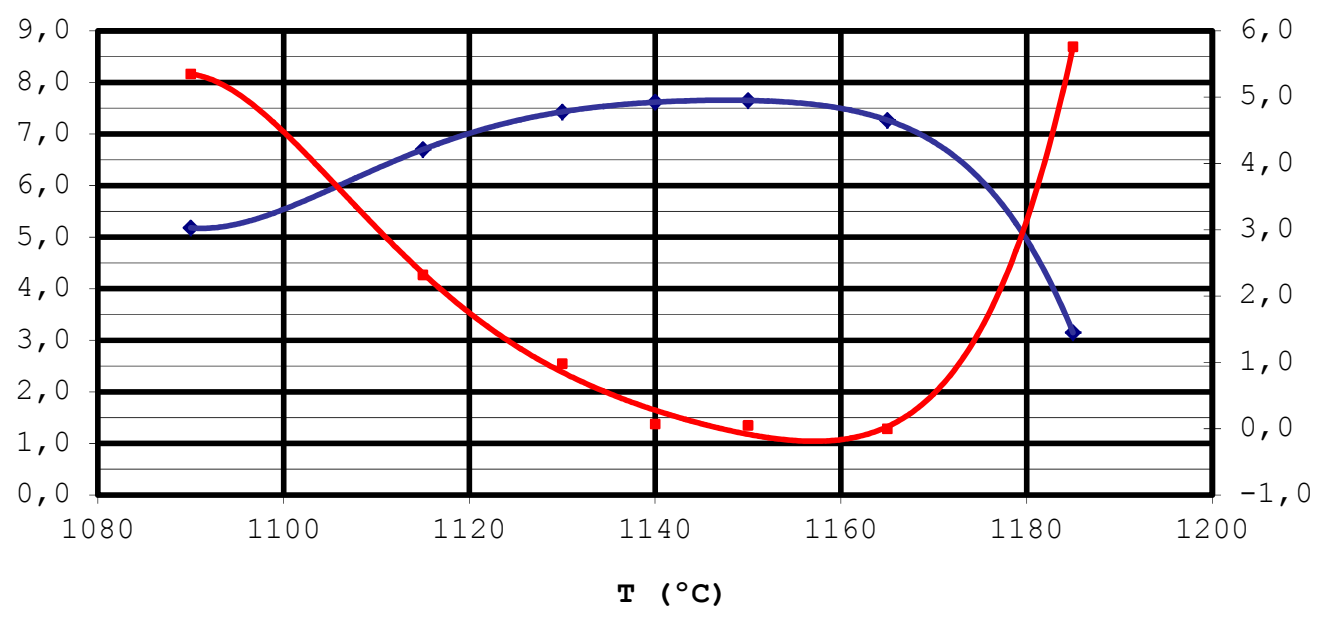


8.20. Caracterización cerámica de la composición (REV-STD).

\begin{tabular}{|l|l|}
\hline \multicolumn{2}{|l|}{ REV-STD } \\
\hline
\end{tabular}

$\begin{array}{lr}\text { CALCIMETRIA. } & 11,43 \% \\ \text { PLASTICIDAD. } & 20,96 \% \\ \text { RESIDUO MASICO }(63 \mu \mathrm{m}) . & 3,08 \% \\ \text { RESIDUO MÁSICO }(100 \mu \mathrm{m}) . & 1,30 \% \\ \therefore \text { CARBONO ORGANICO } & 0,00 \%\end{array}$

RESISTENCIA MECÁNICA EN SECO

$3,10 \mathrm{~N} / \mathrm{mm}^{2}$

\% CARBONO ORGANICO

$0,00 \%$

CARACTERTSTICAS DE PRENSAD $\odot$

HUMEDAD (base humeda)

$5,84 \%$

Densidad aparente verde

$2,038 \mathrm{~g} / \mathrm{cm}^{3}$

P.esp

$213 \mathrm{Kg} / \mathrm{cm}^{2}$

$C A R A C T E R T S T$ TAS DE COCCION

\begin{tabular}{|c|c|c|c|c|c|}
\hline $\mathrm{T}^{\mathrm{a}}$ máx. $\left({ }^{\circ} \mathrm{C}\right)$ & 1045 & 1090 & 1115 & 1140 & 1165 \\
\hline$\therefore$ C.L. & 0,02 & 0,05 & 0,15 & 0,26 & 0,69 \\
\hline$\therefore \mathrm{Aa}$. & 19,08 & 18,38 & 18,32 & 17,60 & 16,45 \\
\hline Dap. (seco) & 1,92 & 1,92 & 1,92 & 1,92 & 1,92 \\
\hline Dap. (cocido) & 1,72 & 1,73 & 1,73 & 1,75 & 1,77 \\
\hline$L^{*}$ & - & - & 81,24 & 80,07 & 78,92 \\
\hline$a *$ & - & - & 5,05 & 4,68 & 4,14 \\
\hline$b^{*}$ & - & - & 14,94 & 15,00 & 14,90 \\
\hline
\end{tabular}

( $\%$ ) C.L. DIAGRAMA DE GRESIFICACION

(

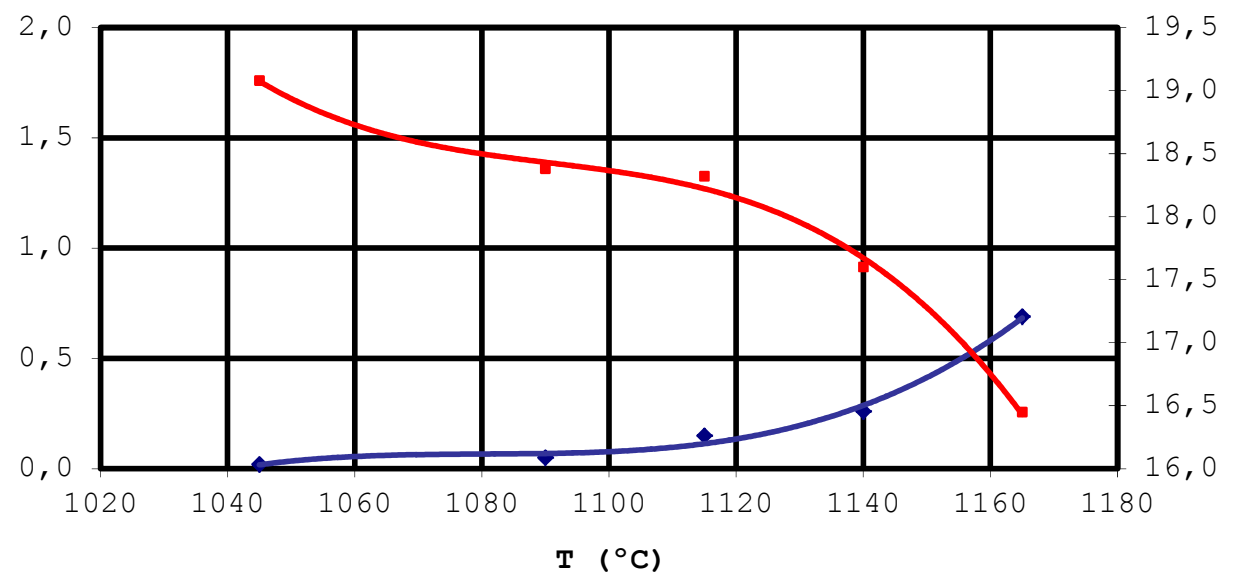




\subsection{Caracterización cerámica de la composición ( $R E V-1 A)$.}

\section{REV-1A}

$\begin{array}{lr}\text { CALCIMETRIA. } & 11,01 \% \\ \text { PLASTICIDAD. } & 20,52 \% \\ \text { RESIDUO MASICO }(63 \mu \mathrm{m}) . & 2,79 \div \\ \text { RESIDUO MÁSICO }(100 \mu \mathrm{m}) . & 0,71 \div \\ \therefore \text { CARBONO ORGANICO } & 0,05 \div\end{array}$

RESISTENCIA MECÁNICA EN SECO

$2,90 \mathrm{~N} / \mathrm{mm}^{2}$

CARBONO ORGANICO

$0,05 \frac{0}{8}$

$C A R A C T E R T S T C A S$ DE PRHNSADQ

HUMEDAD (base humeda)

Densidad aparente verde
$5,97 \div$

$2,045 \mathrm{~g} / \mathrm{cm}^{3} \quad$ P.esp

CARACTERTSTICAS DE COCCION

\begin{tabular}{|c|c|c|c|c|c|}
\hline $\mathrm{T}^{\mathrm{a}}$ máx. $\left({ }^{\circ} \mathrm{C}\right)$ & 1045 & 1090 & 1115 & 1140 & 1165 \\
\hline$\because$ C.L. & 0,08 & 0,12 & 0,18 & 0,31 & 0,48 \\
\hline ㅇa. & 17,09 & 16,90 & 16,16 & 15,51 & 14,52 \\
\hline Dap. (seco) & 1,92 & 1,92 & 1,93 & 1,93 & 1,93 \\
\hline Dap. (cocido) & 1,75 & 1,76 & 1,76 & 1,77 & 1,79 \\
\hline$L^{*}$ & - & - & 77,02 & 75,80 & 73,45 \\
\hline$a *$ & - & - & 6,75 & 5,17 & 3,80 \\
\hline$b^{*}$ & - & - & 15,67 & 14,57 & 14,16 \\
\hline
\end{tabular}

(\%) C.I .

2,0

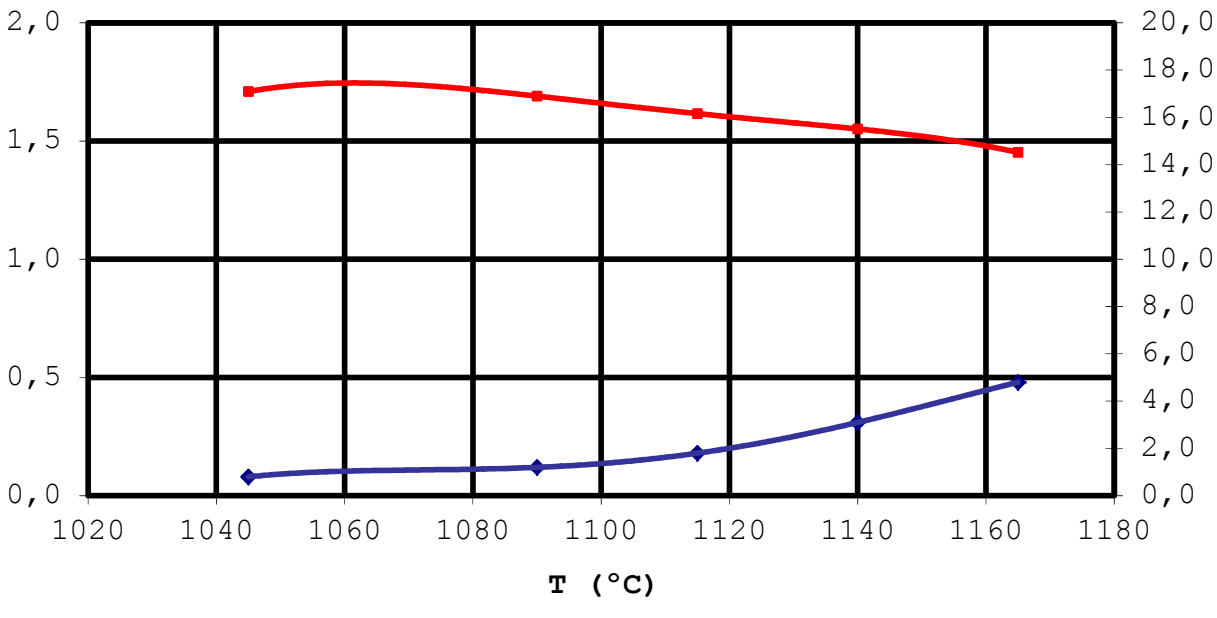

(응 A. a .

20,0

8,0

6,0

14,0

2,0

0,0

0

4,0 $\left({ }^{\circ} \mathrm{C}\right)$ 
8.22. Caracterización cerámica de la composición (REV-1B).

REV-1B

CON ARCILLAS ESPAÑOLAS TRATADAS

CARACTERISTICAS EN SECO

$\begin{array}{lr}\text { CALCIMETRIA. } & 11,53 \% \\ \text { PLASTICIDAD. } & 20,47 \% \\ \text { RESIDUO MASICO (63 } \mu \mathrm{m}) . & 2,51 \% \\ \text { RESIDUO MÁSICO }(100 \mu \mathrm{m}) . & 0,76 \% \\ \% \text { CARBONO ORGANICO } & 0,01 \%\end{array}$

CARACTERISTICAS DE DRENSADO

HUMEDAD (base humeda) 5,71\%

Densidad aparente verde $\quad 2,041 \mathrm{~g} / \mathrm{cm}^{3} \quad$ P.esp. $\quad 191 \mathrm{Kg} / \mathrm{cm}^{2}$

CARACTERISTICAS DE COCCION

\begin{tabular}{|c|c|c|c|c|c|}
\hline T $^{\text {a }}$ máx. $\left({ }^{\circ} \mathrm{C}\right)$ & 1045 & 1090 & 1115 & 1140 & 1165 \\
\hline ○ C.L. & 0,05 & 0,07 & 0,10 & 0,23 & 0,35 \\
\hline$\therefore$ Aa. & 18,21 & 17,56 & 17,01 & 16,25 & 15,26 \\
\hline Dap. (seco) & 1,92 & 1,92 & 1,93 & 1,93 & 1,93 \\
\hline Dap. (cocido) & 1,74 & 1,75 & 1,75 & 1,76 & 1,78 \\
\hline L* $^{*}$ & - & - & 78,95 & 76,97 & 74,21 \\
\hline $\mathbf{a}^{*}$ & - & - & 5,32 & 4,21 & 2,87 \\
\hline b* $^{*}$ & - & - & 14,28 & 14,32 & 14,06 \\
\hline
\end{tabular}

(\%) C.L.

DIAGRAMA DE GRESIFICACION

(\%) A. a .

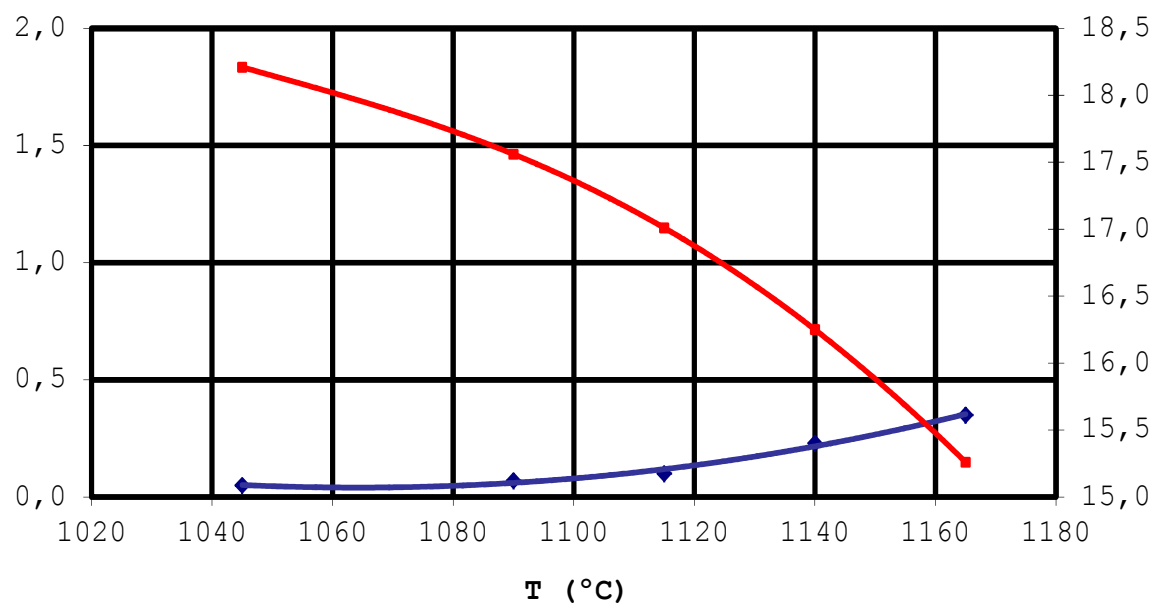




\subsection{Caracterización cerámica de la composición (REV-2).}

REV-2

CON ARCILLAS ESPAÑOLAS TRATADAS Y RESIDUO COCIDO

\section{CARACTERTSTICAS EN SECO}

$\begin{array}{lr}\text { CALCIMETRIA. } & 11,20 \% \\ \text { PLASTICIDAD. } & 19,68 \% \\ \text { RESIDUO MASICO (63micras). } & 2,65 \% \\ \text { RESIDUO MÁSICO (100 } \mu \mathrm{m}) . & 0,85 \% \\ \% \text { CARBONO ORGANICO } & 0,01 \%\end{array}$

RESISTENCIA MECÁNICA EN SECO

$3,35 \mathrm{~N} / \mathrm{mm}^{2}$

\section{$C A R A C T E R T S T I C A S$ DE PRENSADOS}

HUMEDAD (base humeda)

Densidad aparente verde
$5,47 \%$

$2,043 \mathrm{~g} / \mathrm{cm}^{3} \quad$ P.esp.

$250 \mathrm{Kg} / \mathrm{cm}^{2}$

CARACTERTSTICAS DE COCCION

\begin{tabular}{|c|c|c|c|c|c|c|}
\hline $\mathrm{T}^{\mathrm{a}}$ máx. $\left({ }^{\circ} \mathrm{C}\right)$ & 1000 & 1045 & 1090 & 1115 & 1140 & 1165 \\
\hline$\because$ C.L. & 0,39 & 0,57 & 0,74 & 0,98 & 1,05 & 1,18 \\
\hline$\frac{\circ}{8}$ Aa. & 15,25 & 15,23 & 14,90 & 14,60 & 14,00 & 13,10 \\
\hline Dap. $(\operatorname{seco})$ & 1,92 & 1,93 & 1,92 & 1,92 & 1,93 & 1,92 \\
\hline Dap. (cocido) & 1,79 & 1,79 & 1,80 & 1,80 & 1,81 & 1,81 \\
\hline$L^{*}$ & 78,50 & 77,85 & 77,24 & 76,56 & 76,05 & 75,12 \\
\hline$a^{*}$ & 4,59 & 4,47 & 4,48 & 4,52 & 4,54 & 4,86 \\
\hline$b *$ & 13,85 & 13,94 & 13,74 & 13,58 & 13,69 & 13,58 \\
\hline
\end{tabular}

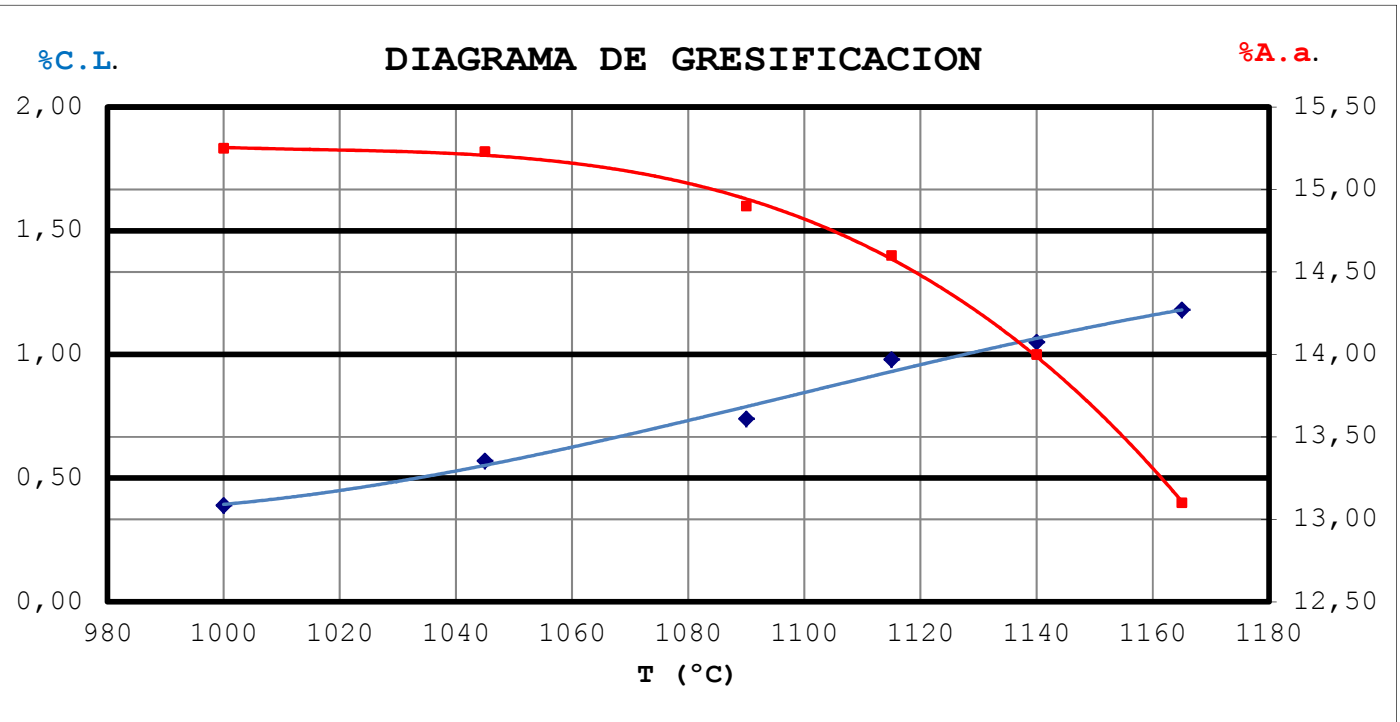

